Investigação de técnicas de classificação hierárquica para problemas de bioinformática 



\section{Investigação de técnicas de classificação hierárquica para problemas de bioinformática}

Eduardo de Paula Costa

Orientador: Prof. Dr. André Carlos Ponce de Leon Ferreira de Carvalho

Dissertação apresentada ao Instituto de Ciências Matemáticas e de Computação - ICMC-USP como parte dos requisitos para obtenção do título de Mestre em Ciências - Ciências de Computação e Matemática Computacional.

USP - São Carlos

Fevereiro/2008 

A meus pais 



\section{Agradecimentos}

Gostaria de agradecer primeiramente a Deus, o Aba Pai, que tem me sustentado em todo tempo.

Aos meus pais, meus irmãos e a toda a minha família, cujo carinho e apoio me deram a estrutura para trilhar mais esta etapa da minha vida.

Ao meu orientador, André Carvalho, pelo apoio, compreensão e incentivo em todos os momentos desses dois anos de mestrado.

À minha co-orientadora, Ana Carolina Lorena, da Universidade Federal do $\mathrm{ABC}$, pela incansável ajuda neste projeto, em especial nas etapas mais difíceis.

Ao professor Alex Freitas, da Universidade de Kent, pelas sugestões e críticas sempre oportunas, que trouxeram valiosas contribuições para esta pesquisa.

Ao Nicholas Holden, da Universidade de Kent , por gentilmente ter disponibilizado os conjuntos de dados utilizados na fase experimental do projeto.

Aos amigos e colegas do LABIC (Laboratório de Inteligência Computacional) - ICMC/USP, pela convivência e pela ajuda "homeopática" no dia a dia de trabalho, que fizeram toda a diferença.

Àqueles com quem dividi a república onde morei, por me proporcionarem momentos de distração e divertimento, mesmo em períodos em que a tensão, por conta das atividades acadêmicas, se fazia presente.

Ao meu amigo Mouse (Thiago), que mesmo não sendo da área da computação, me ajudou em momentos importantes da pesquisa, ouvindo e discutindo idéias a respeito do projeto, assistindo prévias das minhas apresentações de trabalhos em congressos, e revisando alguns textos.

Às minhas amigas Thaís, Elaine e Vanis, por proporcionarem momentos tão importantes e memoráveis no Vilarejo.

Aos meus amigos e irmãos da ABU (Aliança Bíblica Universitária), pelo acolhimento e companheirismo.

À todos amigos que cultivei em São Carlos, em especial à Raquel, ao Felipe e ao Victor, por estarem presentes em momentos por demais importantes nesse 
período.

Aos meus amigos dos tempos de graduação em Rio Claro, pelo carinho, pelo incentivo e por continuarem a vibrar com cada conquista minha, como se fosse deles mesmos.

À Fapesp, à Capes e ao CNPq, pelo apoio financeiro para a realização do projeto. 


\section{Resumo}

Em Aprendizado de Máquina e Mineração de Dados, muitos dos trabalhos de classificação reportados na literatura envolvem classificação plana (flat classification), em que cada exemplo é associado a uma dentre um conjunto finito (e normalmente pequeno) de classes, todas em um mesmo nível. Entretanto, existem problemas de classificação mais complexos em que as classes a serem preditas podem ser dispostas em uma estrutura hierárquica. Para esses problemas, a utilização de técnicas e conceitos de classificação hierárquica tem se mostrado útil. Uma das linhas de pesquisa com grande potencial para a utilização de tais técnicas é a Bioinformática. Dessa forma, esta dissertação apresenta um estudo envolvendo técnicas de classificação hierárquica aplicadas à predição de classes funcionais de proteínas. No total foram investigados doze algoritmos hierárquicos diferentes, sendo onze deles representantes da abordagem Top-Down, que foi o enfoque da investigação realizada. O outro algoritmo investigado foi o $\mathrm{HC} 4.5$, um algoritmo baseado na abordagem BigBang. Parte dos algoritmos estudados foram desenvolvidos com base em uma variação da abordagem Top-Down, denominada de Top-Down Ensemble, que foi proposta neste estudo. Alguns do algoritmos baseados nessa nova abordagem apresentaram resultados promissores, superando os resultados dos demais algoritmos. Para avaliação dos resultados, foi utilizada uma medida específica para problemas hierárquicos, denominada taxa de acerto dependente da profundidade. Além dessa, outras três medidas de avaliação foram utilizadas, de modo a comparar os resultados reportados por diferentes medidas. 


\section{Abstract}

In Machine Learning and Data Mining, most of the research in classification reported in the literature involve flat classification, where each example is assigned to one class out of a finite (and usually small) set of flat classes. Nevertheless, there are more complex classification problems in which the classes to be predicted can be disposed in a hierarchy. In this context, the use of hierarchical classification techniques and concepts have been shown to be useful. One research with great potential is the application of hierarchical classification techniques to Bioinformatics problems. Therefore, this MSc thesis presents a study involving hierarchical classification techniques applied to the prediction of functional classes of proteins. Twelve different algorithms were investigated - eleven of them based on the Top-Down approach, which was the focus of this study. The other investigated algorithm was HC4.5, an algorithm based on the Big-Bang approach. Part of these algorithms are based on a variation of the Top-Down approach, named Top-Down Ensembles, proposed in this study. Some of the algorithms based on this new approach presented promising results, which were better than the results presented by other algorithms. A specific evaluation measure for hierarchical classification, named depth-dependent accuracy, was used to evaluate the classification models. Besides, other three evaluation measures were used in order to compare the results reported by them. 


\section{Sumário}

Dedicatória $\quad$ i

Agradecimentos $\quad$ iii

Resumo v v

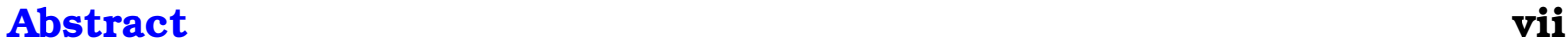

Sumário $\quad$ ix

Lista de Abreviaturas $\quad$ xiii

Lista de Figuras $\quad$ xv

Lista de Tabelas $\quad$ xvii

1 Introdução 1

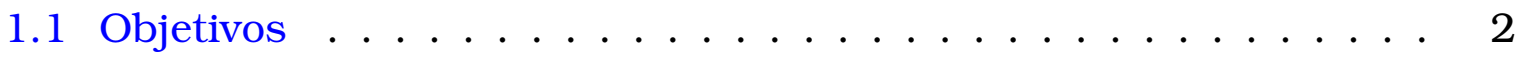

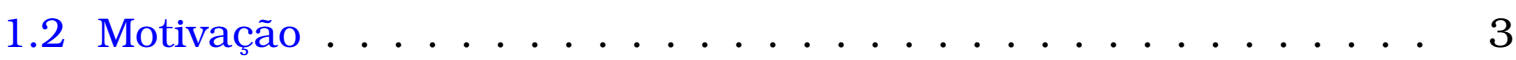

1.3 Técnicas Investigadas . . . . . . . . . . . . . . . 4

1.4 Resumo dos Resultados . . . . . . . . . . . . . . . . . . . 6

1.5 Organização do Documento . . . . . . . . . . . 7

2 Classificação de Dados 9

2.1 Aprendizado Supervisionado . . . . . . . . . . . . . . . . 10

2.2 Conceitos Básicos de Classificação . . . . . . . . . . . . . . 12

2.3 Técnicas de AM para Classificação de Dados . . . . . . . . . . 13

2.3.1 Paradigma Simbólico: C4.5 e RIPPER . . . . . . . . . . . . . 14

2.3.2 Paradigma Estatístico: SVMs e Redes Bayesianas . . . . . . 18

2.3.3 Paradigma Baseado em Exemplos: KNN . . . . . . . . . . 22

2.4 Combinação de Classificadores . . . . . . . . . . . . 23 
2.5 Avaliação de Algoritmos de Classificação . . . . . . . . . . . 28

2.6 Considerações Finais . . . . . . . . . . . . . . . . 32

3 Classificação Hierárquica 35

3.1 Conceitos Básicos . . . . . . . . . . . . . . 36

3.2 Abordagens para tratar Problemas Hierárquicos . . . . . . . . 38

3.2.1 Transformação de um Problema de Classificação Hierárquica em um Problema de Classificação Plana . . . . . . . . 39

3.2.2 Predição Hierárquica de Classes utilizando Algoritmos de Classificação Plana . . . . . . . . . . . . . . . 40

3.2.3 Classificação Hierárquica Top-Down . . . . . . . . . . . 41

3.2.4 Classificação Hierárquica Big-Bang . . . . . . . . . . . . 43

3.3 Combinação Hierárquica de Classificadores . . . . . . . . . . . . 44

3.4 Avaliação de Modelos Hierárquicos de Classificação . . . . . . . 48

3.4.1 Geração das Matrizes de Confusão . . . . . . . . . . 49

3.4.2 Medidas de desempenho . . . . . . . . . . . . . 56

3.5 Considerações Finais . . . . . . . . . . . . . . . . 68

4 Classificação Hierárquica em Bioinformática $\quad 71$

4.1 Tipo de Hierarquia de Classes . . . . . . . . . . . . . . . 71

4.2 Nível Hierárquico de Predição de Classes . . . . . . . . . . . . . 73

4.3 Abordagem utilizada para tratar o problema hierárquico . . . . 74

4.3.1 Transformação de um Problema de Classificação Hierárquica em um Problema de Classificação Plana . . . . . . . . 75

4.3.2 Predição Hierárquica de Classes utilizando Algoritmos de Classificação Plana . . . . . . . . . . . . . 76

4.3.3 Classificação Hierárquica Top-Down . . . . . . . . . . 79

4.3.4 Classificação Hierárquica Big-Bang . . . . . . . . . . . . 81

4.4 Avaliação e Medidas de Desempenho . . . . . . . . . . . . . . 83

4.5 Considerações Finais . . . . . . . . . . . . . . . 87

5 Experimentos $\quad 89$

5.1 Conjuntos de Dados . . . . . . . . . . . . . . . 90

5.2 Metodologia . . . . . . . . . . . . . . . . 93

5.2 .1 Pré-processamento dos Dados . . . . . . . . . 93

5.2 .2 Ferramentas de Software . . . . . . . . . . . . . . . 95

5.2 .3 Avaliação . . . . . . . . . . . . . . . . 96

5.2 .4 Testes Estatísticos . . . . . . . . . . . . . . . 97

5.3 Resultados . . . . . . . . . . . . . . . . . . . . . 99

5.3.1 Algoritmos Top-Down Convencionais . . . . . . . . . . . 99

5.3 .2 Selective Top-Down . . . . . . . . . . . . . . . . . . 107 
5.3.3 Combinações Hierárquicas de Classificadores . . . . . . . . 109

5.3.4 Comparações de Diferentes Abordagens . . . . . . . . . . 112

5.4 Considerações Finais . . . . . . . . . . . . . . . 114

6 Conclusão $\quad 117$

6.1 Principais Resultados .................. 119

6.2 Contribuições do Trabalho . . . . . . . . . . . . . 120

6.3 Trabalhos Futuros .................. 121

$\begin{array}{ll}\text { Referências Bibliográficas } & 123\end{array}$

$\begin{array}{ll}\text { Referências } & 131\end{array}$

A Testes Estatísticos 133

A. 1 Algoritmos Top-Down Convencionais . . . . . . . . . . . . . 135

A.2 Algoritmo Selective Top-Down . . . . . . . . . . . . . . . . . 141

A.3 Algoritmos Ensemble Top-Down . . . . . . . . . . . . . . . . . 143

A.4 Comparação entre várias abordagens . . . . . . . . . . . . 145

A.5 Considerações Finais . . . . . . . . . . . . . 149

B Diversidade em Combinações de Classificadores $\quad 151$

B.1 Análise dos Resultados do Conjunto GPCR . . . . . . . . . . . . . 152

B.2 Análise dos Resultados do Conjunto EC . . . . . . . . . . . . 156

B.3 Considerações Finais . . . . . . . . . . . . . . . . 159 


\section{Lista de Abreviaturas}

ACO

$\mathrm{AD}$

AG

AM

ANN

ATI

AUC

DAG

DM

DMP

EnsTPVotM

EnsTPVotP

EnsTPVotR

FN

FP

GO

GPCR

IA

KNN

MD

MDE

MIPS

ORFs

PDB

PSO

RIPPER

$\mathrm{RBC}$
Ant Colony Optimization 79

Árvore de Decisão ........................................ 11

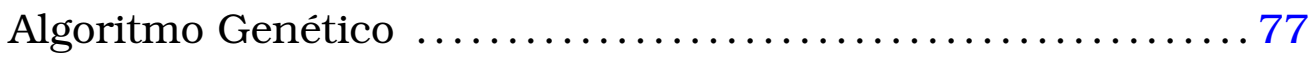

Aprendizado de Máquina....$\ldots \ldots \ldots \ldots \ldots \ldots \ldots \ldots \ldots \ldots \ldots$

Artificial Neural Network (Rede Neural Artificial) ............ 11

Averaged Tanimoto Index ........................... 78

Area Under the ROC Curve ............................... 32

Directed Acyclic Graph (Grafo Direcionado Acíclico) ............ 4

Data Mining (Mineração de Dados) ........................ 1

Data Mining Prediction ................................ 81

Ensemble Top-Down com Votação por Maioria .............. 45

Ensemble Top-Down com Votação Ponderada .............. 45

Ensemble Top-Down com Votação Ponderada por Ranking . . 45

False Negatives (Falsos Negativos) ...................... 30

False Positives (Falsos Positivos) ........................ 30

Gene Ontology ........................................ 3

G-Protein-Coupled Receptor ......................... 90

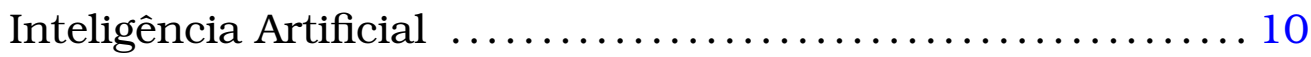

K-Nearest Neighbor ................................ 22

Medida de Dissimilaridade ...........................26

Medida de Duplo Erro ................................27

Munich Information Center for Protein Sequences ............ 73

Open Reading Frames ................................ 72

Protein Data Bank ................................. 72

Particle Swarm Optimization ........................... 79

Repeated Incremental Pruning to Produce Error Reduction....... 5

Raciocínio Baseado em Casos 
StackEnsTP Stack Ensemble Top-Down

StackEns-

TPSel Stack Ensemble Top-Down com Procedimento Seletivo ....... 45

S. Top-Down Selective Top-Down ............................ 108

SVMs Support Vector Machines (Máquinas de Vetores de Suporte) ....5

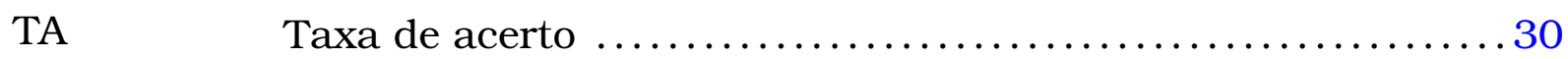

TAM Taxa de acerto majoritária............................

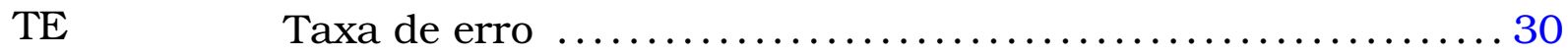

TN True Negatives (Verdadeiros Negativos) ...................... 30

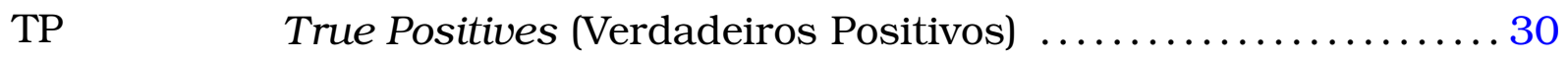

TP-BayesNet Top-Down baseado na técnica BayesNet ............... 101

TP-C4.5 Top-Down baseado na técnica C4.5....................99

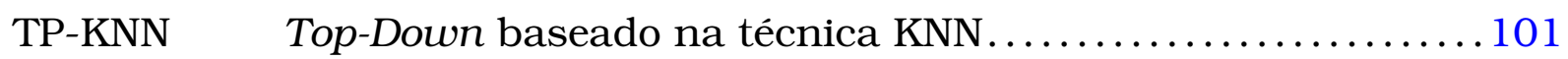

TP-RIPPER Top-Down baseado na técnica RIPPER ................. 101

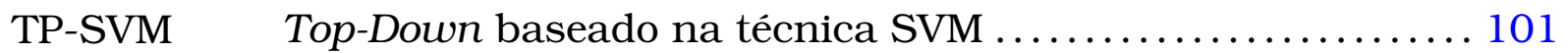




\section{Lista de Figuras}

1.1 Esquema simplificado da hierarquia de classes do código EC. . . 4

2.1 Hierarquia do Aprendizado . . . . . . . . . . . . . 11

2.2 Processo de Classificação . . . . . . . . . . . . . . . . 12

2.3 Exemplo de uma função de classificação. . . . . . . . . . . . . 14

2.4 Exemplo de Árvore de Decisão . . . . . . . . . . . . . . . . . . . . 16

2.5 Problema de separação de dados por SMVs . . . . . . . . . . 19

2.6 Exemplos vetores de suporte . . . . . . . . . . . . . 19

2.7 Exemplos de uma Rede Bayesiana . . . . . . . . . . . . 21

2.8 Esquema padrão de uma combinação de classificadores. . . . . . 24

2.9 Exemplo de uma curva ROC . . . . . . . . . . . . . . . . . 32

3.1 Classificação Plana x Classificação Hierárquica . . . . . . . . . . . 36

3.2 Exemplo de uma hierarquia de classes estruturada como uma árvore ........................ 37

3.3 Exemplo de uma hierarquia de classes estruturada como um

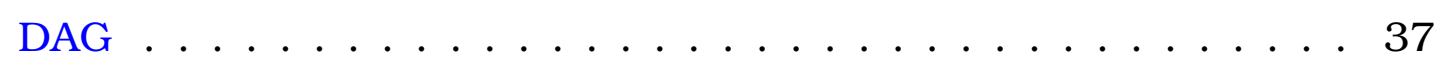

3.4 Abordagens para resolução de problemas hierárquicos. . . . . . . 39

3.5 Hierarquia de classes de um caso hipotético de classificação hierárquica. .................... 50

3.6 Exemplo de hierarquia de classes: análise de custos. . . . . . . 58

3.7 Hierarquia de classes com ligações ponderadas. . . . . . . . . . 62

4.1 Esquema Geral do DMP . . . . . . . . . . . . . . 82 



\section{Lista de Tabelas}

2.1 Conjunto de treinamento - combinação de classificadores . . . . 26

2.2 Matriz de Confusão. . . . . . . . . . . . . . . . . . . . 30

3.1 Exemplo de atribuição de pesos - EnsTPVotR. . . . . . . . . . . 46

3.2 Matriz de Confusão Hipotética - Estágio Inicial . . . . . . . . 50

3.3 Matriz de Confusão Hipotética - Passo 1 . . . . . . . . . . . 51

3.4 Matriz de Confusão - Nível 1 - Passo $2 \ldots \ldots$. . . . . . . . 53

3.5 Matriz de Confusão - Nível 2 - Passo $2 \ldots \ldots$. . . . . . . 53

3.6 Matriz de Confusão - Nível 1 - Passo 2 . . . . . . . . . . . . . 54

3.7 Matriz de Confusão - Nível 2 - Passo 3 . . . . . . . . . . . . 55

3.8 Matriz de Confusão - Nível 3 - Final . . . . . . . . . . . . . 56

3.9 Exemplo de uma matriz de custos . . . . . . . . . . . . . 68

4.1 Trabalhos de classificação hierárquica para problemas de Bioin-

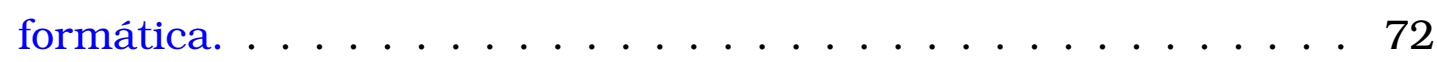

4.2 Hierarquias de classes. . . . . . . . . . . . . . . 73

4.3 Níveis de predição. . . . . . . . . . . . . . . . . 75

4.4 Abordagens e metodologias. . . . . . . . . . . . . . . 84

4.5 Avaliação de desempenho. . . . . . . . . . . . . . . . . 87

5.1 Conjuntos de Dados . . . . . . . . . . . . . . . . . . . . 92

5.2 Resultados - Algoritmos Top-Down Convencionais - GPCR - Nível 1100

5.3 Resultados - Algoritmos Top-Down Convencionais - GPCR - Nível 2100

5.4 Resultados - Algoritmos Top-Down Convencionais - GPCR - Nível 3100

5.5 Resultados - Algoritmos Top-Down Convencionais - GPCR - Nivel 4101

5.6 Resultados - Algoritmos Top-Down Convencionais - EC - Nível 1 . 103

5.7 Resultados - Algoritmos Top-Down Convencionais - EC - Nível 2 . 103

5.8 Resultados - Algoritmos Top-Down Convencionais - EC - Nível 3 . 103

5.9 Resultados - Algoritmos Top-Down Convencionais - EC - Nível 4 . 104 
5.10 Resultados - Selective Top-Down - GPCR . . . . . . . . . . 108

5.11 Resultados - Selective Top-Down - EC . . . . . . . . . . . . 108

5.12 Resultados - Ensemble Top-Down - GPCR . . . . . . . . . . . 110

5.13 Ordem de desempenho - Ensemble Top-Down - GPCR . . . . . . 110

5.14 Resultados - Ensemble Top-Down - EC . . . . . . . . . . . 111

5.15 Ordem de desempenho - Ensemble Top-Down - EC . . . . . . . . . 111

5.16 Comparação entre diferentes abordagens - GPCR . . . . . . . . 113

5.17 Comparação entre diferentes abordagens - EC . . . . . . . . 113

A.1 Legenda para as tabelas com os resultados dos testes estatísticos. . . . . . . . . . . . . . . . . . . 134

A.2 Análise Estatística - Top-Down - GPCR - Nível 1 - todas as medidas 136

A.3 Análise Estatística - Top-Down - GPCR - Nível 2 - TA / TA dist. / F-measure . . . . . . . . . . . . . . . . 136

A.4 Análise Estatística - Top-Down - GPCR - Nível 2 - TA prof. . . . . 137

A.5 Análise Estatística - Top-Down - GPCR - Nível 3 - TA / TA dist. / F-measure . . . . . . . . . . . . . . . . . . . 137

A.6 Análise Estatística - Top-Down - GPCR - Nível 3 - TA prof. . . . 137

A.7 Análise Estatística - Top-Down - GPCR - Nível 4 - TA . . . . . . . 138

A.8 Análise Estatística - Top-Down - GPCR - Nível 4 - TA dist. / TA prof. / F-measure . . . . . . . . . . . . . . . . . . . 138

A.9 Análise Estatística - Top-Down - EC - Nível 1 - todas as medidas 139 A.10Análise Estatística - Top-Down - EC - Nível 2 - TA . . . . . . . 139

A.11Análise Estatística - Top-Down - EC - Nível 2 - TA dist. / TA prof.

/ F-measure. . . . . . . . . . . . . . . . . . . . . 139

A.12Análise Estatística - Top-Down - EC - Nível 3 - TA . . . . . . . 140 A.13Análise Estatística - Top-Down - EC - Nivel 3 - TA dist. / TA prof.

/ F-measure. . . . . . . . . . . . . . . . . . . 140

A.14Análise Estatística - Top-Down - EC - Nível 4 - TA . . . . . . 141

A.15Análise Estatística - Top-Down - EC - Nível 4 - TA dist. . . . . . 141

A. 16Análise Estatística - Top-Down - EC - Nível 4 - TA prof. / F-measure 142

A.17Análise Estatística - S. Top-Down - GPCR . . . . . . . . . . 142

A.18Análise Estatística - S. Top-Down - EC . . . . . . . . . . . . . 143

A.19Análise Estatística - Ensemble Top-Down - GPCR - Nível 1 . . . 144

A.20Análise Estatística - Ensemble Top-Down - GPCR - Nível 2 . . . 144

A.21Análise Estatística - Ensemble Top-Down - GPCR - Nível 3 . . . 144

A.22Análise Estatística - Ensemble Top-Down - GPCR - Nível 4 . . . 144

A.23Análise Estatística - Ensemble Top-Down - EC - Nível 1 . . . . . 145

A.24Análise Estatística - Ensemble Top-Down - EC - Nível 2 . . . . . 145

A.25Análise Estatística - Ensemble Top-Down - EC - Nível 3 . . . . . 146 
A.26Análise Estatística - Ensemble Top-Down - EC - Nível 4 . . . . . . 146

A.27Análise Estatística - Várias abordagens - GPCR - Nível 1 . . . . . 147

A.28Análise Estatística - Várias abordagens - GPCR - Nível 2 . . . . . 147

A.29Análise Estatística - Várias abordagens - GPCR - Nível 3 . . . . . 147

A.30Análise Estatística - Várias abordagens - GPCR - Nível 4 . . . . . 148

A.31 Análise Estatística - Várias abordagens - EC - Nivel 1 . . . . . . . 148

A.32Análise Estatística - Várias abordagens - EC - Nível 2 . . . . . . . 149

A.33Análise Estatística - Várias abordagens - EC - Nivel 3 . . . . . . . 149

A.34Análise Estatística - Várias abordagens - EC - Nível 4 . . . . . . . 149

B.1 Medida de Dissimilaridade para o EnsTPVotM - GPCR - Nível 1 . . 154

B.2 Medida de Dissimilaridade para o EnsTPVotM - GPCR - Nivel 2 . . 154

B.3 Medida de Dissimilaridade para o EnsTPVotM - GPCR - Nível 3 . . 154

B.4 Medida de Dissimilaridade para o EnsTPVotM - GPCR - Nível 4 . . 154

B.5 Complementaridade - GPCR - Nivel 1 . . . . . . . . . . . . 155

B.6 Medida de Duplo Erro para o EnsTPVotM - GPCR - Nivel 1 . . . 155

B.7 Medida de Duplo Erro para o EnsTPVotM - GPCR - Nível 2 . . . . 155

B.8 Medida de Duplo Erro para o EnsTPVotM - GPCR - Nível 3 . . . . 155

B.9 Medida de Duplo Erro para o EnsTPVotM - GPCR - Nivel 4 . . . . 156

B.10Média e desvio padrão dos valores da MD e da MDE para o con-

junto GPCR. . . . . . . . . . . . . . . . . 156

B.11Medida de Dissimilaridade para o EnsTPVotM - EC - Nível 1 . . 157

B.12Medida de Dissimilaridade para o EnsTPVotM - EC - Nível 2 . . . 157

B.13Medida de Dissimilaridade para o EnsTPVotM - EC - Nível 3 . . . 157

B.14Medida de Dissimilaridade para o EnsTPVotM - EC - Nivel 4 . . . 157

B.15Medida de Duplo Erro para o EnsTPVotM - EC - Nível 1 . . . . . . 158

B.16Medida de Duplo Erro para o EnsTPVotM - EC - Nível 2 . . . . . . 158

B.17Medida de Duplo Erro para o EnsTPVotM - EC - Nível 3 . . . . . . 159

B.18Medida de Duplo Erro para o EnsTPVotM - EC - Nível 4 . . . . . . 159

B.19Média e desvio padrão dos valores da MD e da MDE para o con-

junto EC. . . . . . . . . . . . . . . . 159 



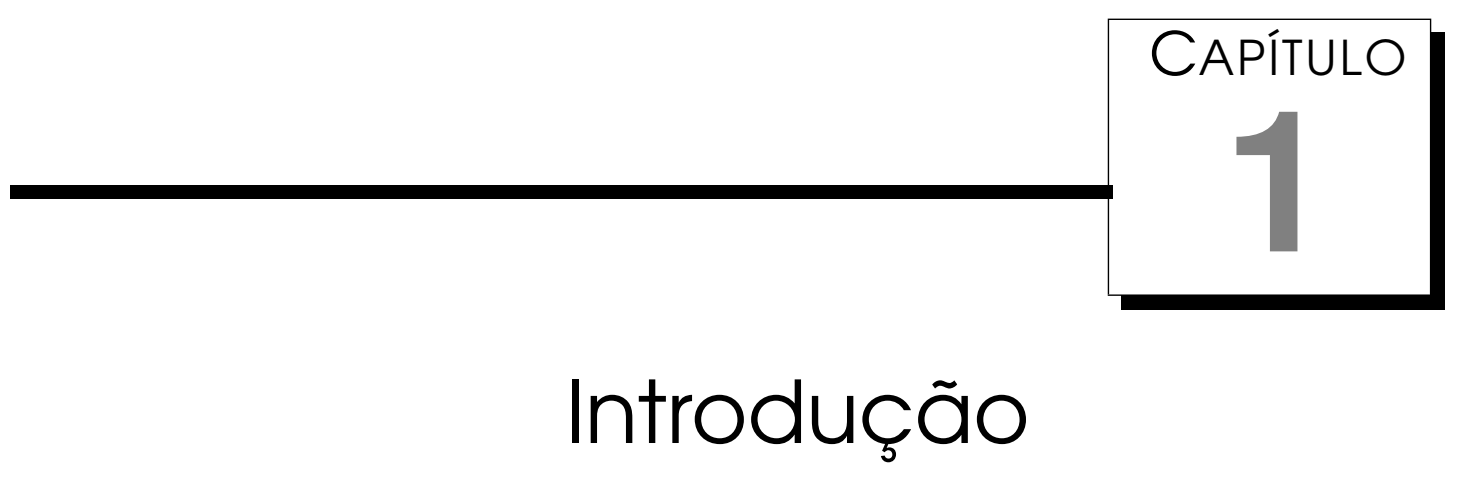

Classificação é um dos mais importantes problemas em Aprendizado de Máquina (AM) e Mineração de Dados (DM - Data Mining). Nessas áreas de pesquisa, um problema de classificação pode ser definido como a tarefa de se encontrar uma função que, dado um conjunto de exemplos de treinamento composto por pares $\left(T_{i}, y_{i}\right)$, mapeie cada $T_{i}$ para sua classe associada $y_{i}$, tal que $i=1,2, \ldots, n$, em que $n$ é o número de exemplos de treinamento.

A grande maioria dos problemas de classificação descritos na literatura envolve classificação plana (flat classification). Nesse tipo de classificação, cada exemplo é associado com uma classe pertencente a um conjunto finito de classes, não considerando a existência de relacionamentos entre elas. No entanto, existe um grande número de problemas em que uma ou mais classes podem ser divididas em subclasses ou agrupadas em superclasses. Esses problemas são conhecidos na literatura de AM como problemas de classificação hierárquica (Freitas \& Carvalho, 2007).

Uma linha de pesquisa que apresenta um vasto campo para a aplicação de técnicas de classificação hierárquica é a Bioinformática. Essa nova área interdisciplinar pesquisa o desenvolvimento e utilização de ferramentas computacionais, matemáticas e estatísticas para resolução de problemas da Biologia, trazendo benefícios para vários setores, tais como a Medicina, a Farmácia e a Agricultura (Meidanis \& Setúbal, 1997). As pesquisas em Bioinformática começaram na década de 1960, quando foram mapeadas as primeiras bases de dados de seqüências de aminoácidos. Entre as décadas de 1960 e 1970, pesquisadores desenvolveram algoritmos específicos para analisar esses dados. Em 1980, o GenBank (Benson et al., 2007) e outras bases de dados públicas 
foram disponibilizadas, junto com ferramentas de análise. Na década de 1990, houve um enorme crescimento das bases de dados (Carvalho et al., 2004).

Um dos problemas biológicos que pode ser tratado de modo eficiente por meio de técnicas e conceitos de classificação hierárquica é a predição de funções de proteínas, que são macro-moléculas formadas por longas seqüências de aminoácidos e que executam quase todas as funções celulares nos seres vivos.

Este capítulo está organizado da seguinte forma: na Seção 1.1, são apresentados os principais objetivos deste projeto; as motivações são destacadas na Seção 1.2; na Seção 1.3, são introduzidos os principais métodos e abordagens de classificação hierárquica que foram investigados; os principais resultados são resumidos na Seção 1.4; por fim, na Seção 1.5, a organização geral da dissertação é apresentada.

\subsection{Objetivos}

Em linhas gerais, três objetivos principais direcionaram esta pesquisa:

- Investigação de técnicas de classificação hierárquica: Esse, que foi o objetivo principal da pesquisa, consistiu: em realizar uma pesquisa bibliográfica dos principais abordagens e algoritmos de aprendizado propostos para a resolução de problemas hierárquicos; e em desenvolver algoritmos baseados em algumas das abordagens investigadas, de modo a realizar um estudo comparativo entre eles, abrindo possibilidades para contribuições originais deste trabalho para o avanço do estado da arte na área.

- Aplicação dos modelos hierárquicos de classificação a um problema atual e relevante na área de Bioinformática: Como importantes problemas biológicos, como a predição de funções de proteínas, podem ser tratados a partir de técnicas de classificação hierárquica, um dos objetivos deste projeto foi a utilização dos modelos desenvolvidos para a resolução de um problema de Bioinformática.

- Avaliação dos resultados por meio de medidas de desempenho preditivo específicas para classificação hierárquica: Tendo em vista as peculiaridades inerentes a problemas de classificação hierárquica, a avaliação de modelos desenvolvidos para tais problemas requer algumas considerações adicionais, além dos aspectos normalmente considerados na avaliação de modelos convencionais de classificação. Dessa forma, um dos objetivos deste trabalho foi avaliar os modelos de classificação hierárquica por meio de medidas específicas para esse contexto. 


\subsection{Motivação}

Diversas motivações podem ser mencionadas para investigar a aplicação de técnicas de classificação hierárquica para problemas de Bioinformática.

Em primeiro lugar, a utilização de técnicas de classificação hierárquica é uma área de pesquisa relativamente nova e pouco explorada, na qual há muitas oportunidades para a realização de pesquisas e melhoria da prática atual. Recentemente, novas abordagens e métodos de classificação têm sido propostos com o intuito atender às características específicas dos problemas hierárquicos. Além das oportunidades de pesquisa no desenvolvimento de modelos de classificação hierárquica, pode-se destacar a necessidade da definição de protocolos de avaliação de tais modelos, assunto ainda pouco discutido na comunidade de AM.

Adicionalmente, a Biologia Molecular oferece muitas oportunidades para a aplicação de técnicas de classificação hierárquica. Muitos processos e elementos celulares podem ser caracterizados de maneira hierárquica. Dessa forma, não é rara a utilização de estruturas organizadas como uma árvore ou um grafo como meio de representação do conhecimento biológico.

Nesse contexto, um exemplo de uma hierarquia de classes de dados biológicos estruturada em forma de árvore é a classificação funcional de enzimas (proteínas especializadas em acelerar reações químicas) provida pela Enzyme Commission (Nomenclature, 1972). Nessa classificação, as classes são identificadas por um esquema numérico denominado EC. Esse esquema é composto por quatro números, que são associados às classes de enzimas, sendo que o primeiro especifica a classe mais geral e o último traz a informação referente à classe mais específica. Por exemplo, o código EC 3.2.1.1 é associado à enzima $\alpha$-amylase, que é uma subclasse das glicosidades, referenciadas por $E C 3.2 .1$.- . As glicosidades constituem uma subclasse das lycosylases, associadas pelo código EC3.2. - .-, que por sua vez constituem uma subclasse das hydrolases, que compõem a classe $E C 3 .-$.- .-, presente no primeiro nível do esquema hierárquico.

Na Figura 1.1 é apresentado um esquema simplificado da hierarquia de classes do código EC. Esse esquema mostra apenas dois níveis da hierarquia, que é composta por quatro níveis em seu esquema completo. Nessa figura, o primeiro nível está completo e o segundo nível apresenta apenas quatro das subclasses constituintes da classe 3 (Hydrolases). Adotou-se como notação, para todas as hierarquias representadas nesta monografia, que a raiz da hierarquia é um nó denominado "qualquer classe", indicando o caso em que a classe de um exemplo é desconhecida.

Outro exemplo de hierarquia para dados biológicos é o Gene Ontology - GO 


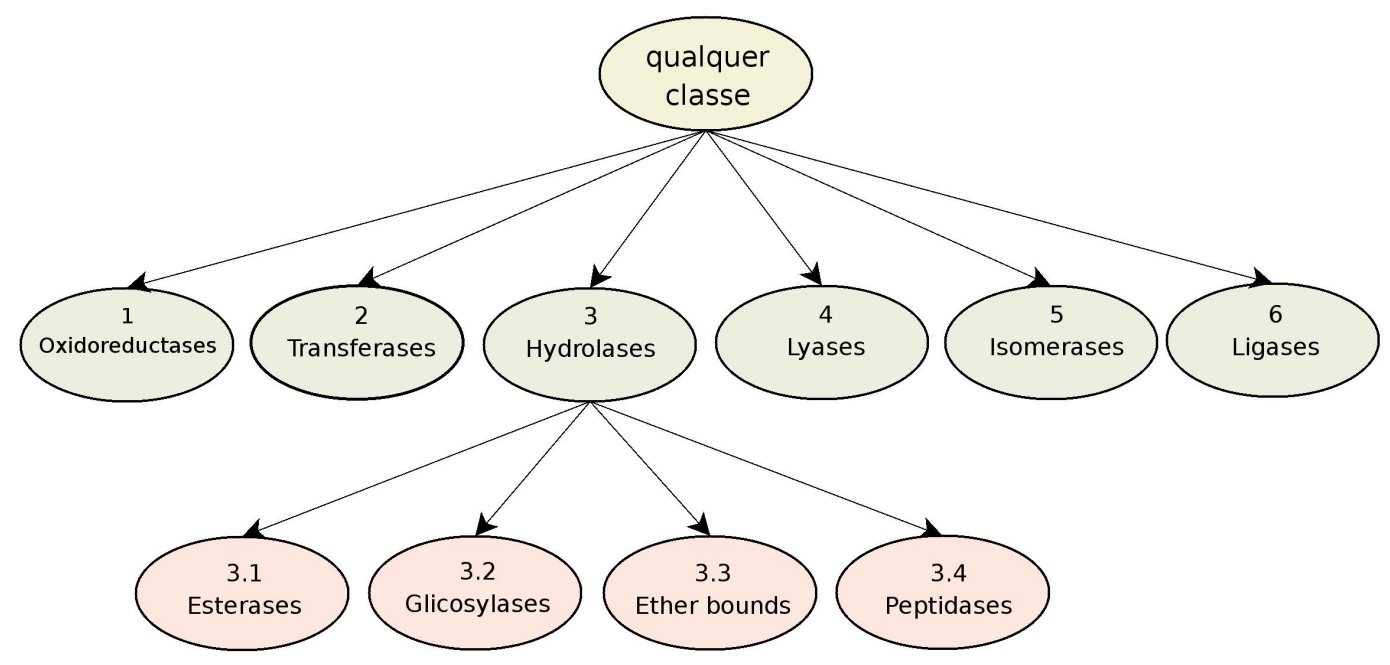

Figura 1.1: Esquema simplificado da hierarquia de classes do código EC.

(Blake, 2003), que é composto de três ontologias que cobrem áreas básicas da Biologia Molecular: ontologia de funções moleculares, ontologia de processos celulares e ontologia de componentes celulares. Nessas ontologias, as informações estão estruturadas em um grafo direcionado acíclico (Directed Acyclic Graph - DAG).

Por fim, pode-se destacar uma motivação do ponto de vista biológico. A aplicação de técnicas computacionais para a resolução de problemas desse contexto tem recebido cada vez mais atenção, uma vez que os recursos da computação podem trazer contribuições para o diagnóstico e o tratamento de doenças, o desenvolvimento de medicamentos mais efetivos, entre outras.

\subsection{Técnicas Investigadas}

Nos últimos anos, diversas soluções têm sido propostas para a indução de modelos de classificação para problemas hierárquicos. Tais soluções podem ser agrupadas em quatro tipos de abordagens: transformação do problema hierárquico em um problema de classificação plana, predição hierárquica utilizando algoritmos de classificação plana, classificação Top-Down e classificação Big-Bang.

As duas primeiras abordagens têm como fundamento a simplificação do problema hierárquico, reduzindo-o a um ou mais problemas de classificação plana. Essa simplificação é possível dado que a classificação plana pode ser considerada como um caso particular da classificação hierárquica em que as classes não apresentam relacionamentos hierárquicos entre si. Porém, a principal desvantagem desse procedimento é que, ao ignorar os relacionamentos 
existentes entre as classes, informações são omitidas do processo de geração do modelo de classificação. Por esse motivo, tais abordagens não foram exploradas neste projeto.

Em contrapartida, as abordagens Big-Bang e Top-Down consideram os relacionamentos hierárquicos entre as classes tanto no processo de treinamento do modelo de classificação, quanto na predição das classes de novos exemplos. A abordagem Top-Down realiza a classificação em etapas, por meio do princípio "Dividir para Conquistar". Essa característica confere maior facilidade e flexibilidade ao desenvolvimentos de métodos baseados nessa abordagem. Entretanto, erros podem ser propagados de um passo para outro. A abordagem Big-Bang gera um único classificador para toda a hierarquia, o que confere um grau de complexidade maior aos métodos baseados nessa abordagem.

Neste projeto, foram investigados métodos de classificação baseados na abordagem Top-Down e seus resultados foram comparados com os resultados obtidos por um algoritmo Big-Bang denominado HC4.5 (Clare \& King, 2003). Além da abordagem Top-Down convencional, duas variações dessa abordagem foram exploradas: a abordagem Selective Top-Down (Secker et al., 2007), recentemente proposta na literatura, que utiliza um procedimento seletivo entre múltiplas técnicas de AM na classificação Top-Down, de modo a escolher qual técnica deve ser usada em cada passo do algoritmo; e a abordagem Ensemble Top-Down, proposta neste projeto, que é baseada na combinação da saída de classificadores gerados por diferentes técnicas de AM (classificadores bases) em cada passo do algoritmo Top-Down. Ao contrário de suas variações, a abordagem Top-Down convencional utiliza apenas uma técnica de AM.

$\mathrm{Na}$ abordagem Ensemble Top-Down foram utilizadas cinco diferentes estratégias para a combinação das saídas dos classificadores bases, dando origem a cinco algoritmos diferentes: votação por maioria (algoritmo EnsTPVotM); votação ponderada (algoritmo EnsTPVotP); votação ponderada por ranking (algoritmo EnsTPVotR); treinamento de um classificador para realizar a combinação (algoritmo StackEnsTP); e uma variação dessa última estratégia por meio da adição de um processo seletivo na indução do classificador responsável pela combinação (algoritmo StackEnsTPSel). Esses algoritmos são descritos no Capítulo 3.

Para o desenvolvimento dos algoritmos Top-Down foram utilizadas as seguintes técnicas de AM: C4.5 (Quinlan, 1993), RIPPER (Repeated Incremental Pruning to Produce Error Reduction) (Cohen, 1995), Redes Bayesianas (Friedman et al., 1997), Máquinas de Vetores de Suporte (Support Vector Machines SVMs) (Cristianini \& Shawe-Taylor, 2000) e KNN (K-Nearest Neighbor) (Cover \& Hart, 1967). Essas técnicas foram utilizadas em sua forma convencional, uma vez que, ao contrário do que ocorre na abordagem Big-Bang, na aborda- 
gem Top-Down as técnicas convencionais de classificação podem ser utilizadas sem modificações.

\subsection{Resumo dos Resultados}

Para a realização dos experimentos, foram selecionados dois conjuntos de dados biológicos: um conjunto envolvendo dados da família de proteínas $G$ Protein-Coupled Receptor (conjunto GPCR), e um conjunto envolvendo dados de enzimas (conjunto EC). Tais conjuntos foram disponibilizados pelos autores dos trabalhos (Holden \& Freitas, 2006) e (Holden \& Freitas, 2005), nos quais os dados foram utilizados originalmente.

Dentre os algoritmos baseados na abordagem Top-Down convencional, o algoritmo baseado na técnica KNN obteve o melhor resultado para o conjunto GPCR, enquanto que o algoritmo baseado na técnica SVM obteve o melhor resultado para o conjunto EC.

O algoritmo Selective Top-Down apresentou melhoras no desempenho preditivo em relação a utilização das técnicas individualmente. Entretanto, para o conjunto GPCR, os resultados do algoritmo Top-Down baseado na técnica KNN foram ligeiramente melhores do que os obtidos pelo Selective Top-Down, para todos os níveis da hierarquia.

Dentre os algoritmos baseados na abordagem Ensemble Top-Down, o algoritmo StackEnsTPSel obteve melhor desempenho preditivo para o conjunto GPCR, enquanto que o algoritmo StackEnsTP obteve um melhor desempenho para o conjunto EC. Dessa forma, para os experimentos realizados, a estratégia de combinação de saídas dos classificadores bases por meio de um outro classificador apresentou melhores resultados do que as demais estratégias de combinação.

Em uma análise comparativa entre várias abordagens foram incluídos os melhores resultados obtidos pelos algoritmos Top-Down e resultados obtidos pelo HC4.5 (algoritmo Big-Bang). O algoritmo StackEnsTPSel (representante da abordagem Ensemble Top-Down) obteve melhor desempenho preditivo para todos os níveis da hierarquia GPCR, enquanto que o algoritmo StackEnsTP (representante da abordagem Ensemble Top-Down) obteve melhor desempenho preditivo para os três últimos níveis da hierarquia EC e se equiparou no primeiro nível aos resultados do algoritmo Selective Top-Down e do algoritmo Top-Down baseado na técnica SVM.

Dessa forma, dentre todas as abordagens investigadas, a abordagem Ensemble Top-Down foi que a que obteve melhores resultados por meio de seus algoritmos. Deve ser observado, porém, que a melhora do desempenho preditivo apresentada pelos algoritmos Ensemble Top-Down não foi estatisticamente 
significativa em relação a todos os algoritmos envolvidos na comparação entre várias abordagens.

\subsection{Organização do Documento}

Este documento está organizado da seguinte forma: no Capítulo 2, são discutidos os principais aspectos que envolvem a tarefa de classificação de dados; no Capítulo 3, são introduzidos os principais conceitos de classificação hierárquica e as abordagens investigadas neste projeto; no Capítulo 4, é apresentada uma revisão bibliográfica abrangendo trabalhos que tratam problemas hierárquicos do domínio biológico; no Capítulo 5, são descritos a metodologia utilizada para condução dos experimentos e os resultados obtidos; por fim, as conclusões da pesquisa são apresentadas no Capítulo 6. No Apêndice A, são descritas as análises estatísticas realizadas para os resultados experimentais; e no Apêndice B, são descritos os resultados para uma análise de diversidade dos classificadores bases gerados para um dos algoritmos Ensemble Top-Down. 


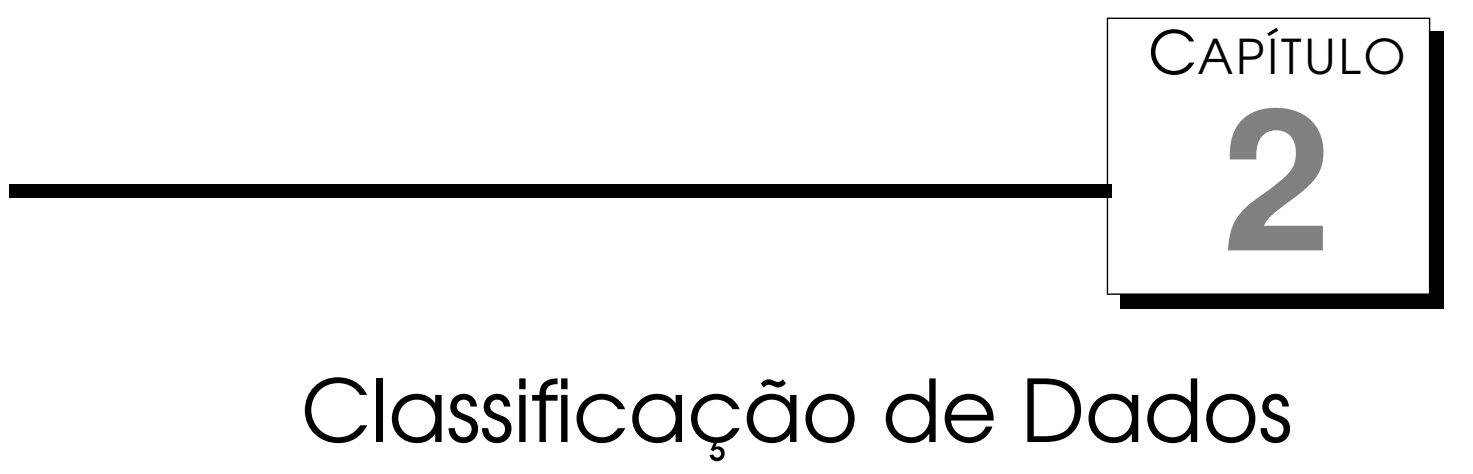

Classificação de dados é um processo que permite a extração de informações a partir de um conjunto de dados brutos por meio de sua categorização. De maneira geral, um processo de classificação consiste na atribuição de rótulos aos dados, de tal forma que esses rótulos confiram informações aos dados categorizados sob o mesmo rótulo.

Embora o conceito de classificação de dados seja mais comum em Computação, Engenharia, Matemática, Estatística e outras Ciências Exatas, esse processo pode ser identificado no cotidiano de seres humanos e animais. Guando uma pessoa observa um indivíduo passando do outro lado da rua, ela consegue, por meio de processos cerebrais, atribuir algumas informações aos dados captados pelos seus mecanismos visuais. Ao observar as características físicas da pessoa no outro lado da rua, o observador pode, com certo grau de certeza (que depende da capacidade visual do observador, características do observado, bem como das condições do ambiente que separa os dois indivíduos), identificar a pessoa como um homem ou uma mulher, um adulto ou uma criança, uma pessoa conhecida ou desconhecida, assim como combinações dessas categorias. Raciocínios como esses, muitas vezes realizados de forma automática pelo cérebro, são exemplos de processos de classificação. Um outro exemplo de classificação pode ser observado quando um animal, ao se deparar com um outro ser vivo em sua proximidades, precisa, em sua luta por sobrevivência, classificar tal ser vivo como presa, predador ou indivíduo da mesma espécie.

Em computação, uma área de estudo com amplo interesse em classificação de dados é área de AM, cuja definição é apresentada na Seção 2.1. As demais 
seções do capítulo estão organizadas da seguinte forma: na Seção 2.2, são apresentados os conceitos básicos que envolvem um processo de classificação; na Seção 2.3, são descritas de modo sucinto as cinco técnicas de aprendizado supervisionado que foram utilizadas para a realização dos experimentos de classificação nesta dissertação; estratégias de combinações de classificadores são descritas na Seção 2.4; na Seção 2.5, são discutidas algumas abordagens que podem ser utilizadas para a avaliação de algoritmos de classificação; por fim, algumas considerações finais são feitas na Seção 2.6.

\subsection{Aprendizado Supervisionado}

AM é uma área de Inteligência Artificial (IA) cujo objetivo é desenvolver técnicas computacionais que possibilitem que o computador tome decisões baseadas em experiências acumuladas. Dessa maneira, AM é a área que trata a questão de como construir programas que melhorem seu desempenho automaticamente com a experiência (Mitchell, 1997).

Técnicas de AM possibilitam a aquisição automática de conhecimento. A aplicação de métodos de AM para grandes bases de dados é parte do processo de Mineração de Dados (Data Mining - DM).

Muitas técnicas de AM têm sido propostas com o intuito de melhorar o desempenho obtido na realização de uma determinada tarefa ou tomada de decisão. Embora, em alguns casos, tais técnicas utilizem metodologias bem distintas, elas estão fundamentadas no conceito de indução.

A indução é um processo de raciocínio por meio do qual podem ser feitas inferências gerais a respeito de um determinado conjunto de exemplos, tendo como base observações em um subconjunto particular. Em outras palavras, busca-se formular hipóteses ou proposições gerais com base em um certo número de dados que sejam representativos do domínio para o qual se quer fazer a generalização. O processo de aquisição de conhecimento baseado na indução é conhecido como Aprendizado Indutivo.

Como pode ser observado na hierarquia do aprendizado mostrada na Figura 2.1, o processo indutivo de aprendizado pode ser dividido em duas categorias: aprendizado supervisionado e aprendizado não-supervisionado. $\mathrm{O}$ aprendizado supervisionado, por sua vez, pode ser dividido em problemas de classificação e regressão.

A diferença entre aprendizado supervisionado e não-supervisionado diz respeito à forma como é feito este processo de generalização do conhecimento.

No aprendizado supervisionado são construídos algoritmos de indução (também chamados de indutores) que realizam inferências a partir de exemplos rotulados. Assim, no seu treinamento, o indutor ajusta um modelo utilizando 


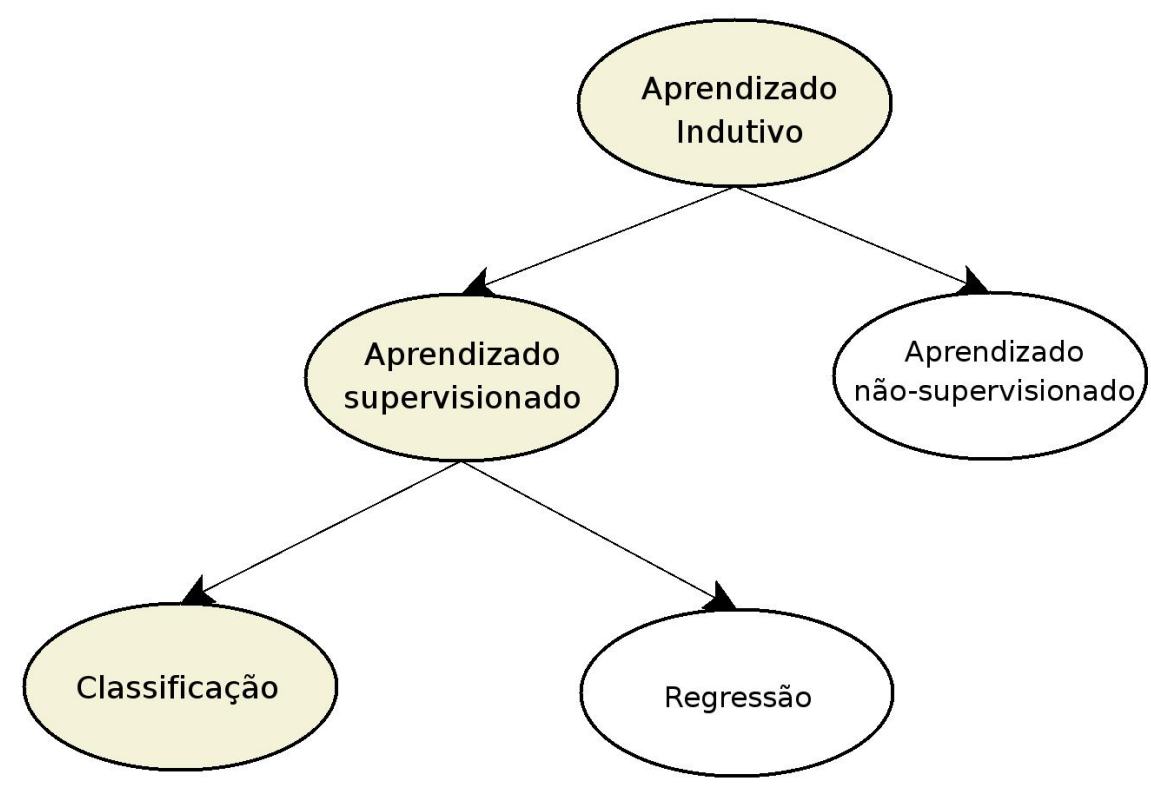

Figura 2.1: Hierarquia do Aprendizado (Monard \& Baranauskas, 2003).

exemplos junto com a informação de sua saída esperada (alvo). O objetivo do algoritmo é construir um modelo com a capacidade de obter a saída desejada a partir de exemplos não rotulados, quando esses são utilizados como entrada. Rede Neural Artificial (Artificial Neural Network - ANN), SVMs, e algoritmos de indução de Árvores de Decisão (ADs) (Quinlan, 1986) são exemplos de técnicas supervisionadas de aprendizado.

Pode-se fazer a analogia do aprendizado supervisionado com o processo de aprendizado de um aluno com a presença de um professor ou supervisor. $\mathrm{O}$ aluno resolve um determinado problema e depois conta com a avaliação do professor, que o informa qual seria a saída correta. O procedimento é repetido até que o aluno saiba gerar por si só a resposta correta para o problema, assim como para novos problemas similares.

Formalmente, pode-se dizer que o objetivo do aprendizado supervisionado é encontrar uma função $f$ que mapeie os valores de $T_{i}=\left(x_{i 1}, x_{i 2}, \ldots, x_{i m}\right)$ em valores de $y(f: T \mapsto y)$, com base em pares de exemplos $\left(T_{i}, y_{i}\right)$. Nessa notação, $T_{i}$ é um exemplo de entrada e $y_{i}$ é o seu rótulo.

Os rótulos fornecidos nos exemplos de aprendizado supervisionado dizem respeito à classe a qual o exemplo pertence. Um exemplo é dito rotulado quando esse rótulo da classe, também chamado de atributo alvo ou dependente, é fornecido juntamente com seus atributos de entrada, também chamados de atributos independentes. Quando os rótulos são discretos (exemplo: 
classe A, classe B, etc.), o problema é denominado de classificação. Quando os rótulos são contínuos (exemplo: preço esperado de um produto no mercado em função da variação de suas características), o problema é denominado de regressão.

Em contraste ao aprendizado supervisionado, no aprendizado não-supervisionado são disponiveis apenas os exemplos de entradas e o indutor não tem informações a respeito da saída esperada. Técnicas de aprendizado nãosupervisionado têm por objetivo encontrar padrões entre os exemplos de entrada por meio da realização de agrupamentos (clustering). O algoritmo $k$ médias e o algoritmo de agrupamento hierárquico são exemplos de técnicas de aprendizado não-supervisionado.

\subsection{Conceitos Básicos de Classificação}

Um processo de classificação em AM se dá por meio da utilização de um algoritmo de aprendizado (indutor), cujo objetivo é encontrar um bom classificador a partir dos exemplos de entrada rotulados. Na Figura 2.2 o esquema geral envolvido em um processo de classificação é resumido.

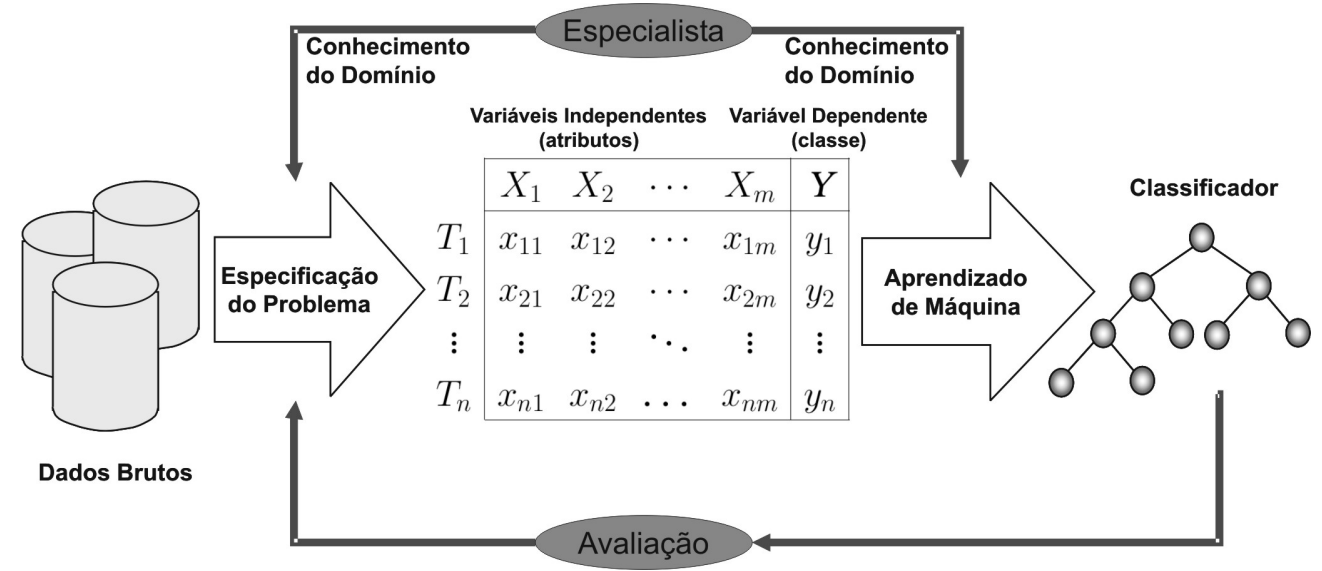

Figura 2.2: Processo de Classificação (Monard \& Baranauskas, 2003).

Inicialmente, os dados brutos pertencentes ao domínio sobre o qual será aplicado o algoritmo de classificação são representados de forma adequada a serem processados. Os dados são organizados em um conjunto de exemplos, de forma que cada exemplo seja constituído por uma tupla de atributos. Cada atributo de entrada corresponde a uma característica ou propriedade do exemplo. Juntamente com os atributos, também é fornecido o rótulo de cada exemplo. Exemplos de atributos que descrevam dados de clientes bancários podem ser "Rendimento mensal" e "Data da abertura da conta". Rótulos para 
tais dados poderiam ser o status do cliente perante o banco: "Cliente Especial”, “Cliente Padrão”, etc.

Após o processamento dos dados, esses são então fornecidos como entrada para o indutor para que seja realizado o processo de treinamento. Nessa fase, cada exemplo pode ser representado por um par $\left(T_{i}, y_{i}\right)$, tal que $i=$ $1,2, \ldots, n, n$ é o número de exemplos de treinamento, $T_{i}$ é uma tupla de atributos que descrevem cada exemplo e $y_{i}$ é o atributo alvo (rótulo). O objetivo do processo de treinamento é obter uma função que mapeie cada $T_{i}$ a seu $y_{i}$ correspondente. A função de mapeamento é encontrada com base nos ajustes dos parâmetros livres do modelo.

Finalizado o treinamento do modelo de classificação, o modelo resultante consiste em um classificador que deve ser capaz de realizar o processo de predição da classe à qual pertence um exemplo de entrada. Dependendo da fase de treinamento, pode ser que o classificador resultante esteja sub-ajustado ou super-ajustado, situações essas que são indesejadas. O sub-ajustamento (underfitting) ocorre quando a hipótese ajusta-se muito pouco aos exemplos de treinamento. Essa situação se dá, por exemplo, quando a amostra de exemplos utilizados no treinamento é pouco representativa, prejudicando assim o processo de indução. Outra situação é quando o tamanho do classificador não é suficiente para uma boa generalização. Essa situação pode ocorrer, por exemplo, quando um número insuficiente de neurônios é especificado para uma ANN. O super-ajustamento (overfitting), por sua vez, ocorre quando a hipótese resultante é muito específica. Neste caso a hipótese se ajusta muito aos exemplos de treinamento e não é eficaz para exemplos diferentes. Dessa forma, a construção de um conjunto de treinamento adequado e o ajuste correto dos modelos são fundamentais para a obtenção de um classificador confiável.

Após a fase de treinamento, o desempenho do classificador gerado pelo indutor é avaliado por meio da utilização de novos exemplos, que não foram vistos durante o treinamento. Essa etapa é conhecida como fase de teste ou validação.

Na Figura 2.3 é mostrada uma função de classificação simples para um problema de duas classes. Por meio do conjunto de exemplos oferecidos como treinamento, a função gerada é capaz de distinguir entre exemplos da Classe A e da Classe B, com base na reta que foi ajustada para separar as duas classes.

\subsection{Técnicas de AM para Classificação de Dados}

Pode-se destacar, em aprendizado supervisionado, diversos paradigmas de aprendizado, que determinam a abordagem fundamental utilizada pela téc- 


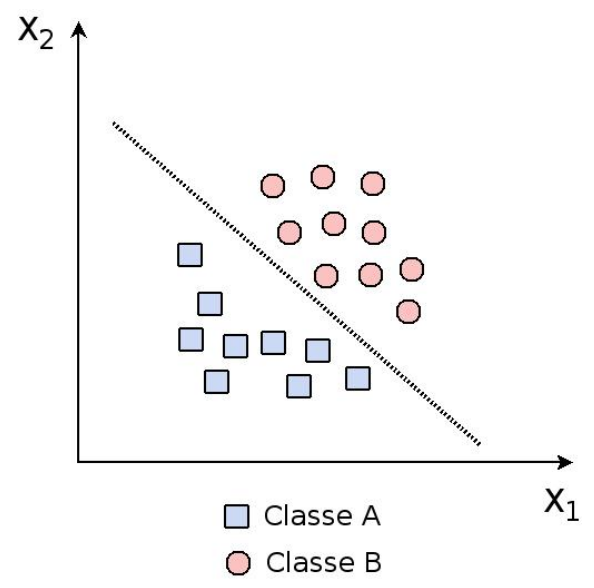

Figura 2.3: Exemplo de uma função de classificação.

nica de AM para a realização do processo de indução. Neste projeto foram utilizadas técnicas representativas de três paradigmas - Simbólico, Estatístico e Baseado em Exemplos, que são discutidos ao longo desta seção. Além desses, pode-se destacar os paradigmas Conexionista e Evolutivo. O Paradigma Conexionista utiliza construções matemáticas para realizar o processo de indução e tem como principal representante as ANNs (Haykin, 1999a). ANNs são inspiradas no sistema nervoso cerebral, cujas unidades básicas - neurônios - são altamente interconectadas (daí a origem do nome conexionismo). $\mathrm{O}$ Paradigma Evolutivo também é inspirado na Biologia, porém com enfoque nos mecanismos utilizados para a sobrevivência de uma espécie em seu ambiente. A idéia geral desse paradigma consiste na competição e combinação de indivíduos pertencentes a uma população de soluções candidatas. O objetivo é encontrar um indivíduo que atenda de forma adequada aos requisitos para a solução do problema em questão.

\subsection{Paradigma Simbólico: C4.5 e RIPPER}

O Paradigma Simbólico está fundamentado na construção de representações simbólicas para a generalização do conhecimento. Em um problema de classificação, tais representações são formadas a partir do estabelecimento de relacionamentos lógicos entre os atributos de entrada que descrevem o conjunto de dados e os rótulos (classes) envolvidos no problema. Representações simbólicas podem estar no forma de uma expressão lógica, $\mathrm{AD}$, regras ou rede semântica (Monard \& Baranauskas, 2003). Um exemplo de uma lógica proposicional, que utiliza conjunções, disjunções e negações para representar relações entre os atributos individuais, é apresentado a seguir. Essa regra pode ser diretamente interpretada da seguinte forma: se um aluno obteve, 
pelo menos, a nota mínima exigida em um curso e obteve a freqüência satisfatória, ele será aprovado no curso.

Nota_Minima_Atingida $\wedge$ Freqüência_Satisfatória $\longrightarrow$ APROVADO

Uma das premissas do Aprendizado Simbólico é a exigência de que as descrições (representações) simbólicas sejam facilmente compreendidas e interpretadas em linguagem natural, de maneira similar à representação do conhecimento humano. Dessa forma, sistemas baseados nesse paradigma são denominados de sistemas orientados ao conhecimento. Sistemas desse tipo são muito úteis quando o modelo gerado precisa ser analisado por um especialista da área do problema ao qual o sistema está sendo aplicado. Quando um sistema não é orientado ao conhecimento, ele é denominado de sistema de caixa-preta, uma vez que o modelo de generalização do conhecimento gerado não é diretamente interpretável.

Dois tipos de técnicas muito utilizados em AM simbólico e que foram utilizados neste projeto são: técnicas para indução de ADs e técnicas para indução direta de regras. Esses dois tipos de técnicas são baseados em regras, com a distinção de que para o primeiro tipo as regras são obtidas após a construção da $\mathrm{AD}$ (método indireto de extração de regras), enquanto que para o último as regras de classificação são obtidas diretamente dos dados (método direto de extração de regras).

Para que um método de classificação baseado em regras funcione adequadamente, o conjunto final de regras deve possuir duas propriedades fundamentais. A primeira exige que as regras sejam mutuamente exclusivas, ou seja, que cada exemplo de entrada seja somente coberto por uma das regras do conjunto. Quando essa propriedade não pode ser atendida, duas soluções podem ser tomadas: ordenação das regras por ordem decrescente de prioridade, de modo que a regra que primeiro cobrir um registro, seguindo a ordem estabelecida, seja selecionada; ou votação (comum ou ponderada) entre as regras que cobrem um exemplo. Outra propriedade exige que as regras sejam exaustivas, ou seja, que haja uma regra para cada combinação de atributos. Quando essa propriedade não pode ser atendida, uma solução possível consiste na escolha de uma das classes como default (padrão), para o caso dos valores dos atributos de entrada não serem cobertos por nenhuma regra. Essas duas propriedades juntas (ou as soluções descritas para as mesmas) garantem que cada exemplo seja coberto por uma regra e que não haja conflitos no modelo de classificação. 


\section{Árvores de Decisão}

Uma $\mathrm{AD}$ é uma estrutura de dados definida recursivamente como: um nó folha que corresponde a uma classe ou um nó de decisão que contém um teste sobre algum atributo. Para cada resultado do teste existe uma aresta para uma subárvore. Cada subárvore tem a mesma estrutura que a árvore (Monard \& Baranauskas, 2003).

Na Figura 2.4 é apresentado um exemplo ilustrativo de uma AD que utiliza informações climáticas para realizar a inferência se será possível jogar tênis em um determinado dia.

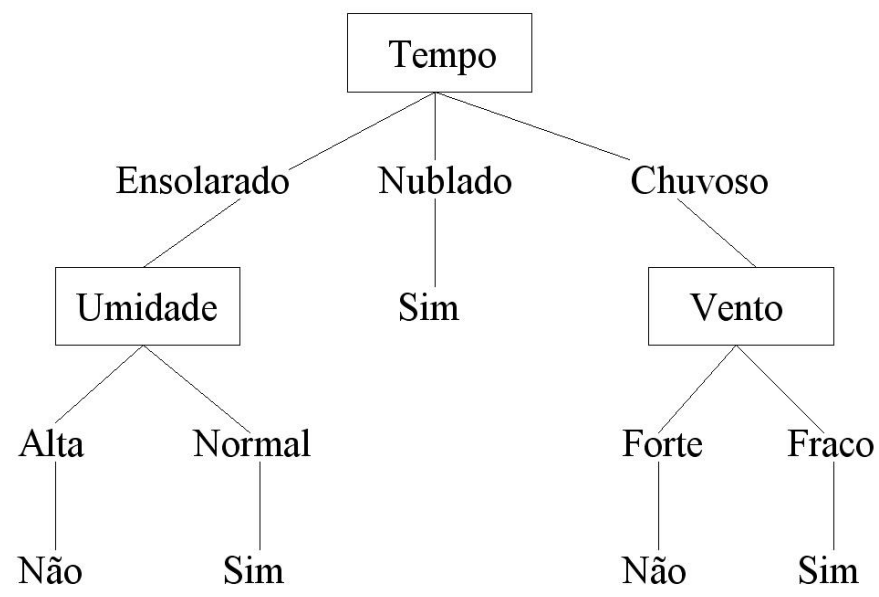

Figura 2.4: Exemplo de Árvore de Decisão (Mitchell, 1997)

A partir dessa $\mathrm{AD}$, regras podem ser obtidas. Por exemplo, se o tempo estiver ensolarado e o índice de umidade estiver normal, as condições estarão propícias para se jogar tênis. Essa regra é representada a seguir:

$$
\text { Tempo }=\text { Ensolarado } \wedge \text { Umidade }=\text { Normal } \longrightarrow \text { JOGAR TÊNIS }
$$

A classificação de dados em uma $\mathrm{AD}$ se dá a partir da raiz em direção a alguma folha, que providencia a classificação. Nesse processo, ao testar um atributo em um determinado nó, move-se para baixo no ramo da árvore correspondente ao valor do atributo presente no dado de teste. O processo é então repetido para a subárvore enraizada no novo nó. Exemplos de algoritmos que induzem ADs são: ID3 (Guinlan, 1986) e seu sucessor C4.5 (Quinlan, 1993).

$\mathrm{O}$ algoritmo $\mathrm{C} 4.5$, que foi selecionado como uma das técnicas utilizadas neste projeto, induz ADs a partir de um mecanismo Top-Down. Nesse processo, a cada estágio, é feita uma decisão com base em uma medida interna denominada entropia. Tal decisão utiliza o valor de entropia de cada atributo para um conjunto de treinamento para definir qual atributo melhor classifica 
o restante dos exemplos de treinamento.

Um problema comumente enfrentado por técnicas de AM que utilizam ADs é o super-ajustamento da hipótese aos dados, o que pode levar a uma queda significante do desempenho preditivo do modelo de classificação (Mitchell, 1997). Para evitar que isso ocorra, alguns mecanismos podem ser utilizados. Entre eles, pode-se destacar a pré-poda e a pós-poda. A pré-poda tem como objetivo controlar o super-ajustamento durante a indução do modelo de classificação, o que pode ser feito, por exemplo, por meio do descarte de alguns exemplos durante a fase de treinamento. A pós-poda consiste em tratar o super-ajustamento após a indução do modelo. Isso pode ser feito por meio do corte de alguns dos ramos da AD. Procedimentos de poda (prunning) como esses também podem ser aplicados a outras técnicas de AM, como métodos baseados em regras e ANNs.

ADs foram consideradas na implementação dos modelos hierárquicos investigados neste projeto principalmente devido a sua alta legibilidade, ou seja, pelo fato de serem fáceis de entender e interpretar.

\section{Extração Direta de Regras}

Métodos que implementam extração direta de regras freqüentemente utilizam um algoritmo de cobertura seqüencial dos exemplos, que consiste em uma maneira gulosa (greedy) para obtenção das regras, tendo como base uma medida de avaliação. O conjunto de regras, inicialmente vazio, é incrementado a medida que as regras são selecionadas. Em cada iteração uma classe é analisada, sendo considerada como positiva e todas as outras como negativas, e a melhor regra é selecionada para compor o conjunto de regras. É desejável que uma regra cubra a maioria dos exemplos positivos do conjunto de treinamento e nenhum (ou poucos) exemplo negativo.

O algoritmo RIPPER (Cohen, 1995) é um método de extração direta de regras muito utilizado. Para problemas multiclasses, o RIPPER ordena, de maneira crescente, as classes envolvidas no problema de acordo com a sua freqüência no conjunto de treinamento. A classe majoritária (com maior freqüência no conjunto de treinamento) é escolhida como classe default e regras para cobrir as demais classes são geradas de maneira iterativa, iniciando-se pela menos freqüente. Para problemas binários o procedimento é o mesmo, com a diferença de que as regras só serão geradas para reconhecer uma classe - a classe minoritária, uma vez que a classe majoritária é escolhida como default.

Esse algoritmo é particularmente adequado para construção de modelos para conjuntos de dados que apresentam desbalanceamento entre o número de exemplos das classes. Além disso, ele trabalha bem com dados com ruídos, 
devido ao seu mecanismo de validação, que previne o super-ajuste da hipótese ao conjunto de treinamento. Essas potencialidades do RIPPER foram as principais motivações para a sua escolha como uma das técnicas utilizadas neste projeto.

\subsubsection{Paradigma Estatístico: SVMs e Redes Bayesianas}

O Paradigma Estatístico tem como fundamento a exploração das dependências funcionais de um conjunto de dados por meio de modelos estatísticos. $\mathrm{O}$ objetivo do aprendizado é encontrar uma função ou modelo (classificador) que separe os dados em suas respectivas classes. Assume-se, inicialmente, que os dados são gerados de forma independente e identicamente distribuída de acordo com modelo de distribuição de probabilidade assumido para o problema.

SVMs constituem uma técnica de AM embasada na Teoria do Aprendizado Estatístico, desenvolvida por (Vapnik, 1995). No Paradigma Estatístico, podese destacar também o Aprendizado Bayesiano, que faz uso da manipulação direta de probabilidades para a realização do processo de indução. Naive Bayes (Mitchell, 1997) e Redes Bayesianas (Friedman et al., 1997) são técnicas representantes desse tipo de aprendizado.

\section{Máquinas de Vetores de Suporte}

No projeto de SVMs, funções não-lineares de kernel mapeiam os vetores de entrada em um espaço de dimensão mais elevada (espaço de características), no qual um hiperplano de separação é obtido para a resolução do problema de classificação (Cristianini \& Shawe-Taylor, 2000).

Busca-se o hiperplano que maximize a margem de separação entre os dados das diferentes classes. De acordo com a Teoria do Aprendizado Estatístico, esse é o hiperplano com maior capacidade de generalização que pode ser obtido a partir dos dados de treinamento.

O processo de mapeamento dos dados para o espaço de características permite obter fronteiras não lineares para separação dos dados. Isso é ilustrado na Figura 2.5. O conjunto de dados bidimensional da Figura 2.5.a é mapeado para o espaço tridimensional representado na Figura 2.5.c. Nesse novo espaço, determina-se o hiperplano que maximiza a separação entre as classes. Essa função linear em $\Re^{3}$ corresponde à fronteira não linear em $\Re^{2}$ apresentada na Figura 2.5.b.

A margem de separação entre as classes é um conceito fundamental no projeto de SVMs e está associada ao erro permitido na classificação. Os dados que estão dentro da margem de separação ou sobre ela são denominados 


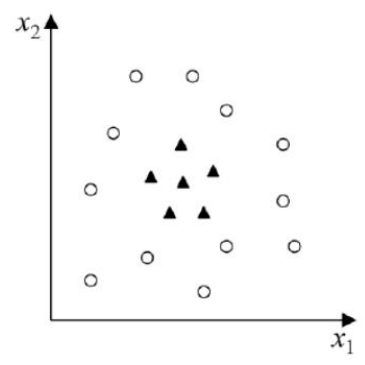

(a)

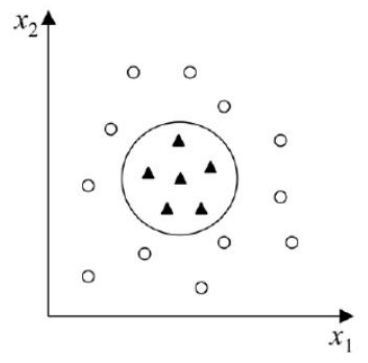

(b)

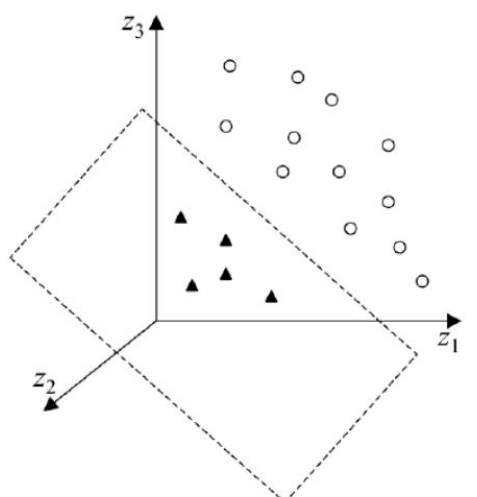

(c)

Figura 2.5: Exemplo de problema de separação de dados por SMVs: (a) Conjunto de dados não linear; (b) Fronteira não linear no espaço de entradas; (c) Fronteira linear no espaço de características (Lorena, 2006)

vetores de suporte e irão definir a superfície de separação. Na Figura 2.6 os vetores de suporte são indicados por um círculo extra.

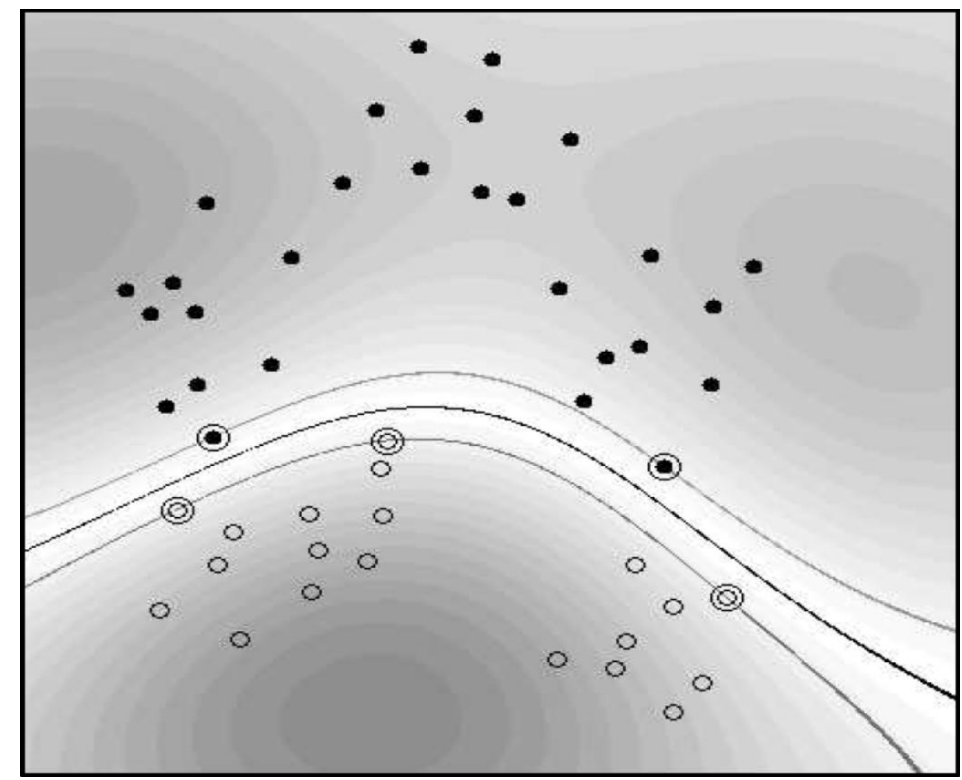

Figura 2.6: Exemplos vetores de suporte (dados com círculo extra) (Chen et al., 2005)

A escolha de SVMs como uma das técnicas de AM utilizadas na investigação dos modelos hierárquicos foi motivada pela sua boa capacidade de generalização, mesmo para problemas com muitos atributos, os quais são comuns no domínio da Bioinformática. 


\section{Aprendizado Bayesiano: Redes Bayesianas}

Técnicas de AM baseadas no Aprendizado Bayesiano, tais como Naive Bayes e Redes Bayesianas, estão fundamentadas na manipulação de probabilidades explícitas para hipóteses. O cálculo das probabilidade é feito com base no Teorema de Bayes, representado na Equação 2.1.

$$
P(A / B)=\frac{P(B / A) * P(A)}{P(B)}
$$

Essa equação envolve dois tipos de probabilidades: probabilidades a priori e probabilidades a posteriori. $P(A)$ e $P(B)$ são probabilidades a priori de $A$ e $B$, respectivamente. O termo "probabilidade a priori" indica que a probabilidade $P(A)$ (ou $P(B)$ ) não leva em consideração nenhuma informação a respeito de $B$ (ou $A$ ). $P(B / A)$ e $P(A / B)$ são denominadas de probabilidades a posteriori de $B$ condicional a $A$ e de $A$ condicional a $B$, respectivamente.

A abordagem adotada no classificador Naive Bayes consiste em classificar um novo dado $T$ com o valor mais provável, $Y_{s}$, dado os valores de atributos de entrada $<x_{1}, x_{2} \ldots x_{m}>$ que o descrevem e um conjunto de possiveis valores $Y$. O fórmula para o cálculo de $Y_{s}$ é mostrada na Equação 2.2.

$$
Y_{s}=\arg \max _{y_{j} \in Y} P\left(y_{j}\right) \prod_{i} P\left(x_{i} \mid y_{j}\right)
$$

Tomando o exemplo de um gerente bancário que tem que decidir se um cliente deve ou não receber um empréstimo, o conjunto $Y$ é igual a \{sim, não\}. Os atributos $\left\langle x_{1}, x_{2} \ldots x_{m}>\right.$ podem ser informações a respeito do cliente e/ou variáveis que definam a situação financeira do banco.

Como pode ser observado na equação, o classificador Naive Bayes é baseado na simplificação que os valores dos atributos são condicionalmente independentes. Em outras palavras, a probabilidade de observar a conjunção de atributos $\left\langle x_{1}, x_{2} \ldots x_{m}>\right.$ é igual ao produto de suas probabilidades individuais. Essa suposição feita pelo Naive Bayes pode ser considerada rígida, pois em muitos casos os atributos não são condicionalmente independentes. Dessa forma, optou-se por utilizar Redes Bayesianas, uma abordagem mais flexível para a modelagem das probabilidades.

A abordagem de Redes Bayesianas utiliza uma representação gráfica para descrever os relacionamentos entre as variáveis (atributos e rótulos) do conjunto de dados. Essa representação é constituída de dois tipos de elementos: um DAG, no qual os nós representam as variáveis e os arcos representam relações de dependência entre pares de variáveis; e uma tabela de probabilidades para cada nó do DAG. Na Figura 2.7, é mostrado um exemplo de uma representação gráfica utilizada por uma Rede Bayesiana para detecção de do- 
ença cardíaca ou azia. Os atributos utilizados dizem respeito às seguintes informações relacionadas ao paciente: alimentação, prática regular ou não de exercícios, e sintomas apresentados (pressão sangüínea alta e dor no peito).

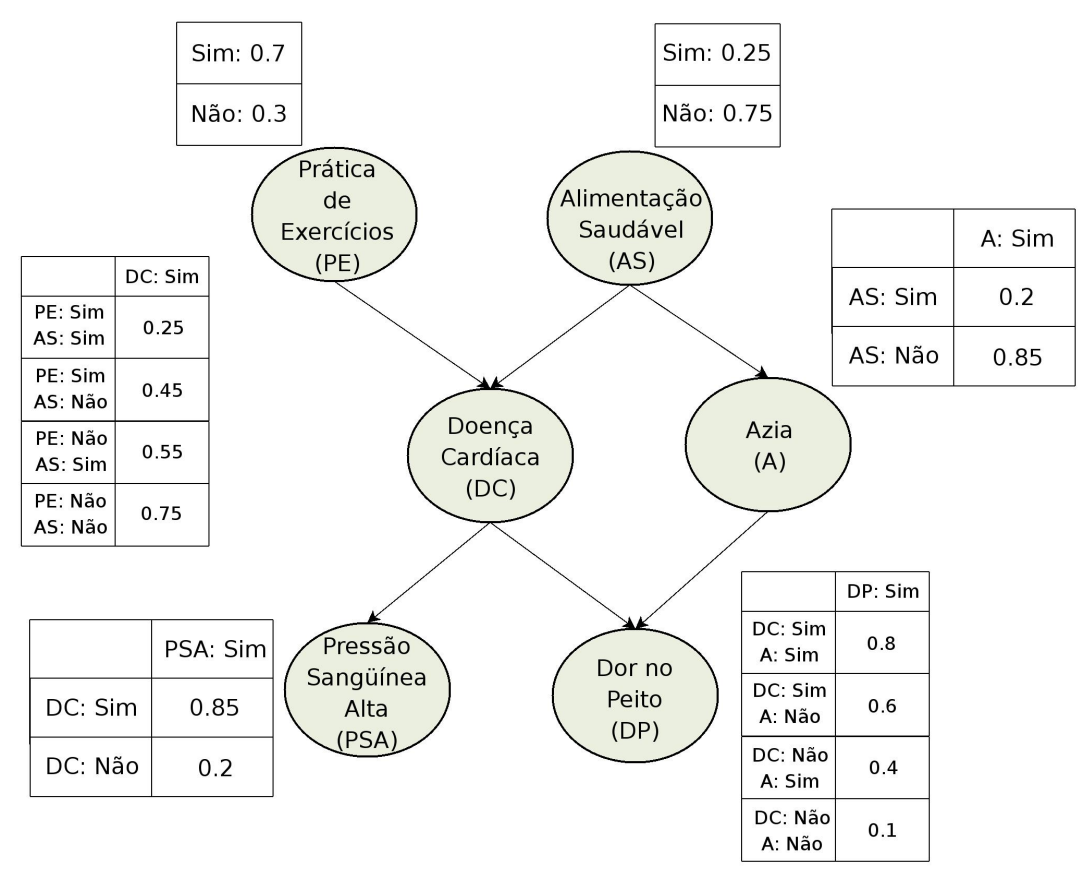

Figura 2.7: Exemplo de uma Rede Bayesiana para detecção de doença cardíaca ou azia em paciente (figura adaptada de (Tan et al., 2005)).

Em uma Rede Bayesiana, uma variável $A$ é dita condicionalmente dependente de $B$ quando o nó que a representa tem como nó-pai o nó que representa a variável $B$. No exemplo mostrado na Figura 2.7, o sintoma "Pressão Sanguínea Alta" é condicionalmente dependente do quadro de doença cardíaca. A probabilidade da pressão sanguínea apresentar-se alta em um caso de doença cardíaca é de $85 \%$, muito mais alta do que em um caso que o paciente não apresenta a doença (20\%), como pode ser observado na tabela localizada ao lado do nó relativo à pressão sangüínea.

Uma vez gerada a topologia da Rede Bayesiana, a classe predita é dada pelo rótulo mais provável, baseado nos atributos apresentados pelo registro de entrada.

A utilização de Redes Bayesianas neste projeto foi motivada pelo fato dessa técnica fornecer probabilidades que denotam o grau de certeza na classificação e estar entre as abordagens mais práticas para alguns de problemas de aprendizado. Além disso, o método é robusto em relação a super-ajustamento (Tan et al., 2005). 


\subsubsection{Paradigma Baseado em Exemplos: KNN}

O Paradigma Baseado em Exemplos (Instance-Based) tem como pressuposto que se dois exemplos são similares, então eles pertencem à mesma classe. Assim, quando um novo exemplo é similar a um exemplo conhecido, a classe deste é atribuída ao novo exemplo. Para isso, o algoritmo deve manter em memória os exemplos pertencentes ao conjunto de treinamento. Entretanto, dependendo da técnica, nem todos os exemplos do conjunto de treinamento necessitam permanecer armazenados na memória; nesse caso, apenas os exemplos mais significativos são armazenados.

Como algoritmos desse paradigma não geram um modelo explícito a partir do conjunto de treinamento, tais algoritmos são denominados de lazy (preguiçosos); em contraposição com os algoritmos de outros paradigmas, que na fase de treinamento geram um modelo explícito de classificação e depois descartam os dados de treinamento. Uma importante vantagem do Paradigma Baseado em Exemplos é que ele constrói uma diferente aproximação da função objetivo para cada exemplo. Porém, também deve ser levado em conta o alto custo computacional envolvido na tarefa de classificação de novos exemplos.

Duas técnicas muito utilizadas desse paradigma são: técnica dos $k$ vizinhos mais próximos - KNN ( $k$-Nearest Neighbor) (Cover \& Hart, 1967) e Raciocínio Baseado em Casos (RBC) (Kolodner, 1993). Neste projeto, a técnica escolhida desse paradigma foi o KNN.

\section{KNN (k-Nearest Neighbor)}

$\mathrm{O}$ algoritmo KNN relaciona cada um dos exemplos a um ponto em um espaço m-dimensional $\Re^{m}$, sendo que $m$ é o número de atributos de entrada que descrevem o conjunto de dados. Assim, quando um novo exemplo necessita ser classificado, a similaridade com os exemplos já conhecidos é calculada por meio da distância de tais exemplos em relação ao novo exemplo. Essa distância é usualmente calculada por meio da distância euclidiana entre os exemplos, considerando os valores dos seus atributos de entrada. Considerando $\left\langle x_{1}, x_{2} \ldots x_{m}>\right.$ como o vetor de atributos, a distância entre dois exemplos $T_{1}$ e $T_{2}$ é dada pela Equação 2.3.

$$
d\left(T_{1}, T_{2}\right)=\sqrt{\sum_{r=1}^{m}\left(x_{r}\left(T_{1}\right)-x_{r}\left(T_{2}\right)\right)}
$$

Se $k$ é igual a 1, a classe do novo exemplo será igual à classe do exemplo com a menor distância em relação a ele. No caso de $k$ ser maior que 1 , é formada uma lista contendo os $k$ vizinhos mais próximos do novo exemplo. 
Então, a Equação 2.4 é utilizada para calcular a classe à qual o novo exemplo pertence.

$$
Y^{*}=\arg \max _{v} \sum_{\left(T_{i}, Y_{i}\right) \in D_{z}} f\left(v=Y_{i}\right)
$$

Nessa equação $v$ representa um rótulo, $\left(T_{i}, Y_{i}\right)$ são exemplos pertencentes à lista dos $k$ vizinhos mais próximos $\left(D_{z}\right)$, e $f(\cdot)$ é uma função que retorna 1 se $v=Y_{i}$ e 0 caso contrário. Em linhas gerais, a equação encontra o rótulo que estiver mais presente na lista dos vizinhos mais próximos, realizando assim uma votação pela maioria. Uma variação dessa abordagem consiste em atribuir pesos à votação dos vizinhos mais próximos. Porém, neste projeto foi utilizada a abordagem convencional.

Uma das vantagens dos classificadores KNN é que eles fazem sua predição baseada em informações locais, enquanto outros classificadores buscam encontrar um modelo que se ajuste a todo o espaço de entrada. Além disso, classificadores KNN podem produzir formas arbitrárias de fronteiras de decisão, em contraste com outros métodos que estão limitados a certos tipos de fronteiras, tais como ADs e classificadores baseados em regras, cujas fronteiras são determinadas por retas (Tan et al., 2005). Essas vantagens foram as principais motivações para a inserção do KNN neste estudo.

\subsection{Combinação de Classificadores}

Métodos de combinação de classificadores, também conhecidos na comunidade de AM como métodos de ensemble, são métodos que combinam múltiplos classificadores para gerar a saída do modelo de classificação (Kuncheva, 2004), (Dietterich, 2000). O objetivo de tais métodos é melhorar a estabilidade e o desempenho preditivo do modelo de classificação.

A idéia básica dos métodos de ensemble é gerar múltiplos classificadores (classificadores bases) a partir dos dados de treinamento. Então, na fase de teste, os registros são fornecidos como entrada para todos os classificadores envolvidos e a saída do modelo é obtida por meio de uma combinação das saídas de cada um dos classificadores bases, como pode ser observado na Figura 2.8.

Os métodos de combinação podem ser agrupados em quatro abordagens principais (Tan et al., 2005): métodos que manipulam o conjunto de treinamento; métodos que manipulam os atributos que descrevem o conjunto de dados; métodos que manipulam os rótulos das classes; e métodos que manipulam o algoritmo de aprendizado.

A abordagem que manipula o conjunto de treinamento consiste em deri- 


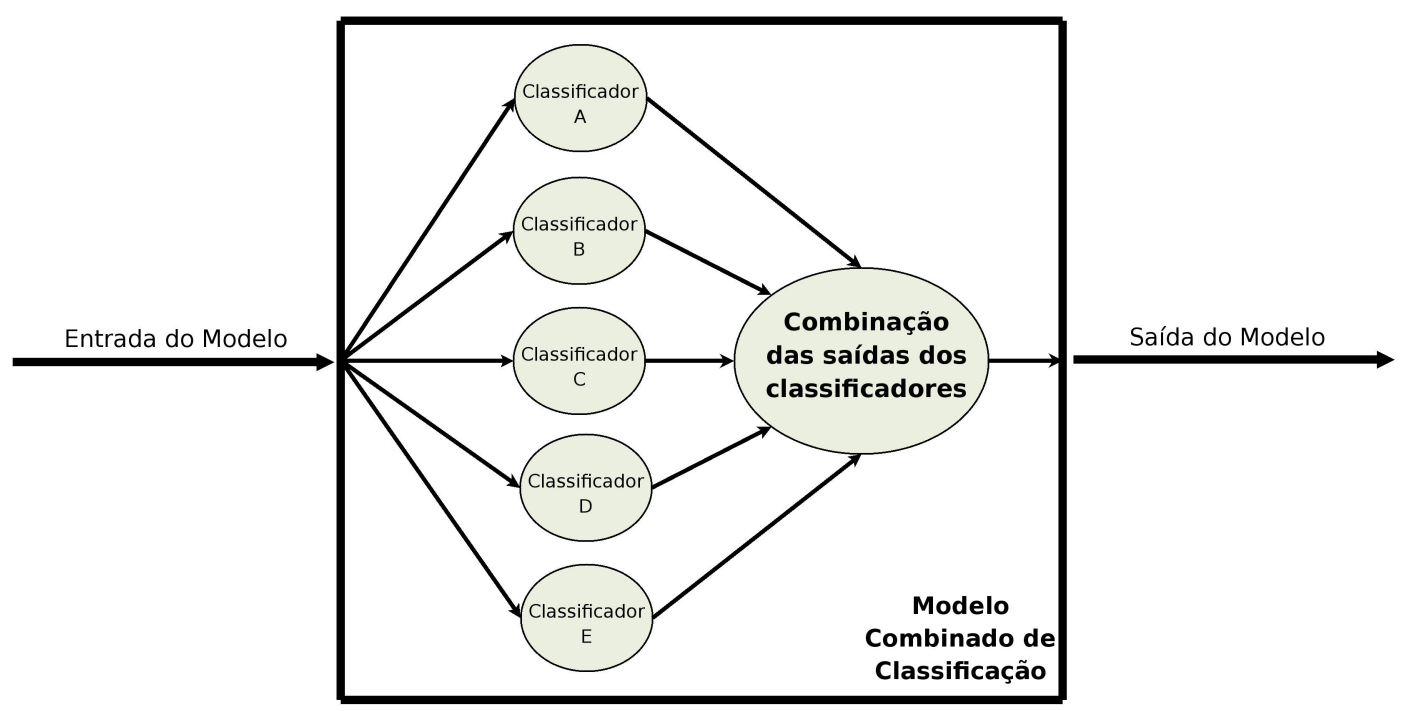

Figura 2.8: Esquema padrão de uma combinação de classificadores.

var conjuntos de treinamento a partir do conjunto de treinamento original, a partir de um processo de reamostragem. Geralmente, os conjuntos derivados têm o mesmo tamanho do conjunto original, porém com uma distribuição diferente dos dados. Além disso, alguns dados podem aparecer mais de uma vez nos conjuntos derivados, enquanto outros podem não estar presentes. Em seguida, um algoritmo de aprendizado é utilizado para gerar um classificador para cada um dos conjunto de treinamento gerados. Dois exemplos de métodos que seguem essa abordagem são bagging (Breiman, 1996) e boosting (Freund \& Schapire, 1999).

A abordagem que manipula os atributos consiste em escolher um subconjunto dos atributos de modo a formar conjuntos de treinamento com diferentes atributos, formados a partir de um conjunto de treinamento original. A escolha de um subconjunto de atributos diferente para cada conjunto de treinamento faz com que classificadores diferentes sejam gerados. Random forests (Breiman, 2001) é um exemplo de método que segue esse tipo de abordagem.

A abordagem que manipula os rótulos das classes consiste em transformar, por exemplo, um problema de classificação multiclasses em um problema binário. Esse procedimento consiste em selecionar um subconjunto de classes, retiradas do conjunto de todas as classes possiveis, e agrupá-las em um conjunto $A$. As demais classes são agrupadas em um conjunto $B$. Em seguida, os exemplos que pertencerem às classes presentes em $A$ têm seus rótulos renomeados para um único rótulo associado a $A$. O mesmo é feito para o subconjunto $B$. Essa divisão de classes em subconjuntos pode ser feita de maneira aleatória várias vezes, de modo a gerar um classificador para cada vez que esse 
procedimento é repetido. Na fase de teste, todos os classificadores gerados são utilizados e suas saídas são combinadas. Quando um exemplo é classificado como pertencente a um subconjunto $A$ por um classificador, todas as classes pertencentes a esse subconjunto recebem um voto. Ao final, a classe que receber mais votos é escolhida como saída do modelo de classificação para o exemplo em questão. O método error-correcting output coding (Dietterich \& Bakiri, 1991) é um exemplo de um método que segue esse tipo de abordagem.

A abordagem que manipula o algoritmo de aprendizado consiste em aplicar variações de um algoritmo de aprendizado para um conjunto de treinamento, de modo que um classificador diferente seja gerado para cada aplicação do algoritmo ao conjunto de treinamento. Ao final, as saídas geradas pelos classificadores bases são combinadas para gerar a saída para cada um dos exemplos de teste. Uma outra estratégia dessa abordagem, que foi utilizada para as combinações herárquicas de classificadores propostas neste projeto, consiste em utilizar técnicas diferentes na geração dos classificadores, ao invés de realizar variações em apenas uma técnica.

As abordagens descritas dizem respeito à forma como os classificadores são gerados. Porém, também existem diferentes estratégias para a combinação das saídas dos classificadores. No método bagging, por exemplo, é utilizado um método de votação por maioria, ou seja, a classe que recebe o maior número de votos para um exemplo de teste é escolhida como a classe predita para o exemplo em questão. Uma outra estratégia de combinação das saídas dos classificadores base consiste em utilizar um esquema de votação ponderada, ou seja, classificadores diferentes possuem pesos diferentes na votação, fazendo com que o voto de alguns classificadores tenha um peso maior na escolha da classe predita. Um método que utiliza essa estratégia é o boosting.

Uma estratégia mais sofisticada na combinação das saídas dos classificadores bases consiste em treinar um classificador para realizar tal tarefa - esse procedimento é denominado de "generalização stack" (Kuncheva, 2004). Inicialmente, todos os classificadores são treinados da mesma maneira como nas demais estratégias. Em seguida, um novo conjunto de treinamento é utilizado para induzir um classificador para combinação das saídas desses classificadores. Uma maneira de gerar esse novo conjunto de treinamento é utilizar os dados do conjunto de treinamento original e verificar quais são as saídas para essas entradas para cada um dos classificadores. As saídas dos classificadores, bem como a classe verdadeira, são utilizadas para a construção do novo conjunto de treinamento, que é então utilizado para treinar o classificador que irá combinar as saídas dos classificadores bases (um exemplo de um conjunto de treinamento desse tipo para um problema binário de classificação é ilustrado na Tabela 2.1). Na fase de teste, os exemplos são fornecidos como 
entradas para cada um dos classificadores bases e a saída desses é fornecida como entrada para o classificador responsável pela combinação das predições. A saída desse classificador será a classe predita para cada um dos exemplos de teste.

Tabela 2.1: Conjunto de exemplos de treinamento que contém como atributos de entrada as saídas de outros cinco classificadores.

\begin{tabular}{|c|c|c|c|c|c|c|}
\hline Elem. & Class. A & Class. B & Class. C & Class. D & Class. E & Classe Verdadeira \\
\hline 1 & 1 & 2 & 1 & 1 & 2 & 1 \\
\hline 2 & 1 & 2 & 2 & 1 & 1 & 1 \\
\hline$:$ & $:$ & $:$ & $:$ & $:$ & $:$ & $:$ \\
$:$ & $:$ & $:$ & $:$ & $:$ & $:$ & $:$ \\
\hline $\mathrm{n}$ & 2 & 1 & 2 & 2 & 2 & 2 \\
\hline
\end{tabular}

Um conceito importante para a análise e avaliação de um método de ensemble diz respeito à diversidade entre os classificadores bases envolvidos na combinação. A diversidade de predições entre classificadores é importante para que haja uma complementaridade entre as predições. Em outras palavras, espera-se que os classificadores bases comentam erros diferentes, de modo que haja uma diminuição do efeito dos erros individuais de cada classificador na predição final. Dessa forma, a diversidade entre os classificadores é vital para o sucesso de uma combinação (Kuncheva, 2004). Se na combinação fossem usados classificadores idênticos, eles cometeriam os mesmos erros e, ao final, o modelo combinado produziria a mesma taxa de erro (TE) produzida por cada um dos classificadores individualmente.

Várias medidas têm sido propostas na literatura para analisar a diversidade de classificadores em métodos de ensemble. Tais medidas podem ser categorizadas em dois grupos: (a) Medidas pairwise (par a par), que calculam a diversidade entre cada par de classificadores (um único valor pode ser obtido por meio da média dos valores de diversidade calculados para os possíveis pares de classificadores); e (b) Medidas nonpairwise, que consideram todos os classificadores juntos no cálculo da diversidade (nesse caso apenas um valor é reportado). Para um descrição das principais medidas de diversidade de ensembles, consultar (Kuncheva \& Whitaker, 2003).

Duas medidas pairwise foram utilizadas para a análise da diversidade reportada no Apêndice B: Medida de Dissimilaridade e Medida de Duplo Erro. Uma das vantagens de medidas que calculam a diversidade para cada par de classificadores bases é a possibilidade de análise da diversidade de cada um desses pares isoladamente.

A Medida de Dissimilaridade (MD) tem como objetivo calcular a proporção de exemplos para os quais houve discordância entre dois classificadores 
(classificadores $A$ e $B$, por exemplo). Seja $N_{10}$ (e $N_{01}$ ) o número de exemplos que foram classificados corretamente pelo classificador $A$ (pelo classificador $B$ ) e incorretamente pelo classificador $B$ (pelo classificador $A$ ), $N_{00}$ o número de exemplos classificados incorretamente pelos dois classificadores e $N_{11}$ o número de exemplos classificados corretamente pelos dois classificadores. $\mathrm{O}$ cálculo da MD é ilustrado pela Equação 2.5.

$$
M D=\frac{N_{10}+N_{01}}{N_{10}+N_{01}+N_{00}+N_{11}}
$$

Quanto menor o valor da MD para dois classificadores, menor é a diversidade entre eles. O valor mínimo que a MD pode assumir é 0 . Nesse caso, a diversidade é nula. Em contrapartida, quanto maior o valor da MD, maior é a diversidade entre os classificadores. O valor máximo que a MD pode assumir é 1. Nesse caso, os classificadores não possuem nenhuma interseção entre suas predições, ou seja, não existe nenhum exemplo que seja classificado corretamente ou incorretamente pelos dois classificadores, simultaneamente. Situações como essas não são comuns, pois, geralmente, os classificadores "concordam" na predição de, pelo menos, uma parcela dos dados. Por exemplo, se dois classificadores classificam corretamente $80 \%$ dos exemplos, esses classificadores realizam, no mínimo, as mesmas predições para $60 \%$ dos exemplos (se o conjuntos de erros dos classificadores não tiverem nenhuma interseção, 40\% dos dados são classificados incorretamente por apenas um dos dois classificadores - 20\% por cada classificador - e os dados restante 60\% - são classificados corretamente pelos dois classificadores). Dessa forma, para esse caso, o valor da MD pode ser, no máximo, 0.4. Se, ao invés de $80 \%$, os dois classificadores tiverem $90 \%$ de acerto em suas predições, o valor máximo que a MD pode assumir é 0.2 (utilizando um raciocínio similar).

Dessa forma, se o valor da MD for analisado de forma isolada, possíveis erros de interpretação podem acontecer. Por exemplo, se o valor da MD fosse 0.2 para o primeiro exemplo (classificadores com $80 \%$ de acerto), isso significaria que $20 \%$ dos dados foram classificados incorretamente por apenas um dos classificadores e $20 \%$ dos dados foram classificados incorretamente pelos dois classificadores. Em contrapartida, se para o segundo exemplo (classificadores com 90\% de acerto), o valor da MD fosse 0.2 , isso significaria que $20 \%$ dos dados foram classificados incorretamente por apenas um dos classificadores e que nenhum exemplo foi classificado incorretamente pelos dois classificadores.

A Medida de Duplo Erro (MDE) pode ser utilizada para ajudar na interpretação da MD. A MDE tem como objetivo calcular a proporção de exemplos que foram classificados incorretamente pelos dois classificadores. O cálculo 
da MDE é ilustrado pela Equação 2.6. A proporção de exemplos classificados corretamente pelos dois classificadores pode ser derivada diretamente dos valores de MD e MDE $(1-M D-M D E)$.

$$
M D E=\frac{N_{00}}{N_{10}+N_{01}+N_{00}+N_{11}}
$$

Assim como a MD, a MDE varia entre 0 e 1 . Se a MDE para dois classificadores é igual a 0 , isso indica que eles não cometeram nenhum erro em comum. Em contrapartida, se a MDE é igual a 1, isso significa que os dois classificadores fizeram predições erradas para todos os exemplos, ou seja, a taxa de acerto (TA) é igual a 0 para os dois classificadores. Valores baixos de MDE podem indicar uma maior diversidade nas predições. Entretanto, se o valor da MDE for analisado de forma isolada, há riscos de interpretações equivocadas, assim como para a MD. Por exemplo, se o valor da MDE for igual a 0 (classificadores não cometeram erros em comum), isso pode significar: que existe uma parcela de dados que são classificados incorretamente por apenas um dos classificadores, o que revela diversidade entre eles; ou que os dois classificadores fazem todas as predições corretamente, o que revela uma diversidade nula.

Quando a MD e a MDE são analisadas em conjunto, as informações providas por uma medida auxiliam na interpretação das informações providas pela outra, e vice-versa. Se para dois classificadores, o valor da MDE é menor que o valor da $\mathrm{MD}$, isso indica que há uma maior diversidade entre os classificadores, uma vez que uma maior porcentagem dos erros é cometida por apenas um dos classificadores. Guando a situação é a inversa, há uma menor diversidade entre os classificadores, uma vez que, dentre os exemplos incorretamente classificados, a maioria foi predita de maneira incorreta pelos dois classificadores.

\subsection{Avaliação de Algoritmos de Classificação}

Como vários algoritmos de classificação podem ser construídos, é importante que exista algum mecanismo de avaliação desses algoritmos. Para que essa avaliação seja eficaz e fiel às características do algoritmo de classificação, é preciso cuidado na escolha das amostras que serão utilizadas no treinamento e teste do classificador.

O método de resubstituição emprega o mesmo conjunto utilizado no treinamento para realizar os testes do classificador. Essa característica faz com que a medida de desempenho obtida no teste seja otimista, não sendo necessariamente mantida quando são empregados exemplos de um conjunto distinto do 
utilizado no treinamento (Monard \& Baranauskas, 2003).

Em contraste, métodos de reamostragem baseiam-se no princípio de que o conjunto de exemplos de treinamento e o conjunto utilizado para testar o classificador devem ser disjuntos. Holdout, amostragem aleatória, $k$-fold crossvalidation, leave-one-out e bootstrap são alguns dos métodos de reamostragem mais utilizados.

O método holdout divide os exemplos em uma porcentagem fixa de exemplos $p$ para o treinamento e $(1-p)$ para o teste.

$\mathrm{Na}$ amostragem aleatória são gerados $L$ conjuntos de treinamento e teste aleatoriamente e são então induzidas $L$ hipóteses, uma a partir de cada conjunto de treinamento. Para obter o erro final é calculada a média entre os erros de cada hipótese para os conjuntos de teste.

O $k$-fold cross-validation consiste em dividir o conjunto de exemplos em $k$ subconjuntos ou partições. Em cada iteração, um subconjunto é utilizado como conjunto de teste para o classificador e os demais são utilizados no processo de treinamento. Esse procedimento é repetido tantas vezes quanto for o número de partições, de modo que cada partição seja utilizada uma vez no conjunto de teste e todas as outras no conjunto de treinamento. O erro é medido por meio da média dos erros de cada uma das partições. O stratified cross-validation utiliza a proporção de exemplos para cada uma das classes do problema para formar as amostras. Assim, cada amostra reflete a mesma porcentagem de distribuição de exemplos para cada classe no conjunto original. Por exemplo, se o conjunto original tem $50 \%$ de exemplos da classe A e $50 \%$ da classe B, cada amostra deve ter também 50\% de cada classe.

O método leave-one-out é um caso especial do cross-validation em que cada partição é de tamanho 1. Assim, tem-se tantas partições quantos forem o número de exemplos. Este método é caro computacionalmente e, portanto, viável apenas para conjuntos pequenos (Monard \& Baranauskas, 2003).

O bootstrap gera novos exemplos a partir dos exemplos originais utilizando reamostragem com reposição. O processo geralmente é repetido várias vezes de modo a gerar múltiplos conjuntos de treinamento/teste.

Uma vez escolhido o método para particionamento dos dados, uma outra decisão importante é a definição de como será avaliado o desempenho preditivo do classificador induzido pelo algoritmo de AM. Diferentes medidas de qualidade de classificação avaliam diferentes características de um algoritmo. O resultado de um estudo extensivo na área de avaliação e comparação de algoritmos e classificadores pode ser encontrado em: (Sokolova et al., 2006).

Medidas de qualidade de classificação são calculadas a partir de uma matriz que armazena os exemplos que foram classificados corretamente e incorretamente para cada classe, denominada matriz de confusão. Para um problema 
de classificação binária, ou seja, que possui apenas duas classes, a matriz de confusão é mostrada na Tabela 2.2, em que FP representa falsos positivos, FN - falsos negativos, TP - verdadeiros positivos, e TN - verdadeiros negativos.

Tabela 2.2: Matriz de Confusão.

\begin{tabular}{|c|c|c|}
\hline & \multicolumn{2}{|c|}{ Classe Predita } \\
\hline Classe Verdadeira & Positiva & Negativa \\
\hline Positiva & TP & FN \\
Negativa & FP & TN \\
\hline
\end{tabular}

Em problemas de classificação binária, uma classe é definida como positiva e a outra como negativa. Assim, os conceitos de FP, FN, TP e TN são descritos da seguinte forma:

- Falsos positivos (FP - False Positives) são exemplos que são preditos como pertencentes à classe positiva, mas pertencem à classe negativa.

- Falsos negativos (FN - False Negatives) são exemplos que são preditos como pertencentes à classe negativa, mas pertecem à classe positiva.

- Verdadeiros positivos (TP - True Positives) são exemplos que são preditos corretamente como pertencentes à classe positiva.

- Verdadeiros negativos (TN - True Negatives) são exemplos que são preditos corretamente como pertencentes à classe negativa.

A medida empírica mais utilizada é a taxa de acerto (TA), também conhecida como acurácia (accuracy). Essa medida avalia quão efetivo um algoritmo é, por meio da probabilidade do algoritmo realizar predições corretas. Na Equação 2.7, é mostrada a fórmula para o cálculo da TA.

$$
T A=\frac{|T N|+|T P|}{|F N|+|F P|+|T N|+|T P|}
$$

A medida complementar à TA é a taxa de erro (TE), que mede a propabilidade do algoritmo realizar falsas predições, como pode ser observado na Equação 2.8.

$$
T E=\frac{|F N|+|F P|}{|F N|+|F P|+|T N|+|T P|}
$$

A TA e a TE são as duas medidas mais gerais e podem ser facilmente adaptadas para problemas multiclasses, problemas de classificação que consideram mais de duas classes. A seguir são descritas algumas medidas que são definidas mais especificamente para problemas binários de classificação. 
As medidas sensibilidade $(S)$ e especificidade $(E)$ avaliam a efetividade de um algoritmo para uma única classe. O cálculo da sensibilidade, também conhecida como revocação (recall) ou taxa de TP, estima a probabilidade de um exemplo pertencente à classe positiva ser predito como positivo, enquanto que o cálculo da especificidade estima a probabilidade de um exemplo pertencente à classe negativa ser predito corretamente como negativo. A taxa de FP ( $T f p$ ) estima a probabilidade um exemplo pertencente à classe negativa ser predito como positivo. As fórmulas de sensibilidade, especificade e taxa de FP são dadas pelas esquações $2.9,2.10$ e 2.11 , respectivamente.

$$
\begin{gathered}
S=\frac{|T P|}{|T P|+|F N|} \\
E=\frac{|T N|}{|F P|+|T N|} \\
T f p=\frac{|F P|}{|F P|+|T N|}
\end{gathered}
$$

Precisão $(P)$ é a medida que estima probabilidade da predição positiva estar correta. A fórmula da precisão é dada pela Equação 2.12. Essa medida pode ser combinada com a sensibilidade através da Medida-F (F-measure), que realiza uma combinação balanceada dessas duas medidas. Para tal balanceamento, é utilizada uma constante $\beta$, como pode ser visto na Equação 3.17. Geralmente $\beta$ recebe valor 1 .

$$
\begin{gathered}
P=\frac{|T P|}{|T P|+|F P|} \\
F-\text { measure }=\frac{\left(\beta^{2}+1\right) * P * S}{\beta^{2} * P+S}
\end{gathered}
$$

ROC (Receiver Operating Characteristics) ilustra a relação entre sensibilidade e especificidade. Essa curva é definida por um conjunto de pontos correspondentes a pares de valores da taxa de TP (sensibilidade) e da taxa de FP $(1-E)$. Esses pontos são gerados por meio de variações no limiar utilizado nos cálculos das técnicas para definir quando um exemplo é classificado como positivo e quando ele é classificado como negativo. Dessa forma, a curva ROC retrata varias relações entre custos (taxa de FP) e benefícios (taxa de TP) da predição de um exemplo como positivo (Fawcett, 2004). Um exemplo de uma 
curva $R O C$ é mostrado na Figura 2.9.

A área abaixo da curva ROC é denominada AUC (Area Under the ROC Curve) e é uma medida quantitativa, entre zero e um, que pode ser utilizada na comparação entre dois algoritmos. A AUC de um classificador é a probabilidade de que, para um exemplo positivo e um exemplo negativo, ambos escolhidos aleatoriamente, seja atribuído um pontuação (escore) maior para o exemplo positivo.

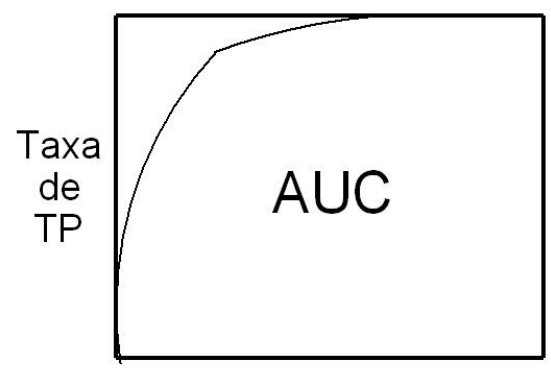

Taxa de FP

Figura 2.9: Exemplo de uma curva ROC.

Essas são as principais medidas para avaliação do desempenho de algoritmos de classificação. O problema de avaliação é alvo de grande debate entre os pesquisadores de AM, mesmo para situações em que são consideradas apenas classificações binárias.

Para problemas de classificação hierárquica, além da característica multiclasses, deve-se considerar os relacionamentos hierárquicos entre as classes. Portanto, uma análise mais cuidadosa é requerida, tanto na hora de se definir custos de erros de classificação, quanto na hora de associar tais erros a uma medida de avaliação. Medidas de avaliação para classificadores hierárquicos são discutidas na Seção 3.4.

\subsection{Considerações Finais}

Neste capítulo, foram apresentados os principais conceitos que envolvem um processo de classificação de dados, um dos principais problemas em AM, área de IA em que se situa este projeto de mestrado. Após a definição dos aspectos gerais envolvidos em AM e na classificação de dados, foram introduzidos os paradigmas de aprendizado, bem como as técnicas de AM representantes desses paradigmas que foram utilizadas no desenvolvimento dos algoritmos hierárquicos estudados neste projeto: C4.5, RIPPER, SVMs, Redes Bayesianas e KNN. Além disso, foram discutidas estratégias de combinação de 
classificadores, cujos conceitos fundamentais são necessários para o entendimento dos algoritmos baseados na combinação hierárquica de classificadores propostos no próximo capítulo. Também foram discutidos os principais métodos de particionamento do conjunto de dados em conjuntos de treinamento e teste, e as principais medidas de avaliação dos resultados obtidos para um classificador.

Uma vez definidos os principais conceitos e processos envolvidos em um problema convencional de classificação de dados, no próximo capítulo são discutidos os principais aspectos de problemas de classificação hierárquica. Além disso, são introduzidos os algoritmos para geração dos modelos hierárquicos de classificação utilizados nos experimentos descritos no Capítulo 5. 


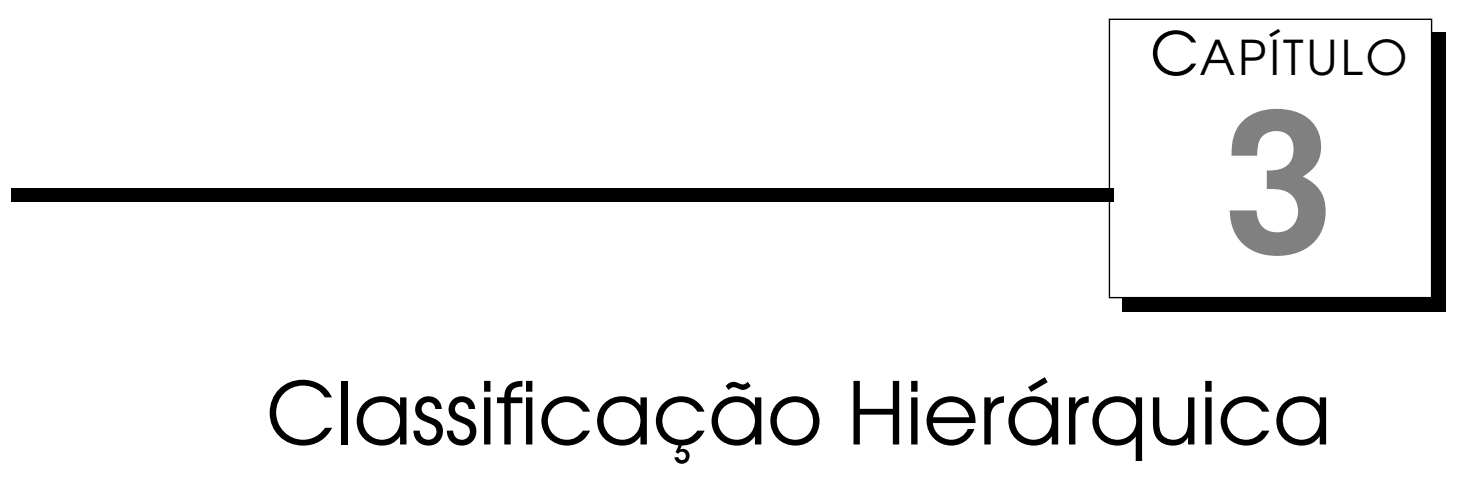

A grande maioria dos problemas de classificação descritos na literatura de AM envolve classificação plana (flat classification). Neste tipo de classificação, cada exemplo é associado a uma classe pertencente a um conjunto finito de classes, não considerando a existência de relacionamentos entre elas. No entanto, existe um grande número de problemas em que as classes são dispostas em uma estrutura hierárquica, tal como uma árvore ou um DAG. Esses problemas são conhecidos na literatura como problemas de classificação hierárquica (Freitas \& Carvalho, 2007).

Dessa forma, um problema de classificação hierárquica difere de um problema de classificação plana fundamentalmente na forma como as suas classes estão relacionadas entre si, como pode ser observado na Figura 3.1. Tanto para classificação plana como para classificação hierárquica, os nós representam as classes envolvidas no problema, com exceção do nó identificado sob o rótulo "qualquer classe". Esse é o nó-raiz e o ponto de partida para o processo de classificação, indicando a total ausência de conhecimento a respeito da classe a qual um exemplo pertença, se ele estiver posicionado sobre esse nó.

Na classificação plana, supõe-se a independência entre as classes envolvidas. Nesse caso, a única conexão entre as classes é a ligação com o nó-raiz. Na classificação hierárquica, as classes que se ramificam a partir do nó-raiz podem se relacionar com outras classes - classes descendentes ou subclasses.

Neste capítulo, são abordados os principais aspectos que caracterizam um problema de classificação hierárquica. Além disso, são introduzidas as abordagens utilizadas para o desenvolvimento dos algoritmos analisados experi- 


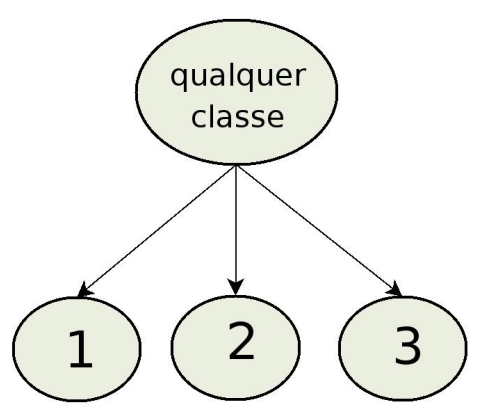

(a) Classificação Plana

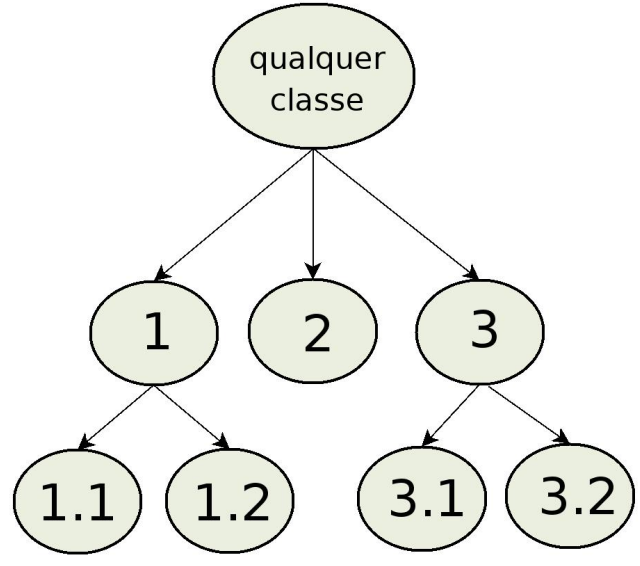

(b) Classificação Hierárquica

Figura 3.1: Classificação Plana x Classificação Hierárquica (Freitas \& Carvalho, 2007).

mentalmente no Capítulo 5. As seções estão organizadas da seguinte forma: na Seção 3.1, são descritos os conceitos básicos de um processo de classificação hierárquica; na Seção 3.2, são descritas as principais abordagens utilizadas para a resolução de um problema hierárquico; estratégias para a combinação hierárquica de classificadores são propostas e discutidas na Seção 3.3; métodos e medidas para avaliação de modelos hierárquicos são discutidas na Seção 3.4; por fim, algumas considerações finais a respeito dos tópicos discutidos no capítulo são apresentadas na Seção 3.5.

\section{1 Conceitos Básicos}

Classificação hierárquica é um tipo de problema de classificação no qual as classes envolvidas podem ser divididas em subclasses ou agrupadas em superclasses, dando origem a uma hierarquia. Nos métodos hierárquicos de classificação, o algoritmo de aprendizagem induz um modelo que captura os relacionamentos mais relevantes entre as classes funcionais no conjunto de dados de treinamento, considerando os relacionamentos hierárquicos entre elas. Essa abordagem permite a utilização de uma grande variedade de algoritmos de AM no processo de classificação (Freitas \& Carvalho, 2007).

Dois importantes aspectos que caracterizam um problema de classificação hierárquica são: o tipo de hierarquia empregado para representar os relacionamentos entre as classes; e o nível hierárquico em que as predições são feitas. 


\section{Tipos de Hierarquia de Classes}

Existem duas maneiras em que as classes podem estar dispostas hierarquicamente: como uma árvore ou um DAG.

A principal diferença entre a estrutura em árvore (Figura 3.2) e a estrutura DAG (Figura 3.3) é que, na estrutura em árvore, cada nó, exceto o nó-raiz, tem somente um nó-pai, enquanto que no DAG cada nó, exceto o nó-raiz, pode ter um ou mais nós-pai.

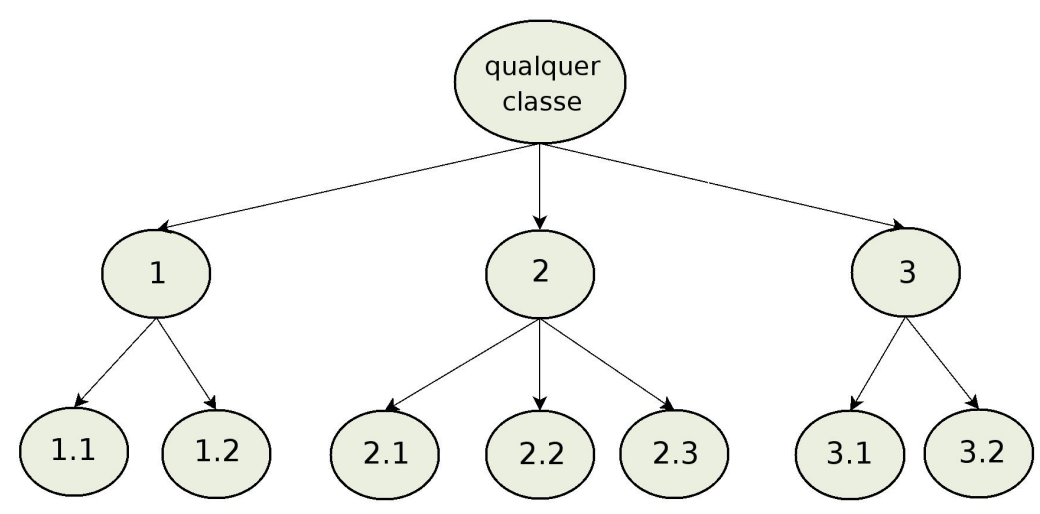

Figura 3.2: Exemplo de uma hierarquia de classes estruturada como uma árvore (Freitas \& Carvalho, 2007).

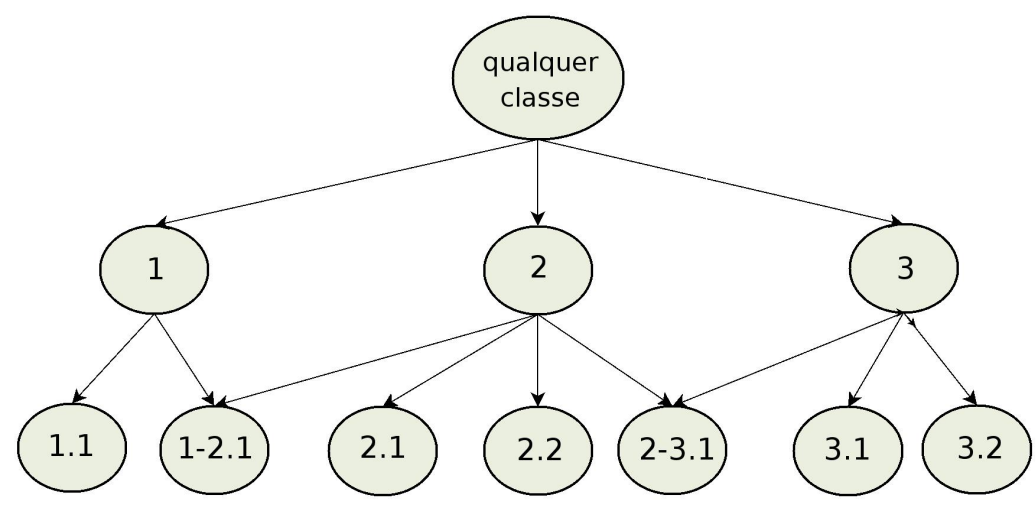

Figura 3.3: Exemplo de uma hierarquia de classes estruturada como um DAG (Freitas \& Carvalho, 2007).

Problemas de classificação hierárquica têm por objetivo a classificação de cada novo dado de entrada em um dos nós-folha, pois quanto mais profunda a classe na hierarquia, mais específico e útil é o conhecimento. Pode ocorrer, no entanto, do classificador não apresentar uma confiabilidade desejada na classificação em uma das classes do nível mais profundo, sendo mais seguro realizar a classificação nos niveis mais elevados. 
Para estruturas de classes em árvore, quanto mais profundo é o nível, mais difícil é o processo de predição. Isso se deve ao fato de que o número de exemplos por classe em níveis mais profundos tende a ser menor e, conseqüentemente, a confiabilidade do modelo de classificação induzidos para esses níveis também tende a ser menor.

Para estruturas em DAG, a análise é um pouco mais complexa porque, como um nó-filho pode ter mais de um nó-pai, algumas classes em níveis mais profundos podem ter mais exemplos do que seus ancestrais. Apesar disso, na prática, mesmo para DAGs, a TA de predição decresce com o aumento do nível de profundidade (Freitas \& Carvalho, 2007).

Dessa forma, quanto mais próxima da raiz da hierarquia ocorrer a associação de um dado de entrada com um nó, menor tende a ser a TE de classificação. Por outro lado, menos específica, e por conseqüência menos útil, será a classificação obtida. Assim, um classificador hierárquico terá que lidar com o trade-off especificidade $X$ TE de classificação.

\section{Nível hierárquico de predição de classes}

Em alguns problemas, todos os exemplos devem ser associados com classes representadas por nós-folha. Tais problemas são chamados de "problemas de predição obrigatória em nós-folha”.

Em contraste, existe uma outra categoria de problemas em que não existe essa restrição de obrigatoriedade de classificação nos nós-folha. Tais problemas, denominados de "problemas de predição opcional em nós-folha", permitem que um exemplo seja associado a uma classe representada por um nó interno da hierarquia. Essa característica pode ser útil para problemas que optam pela liberdade em realizar uma predição mais geral, porém com maior confiabilidade. Lembrando que quanto mais específica é uma predição, maior é sua utilidade.

\subsection{Abordagens para tratar Problemas Hierárquicos}

Nos últimos anos, algumas soluções têm sido propostas para a indução de modelos de classificação para problemas hierárquicos. Seguindo a nomenclatura definida em (Freitas \& Carvalho, 2007), tais soluções podem ser agrupadas em quatro tipos de abordagens: transformação do problema hierárquico em um problema de classificação plana, predição hierárquica utilizando algoritmos de classificação plana, classificação Top-Down e classificação Big-Bang.

A seguir são descritas as quatro principais abordagens utilizadas para tratar problemas de classificação hierárquica. Para ilustrar as características de 
cada uma dessas abordagens, um problema de classificação é ilustrado na Figura 3.4. Nessa figura, é mostrada a classificação de um exemplo $T$ por meio das quatro abordagens, baseado na hierarquia de classes representada na Figura 3.4.a.

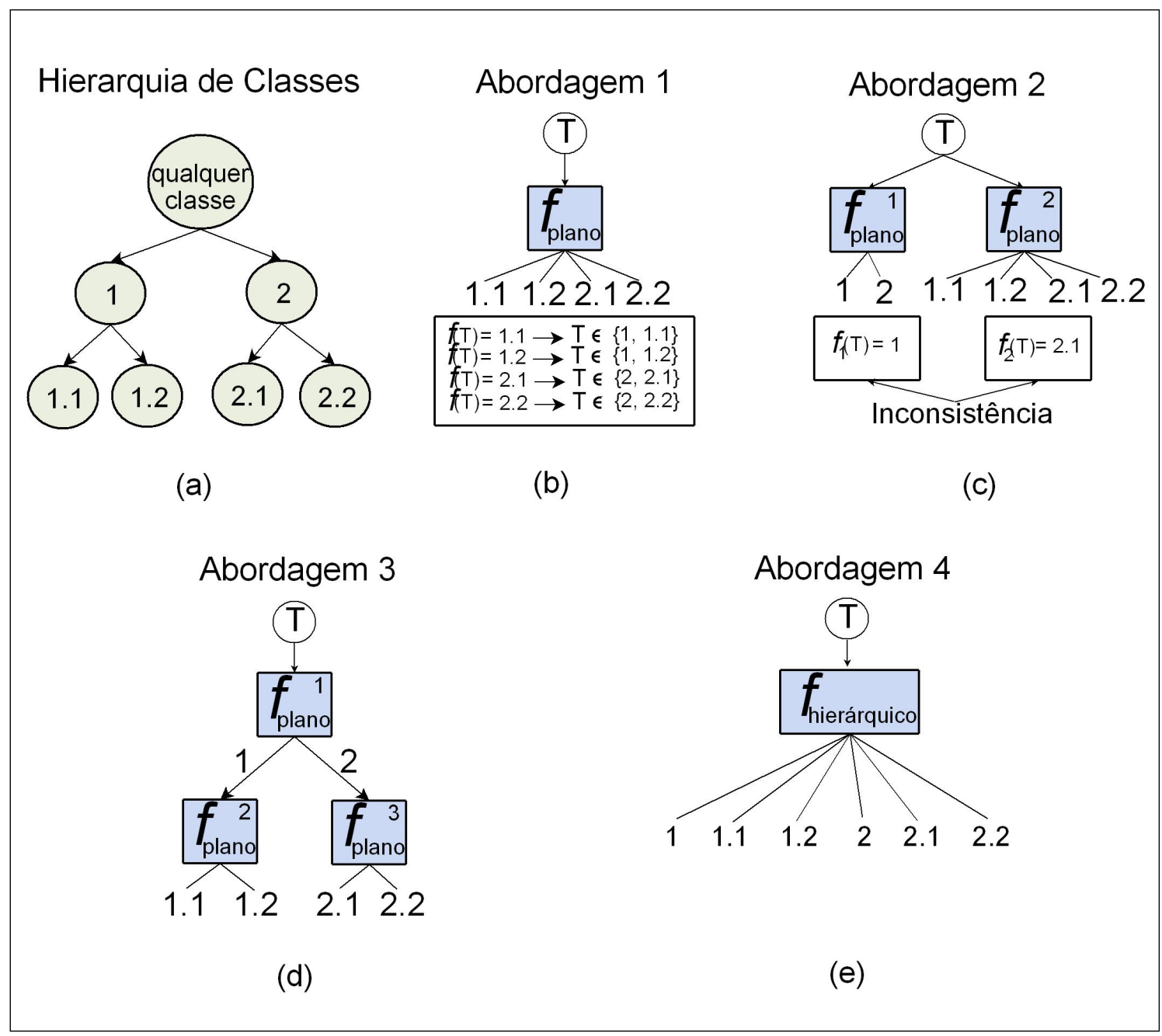

Figura 3.4: Ilustração das abordagens para resolução de problemas hierárquicos: (a) Exemplo de uma hierarquia de classes; (b) Abordagem 1 - Transformação de um Problema de Classificação Hierárquica em um Problema de Classificação Plana; (c) Abordagem 2 - Predição Hierárquica de Classes utilizando Algoritmos de Classificação Plana; (d) Abordagem 3 - Classificação Hierárquica Top-Down; (e) Abordagem 4 - Classificação Hierárquica Big-Bang.

3.2.1 Transformação de um Problema de Classificação Hierárquica em um Problema de Classificação Plana

Embora considere problemas em que as classes estão dispostas originalmente em uma hierarquia, essa abordagem opta por reduzí-los a problemas 
de classificação plana. Essa idéia apoia-se no fato de que um problema de classificação plana pode ser encarado como um caso particular de classificação hierárquica, no qual não são consideradas subclasses e superclasses. Assim, abordagens tradicionais de classificação plana podem ser aplicadas neste contexto, sem a necessidade de alterações ou ajustes.

Uma alternativa para essa transformação é considerar apenas o primeiro nível da hierarquia. Porém, esse procedimento tem a desvantagem de não explorar os níveis mais profundos, cujas classes representam informações mais específicas. Um outra alternativa consiste em fazer a predição para um nível mais específico da hierarquia, o que naturalmente se reflete em predições nos níveis superiores. Considere a ilustração dessa abordagem mostrada na Figura 3.4.b. Na figura, um classificador plano considera as classes do segundo (e último) nível da hierarquia representada na Figura 3.4.a. Quando um exemplo $T$ é fornecido como entrada para o classificador, existem quatro possibilidades de saídas, que são mostradas na parte inferior da Figura 3.4.b. Por exemplo, se $T$ é classificado como pertencente à classe 1.1, ele também é automaticamente predito como pertencente à classe 1. Entretanto, ao considerar todas as classes de um nível mais específico, sem explorar as informações contidas nos níveis mais gerais, a classificação tende a ser mais difícil.

\subsubsection{Predição Hierárquica de Classes utilizando Algoritmos de Classificação Plana}

Esse segundo tipo de abordagem divide um problema de classificação hierárquica em um conjunto de problemas de classificação plana. Uma implementação possível para essa abordagem consiste em considerar cada nível da hierarquia como um problema de classificação independente dos outros. Para cada nível, um classificador é induzido por meio de um algoritmo de classificação plana. Entretanto, uma desvantagem dessa abordagem é a possibilidade de ocorrência de inconsistências entre as predições feitas pelos diferentes classificadores.

No modelo de classificação representado na Figura 3.4.c, há um classificador para cada nível da hierarquia. Na classificação de um exemplo $T$, esse é fornecido, simultaneamente, como entrada para os dois classificadores. Em seguida, as saídas desses classificadores devem ser combinadas. Como pode ser observado na figura, uma inconsistência pode acontecer quando as saídas dos classificadores não são coerentes entre si. 


\subsubsection{Classificação Hierárquica Top-Down}

Na abordagem Top-Down, um ou mais classificadores são treinados para cada nó da hierarquia, de forma que, ao final da fase de treinamento, uma árvore de classificadores seja gerada.

Uma vez obtido esse conjunto de classificadores, os exemplos pertencentes ao conjunto de teste são classificados de maneira iterativa e Top-Down ao longo dos níveis da hierarquia. Quando um exemplo é classificado como pertencente a uma classe, ele é então aplicado a um classificador para predizer a qual das subclasses da classe predita no nivel anterior ele pertence. Esse procedimento é repetido até atingir uma classe representada por um nó-folha, em caso de predição obrigatória em nós-folha, ou até que se opte por associar o exemplo a um nó-interno da hierarquia, em caso de predição opcional em nós-folha.

Deve-se ressaltar, entretanto, que um classificador só é gerado para os nós nos quais haja a necessidade de um processo de decisão, ou seja, quando a classe representada tenha mais de uma subclasse. Nesses casos, deve ocorrer uma decisão (classificação) entre as subclasses para que o percurso Top-Down prossiga na hierarquia, configurando assim a necessidade da indução de um classificador. Classes representadas por nós internos que possuem apenas uma subclasse e por nós-folha não apresentam a necessidade de criação de classificadores.

Como pode ser observado na Figura 3.4.d, na classificação Top-Down de um exemplo $T$, esse é fornecido, inicialmente, como entrada para o classificador plano que considera apenas as classes do primeiro nível. Se, por exemplo, esse classificador fizer a predição de que $T$ pertence à classe 1 , o classificador induzido para essa classe é utilizado para predizer se $T$ pertence à classe 1.1 ou à classe 1.2 .

Em sua forma convencional, a abordagem Top-Down utiliza uma única técnica de AM para a geração da árvore de classificadores. Secker et al. (2007) propuseram uma variação da abordagem Top-Down de modo que múltiplas técnicas possam ser utilizadas na geração do modelo de classificação. Essa variação da abordagem Top-Down, que foi denominada Selective Top-Down, utiliza um procedimento seletivo para decidir qual técnica é utilizada a cada iteração do processo de treinamento da árvore de classificadores. A fase de teste ocorre da mesma forma que na abordagem Top-Down convencional.

O procedimento seletivo empregado pela abordagem Selective Top-Down consiste em, para cada nó em que um classificador deve ser gerado, dividir o conjunto de treinamento em duas partições: uma partição para treinamento de um classificador para cada técnica de AM envolvida; e uma partição para 
validação dos classificadores gerados por meio da partição utilizada para treinamento. A técnica que gerar o classificador com a maior TA no conjunto de validação é selecionada para a indução do classificador para o nó em questão. Se houver empate entre duas ou mais técnicas, algum mecanismo de desempate deve ser empregado. Uma vez selecionada a técnica, ela é utilizada novamente para o treinamento de um classificador, só que dessa vez utilizando todo o conjunto de treinamento. Esse processo é repetido para todos os nós em que um classificador é necessário, de modo que ao final da fase de treinamento a árvore de classificadores gerada pode conter classificadores gerados por diferentes técnicas de AM.

As duas vertentes da abordagem Top-Down descritas - convencional e selective - foram utilizadas nos algoritmos utilizados para os experimentos descritos no Capítulo 5. Além disso, também foram implementados algoritmos utilizando uma nova variação proposta para a abordagem Top-Down: Ensemble Top-Down (discutida na Seção 3.3).

Na implementação do algoritmo Selective Top-Down foi adotada a seguinte estratégia de desempate: sempre que duas ou mais técnicas apresentam o mesmo desempenho preditivo no conjunto de validação, o desempate é feito por meio da verificação do histórico de vitórias das técnicas empatadas para os processos seletivos realizados até aquele momento. Para isso, o algoritmo armazena a técnica vencedora em cada processo seletivo e, em caso de empate, a técnica (dentre das técnicas empatadas) com maior número de vitórias nos processos seletivos realizados até então é escolhida. Se mesmo assim o empate persistir, é feita uma escolha aleatória entre as técnicas técnicas envolvidas no empate.

A verificação do histórico foi utilizada como um critério de desempate com prioridade sobre a escolha aleatória baseada na suposição de que, em geral, uma técnica que apresentou melhor desempenho preditivo para os passos anteriores do algoritmo Top-Down tem uma maior probabilidade de apresentar melhor desempenho para os demais passos. Embora cada passo compreenda um problema de classificação diferente, os mesmos atributos de predição são utilizados em todos eles, justificando assim a suposição de que os desempenhos preditivo das técnicas em cada passo não são independentes dos desempenhos apresentados para os demais passos. Em cada passo são utilizados os resultados dos passos anteriores porque são essas as informações disponíveis até aquele momento. 


\subsubsection{Classificação Hierárquica Big-Bang}

Na abordagem Big-Bang, um modelo de classificação é criado considerando a hierarquia de classes como um todo, apresentando assim uma maior complexidade. Desse modo, após a fase de treinamento do modelo de classificação, a predição da classe de um exemplo é feita em um único passo.

Ao contrário das demais abordagens, na Big-Bang não podem ser utilizadas as técnicas de classificação plana em sua forma padrão. Se na construção de uma técnica Big-Bang for adotada como base uma técnica de classificação plana, devem ser efetuadas modificações no modo como é feita a indução do classificador, para que o modelo gerado considere toda a hierarquia. Dessa forma, a construção de um algoritmo Big-Bang é mais complexa quando comparada a um algoritmo Top-Down, que realiza a classificação por meio de um processo de modularização. Porém, apesar de mais simples, a abordagem TopDown possui a desvantagem de erros cometidos nos níveis superiores serem propagados para os níveis mais específicos.

Como pode ser visto com mais detalhes na Seção 4.3.4, Clare \& King (2003) desenvolveram um algoritmo Big-Bang utilizando ADs, denominado HC4.5. Para tal, foram realizadas modificações no cálculo da entropia realizado pelo algoritmo $\mathrm{C} 4.5$ para a indução da $\mathrm{AD}$. Esse algoritmo também foi utilizado nos experimentos realizados neste projeto, com o intuito de comparar os seus resultados com àqueles apresentados pelos algoritmos Top-Down investigados. Porém, para que esse estudo comparativo fosse possível, algumas modificações foram realizadas na implementação do HC4.5. Tais modificações são discutidas na Seção 5.3.4.

Na ilustração dessa abordagem mostrada na Figura 3.4.d, um único classificador considera, simultaneamente, todas as classes da hierarquia. Quando um exemplo $T$ é fornecido como entrada para esse classificador, a predição é feita em um único passo, utilizando informações de toda a hierarquia. Se a predição for opcional em nós-folha, a predição pode ser feita para qualquer nó da hierarquia. Se a predição for obrigatória para nós-folha, a predição é feita para um desses nós e as predições nos níveis superiores são derivadas dessa predição. Por exemplo, se a predição for feita para a classe 1.1, a classe 1 é predita automaticamente, por ser a superclasse de 1.1. Caso a predição em nós-folha não seja obrigatória, um exemplo pode ser predito como pertencente a um dos nós internos da hierarquia (classe 1, por exemplo). Nesse caso, o modelo não fornece informações para os níveis mais específicos. 


\subsection{Combinação Hierárquica de Classificadores}

Os algoritmos Top-Down convencionais e Selective Top-Down geram ao final do treinamento uma árvore de classificadores. Nessa árvore, cada nó é constituído por um classificador, que é responsável pela predição dos exemplos durante a classificação Top-Down. Porém, uma extensão possível para essa árvore de classificadores é permitir que cada nó seja constituído por uma combinação de classificadores e não apenas por um classificador. Essa nova variação da abordagem Top-Down foi denominada Ensemble Top-Down.

A motivação para a exploração de algoritmos Top-Down baseados na combinação de classificadores neste projeto se deu pelo fato de o custo computacional exigido ser similar ao requerido para o Selective Top-Down, uma vez que nos dois casos vários classificadores são gerados. No caso do algoritmo Selective Top-Down, um classificador é treinado para cada técnica e, ao final do procedimento seletivo, a técnica escolhida é utilizada para indução de um classificador a partir de todo o conjunto de treinamento. Dessa forma, se $L$ técnicas estão envolvidas no algoritmo Selective Top-Down, $L+1$ classificadores são induzidos. No caso dos algoritmos Ensemble Top-Down, um classificador é gerado para cada técnica a partir de todo o conjunto de treinamento. Dessa forma, são induzidos $L$ classificadores. A vantagem da combinação de classificadores é que, ao invés de escolher apenas um dos classificadores e treiná-lo novamente, descartando os demais, como ocorre no Selective Top-Down, todos os classificadores podem ser utilizados na predição final, por meio de uma combinação de suas saídas. Além disso, não se tem conhecimento de trabalho prévios com essa alternativa.

A abordagem adotada para a geração dos classificadores a serem combinados foi a de manipulação do algoritmo de aprendizado (ver Seção 2.4). Porém, ao invés de utilizar variações de uma mesma técnica para gerar diferentes classificadores, foram utilizadas diferentes técnicas de AM na geração dos classificadores.

Como discutido na Seção 2.4, existem diferentes formas para a combinação das saídas dos classificadores bases. Além das formas citadas na seção - votação por maioria, votação ponderada e generalização stack, foram derivadas mais duas novas formas de combinação: uma derivada da votação ponderada, que utiliza um esquema de ranqueamento entre os classificadores para fazer a votação ponderada; e outra derivada da estratégia da generalização stack, que utiliza um procedimento seletivo na escolha de qual técnica é utilizada para gerar o classificador que combina as saídas dos classificadores bases.

Para facilitar a identificação dos algoritmos desenvolvidos a partir das diferentes formas de combinação das saídas dos classificadores, bem como 
a representação dos seus resultados, foram atribuídos nomes para tais algoritmos: Ensemble Top-Down com Votação por Maioria (EnsTPVotM), Ensemble Top-Down com Votação Ponderada (EnsTPVotP), Ensemble Top-Down com Votação Ponderada por Ranking (EnsTPVotR), Stack Ensemble Top-Down (StackEnsTP), e Stack Ensemble Top-Down com Procedimento Seletivo (StackEnsTPSel).

\section{Ensemble Top-Down com Votação por Maioria - EnsTPVotM}

Nesse algoritmo, foi implementada a estratégia de votação por maioria para a combinação das sáidas dos classificadores. De acordo com essa estratégia, a classe que for votada pelo maior número de classificadores é escolhida como a classe predita.

Em caso de empate entre duas ou mais classes, a estratégia de desempate consiste em verificar qual das classes que estão empatadas aparece com maior freqüência na conjunto de dados. Se mesmo assim o empate persistir entre duas ou mais classes, é utilizado o critério aleatório para a escolha da classe predita.

\section{Ensemble Top-Down com Votação Ponderada - EnsTPVotP}

Nesse algoritmo, foi implementado a estratégia de votação ponderada para combinação das saídas dos classificadores. Para determinação do peso atribuído ao voto de cada classificador, foi utilizada a TA obtida para o conjunto de treinamento. Então, se um classificador tiver acerto de $100 \%$ no conjunto de treinamento, seu voto valerá 1; em contrapartida, se um classificador tiver acerto de $50 \%$, seu voto valerá 0.5 .

Em caso de empate entre duas ou mais classes, a estratégia de desempate adotada é a mesma utilizada para o EnsTPVotM: inicialmente, verifica-se qual das classes empatadas apresenta a maior freqüência no conjunto de dados e depois, se o empate persistir, o critério aleatório é utilizado.

\section{Ensemble Top-Down com Votação Ponderada por Ranking - EnsTP- VotR}

Nesse algoritmo, foi utilizada uma estratégia de combinação derivada da votação ponderada. A idéia principal dessa estratégia é conferir pesos com valores inteiros para os votos dos classificadores por meio de um esquema de ranqueamento. Por isso, essa estratégia foi denominada de Votação Ponderada por Ranking. 
O primeiro passo é obter as TAs dos classificadores para o conjunto de treinamento, assim como na votação ponderada convencional. Porém, ao invés de utilizar tais taxas para ponderar a votação, elas são ranqueadas de modo que, em uma combinação de $k$ classificadores, o classificador com maior TA receba peso $k$ para seu voto e o classificador com menor TA receba peso 1 para seu voto. Se houver empate entre TAs entre $m$ classificadores, é feita um média aritmética entre os pesos inteiros que seriam assumidos pelas próximas $m$ posições livres do ranking. Para ilustrar essa atribuição de valores, considere o exemplo da Tabela 3.1. Essa tabela possui as TAs obtidas na classificação dos dados de treinamento para cinco classificadores e os respectivos pesos atribuídos a cada classificador de acordo com a sua posição no ranking. O classificador com maior TA - classificador 5 - recebe o maior peso: peso 5. A segunda posição fica com classificador 1 , que recebe peso 4. Como os classificadores 2 e 4 empatam e as duas próximas posições do ranking são a terceira e a quarta posição, esses classificadores recebem a média aritmética dos valores associados a essas posições do ranking: a terceira e a quarta posição correspondem aos valores 3 e 2, respectivamente; logo, cada um dos classificadores recebe peso 2.5. O classificador 3 , que apresentou a menor TA para os dados de treinamento, recebe o menor peso: peso 1 .

Tabela 3.1: Exemplo de um caso de atribuição de pesos para o Ensemble TopDown com Votação Ponderada por Ranque - EnsTPVotR.

\begin{tabular}{|l|c|c|c|c|c|}
\cline { 2 - 6 } \multicolumn{1}{c|}{} & Class. 1 & Class. 2 & Class. 3 & Class. 4 & Class. 5 \\
\hline TA & 0.90 & 0.85 & 0.70 & 0.85 & 0.95 \\
\hline Peso & 4 & 2.5 & 1 & 2.5 & 5 \\
\hline
\end{tabular}

Em caso de empate entre duas ou mais classes, a estratégia de desempate obedece aos meus critérios utilizados na votação por maioria e na votação ponderada.

\section{Stack Ensemble Top-Down - StackEnsTP}

No StackEnsTP, um classificador é treinado para combinar as predições que são fornecidas como saídas do classificadores bases. Como nesse caso a decisão de qual é a classe predita pelo modelo combinado é uma decisão de um classificador, não é necessário o estabelecimento de critérios de desempate entre classes. Porém, para o uso desse algoritmo, é necessário o estabelecimento de critérios para a definição de qual técnica de AM deve ser utilizada para treinamento do classificador responsável pela combinação das saídas dos classificadores bases. 
Dessa forma, optou-se por selecionar, dentre as técnicas utilizadas para a indução dos classificadores bases, aquela que gerar o classificador base com maior TA para o conjunto de treinamento original. Caso haja empate, utilizase informações do histórico de vitórias. Assim como no Selective Top-Down, a técnica escolhida é aquela que, dentre as técnicas que estão empatadas, tiver sido selecionada mais vezes nos demais nós da árvore de classificadores que está sendo gerada. Se o mesmo assim o empate persistir, uma das técnicas empatas é escolhida de forma aleatória.

Após uma das técnicas ter sido escolhida, ela é utilizada para treinar o classificador que combina as saídas dos classificadores bases. Para isso, o novo conjunto de treinamento, formado a partir das saídas de cada um desses classificadores para os dados originais de treinamento, é utilizado.

Stack Ensemble Top-Down com Procedimento Seletivo - StackEnsTPSel

Com o intuito de verificar possibilidades de melhoramentos do StackEnsTP, foram feitas algumas modificações em sua implementação, originando um novo algoritmo. No StackEnsTP, as TAs obtidas para os dados de treinamento do conjunto original são utilizadas como critério principal de escolha entre as técnicas. Em contraste, o StackEnsTPSel utiliza as TAs obtidas para o novo conjunto de treinamento, formado a partir das saídas de cada um dos classificadores para os dados originais de treinamento.

A motivação para essa mudança é que se tratam de conjuntos diferentes, embora um tenha sido originado do outro. Assim, nesse novo algoritmo, a escolha da técnica para geração do algoritmo de combinação é pautada no próprio conjunto de dados usado para treinamento desse classificador.

Para essa escolha, é realizado um processo seletivo similar ao empregado no Selective Top-Down. Por essa razão, esse algoritmo foi denominado de Stack Ensemble Top-Down com Procedimento Seletivo - StackEnsTPSel. No procedimento seletivo, parte do novo conjunto de treinamento é reservado para validação e o restante é utilizado para treinar classificadores utilizando todas as técnicas envolvidas na combinação. A técnica que apresentar a maior TA para os dados de validação é escolhida. Se houver empate entre duas ou mais técnicas, os mesmos critérios do procedimento seletivo do Selective Top-Down são utilizados: primeiramente, o histórico de vitórias é utilizado; se o empate persistir, a técnica é escolhida de forma aleatória. Uma vez selecionada uma das técnicas, o treinamento do classificador de combinação de saídas é refeito, dessa vez com todo o conjunto de treinamento. 


\subsection{Avaliação de Modelos Hierárquicos de Classifica- ção}

A avaliação é uma parte essencial no desenvolvimento de um modelo de classificação. É por meio dessa etapa que o desempenho preditivo do modelo gerado é analisado. Dessa forma, a avaliação deve ser conduzida do modo mais coerente possivel com a metodologia utilizada para o desenvolvimento do modelo, de modo que o desempenho reportado não seja nem otimista e nem pessimista em relação às predições do modelo.

Em classificação hierárquica, a definição de protocolos de avaliação de modelos de classificação ainda está pouco desenvolvida. Ainda não há um consenso e nem uma tendência geral na condução do processo de avaliação nessa área. Dessa forma, várias propostas têm surgido com o intuito de promover avanços nesse campo ainda pouco explorado.

Uma primeira questão que deve ser levada em consideração antes da avaliação de um modelo hierárquico de classificação é a forma como pretende-se reportar os resultados. Basicamente, pode-se citar três diferentes formas de se reportar resultados para modelos hierárquicos: (1) reportar uma taxa de desempenho para o modelo como um todo; (2) reportar uma taxa de desempenho para cada nivel da hierarquia; e (3) reportar uma taxa de desempenho para cada classe.

A abordagem que reporta um valor de desempenho preditivo para todo o modelo de classificação é muito geral, fazendo com que muitas informações relevantes sejam omitidas. Isso torna a análise dos resultados mais difícil e, conseqüentemente, mais imprecisa. Por exemplo, ao reportar que um modelo de classificação tem $80 \%$ de acerto, não é possivel afirmar com precisão como essa TA se distribui nos níveis da hierarquia. Essa taxa única não fornece informações a respeito de como o modelo se comporta em cada nível: se a TA no primeiro nível é muito alta, mas nos demais é muito baixa; ou se erros só ocorrem no primeiro nível e depois, nos outros níveis, todas os exemplos classificados corretamente no primeiro também o são nos demais níveis; entre outras possibilidades. Em contrapartida, a abordagem que reporta valores de desempenho preditivo para cada classe é muito específica. Geralmente, problemas hierárquicos possuem um número elevado de classes e reportar uma medida para cada uma das classes é, na maioria dos casos, inviável, além de ser de difícil análise.

Por esses motivos, a abordagem adotada nesta dissertação foi a que reporta um valor de desempenho preditivo para cada nível da hierarquia. Essa abordagem tem a vantagem de não ser tão geral quanto a que considera o processo 
como todo, nem de ser tão específica quanto a que considera o desempenho em cada classe.

Uma vez definida a forma como os resultados serão reportados, um segundo passo é tratar a matriz de confusão originada do processo de classificação de modo que medidas de avaliação possam ser derivadas dela. Para se reportar uma taxa de desempenho para cada nível da hierarquia, uma matriz de confusão deve ser derivada para cada nível, a partir da matriz de confusão original. Dessa forma, na Seção 3.4.1, são descritos os passos necessários para a construção das matrizes de confusão para armazenamento dos resultados nível a nível.

Finalizados as modificações e ajustes na matriz de confusão, quando necessários (caso da avaliação nível a nível), o próximo passo é a definição da medida de avaliação que será utilizada para reportar os resultados. Medidas diferentes avaliam aspectos diferentes de um modelo de classificação. Assim, no processo de escolha da medida de avaliação, deve-se ter em mente quais aspectos do modelo pretende-se avaliar. Além disso, deve-se analisar se a medida utilizada é coerente com o modelo hierárquico, ou seja, se ela leva em conta os relacionamentos hierárquicos entre as classes. Assim, na Seção 3.4.2, são apresentadas as principais medidas de avaliação que têm sido utilizadas em classificação hierárquica, entre as quais se encontram as medidas que foram utilizadas para reportar os resultados dos experimentos apresentados no Capítulo 5.

\subsection{Geração das Matrizes de Confusão}

Embora matrizes de confusão sejam estruturas muito utilizadas para reportar resultados de problemas de classificação, a sua utilização em problemas de classificação hierárquica não pode ser feita de maneira direta. Uma série de considerações necessitam ser feitas para que tais matrizes sejam condizentes com as predições dos modelos que a geraram. Isso se deve fundamentalmente à existência de relacionamentos de classes e subclasses (ou classes e superclasses) em uma hierarquia. Dessa forma, tais relacionamentos devem ser considerados na construção da matriz de confusão. Isso é importante porque, quando um classificador hierárquico faz uma predição de um exemplo como pertencente a uma classe da hierarquia, seja ela representada por um nó-folha ou um nó interno, essa predição é transmitida automaticamente para os níveis superiores, por meio dos ancestrais da classe predita. Por exemplo, se um exemplo é predito como pertencente à classe 1.2, ele já está implicitamente predito como pertencente à classe 1, uma vez que a classe 1.2 é uma das subclasses da classe 1 . 
A seguir são considerados os quatro principais passos necessários para a geração das matrizes de confusão nível a nível, que são necessárias para a situação em que a avaliação será feita para cada nível da hierarquia separadamente. Para ilustrar os passos, um caso hipotético de classificação que envolve a hierarquia de classes mostrada na Figura 3.5 é utilizado. Esse problema de classificação envolve 20 exemplos e a relação entre classes verdadeiras e preditas é resumida pela matriz de confusão mostrada na Tabela 3.2. Ao final da explicação dos quatro passos, é apresentada uma explicação resumida do processo de geração das matrizes.

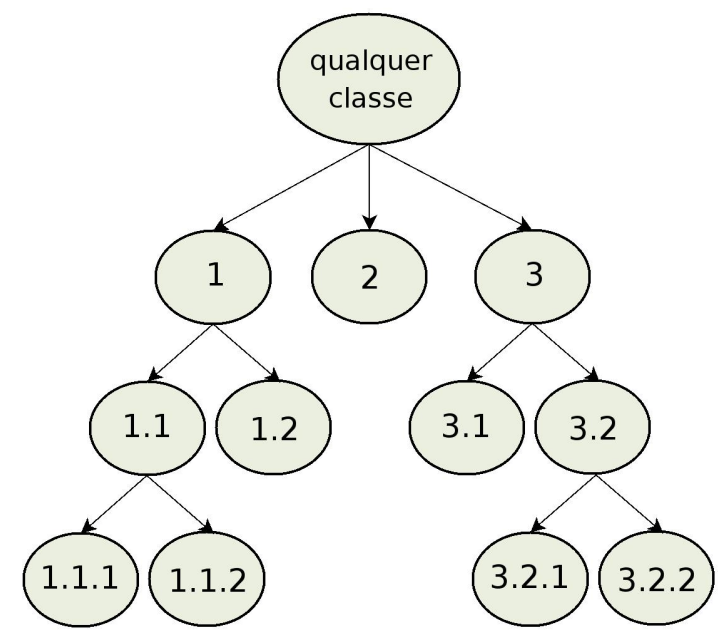

Figura 3.5: Hierarquia de classes de um caso hipotético de classificação hierárquica.

Tabela 3.2: Matriz de confusão hipotética para a simulação dos passos de geração das matrizes de confusão para cada nível.

\begin{tabular}{|c|c|c|c|c|c|c|c|c|c|c|c|}
\cline { 2 - 11 } \multicolumn{1}{c|}{} & \multicolumn{70}{|c|}{ Classe Predita } \\
\hline C. Verd. & 1 & 2 & 3 & 1.1 & 1.2 & 3.1 & 3.2 & 1.1 .1 & 1.1 .2 & 3.2 .1 & 3.2 .2 \\
\hline 1 & & & & & & & & & & & \\
\hline 2 & & & & & 3 & & & & & & 4 \\
\hline 3 & & & & & & & & & & & \\
\hline 1.1 & & & & & & & & & & & \\
\hline 1.2 & & & & & & & & & & & \\
\hline 3.1 & & & & & & & & & & & \\
\hline 3.2 & & & & & & & & & & & \\
\hline 1.1 .1 & & & & & & & & 3 & 1 & & \\
\hline 1.1 .2 & & & & & & & & & 2 & & \\
\hline 3.2 .1 & & & & & 1 & & & & & & \\
\hline 3.2 .2 & & 2 & & & & & & & & & 4 \\
\hline
\end{tabular}




\section{Passo 1: Atribuir predições aos niveis superiores}

Esse passo tem como objetivo refletir os relacionamentos hierárquicos na matriz de confusão resultante do processo de classificação. Essa matriz de confusão inicial apenas reporta as classes preditas e as classes verdadeiras, assim como num problema de classificação plana convencional (como pode ser observado na Tabela 3.2). Nesse estágio inicial, a matriz não deve refletir os relacionamentos hierárquicos do problema de classificação.

O procedimento de atribuição das predições nos níveis superiores iniciase nos nós-folha e prossegue de maneira bottom-up pela hierarquia. Se um exemplo foi predito como pertencente à classe 1.1.1, então ele também foi predito para a classe $1.1 \mathrm{e}$, de maneira consecutiva, para a classe 1. Da mesma forma, se um exemplo pertence à classe 1.1.1, ele também pertence à classe $1.1 \mathrm{e} 1$. Utilizando essa lógica para todos os nós da hierarquia, as predições dos níveis inferiores são passadas para os nós dos níveis superiores. Após aplicar esse passo na matriz de confusão inicial, a matriz de confusão obtida é representada pela Tabela 3.3.

Tabela 3.3: Matriz de confusão hipotética com as modificações resultantes dos procedimentos do Passo 1 de um total de quatro passos para geração das matrizes de confusão nível a nível.

\begin{tabular}{|c|c|c|c|c|c|c|c|c|c|c|c|}
\cline { 2 - 12 } \multicolumn{1}{c|}{} & \multicolumn{10}{c|}{ Classe Predita } \\
\hline C. Verd. & 1 & 2 & 3 & 1.1 & 1.2 & 3.1 & 3.2 & 1.1 .1 & 1.1 .2 & 3.2 .1 & 3.2 .2 \\
\hline 1 & 6 & & & 6 & & & & 3 & 3 & & \\
\hline 2 & 3 & & 4 & & 3 & & 4 & & & & 4 \\
\hline 3 & 1 & 2 & 4 & & 1 & & 4 & & & & 4 \\
\hline 1.1 & 6 & & & 6 & & & & 3 & 3 & & \\
\hline 1.2 & & & & & & & & & & & \\
\hline 3.1 & & & & & & & & & & & \\
\hline 3.2 & 1 & 2 & 4 & & 1 & & 4 & & & & 4 \\
\hline 1.1 .1 & 4 & & & 4 & & & & 3 & 1 & & \\
\hline 1.1 .2 & 2 & & & 2 & & & & & 2 & & \\
\hline 3.2 .1 & 1 & & & & 1 & & & & & & \\
\hline 3.2 .2 & & 2 & 4 & & & & 4 & & & & 4 \\
\hline
\end{tabular}

\section{Passo 2: Criar uma matriz de confusão para cada nível}

Para que os resultados sejam reportados por nível, é necessário que seja gerada uma matriz de confusão para cada nível. Então, a tarefa principal desse passo é derivar uma matriz para cada nível a partir da matriz geral resultante do Passo 1.

Uma alternativa seria considerar na matriz de cada nível apenas as classes que pertencessem àquele nível. Assim, para a matriz de confusão do primeiro 
nível, só haveriam classes pertencentes ao primeiro nível; para a matriz de confusão no segundo nível, só haveriam classes pertencentes ao segundo nível; e assim consecutivamente para todos os níveis da hierarquia. Porém, há a possibilidade dessa alternativa omitir alguns erros que deveriam ser reportados. Isso pode ocorrer para os casos em que a classe predita e a classe verdadeira estão em níveis diferentes. Por exemplo, considere o caso em que três exemplos da classe 2 foram preditos como pertencentes à classe 1.2, como pode ser observado na matriz de confusão inicial representada na Tabela 3.2. Esse erro ocorreu no segundo nível, pois a classe predita foi no segundo nível, mas também deve ser refletido para o primeiro nível, em que a classe predita é a classe 1. Se a alternativa de considerar apenas classes de um único nível em cada matriz de confusão for adotada, será computado o erro no primeiro nível, uma vez que a classes 1 (classe predita) e a classe 2 (classe verdadeira) pertencem ao mesmo nível, mas não será computado para o segundo nível, uma vez que a classes 1.2 (classe predita) não é do mesmo nível que a classe 2 (classe verdadeira). Assim, foi proposto um outro método para a geração das matrizes de confusão.

Na construção da matriz de confusão para cada nível, deve-se ter em mente todos os tipos de erros e acertos que devem ser reportados nessa matriz. Quando um exemplo é predito em um nível, mas na verdade ele deveria ter sido predito em outro, é um falso positivo. Quando um exemplo não foi predito em um nível, mas na verdade ele pertencia àquele nível, ele é um falso negativo. A partir dessas considerações, pode-se decidir quais as classes estarão presentes na matriz de confusão gerada para cada nível da hierarquia.

No primeiro nível, a matriz de confusão gerada só conterá classes do primeiro nível, pois não há como um erro não ser reportado nessa matriz. Todas as classes dos níveis mais específicos têm um ancestral no primeiro nível. No segundo nível, todas as classes em níveis mais específicos têm necessariamente um ancestral nesse nível. Logo, todos os erros cometidos em tais classes são refletidos para as classes do segundo nível. O problema está nas classes mais gerais que as do segundo nível, ou seja, as classes do primeiro nível. Ao considerar apenas as classes do segundo nível, erros que tenham ocorrido no primeiro nível não são reportados por relacionamentos de "classe verdadeira x classe predita” entre classes apenas do segundo nível. Então, a matriz de confusão do segundo nível deve conter classes do segundo nível e todas as classes dos níveis mais gerais, ou seja, as classes do primeiro nível. Os procedimentos para os demais níveis são então derivados dos procedimentos para o segundo nível, ou seja, a matriz de confusão do nível $n$ deve conter as classes do nível $n$ e todas as classes do nível $i$, com $i$ variando de $n-1$ até 1 (primeiro nível). 
Após a determinação de quais classes deverão compor a matriz de confusão de cada nivel, basta copiar os valores necessários da tabela resultante do Passo 2 (Tabela 3.3) para a matriz de confusão de cada nível. Dessa forma, obtém-se as matrizes de confusão para os três niveis do exemplo hipotético. As matrizes para o primeiro, segundo e terceiro niveis são mostradas nas tabelas 3.4, 3.5 e 3.6, respectivamente. É importante ressaltar que ajustes ainda precisam ser feitos nessas matrizes de confusão para que elas sejam coerentes com as predições realizadas. Esses ajustes são feitos nos passos 3 e 4. A exceção é a matriz de confusão do primeiro nível, que já tem sua configuração final no término do Passo 2. Outra observação importante diz respeito à matriz de confusão do terceiro nível. Como pode ser observado, os valores da matriz nesse nível são iguais ao da matriz resultante do Passo 1. Isso ocorre porque segundo os procedimentos do Passo 2, a matriz de confusão do último nível deve conter todas as classes da hierarquia.

Tabela 3.4: Matriz de confusão para o primeiro nível derivada a partir dos procedimentos do Passo 2 de um total de quatro passos para geração das matrizes de confusão nível a nível.

\begin{tabular}{|c|c|c|c|}
\cline { 2 - 4 } \multicolumn{1}{c|}{} & \multicolumn{3}{c|}{ Classe Predita } \\
\hline C. Verd. & 1 & 2 & 3 \\
\hline 1 & 6 & & \\
\hline 2 & 3 & & 4 \\
\hline 3 & 1 & 2 & 4 \\
\hline
\end{tabular}

Tabela 3.5: Matriz de confusão para o segundo nível derivada a partir dos procedimentos do Passo 2 de um total de quatro passos para geração das matrizes de confusão nível a nível.

\begin{tabular}{|c|c|c|c|c|c|c|c|}
\cline { 2 - 8 } \multicolumn{1}{c|}{} & \multicolumn{7}{|c|}{ Classe Predita } \\
\hline C. Verd. & 1 & 2 & 3 & 1.1 & 1.2 & 3.1 & 3.2 \\
\hline 1 & 6 & & & 6 & & & \\
\hline 2 & 3 & & 4 & & 3 & & 4 \\
\hline 3 & 1 & 2 & 4 & & 1 & & 4 \\
\hline 1.1 & 6 & & & 6 & & & \\
\hline 1.2 & & & & & & & \\
\hline 3.1 & & & & & & & \\
\hline 3.2 & 1 & 2 & 4 & & 1 & & 4 \\
\hline
\end{tabular}

\section{Passo 3: Eliminar duplicidades das matrizes de confusão}

As matrizes resultantes do Passo 2 podem possuir algumas duplicidades, com exceção da matriz de confusão do primeiro nível, que já tem sua configuração final. Dessa forma, o Passo 3 tem como objetivo a eliminação de tais 
Tabela 3.6: Matriz de confusão para o terceiro nível derivada a partir dos procedimentos do Passo 2 de um total de quatro passos para geração das matrizes de confusão nível a nível.

\begin{tabular}{|c|c|c|c|c|c|c|c|c|c|c|c|}
\cline { 2 - 13 } \multicolumn{1}{c|}{} & \multicolumn{10}{c|}{ Classe Predita } \\
\hline C. Verd. & 1 & 2 & 3 & 1.1 & 1.2 & 3.1 & 3.2 & 1.1 .1 & 1.1 .2 & 3.2 .1 & 3.2 .2 \\
\hline 1 & 6 & & & 6 & & & & 3 & 3 & & \\
\hline 2 & 3 & & 4 & & 3 & & 4 & & & & 4 \\
\hline 3 & 1 & 2 & 4 & & 1 & & 4 & & & & 4 \\
\hline 1.1 & 6 & & & 6 & & & & 3 & 3 & & \\
\hline 1.2 & & & & & & & & & & & \\
\hline 3.1 & & & & & & & & & & & \\
\hline 3.2 & 1 & 2 & 4 & & 1 & & 4 & & & & 4 \\
\hline 1.1 .1 & 4 & & & 4 & & & & 3 & 1 & & \\
\hline 1.1 .2 & 2 & & & 2 & & & & & 2 & & \\
\hline 3.2 .1 & 1 & & & & 1 & & & & & & \\
\hline 3.2 .2 & & 2 & 4 & & & & 4 & & & & 4 \\
\hline
\end{tabular}

duplicidades. Esses valores duplicados são facilmente perceptíveis ao somar os valores dos elementos de cada matriz. Por exemplo, a matriz de confusão do segundo nível apresenta em suas células valores que somados resultam num valor igual a 62 , sendo que foram realizadas apenas 20 predições.

Essas duplicidades se deram pelo fato de que as predições nos níveis mais específicos terem sido passadas para os niveis mais gerais. Portanto, nesse passo deve-se fazer o procedimento inverso em cada matriz. Se o processo fosse feito na matriz geral resultante do Passo 1, os procedimentos desse passo seriam anulados pelo Passo 3. Porém, ao fazer o procedimento em cada uma das matrizes resultantes do Passo 2, garante-se que não haja mais duplicidades, ao mesmo tempo que os efeitos do Passo 1 são mantidos.

O procedimento do Passo 3 consiste em manter, para a matriz de cada nível, apenas informações de predições no nível mais específico, bem como as informações a respeito de a quais classes do nível mais específico os exemplos pertencem. Por exemplo, a matriz do segundo nivel representada pela Tabela 3.5 possui informações para a classe 1 e para as suas subclasses. Deve-se manter apenas as informações para as suas subclasses, eliminando assim as duplicidades.

A matriz de confusão do segundo nível resultante do Passo 3 é mostrada na Tabela 3.7. Uma observação importante deve ser feita para a matriz de confusão do terceiro nível resultante do Passo 3. Essa matriz é igual à matriz inicial apresentada na Tabela 3.2 (por essa razão, a matriz para esse nível é omitida). Isso ocorre devido à seqüência dos três primeiros passos utilizados para a geração da matriz de confusão do último nível da hierarquia. O Passo 2 cria uma matriz para esse nível idêntica a matriz resultante do Passo 1 (como mencionado no passo anterior). Como o Passo 3 é o inverso do Passo 1, isso 
faz com que a matriz do último nível, ao final do Passo 3, seja igual a matriz anterior ao Passo 1, que é a matriz inicial. Dessa maneira, os passos 1, 2 e 3 não precisam ser realizados para o último nível. Para esse nível, basta fazer uma cópia da matriz de confusão inicial e submetê-la diretamente ao Passo 4.

Tabela 3.7: Matriz de confusão para o segundo nível derivada a partir dos procedimentos do Passo 3 de um total de quatro passos para geração das matrizes de confusão nível a nível.

\begin{tabular}{|c|c|c|c|c|c|c|c|}
\cline { 2 - 8 } \multicolumn{1}{c|}{} & \multicolumn{7}{|c|}{ Classe Predita } \\
\hline C. Verd. & 1 & 2 & 3 & 1.1 & 1.2 & 3.1 & 3.2 \\
\hline 1 & & & & & & & \\
\hline 2 & & & & & 3 & & 4 \\
\hline 3 & & & & & & & \\
\hline 1.1 & & & & 6 & & & \\
\hline 1.2 & & & & & & & \\
\hline 3.1 & & & & & & & \\
\hline 3.2 & & 2 & & & 1 & & 4 \\
\hline
\end{tabular}

\section{Passo 4: Eliminar informações de outros níveis}

O último passo para a obtenção da configuração final das matrizes de confusão consiste em eliminar informações que não dizem respeito ao nível para o qual a matriz de confusão está sendo construída. Isso ocorre quando as classes predita e verdadeira pertencem a um nível mais geral do que o nível da matriz de confusão. Nesse caso, o erro ou o acerto não deve ser computado para o nível em questão. O que deve ser feito é atribuir zero para as células da tabela que estiverem nessa situação.

No exemplo que está sendo considerado, apenas a matriz de confusão do terceiro nível sofre modificações nesse passo. A matriz do segundo nível não sofreu alterações nesse passo por conta das características do exemplo. Porém, com exceção da matriz do primeiro nível, todas as matrizes devem ser submetidas aos procedimentos do Passo 4 e são passiveis de serem alteradas por eles.

Para a matriz de confusão do terceiro nível, os três exemplos da classe 2 (primeiro nível) preditos como pertencentes à classe 1.2 (segundo nível) não devem ser considerados como erros do terceiro nível. Por isso, tais erros são retirados da matriz de confusão desse nível, gerando a matriz mostrada na Tabela 3.8. A matriz final do primeiro nível foi obtida ao final do Passo 2 (Tabela 3.4) e a matriz final do segundo nível não sofreu modificações nesse passo e é igual a matriz resultante do Passo 3 (Tabela 3.7). 
Tabela 3.8: Matriz de confusão para o terceiro nível resultante dos passos para geração das matrizes de confusão nível a nivel.

\begin{tabular}{|c|c|c|c|c|c|c|c|c|c|c|c|}
\cline { 2 - 11 } \multicolumn{1}{c|}{} & \multicolumn{7}{c|}{ Classe Predita } \\
\hline C. Verd. & 1 & 2 & 3 & 1.1 & 1.2 & 3.1 & 3.2 & 1.1 .1 & 1.1 .2 & 3.2 .1 & 3.2 .2 \\
\hline 1 & & & & & & & & & & & \\
\hline 2 & & & & & & & & & & & 4 \\
\hline 3 & & & & & & & & & & & \\
\hline 1.1 & & & & & & & & & & & \\
\hline 1.2 & & & & & & & & & & & \\
\hline 3.1 & & & & & & & & & & & \\
\hline 3.2 & & & & & & & & & & & \\
\hline 1.1 .1 & & & & & & & & 3 & 1 & & \\
\hline 1.1 .2 & & & & & & & & & 2 & & \\
\hline 3.2 .1 & & & & & 1 & & & & & & \\
\hline 3.2 .2 & & 2 & & & & & & & & & 4 \\
\hline
\end{tabular}

Resumo dos procedimentos para geração das matrizes de confusão nível a nível

Os quatro passos descritos têm por objetivo a geração das matrizes de confusão para cada nível da hierarquia, com o intuito de realizar a avaliação do desempenho preditivo nível a nível. A função de cada um dos passos é, nessa ordem: (1) Atribuir predições aos níveis superiores, (2) Criar uma matriz de confusão para cada nível, (3) Eliminar duplicidades das matrizes de confusão, (4) Eliminar informações de outros níveis.

A matriz inicial que deve ser submetida a esses passos deve reportar apenas as classes preditas e as classes verdadeiras, assim como num problema de classificação plana convencional. Nesse estágio inicial, os relacionamentos hierárquicos entre as classes ainda não devem estar refletidos na matriz.

Após a execução dos quatro passos, nessa ordem, é obtida uma matriz de confusão para cada nível, refletindo apenas erros e acertos que dizem respeito àquele nível. Embora os quatro passos possam ser seguidos para a geração das matrizes de confusão para todos os níveis, para alguns deles alguns passos são desnecessários. Para gerar a matriz de primeiro nível, basta seguir os dois primeiros passos. Para gerar a matriz de confusão do último nível, basta fazer uma cópia da matriz de confusão inicial e submetê-la diretamente ao Passo 4. Para todos os demais níveis, todos os passos são necessários para a geração de suas matrizes de confusão.

\subsubsection{Medidas de desempenho}

Existem muitas maneiras de se avaliar o desempenho preditivo de um modelo de classificação. A partir da fase de teste, os erros/acertos de classifica- 
ção são utilizados para avaliação do desempenho preditivo do modelo. Medidas convencionais de avaliação de modelos de classificação foram discutidas no tópico "Avaliação de Algoritmos de Classificação" da Seção 2.5.

As medidas convencionais foram desenvolvidas levando-se em conta a avaliação de modelos de classificação que não possuem uma relação hierárquica entre as classes. Por esse motivo, a utilização dessas, em seu formato original, não é recomendada para avaliação de classificadores hierárquicos. Entretanto, muitos trabalhos em classificação hierárquica ainda utilizam tais medidas para reportar o desempenho preditivo.

O problema com as medidas convencionais é que elas estão baseadas na atribuição de um custo uniforme aos erros de classificação, independente das posições da classe verdadeira e da classe predita na hierarquia. Ao atribuir uma mesma penalidade para qualquer erro de classificação, essas medidas não levam em conta a estrutura hierárquica do modelo.

Para ilustrar o comportamento dessas medidas, denominadas daqui em diante de medidas baseadas no custo uniforme, considere o seguinte exemplo. Com base na hierarquia de classes representada pela Figura 3.6, suponha que dois exemplos, ambos pertencentes à classe 2.1.2, foram preditos erroneamente: o primeiro exemplo foi predito como pertencente à classe 2.1.1, enquanto que o segundo exemplo foi predito como pertencente à classe 1.1.1. Nesse caso, segundo o custo uniforme, os dois erros de classificação são igualmente penalizados. Entretanto, o inconveniente dessa estratégia de penalização é que, ao convencionar que o custo de erro de classificação para ambos os casos são iguais, ignora-se a suposição de que, baseado na hierarquia, as classes 2.1.2 e 2.1.1 são mais similares entre si do que as classes 2.1.2 e 1.1.1. Essa suposição pode ser feita baseada no fato de que as classes $2.1 .2 \mathrm{e}$ 2.1.1 têm um ancestral comum imediato, a classe 2.1 , ao contrário das classes 2.1.2 e 1.1.1, cujo único ancestral comum é o nó-raiz.

Considerando as desvantagens do custo uniforme, que é a estratégia de penalização assumida pelas medidas de avaliação convencionais, muitas medidas alternativas têm sido propostas com o intuito de considerar os relacionamentos hierárquicos entre as classes durante a avaliação. Tais medidas podem ser agrupadas em quatro tipos: medidas baseadas em distância; medidas dependentes da profundidade; medidas baseadas em semântica; e medidas baseadas em relações de ancestralidade e descendência. Além das medidas que seguem essas estratégias, outras medidas podem ser encontradas na literatura. Porém, tais medidas ou são muito específicas para o problema em que foram empregadas, apresentando difícil generalização, ou são apenas propostas teóricas de possíveis abordagens para a definição de medidas. Algumas dessas medidas são citadas na subseção "Outras Medidas”. 


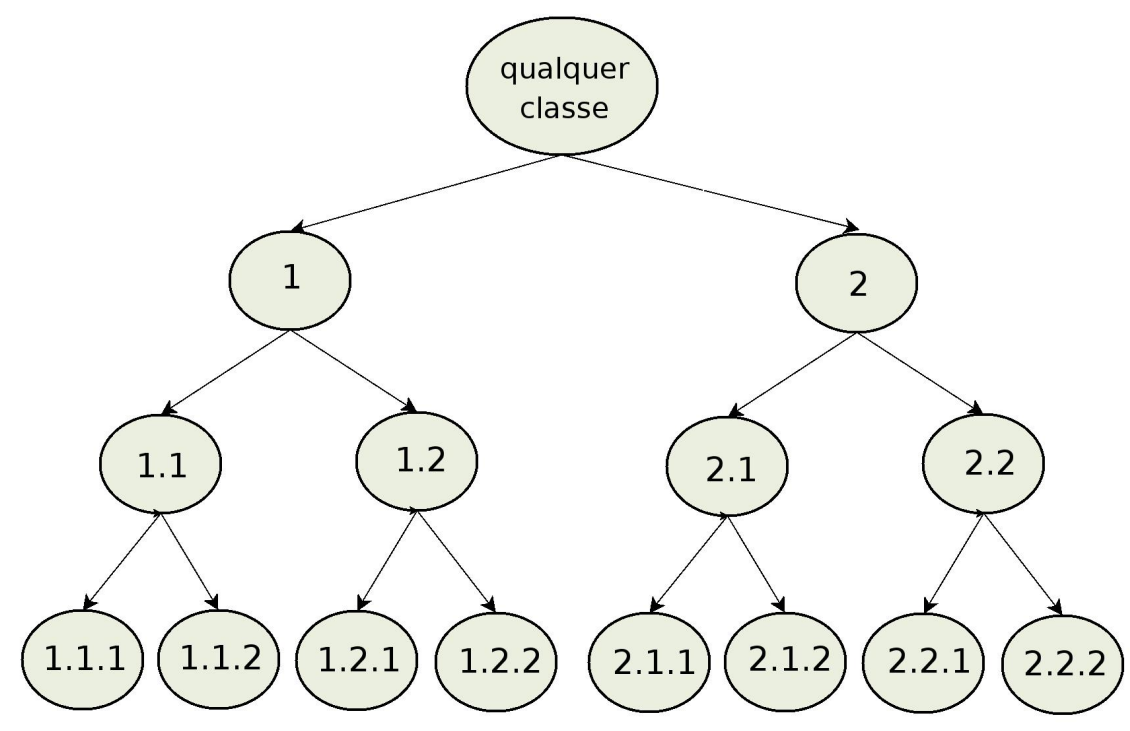

Figura 3.6: Exemplo de hierarquia de classes: análise de custos.

Com o objetivo de facilitar o entendimento das abordagens de avaliação discutidas a seguir, algumas equações são apresentadas para as principais medidas descritas. A seguinte notação foi adotada: $C_{t}$ representa a classe verdadeira de um exemplo, $C_{p}$ a classe predita e $M$ o número total de classes envolvidas no problema de classificação.

\section{Medidas baseadas em distância}

Classes que estão localizadas mais próximas na hierarquia tendem a ser mais similares entre si do que em relação a outras classes mais distantes na hierarquia. Dessa forma, essa abordagem de avaliação considera a distância entre a classe verdadeira e a classe predita como uma forma de computar o erro da predição. Essa distância é definida como o número de ligações entre nós pertencentes ao menor caminho que liga as classes verdadeira e predita. Para ilustrar essa definição, considere novamente o exemplo dado para o custo uniforme, em que dois exemplos da classe 2.1.2 são preditos de maneira incorreta, cada um em uma classe diferente. Ao considerar a distância como um fator para determinar a penalização para um erro de classificação, a predição realizada do exemplo como pertencente à classe 2.1.1 deve ser menos penalizada do que a predição do exemplo como pertencente à classe 1.1.1. Isso porque a distância entre as classes 2.1.2 e 2.1.1 é de duas ligações, enquanto que a distância entre as classes 2.1.2 e 1.1.1 é de seis ligações, como pode ser observado na Figura 3.6. 
Essa abordagem de cálculo do erro de predição foi proposta por Wang et al. (1999) e usada por Sun \& Lim (2001) no contexto de classificação hierárquica de dados textuais. Mais precisamente, Sun \& Lim (2001) modificaram as medidas convencionais de precisão, sensibilidade, TA e TE considerando erros de classificação baseados em distância.

Nas medidas propostas por Sun \& Lim (2001), é calculada a contribuição de falsos positivos para cada classe $C_{i}\left(F p C o n_{i}\right)$ (Equação 3.1, usando termos definidos nas equações 3.2 e 3.3). Para calcular essa contribuição, uma distância aceitável, denotada como $D i s_{\theta}$, é definida. Esse valor deve ser especificado pelo usuário e deve ser maior do que zero. Essas equações foram adaptadas de (Sun \& Lim, 2001), pois elas foram originalmente formuladas para avaliar problemas de classificação hierárquica multirótulos (multilabel). Em problemas de classificação multirótulos, um exemplo pode ser associado a mais do que uma classe simultaneamente. No caso de problemas de classificação hierárquica multirótulos, mais do que um caminho pode ser seguido na hierarquia para a classificação de um novo exemplo.

$$
\begin{gathered}
\text { FpCon }_{i}=\sum_{T \in F P_{i}} R \operatorname{Con}\left(T, C_{p}\right) \\
\operatorname{Con}\left(T, C_{p}\right)=1.0-\frac{\operatorname{Dis}\left(C_{p}, C_{t}\right)}{\operatorname{Dis} s_{\theta}} \\
\operatorname{RCon}\left(T, C_{p}\right)=\min \left(1, \max \left(-1, \operatorname{Con}\left(T, C_{p}\right)\right)\right)
\end{gathered}
$$

Inicialmente, a contribuição de falsos positivos (Con) é calculada (Equação 3.2) para cada classe. Nessa equação, $T$ denota um exemplo de entrada e $\operatorname{Dis}\left(C_{p}, C_{t}\right)$ denota as distância entre $C_{p}$ and $C_{t}$. Em seguida, uma "contribuição refinada” (RCon) é calculada (Equação 3.3), que normaliza a contribuição de cada exemplo no intervalo $[-1,1]$. Uma vez calculado o valor de $R C$ on para cada falso positivo, um somatório é realizado e o valor $F p C o n_{i}$ para a classe $C_{i}$ é obtido, usando a Equação 3.1.

Além de $F p C o n_{i}$, a contribuição dos falsos negativos ( $F n C o n_{i}$ ) também é calculada para cada classe $C_{i}$. Seu cálculo é similar ao descrito para $F p C o n_{i}$, como pode ser observado na Equação 3.4. No cálculo de $R C$ on (Equação 3.3) e $C$ on (Equação 3.2), $C_{p}$ e $C_{t}$ são substituídos por $C_{t}$ and $C_{p}$, respectivamente.

$$
\mathrm{FnCon}_{i}=\sum_{T \in F N_{i}} \operatorname{RCon}\left(T, C_{t}\right)
$$


Baseado nos valores de $\mathrm{FpCon}_{i}$ e $\mathrm{FnCon}_{i}$, algumas medidas estendidas podem ser definidas: precisão, sensibilidade, TA e TE, que são apresentadas nas equações 3.5, 3.6, 3.7 e 3.8, respectivamente.

$$
\begin{aligned}
& P=\frac{\max \left(0,\left|T P_{i}\right|+F p \operatorname{Con}_{i}+\text { FnCon }_{i}\right)}{\left|T P_{i}\right|+\left|F P_{i}\right|+F n \operatorname{Con}_{i}} \\
& S=\frac{\max \left(0,\left|T P_{i}\right|+F p \operatorname{Con}_{i}+F_{n} \operatorname{Con}_{i}\right)}{\left|T P_{i}\right|+\left|F N_{i}\right|+F p \operatorname{Con}_{i}} \\
& T A=\frac{|T N|+|T P|+F p C \text { Fn }_{i}+\text { FnCon }_{i}}{|F N|+|F P|+|T N|+|T P|} \\
& T E=\frac{|F P|+|F N|-F_{p} \text { Con }_{i}-\text { FnCon }_{i}}{|F N|+|F P|+|T N|+|T P|}
\end{aligned}
$$

Uma outra maneira de utilizar a distância no cálculo da TE consiste em, inicialmente, calcular o erro de predição, baseado em distância, de cada exemplo classificado. A TE é então obtida por meio da média do erro medido para todos os exemplos. Uma vez obtido o valor para a TE, a TA pode ser obtida diretamente desse valor. Esse foi o procedimento adotado para obter a TA baseada em distância utilizada para reportar parte dos resultados apresentados na Seção 5.3.1 do Capítulo 5. A seguir, esse procedimento é descrito de maneira mais detalhada.

Para cada exemplo classificado, é calculada a distância entre a classe predita e a classe verdadeira. Em seguida, esse valor de distância é normalizado $\left(\right.$ Dist $\left._{N}\right)$ pela sua divisão pelo valor da distância entre a classe verdadeira e a classe mais distante dela $\left(C_{d}\right)$, como pode ser observado na Equação 3.9.

$$
\operatorname{Dist}_{N}=\frac{\operatorname{Dis}\left(C_{p}, C_{t}\right)}{\operatorname{Dis}\left(C_{d}, C_{t}\right)}
$$

O passo seguinte consiste em um somatório do valor normalizado da distância para todos os exemplos que foram classificados (os exemplos que foram classificados corretamente terão valor de distância igual a zero). Esse somatório é então dividido pelo número total de exemplos classificados (NTotal), obtendo-se a TE para o modelo de classificação, como pode ser observado na Equação 3.10, em que $D_{i s t}^{i}$ é a distância normalizada para o exemplo $i$. A TA pode ser obtida diretamente da TE, conforme ilustrado na Equação 3.11.

$$
T E=\frac{\sum_{i=1}^{N T o t a l} \operatorname{Dist}_{N}^{i}}{\text { NTotal }}
$$




$$
T A=1-T E
$$

Uma desvantagem comum a todas as medidas baseadas na atribuição de erros com base em distância é que elas não consideram o fato de que a classificação em níveis mais profundos da hierarquia tende a ser significantemente mais difícil do que a classificação em níveis superiores (mais próximos à raiz). A explicação para isso é que classes de niveis superiores representam informações mais gerais e possuem um número maior de exemplos de treinamento, o que facilita o processo de classificação em tais níveis, quando comparado a niveis mais profundos.

\section{Medidas dependentes da profundidade}

Essa abordagem, que foi proposta por Blockeel et al. (2002), tem como objetivo evitar a desvantagem das medidas baseadas em distância de não considerar a diferença na dificuldade de predição existente entre os níveis. Para isso, a distância entre a classe verdadeira e a classe predita é definida em termos de dois fatores: (a) o número de ligações entre as duas classes; e (b) a profundidade tanto do nível em que se encontra a classe verdadeira quanto do nivel em que se encontra a classe predita. Essa medida, embora um pouco mais complexa que a distância convencional (independente da profundidade), considera o fato de que classes dos níveis superiores são mais fáceis de prever. Dessa maneira, segundo essa abordagem, as penalizações para erros de classificação nos níveis superiores devem ser maiores do que para erros de classificação nos níveis mais profundos.

Essa diferenciação entre níveis pode ser feita utilizando pesos nas ligações. $\mathrm{Na}$ atribuição de pesos, ligações mais profundas recebem um peso menor que ligações menos profundas. Nesse caso, a distância é dita ponderada e é obtida pelo caminho que apresenta um menor valor da soma dos pesos das ligações que separam duas classes. Na Figura 3.7 é apresentado um esquema de pesos especificado para o modelo da Figura 3.6. A critério de exemplo, os pesos foram distribuídos arbitrariamente, apenas considerando que os pesos de ligações tendem a diminuir a medida que a profundidade aumenta.

Uma questão que deve ser considerada para a estratégia que utiliza pesos nas ligações diz respeito a forma como esse conjunto de pesos é determinada. A solução usada em (Holden \& Freitas, 2006) e (Blockeel et al., 2002) consistiu em diminuir o valor dos pesos exponencialmente com o aumento da profundidade. Porém, essa solução também apresenta problemas, como discutido nos dois próximos parágrafos.

Um desses problemas ocorre quando a hierarquia de classes apresenta um 


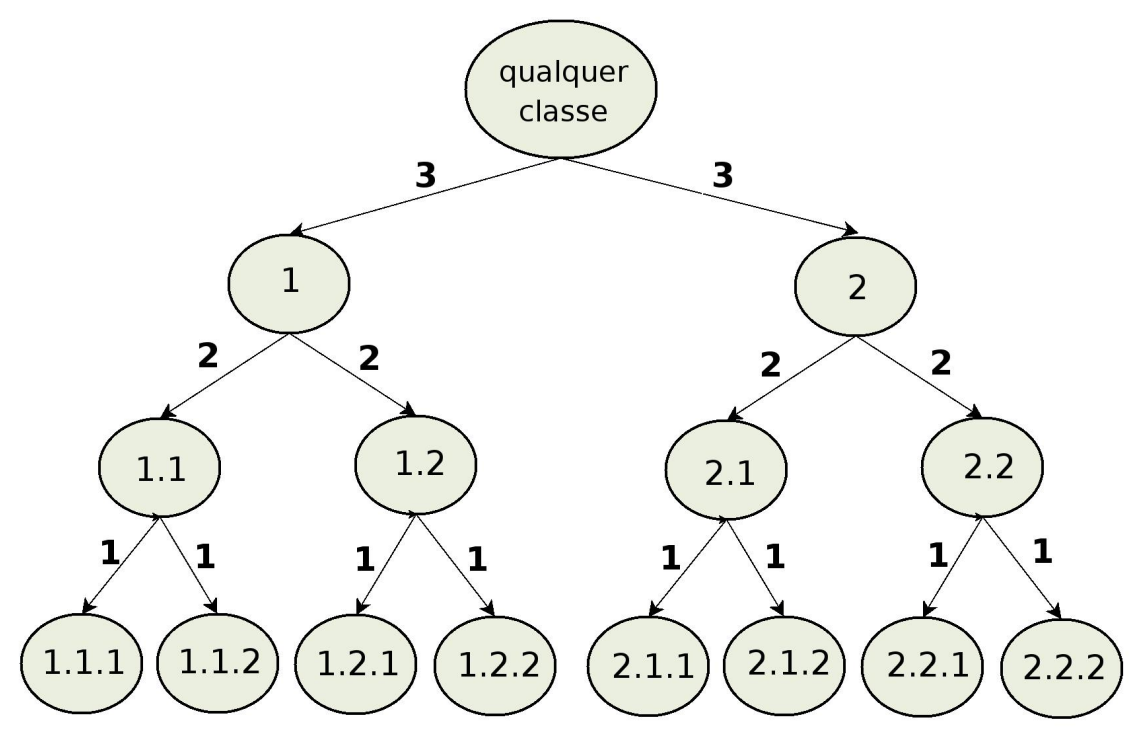

Figura 3.7: Hierarquia de classes com ligações ponderadas.

grande desbalanceameto. Essa situação ocorre quando a profundidade da hierarquia (distância entre o nó-raiz e um nó-folha) varia significantemente para diferentes nós-folhas. Nesse caso, suponha que para dois exemplos pertencentes à mesma classe (à classe 1.2 da hierarquia representada na Figura 3.5, por exemplo) as predições tenham sido feitas em classes diferentes (classe 2 e classe 3.2.1, por exemplo). Ambas a classes preditas estão localizadas em nós-folha, porém uma delas se localiza em um nível mais próximo à raiz (a classe 2 se localiza no primeiro nível) e outra em um nível mais distante (a classe 3.2.1 se localiza no terceiro nível). O erro de classificação cuja classe predita se localiza em um nó-folha de um nível mais próximo à raiz será menos penalizado do que o erro de classificação que envolve a classe mais distante da raiz. Isso ocorre porque na última situação existe um número maior de ligações distanciando a classe verdadeira da predita. Em algumas situações, essa penalização menor pode ser injusta (como é o caso da situação exemplo suposta), pois uma predição pode ter sido feita em um nivel mais geral porque a classe para a qual foi feita a predição não possuía subclasses e não porque optou-se por não fazer uma predição mais específica.

Um outro problema, apontado por Lord et al. (2003), também considera o caso em que a profundidade dos ramos da hierarquia varia significantemente. De acordo com Lord et al. (2003), quando duas classes $C_{1}$ e $C_{2}$ estão localizadas em diferentes subárvores da hierarquia de um nó-raiz (isto é, quando o único ponto de ligação entre as classes $C_{1}$ and $C_{2}$ é o nó-raiz), o fato de uma das classes ser mais profunda do que outra não significa necessariamente que 
a primeira é mais informativa do que a última. Por exemplo, uma classe representada por um nó no terceiro nível pode estar associada com uma informação tão específica quanto uma classe do quinto nível, se elas estiverem localizadas em subárvores distintas. Portanto, a associação de pesos às ligações considerando apenas a profundidade - e não a informação associada com cada classe - pode ser um problema em alguns casos.

Além disso, há uma desvantagem comum tanto às medidas baseadas em distância quanto às medidas dependentes da profundidade. Embora a distância entre a classe predita e a classe verdadeira seja facilmente calculada para uma hierarquia estruturada como uma árvore, a definição da distância, no caso de uma hierarquia estruturada como um DAG, é mais difícil e envolve maior tempo computacional. Em particular, em DAGs, o conceito de "profundidade" de uma classe não é trivial, uma vez que podem haver múltiplos caminhos ligando o nó-raiz a um determinado nó.

Para utilizar o conceito de distância dependente da profundidade para estender a TE e a TA de um modelo de classificação são seguidos os mesmos passos descritos para as medidas baseadas em distância. A única diferença é que, na abordagem que considera a distância dependente da profundidade, o cálculo deverá incluir os pesos das arestas que ligam as classes. Para cada exemplo que foi classificado, após o cálculo da distância ponderada entre as classes predita e a verdadeira, é feita a normalização dessa distância por meio de sua divisão pelo maior valor possível de distância (também ponderada) que poderia ser obtido na classificação do exemplo em questão. Após a normalização, a TE é obtida pela soma de todas as distâncias normalizadas e posterior divisão do valor do somatório pelo número de exemplos classificados. A TA é definida diretamente pelo complemento da TE.

Apesar das desvantagens e problemas descritos para essa abordagem de medição de erros, a sua utilização é vantajosa em muitas situações, uma vez que ela leva em consideração importantes aspectos dos relacionamentos hierárquicos entre as classes, além de permitir uma extensão praticamente direta das medidas de TA e TE convencionais. Os problemas apontados são mais prejudiciais para a avaliação em casos mais extremos, em que a hierarquia apresenta um grande desbalanceamento e quando não há uma uniformidade entre as informações associadas com cada nível da hierarquia (quando em um mesmo nível há variação considerável do grau de especificidade das informações representadas).

No caso dos conjuntos de dados utilizados neste projeto, as hierarquias apresentam apenas pequenos desbalanceamentos e a especificidade das informações representadas por cada nível é bem delimitada. Por esses motivos, a TA dependente da profundidade foi utilizada para reportar os resultados dos 
experimentos descritos no Capítulo 5. Para a atribuição dos pesos às ligações entre as classes da hierarquia foi utilizado o mesmo conjunto definido em (Holden \& Freitas, 2006): $(0.26,0.13,0.07,0.04)$, para quatro níveis hierárquicos.

\section{Medidas baseadas em semântica}

Nessa abordagem, também proposta por Sun \& Lim (2001), o conceito de similaridade semântica entre classes é utilizado como um parâmetro para a definição dos valores de penalização para os erros de classificação. A idéia principal dessa abordagem baseia-se na noção intuitiva de que uma predição que classifica erroneamente uma entrada em uma classe similar àquela que é fornecida como correta é considerada melhor do que uma predição que classifica uma entrada em uma classe que não tem relação alguma com a correta.

Essa similaridade pode ser calculada de diferentes maneiras. Em (Sun \& Lim, 2001), foi proposto um método em que cada classe é descrita por um vetor de características. Por exemplo, a classe $C_{i}$ pode ser descrita por um vetor de características $\left\{w_{1}, w_{2}, \ldots, w_{H}\right\}$, em que $H$ é o número de características presentes no vetor. A similaridade entre classes é então calculada usando esses vetores descritivos. Essa similaridade pode ser usada para definir medidas como precisão, sensibilidade, TA e TE.

Nas medidas propostas em (Sun \& Lim, 2001), para cada par de classes $C_{i} \mathrm{e}$ $C_{j}$, uma medida denominada "Similaridade de Categorias" (Category Similarity - CS) é calculada (Equação 3.12). As similaridades entre categorias são então utilizadas para a definição de uma média de similaridade de categorias ( $A C S$ ), como pode ser observado na Equação 3.13. Para cada categoria, os valores $C S$ e $A C S$ são usados para calcular a contribuição $(C o n)$ dos falsos positivos e dos falsos negativos. Para o caso dos falsos positivos, o cálculo de $C o n$ é dado pela Equação 3.14. Para o caso dos falsos negativos, a mesma equação é usada, apenas substituindo na equação $C_{p}$ e $C_{t}$ por $C_{t}$ e $C_{p}$, respectivamente. Uma vez calculado $C o n$, o procedimento para obtenção das medidas estendidas (precisão, sensibilidade, TA e TE) é o mesmo apresentado para as medidas baseadas em distância (equações 3.5, 3.6, 3.7 e 3.8). Para as equações apresentadas nesta seção, também foram necessárias algumas modificações na forma como elas foram propostas por Sun \& Lim (2001), uma vez que elas foram projetadas originalmente para problemas de classificação hierárquica multirótulos.

$$
C S\left(C_{i}, C_{j}\right)=\frac{\sum_{k=1}^{H} w_{k} \times v_{k}}{\sqrt{\sum_{k=1}^{H} w_{k}^{2} \times \sum_{k=1}^{H} v_{k}^{2}}}
$$




$$
\begin{gathered}
A C S=\frac{2 \times \sum_{i=1}^{M} \sum_{j=i+1}^{M} C S\left(C_{i}, C_{j}\right)}{M \times(M-1)} \\
\operatorname{Con}\left(T, C_{p}\right)=\frac{C S\left(C_{p}, C_{t}\right)-A C S}{1-A C S}
\end{gathered}
$$

O problema com medidas baseadas na semântica é que muitas hierarquias, particularmente as relacionadas a domínios biológicos, já possuem alguma forma de relacionamento semântico retratado em sua estrutura (Freitas \& Carvalho, 2007). Isso ocorre porque tais hierarquias são construídas considerando relacionamentos semânticos entre as classes, tendo como base o conhecimento científico. Assim, a estrutura da hierarquia já carrega uma informação semântica, em que classes similares estão agrupadas próximas umas às outras na hierarquia. Nesses casos, a distância poderia ser considerada na avaliação da predição. Além disso, é importante destacar que a descrição dos relacionamentos semânticos entre classes exige um conhecimento muito específico do domínio, dificultando em muitos casos a sua utilização. Por esses motivos, tal abordagem não foi utilizada na avaliação dos modelos hierárquicos abordados nesta pesquisa.

\section{Medidas baseadas nas relações de ancestralidade e descen- dência}

Essa abordagem utiliza os conceitos de ancestralidade e descendência entre classes para formular novas medidas de avaliação. Um exemplo desse tipo de abordagem é apresentado em (Ipeirotis et al., 2001). Nesse trabalho, os autores usaram o conceito de classes descendentes no processo de avaliação, por meio da análise da subárvore enraizada na classe predita e da subárvore enraizada na classe verdadeira. Segundo essa abordagem, cada subárvore é formada pela classe em questão e por suas subclasses (classes descendentes). A intersecção dessas subárvores é usada no cálculo de duas medidas: precisão hierárquica $(h P)$ e sensibilidade hierárquica $(h S)$. Para calcular a precisão hierárquica, o número de classes pertencentes à intersecção das subárvores é dividido pelo número de classes pertencentes à subárvore enraizada na classe predita, como pode ser observado na Equação 3.15. Nessa equação, $\operatorname{Desc}(C)$ representa o conjunto de classes contidas na subárvore cuja raiz é a classe $C$, incluindo $C$.

$$
h P=\frac{\left|\operatorname{Desc}\left(C_{p}\right) \cap \operatorname{Desc}\left(C_{t}\right)\right|}{\left|\operatorname{Desc}\left(C_{p}\right)\right|}
$$


Para calcular a sensibilidade hierárquica, o número de classes pertencentes à intersecção das subárvores é dividido pelo número de classes pertencentes à subárvore enraizada na classe verdadeira, conforme é mostrado na Equação 3.16. Uma vez calculada a precisão e a sensibilidade hierárquicas, elas podem ser combinadas para a extenção de F-measure: F-measure hierárquica (Equação 3.17).

$$
\begin{gathered}
h S=\frac{\left|\operatorname{Desc}\left(C_{p}\right) \cap \operatorname{Desc}\left(C_{t}\right)\right|}{\left|\operatorname{Desc}\left(C_{t}\right)\right|} \\
h F \_m e a s u r e=\frac{\left(\beta^{2}+1\right) * h P * h S}{\beta^{2} * h P+h S}
\end{gathered}
$$

O problema com essa medida é que ela assume que a classe predita é ou uma subclasse ou uma superclasse da classe verdadeira. Quando essas classes estão no mesmo nível, por exemplo, a intersecção entre as respectivas subárvores é vazia. Conseqüentemente, o valor reportado pelas medidas nesses casos será igual a 0 .

Kiritchenko et al. (2004) propuseram um método similar para a avaliação de modelos hierárquicos de classificação, com a diferença de que o conceitos de classes ancestrais é utilizado ao invés do conceito de classes descendentes. O número de ancestrais comuns entre a classe verdadeira e a classe predita é utilizado para o cálculo de duas medidas: precisão hierárquica e sensibilidade hierárquica. Para calcular a precisão hierárquica, o número de ancestrais comuns é dividido pelo número de ancestrais da classe predita (Equação 3.18). É importante notar que o conjunto $A n c(C)$ inclui a própria classe $C$ no cálculo do número de ancestrais. Além disso, o nó-raiz não é considerado ancestral da classe $C$, porque, por default, todos os exemplos pertencem ao nó-raiz.

$$
h P=\frac{\left|\operatorname{Anc}\left(C_{p}\right) \cap A n c\left(C_{t}\right)\right|}{\left|A n c\left(C_{p}\right)\right|}
$$

Para calcular a sensibilidade hierárquica, o número de ancestrais comuns é dividido pelo número de ancestrais da classe verdadeira, como pode ser observado na Equação 3.19. Assim como na abordagem que considera descendentes, $h P$ (Equação 3.18) e $h S$ (Equação 3.19) podem ser utilizadas na Equação 3.17 para a extensão de $F$-measure. Essa versão hierárquica de $F$ measure, baseada no conceito de classes ancestrais, foi utilizada para reportar parte dos resultados na Seção 5.3.1.

$$
h S=\frac{\left|\operatorname{Anc}\left(C_{p}\right) \cap A n c\left(C_{t}\right)\right|}{\left|A n c\left(C_{t}\right)\right|}
$$

Em (Verspoor et al., 2006), foi proposta uma adaptação dessas medidas 
de modo que elas possam ser utilizadas no contexto multirótulos. Independentemente da pesquisa de Kiritchenko et al. (2004), uma medida similar foi proposta por Eisner et al. (2005). Essa medida é uma extensão da abordagem de Poulin (2004) para o cálculo dos valores de predição e sensibilidade para problemas de classificação hierárquica multirótulos.

\section{Outras medidas de avaliação}

Outras medidas também foram encontradas na literatura, como as definidas em (Cesa-Bianchi et al., 2006), (Cai \& Hofmann, 2004), (Wu et al., 2005), (Wang et al., 2001), (Lord et al., 2003) e (Verspoor et al., 2006). Essas medidas não estão diretamente relacionadas com as quatro categorias descritas anteriormente. Além disso, elas não foram agrupadas em outras categorias ou por serem muito específicas para o problema em que foram empregadas, ou por serem apenas propostas teóricas.

As medidas propostas em (Cesa-Bianchi et al., 2006) e (Cai \& Hofmann, 2004) podem ser consideradas como específicas à aplicação em que elas são empregadas. Wu et al. (2005) e Wang et al. (2001) propuseram medidas para problemas de classificação hierárquica multirótulos; porém, elas perdem o ser poder de avaliação quando aplicadas a problemas hierárquicos que não são multirótulos. Além disso, a medida proposta por Wang et al. (2001) é usada somente na construção do classificador hierárquico e não em sua avaliação. Lord et al. (2003) propôs uma medida de similaridade que combina informação semântica com a estrutura da hierarquia de classes. Porém, essa similaridade não foi usada na avaliação de um modelo de classificação, consistindo em apenas uma proposta teórica.

Outra abordagem que pode ser usada para estimar erros de classificação em uma hierarquia envolve o uso de uma matriz de custos de erros de classificação. Essa abordagem é descrita em (Freitas \& Carvalho, 2007) e é uma generalização da matriz de custos de erro de classificação para problemas de classificação plana (Witten \& Frank, 2000). Essa matriz consiste em especificar o custo associado a cada possível erro de classificação. Na Tabela 3.9, é representada uma matriz de erro de classificação para um problema de predição obrigatória em nós-folha (para predição não obrigatória em nós-folha, a matriz precisa ser estendida para conter a possibilidade de classificação em nós internos), considerando os dois primeiros níveis do esquema definido na Figura 3.6. Os zeros na diagonal indicam que não houve erro na predição e, portanto, nenhum custo será atribuído nesses casos. Quando uma classificação incorreta é feita, o valor de erro especificado pela tabela é atribuído ao classificador. Por exemplo: se uma exemplo é predito como pertencente à 
classe 1.2, mas na verdade pertence à classe 1.1, o valor de erro corresponde ao valor de " $\mathrm{D}$ ".

Tabela 3.9: Exemplo de uma matriz de custos para um problema hierárquico de classificação.

\begin{tabular}{|c|c|c|c|c|c|c|}
\hline & \multicolumn{4}{|c|}{ Classe Verdadeira } \\
\hline & & & \multicolumn{2}{|c|}{1} & \multicolumn{2}{|c|}{2} \\
\hline & & & 1.1 & 1.2 & 2.1 & 2.2 \\
\hline \multirow{4}{*}{$\begin{array}{l}\text { Classe } \\
\text { Predita }\end{array}$} & \multirow[b]{2}{*}{1} & 1.1 & 0 & A & B & $\mathrm{C}$ \\
\hline & & 1.2 & $\mathrm{D}$ & 0 & $\mathrm{E}$ & $\mathrm{F}$ \\
\hline & \multirow{2}{*}{2} & 2.1 & $\mathrm{G}$ & $\mathrm{H}$ & 0 & I \\
\hline & & 2.2 & $\mathrm{~J}$ & $\mathrm{~K}$ & $\mathrm{~L}$ & 0 \\
\hline
\end{tabular}

A desvantagem dessa abordagem é a definição dos custos, que pode ser uma tarefa subjetiva. A abordagem em si não define a forma como os custos são calculados. Além disso, para um problema de classificação com um grande número de classes, que é freqüente no cenário de classificação hierárquica, a dimensão da matriz de custos tem que ser muito alta, o que torna mais custoso e difícil o cálculo dos custos para cada possibilidade de erro de classificação.

\subsection{Considerações Finais}

Neste capítulo, foi caracterizado o problema de classificação hierárquica, que é um problema de classificação de dados em AM cujas classes podem ser divididas em subclasses ou agrupadas em superclasses. Além disso, foram introduzidas as abordagens utilizadas para o desenvolvimento e avaliação dos algoritmos analisados experimentalmente no Capítulo 5.

Foram discutidas as quatro abordagens principais para a resolução de problemas hierárquicos, com destaque para a abordagem Top-Down, que realiza a classificação em etapas, e a abordagem Big-Bang, que gera um único classificador para toda a hierarquia. Além disso, foram descritas duas extensões para a abordagem Top-Down: Selective Top-Down e Ensemble Top-Down. A abordagem Selective Top-Down, recentemente proposta na literatura, utiliza um procedimento seletivo entre várias técnicas de AM na classificação TopDown. A abordagem Ensemble Top-Down, que foi proposta neste projeto, é baseada na combinação hierárquica de classificadores.

Uma questão destacada no capítulo foi a importância de se considerar as peculiaridades de um problema de classificação hierárquica no estabelecimento dos critérios para a condução da avaliação do modelo obtido. Essas considerações envolvem tanto a maneira como os resultados são representa- 
dos em matrizes de confusão, como quais medidas de avaliação são utilizadas para medir o desempenho preditivo. Também foram destacados os procedimentos para avaliação dos resultados dos experimentos realizados neste projeto.

No próximo capítulo é apresentada uma revisão bibliográfica abrangendo trabalhos que tratam problemas hierárquicos do domínio biológico. Cada trabalho é discutido de acordo com o tipo de hierarquia utilizado, nível da hierarquia em que a predição é feita, abordagem utilizada para construção dos modelos e medida de avaliação utilizada para reportar os resultados. 


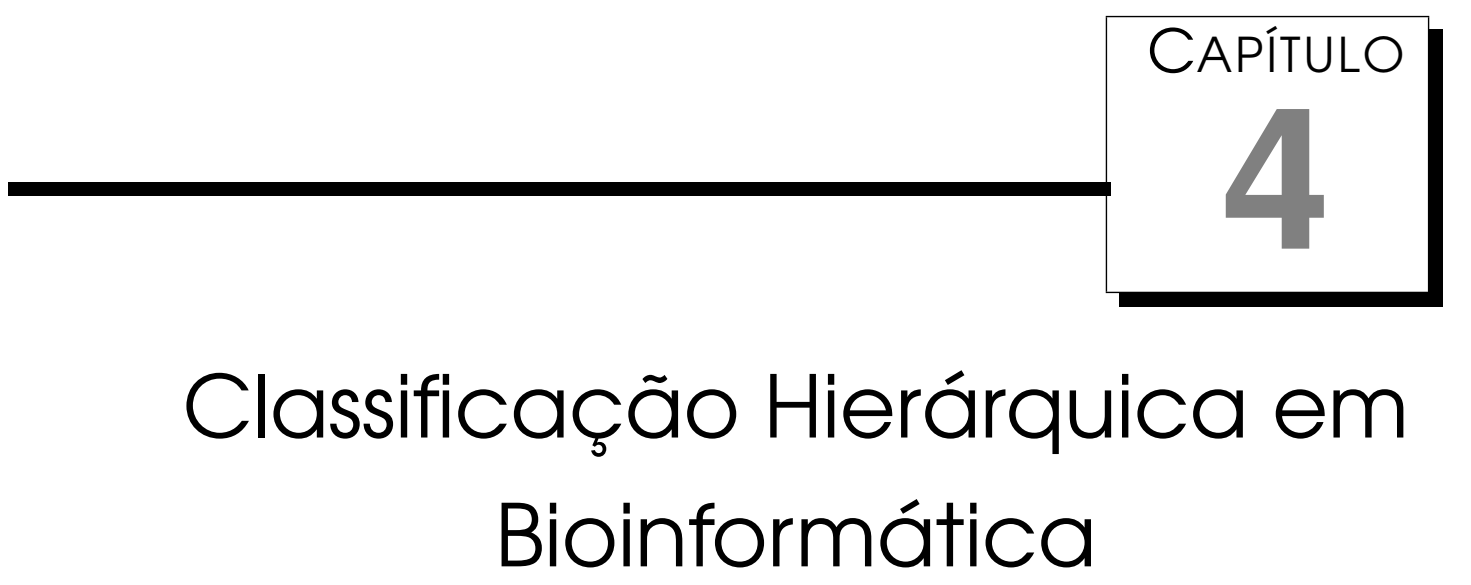

Recentemente, têm sido publicadas várias pesquisas na área de classificação hierárquica, principalmente direcionadas a problemas de Mineração de Textos (Sun \& Lim, 2001), (Sun et al., 2003b), (Sun et al., 2003a). Entretanto, uma linha de pesquisa que apresenta um vasto campo ainda pouco explorado em relação à utilização do modelo de classificação hierárquica é a Bioinformática.

Neste capítulo são, apresentados alguns dos principais trabalhos em classificação hierárquica desenvolvidos para problemas de Bioinformática. Na Tabela 4.1, são mostrados os trabalhos que são abordados no capítulo, bem como a aplicação biológica de cada um deles. Nas seções 4.1, 4.2, 4.3, e 4.4, os trabalhos relacionados na tabela são caracterizados, respectivamente, quanto ao tipo de hierarquia de classes, nível de predição na hierarquia, abordagem utilizada para tratar o problema hierárquico e forma de avaliação do desempenho, de acordo com os conceitos discutidos no Capítulo 3. Considerações finais são apresentadas na Seção 4.5.

\subsection{Tipo de Hierarquia de Classes}

Uma importante decisão em um projeto de classificação hierárquica é a escolha da hierarquia que será utilizada como base para o processo de classi- 
Tabela 4.1: Trabalhos de classificação hierárquica para problemas de Bioinformática.

\begin{tabular}{|c|c|}
\hline Trabalho & Aplicação \\
\hline (Weinert \& Lopes, 2004) & $\begin{array}{l}\text { Classificação de enzimas encontradas no Pro- } \\
\text { tein Data Bank (PDB) }\end{array}$ \\
\hline (Jensen et al., 2002) & $\begin{array}{l}\text { Predição de classes funcionais de proteínas e } \\
\text { categorias de enzimas do genoma humano }\end{array}$ \\
\hline (Clare \& King, 2001) & $\begin{array}{l}\text { Estudo de mutações a partir do estudo de ex- } \\
\text { perimentos de fenótipos de Saccharomyces ce- } \\
\text { revisiae }\end{array}$ \\
\hline (Jensen et al., 2003) & $\begin{array}{l}\text { Predição de função de proteínas humanas uti- } \\
\text { lizando categorias do Gene Ontology (GO) }\end{array}$ \\
\hline (Laegreid et al., 2003) & $\begin{array}{l}\text { Modelagem das relações entre expressão gê- } \\
\text { nica em função do tempo e o envolvimento de } \\
\text { um gene em processos biológicos, utilizando } \\
\text { dados de respostas dos fibroblastos humanos } \\
\text { ao fluido linfático }\end{array}$ \\
\hline (Tu et al., 2004) & $\begin{array}{l}\text { Predição de funções de genes utilizando cate- } \\
\text { gorias do GO, a partir de dados oriundos das } \\
\text { respostas dos fibroblastos humanos ao fluido } \\
\text { linfático }\end{array}$ \\
\hline (Barutcuoglu et al., 2006) & $\begin{array}{l}\text { Predição de funções de genes da S.cerevisiae } \\
\text { utilizando a hierarquia do GO }\end{array}$ \\
\hline (Blockeel et al., 2002) & $\begin{array}{l}\text { Estudo de mutacões a partir do estudo de ex- } \\
\text { perimentos de fenótipos de S.cerevisiae }\end{array}$ \\
\hline (Clare \& King, 2003) & $\begin{array}{l}\text { Predição de classes funcionais para ORFs } \\
\text { (Open Reading Frames) de S.cerevisiae }\end{array}$ \\
\hline (Holden \& Freitas, 2005) & $\begin{array}{l}\text { Predição do código EC de enzimas, provido pela } \\
\text { Enzyme Commission }\end{array}$ \\
\hline (Holden \& Freitas, 2006) & $\begin{array}{l}\text { Predição de classes funcionais de proteínas } \\
\text { GPCRs (G-Protein-Coupled Receptors), a par- } \\
\text { tir de padrões (assinaturas) presentes nas } \\
\text { seqüências }\end{array}$ \\
\hline (Secker et al., 2007) & $\begin{array}{l}\text { Predição de classes funcionais de proteínas } \\
\text { GPCRs, a partir de informações obtidas de } \\
\text { suas propriedades físico-químicas. }\end{array}$ \\
\hline
\end{tabular}

ficação. A escolha da hierarquia está diretamente relacionada ao problema ao qual o modelo de classificação será aplicado.

Jensen et al. (2002), Weinert \& Lopes (2004) e Holden \& Freitas (2005) utilizaram a hierarquia de classes definida pela Enzyme Commission. Essa hierarquia possui seis classes no primeiro nível e se estende até o quarto nível. Entretanto, em (Jensen et al., 2002) e (Weinert \& Lopes, 2004) apenas o primeiro nível da hierarquia foi utilizado. Além da hierarquia de classes de enzimas, Jensen et al. (2002) utilizaram o esquema de Riley (Riley, 1993), desenvolvido originalmente para a Escherichia coli, mas que depois foi estendido para outros organismos. Nesse esquema estão catalogados funções celulares e estruturas relacionadas a produtos gênicos. Holden \& Freitas (2006) e Secker et al. (2007) utilizaram a hierarquia definida para proteínas GPCR (GPCRDB, 
2006), uma hierarquia com doze classes no primeiro nível e se estende até o quarto nível. Em (Secker et al., 2007), apenas os três primeiros níveis da hierarquia foram utilizados. Em (Holden \& Freitas, 2006), todos os níveis da hierarquia foram utilizados.

Clare \& King (2001), Clare \& King (2003) e Blockeel et al. (2002) utilizaram o esquema hierárquico do MIPS (Munich Information Center for Protein Sequences), uma hierarquia com 19 classes no primeiro nível e que se estende até o quarto nível. Especificações do MIPS podem ser encontradas em (Mewes et al., 1999).

Os três esquemas - código EC, esquema de Riley e esquema do MIPS - são hierarquias de classes organizadas em estrutura de árvore.

Jensen et al. (2003), Laegreid et al. (2003), Tu et al. (2004) e Barutcuoglu et al. (2006) utilizaram o esquema hierárquico do GO, que é estruturado como um DAG.

Na Tabela 4.2 são resumidas as informações a respeito da hierarquia utilizada pelos trabalhos descritos neste capítulo.

Tabela 4.2: Hierarquias de classes.

\begin{tabular}{|c|c|c|}
\hline Tipo de Hierarquia & Esquema Hierárquico & Trabalho \\
\hline \multirow{9}{*}{ Árvore } & \multirow{3}{*}{ Código EC } & (Jensen et al., 2002) \\
\hline & & (Weinert \& Lopes, 2004) \\
\hline & & (Holden \& Freitas, 2005) \\
\hline & Esquema de Riley & (Jensen et al., 2002) \\
\hline & \multirow{3}{*}{ Esquema do MIPS } & (Clare \& King, 2001) \\
\hline & & (Clare \& King, 2003) \\
\hline & & (Blockeel et al., 2002) \\
\hline & & (Holden \& Freitas, 2006) \\
\hline & Hierarquia GPCR & (Secker et al., 2007) \\
\hline \multirow{4}{*}{ DAG } & \multirow{4}{*}{ GO } & (Jensen et al., 2003) \\
\hline & & (Laegreid et al., 2003) \\
\hline & & (Tu et al., 2004) \\
\hline & & (Barutcuoglu et al., 2006) \\
\hline
\end{tabular}

\subsection{Nivel Hierárquico de Predição de Classes}

Jensen et al. (2002) utilizaram apenas o primeiro nível da hierarquia do esquema de Riley e do esquema de código EC, assim os nós-folha da hierarquia completa não foram considerados na predição. De maneira similar, Weinert \& Lopes (2004) se restringiram a classificar apenas classes dos niveis superiores da hierarquia do código EC e, portanto, também não consideraram os nósfolha na classificação. 
Em (Clare \& King, 2001), a classificação foi feita por níveis. Dessa maneira, classes foram preditas em todos os níveis da hierarquia e, portanto, esse trabalho considerou predições opcionais em nós-folha.

Jensen et al. (2003), Laegreid et al. (2003) e Tu et al. (2004) construíram classificadores para classes para as quais o algoritmo de aprendizado detectou boa confiabilidade na predição. Como a restrição foi a confiabilidade, as classes selecionadas podem ser de nós de vários níveis da hierarquia e, portanto, esses também são trabalhos que consideraram predições opcionais em nós-folha.

Em (Barutcuoglu et al., 2006), foram treinados classificadores independentes para todas as classes da hierarquia e, ao final, as saídas foram combinadas por meio de um framework Bayesiano. Esse framework foi implementado de forma que as predições finais não precisassem ser feitas obrigatoriamente nos nós-folha.

Em (Holden \& Freitas, 2005), (Holden \& Freitas, 2006) e (Secker et al., 2007), predições foram feitas em cada nível, mas com o objetivo de alcançar a predição das classes pertencentes aos nós-folha da hierarquia. Assim, os exemplos, ao final do processo de classificação, foram obrigatoriamente preditos para nós-folha.

Em (Clare \& King, 2003), foi utilizado o esquema hierárquico do MIPS. Nessa hierarquia, um ORF pode pertencer a muitas classes (cada classe é representada por uma posição na hierarquia), pois uma proteína pode estar envolvida em mais de uma função dentro de uma célula. Além disso, na validação do classificador foram selecionadas apenas as regras que mostraram significância estatística, valorizando assim a confiança da predição, mesmo que ela não forneça a classificação mais específica. Dessa forma, Clare \& King (2003) consideraram predições opcionais em nós-folha. Em (Blockeel et al., 2002), também foi utilizada a abordagem de predição opcional em nós-folha.

Na Tabela 4.3, os níveis de predição adotados nos trabalhos apresentados anteriormente são resumidos.

\subsection{Abordagem utilizada para tratar o problema hie- rárquico}

Os trabalhos relacionados utilizaram diferentes metodologias para tratar os problemas de classificação hierárquica. Eles podem ser agrupados de acordo com as quatro abordagens discutidas na Seção 3.2. 
Tabela 4.3: Niveis de predição.

\begin{tabular}{|l|l|}
\hline \multicolumn{1}{|c|}{ Nivel de Predição } & \multicolumn{1}{|c|}{ Trabalho } \\
\hline $\begin{array}{l}\text { Não foram feitas predições para os } \\
\text { nós-folha }\end{array}$ & (Jensen et al., 2002),(Weinert \& Lopes, 2004) \\
\hline $\begin{array}{l}\text { Problema de predição opcional em } \\
\text { nós-folha }\end{array}$ & $\begin{array}{l}\text { (Jensen et al., 2003), (Laegreid et al., 2003), } \\
\text { (Tu et al., 2004), (Barutcuoglu et al., 2006), } \\
\text { (Clare \& King, 2001), (Clare \& King, 2003), } \\
\text { Blockeel et al. (2002) }\end{array}$ \\
\hline $\begin{array}{l}\text { Problema de predição obrigatória } \\
\text { em nós-folha }\end{array}$ & $\begin{array}{l}\text { (Holden \& Freitas, 2005), (Holden \& Freitas, } \\
\text { 2006), (Secker et al., 2007) }\end{array}$ \\
\hline
\end{tabular}

\subsubsection{Transformação de um Problema de Classificação Hierár- quica em um Problema de Classificação Plana}

(Jensen et al., 2002) e (Weinert \& Lopes, 2004) são dois exemplos da abordagem que transforma um problema hierárquico em um problema de classificação plana.

Jensen et al. (2002) descreveram um método, denominado ProtFun, que utiliza um comitê de ANNs simples, com uma única camada intermediária totalmente conectada, para realizar predições de categorias protéicas.

A abordagem utilizada selecionou algumas categorias dos níveis mais altos do esquema de Riley e utilizou como entrada do método 14 atributos fornecidos por diferentes métodos que fazem inferências sobre características de um gene a partir de sua seqüência.

Primeiramente, para cada categoria funcional foram treinadas ANNs, uma para cada atributo, para fazer a predição se uma determinada seqüência pertencia à categoria em questão. Foram avaliados quais atributos foram capazes de prover informação para a predição de no mínimo uma categoria. Esses atributos selecionados foram então combinados dois a dois e utilizados para treinar outras ANNs. Depois, muitas redes foram treinadas, incrementando o número de atributos utilizados como entrada, e então as cinco melhores redes foram selecionadas para compor o comitê de ANNs.

Weinert \& Lopes (2004) descreveram um modelo de classificação baseado em ANNs Perceptron Multicamadas, que foi aplicado para classificação de enzimas encontradas no PDB (Bernstein et al., 1977), de modo a fazer inferências sobre suas características funcionais e estruturais. A idéia básica do trabalho consistiu em utilizar um conjunto de ANNs para processar informações a respeito das estruturas primárias das proteínas codificadas para um formato apropriado para as redes. A estrutura primária de uma proteína é formada por uma seqüência de letras, que representam os aminoácidos.

Nos dois trabalhos, a hierarquia de classes não foi considerada como um 
todo. Apenas algumas classes dos primeiros níveis foram consideradas. Tais classes foram utilizadas em um processo de classificação plana convencional. Dessa forma, não foram necessárias modificações nas técnicas de classificação utilizadas.

\subsubsection{Predição Hierárquica de Classes utilizando Algoritmos de Classificação Plana}

Como exemplos da abordagem que divide um problema de classificação hierárquica em um conjunto de problemas de classificação plana, os seguintes trabalhos podem ser citados: (Clare \& King, 2001), (Jensen et al., 2003), (Laegreid et al., 2003), (Tu et al., 2004) e (Barutcuoglu et al., 2006).

Clare \& King (2001) propuseram um método de classificação que utiliza o algoritmo C4.5 (Quinlan, 1993), que induz ADs. Esse método foi aplicado a dados de experimentos de fenótipos. Tais experimentos consideraram a possibilidade de um gene poder pertencer a mais de uma classe funcional. Dessa forma, além das propriedades hierárquicas do problema de classificação, esse método também considerou o aspecto multirótulos. Para tratar o aspecto multirótulos, alguns ajustes foram necessários no cálculo da entropia e para nomear os nós-folha das ADs, bem como na execução da poda.

Para realizar a classificação, foram criados classificadores separados para cada nível da hierarquia. Como o número de genes com funções conhecidas não eram suficientes para realizar o treinamento dos classificadores, principalmente nas camadas mais profundas, foi utilizado o método de reamostragem bootstrap, de modo a gerar mais conjuntos de treinamentos.

Em (Jensen et al., 2003), uma extensão do método proposto em (Jensen et al., 2002) foi descrita. Uma ANN feedfoward padrão com uma única camada oculta de neurônios foi utilizada para treinar cada classe do GO (Gene Ontology). As ANNs foram treinadas com diferentes combinações de atributos, fornecendo como saída um valor booleano indicando se o exemplo pertencia à classe ou não. Os atributos utilizados como entrada da ANN foram os mesmos utilizados em (Jensen et al., 2002), com o acréscimo de mais dois atributos.

Para realizar o treinamento dos classificadores, combinações de cinco ANNs cada foram treinadas usando um único atributo como entrada. A partir desse procedimento, muitas categorias não se mostraram fortemente relacionadas com nenhum atributo e então foram descartadas, pois não seriam preditas com uma TA razoável. Para cada uma das classes restantes, consideradas passiveis de serem preditas, foram treinadas combinações de ANNs de modo semelhante ao descrito em (Jensen et al., 2002). Começou-se com um atributo como entrada para os classificadores e então descartou-se os piores atributos 
e realizou-se combinações de atributos (variando o número e o tipo dos atributos), de modo a obter a melhor combinação de atributos para a arquitetura da rede. Ao final, foram descartadas mais classes (que eram muito similares a outras presentes no modelo), de modo a eliminar redundâncias na classificação.

Aparentemente, o relacionamento hierárquico entre classes e suas respectivas subclasses foi virtualmente ignorado durante a fase de treinamento, já que cada execução da rede tratou a classe atual como positiva e as demais como negativas, independentemente de sua posição na hierarquia de classes (Freitas \& Carvalho, 2007).

O trabalho descrito em (Laegreid et al., 2003) aborda a predição de classes do GO utilizando uma combinação de um algoritmo de indução de regras baseado na teoria de rough-set (Pawlak, 1992) e um Algoritmo Genético - AG (Mitchell, 1996). O método descrito consiste em obter regras que modelem as relações entre expressão gênica em função do tempo e o envolvimento de um gene em processos biológicos, de modo a utilizar o modelo de classificação para predizer os papéis biológicos de genes desconhecidos.

O método de aprendizado supervisionado baseado na teoria de rough-set foi utilizado para gerar regras da forma "if-then" a partir de um conjunto de dados que descreve os níveis de transcrição de diferentes genes durante as primeiras 24 horas da resposta dos fibroblastos (célula constituinte das fibras estruturais e da substância fundamental dos tecidos conjuntivos) humanos ao fluido linfático (porção líquida do sangue separada das células) (Iyer et al., 1999). O objetivo foi gerar um conjunto de regras para cada uma das 23 classes de processos metabólicos do GO consideradas na abordagem.

Antes da fase de treinamento, o método necessitou de um pré-processamento. Os genes utilizados no conjunto de treinamento foram agrupados nas 23 classes do GO, de acordo com conhecimento prévio. Se um gene pertencesse a uma classe mais específica da hierarquia, ele era agrupado junto com os genes que pertenciam à classe ancestral, dentre as 23 classes consideradas pelo método, de sua classe original. Após esse processo de agrupamento dos genes, o algoritmo de aprendizado foi aplicado a cada classe, de modo a gerar um conjunto de regras.

A combinação dos perfis das propriedades observadas e dos intervalos de tempo gerou 55 atributos diferentes. Porém, na média, apenas três desses atributos foram utilizados para compor cada regra. Essa redução no número de atributos foi providenciada por meio da utilização de um AG.

Como pode ser notado, no método descrito os algoritmos para a geração de regras não trabalham diretamente com a hierarquia de classes DAG do GO. A hierarquia é utilizada apenas na fase de pré-processamento. 
Embora os métodos propostos por Jensen et al. (2003) e Laegreid et al. (2003) sejam diferentes e utilizem técnicas de AM distintas, eles são similares no que diz respeito à geração dos classificadores. Para os dois métodos, um modelo de classificação foi desenvolvido para cada classe individualmente e na classificação de um novo exemplo todos os modelos foram testados, sendo que aquele que apresenta uma melhor medida de confiança de que a classificação foi feita corretamente foi o utilizado para definir a classe a qual pertencia o exemplo.

Tu et al. (2004) propuseram um modelo de classificação para predição de funções de genes utilizando classes da hierarquia do GO. Este trabalho introduz o termo "predição baseado na capacidade de aprender" (learnability-based prediction), cujo conceito também foi utilizado na seleção de classes em (Laegreid et al., 2003) e (Jensen et al., 2003). Esse conceito baseia-se no pressuposto de que nem todos os nós da hierarquia podem ser preditos com a TA necessária e que, portanto, deve-se focar naqueles para os quais os classificadores podem ser construídos com maior confiança de predição.

Esse modelo, que usa ANNs para classificação plana como algoritmo de aprendizado, foi desenvolvido com o objetivo de inferir anotações para classes mais específicas a partir das anotações conhecidas para suas superclasses. A motivação central para a construção desse modelo foi a de tentar fazer uma predição adicional, ou seja, classificar genes, que foram anotados para uma classe pai, em suas classes filhas. Como aplicação, foram utilizados os dados oriundos do banco de dados das respostas dos fibroblastos humanos ao fluido linfático.

De modo a garantir a TA de predição, foram feitas restrições no número de filhos da classe e no número de genes preditos para a mesma classe. A partir de tais restrições, houve uma redução no número de classes da ontologia de processos do GO considerada pelo método. Cada uma das classes restantes foi utilizada para a geração de espaços de classificação, composto pela classe selecionada e por suas subclasses. Para cada um desses espaços de classificação, foram construídos classificadores candidatos, utilizando ANNs feedforward. Em seguida, a precisão das predições foi medida com base no valor do índice ATI (Averaged Tanimoto Index), que foi originalmente proposto para medir a similaridade entre vetores. Com base nos valores obtidos para o ATI de cada classe, aquelas classes que obtiveram valor menor que um certo limite foram eliminadas e as restantes foram utilizadas para realizar as predições adicionais para os espaços de classificação.

Diferentemente de Jensen et al. (2003), Tu et al. (2004) levaram em conta o relacionamento hierárquico entre as classes, por meio da criação dos espaços de classificação, de modo a representar a relação de uma classe com suas 
subclasses.

Embora com uma abordagem diferente da utilizada em (Laegreid et al., 2003), pode-se dizer que em (Tu et al., 2004), o modelo de classificação também só trabalha com a hierarquia de classes DAG do GO numa fase de préprocessamento, na qual são selecionados os espaços de classificação candidatos. Após essa etapa, cada espaço de classificação se transforma em um problema de classificação plana.

Em (Barutcuoglu et al., 2006), são utilizadas SVMs para indução dos modelos de classificação. Inicialmente, são treinados classificadores independentemente para cada classe. Para permitir colaboração na correção de erros entre todos os nós, é projetado um esquema combinacional hierárquico Bayesiano. O framework Bayesiano combina os múltiplos classificadores baseados nos limites da hierarquia funcional, de modo a obter o mais provável conjunto consistente de predições.

\subsubsection{Classificação Hierárquica Top-Down}

(Holden \& Freitas, 2005) e (Holden \& Freitas, 2006) são exemplos de trabalhos que utilizaram métodos Top-Down para classificação hierárquica. Em Secker et al. (2007), foi proposta uma variação da abordagem Top-Down, além de terem sido implementados algoritmos seguindo a abordagem convencional.

Em (Holden \& Freitas, 2005), foi proposto um algoritmo híbrido para tratar problemas de classificação hierárquica, por meio da combinação de características dos algoritmos PSO (Particle Swarm Optimization) (Sousa et al., 2004) e ACO (Ant Colony Optimization) (Parpinelli et al., 2002). Embora os dois algoritmos tenham sido desenvolvidos, individualmente, para tarefas de classificação, o algoritmo híbrido foi desenvolvido com o intuito de tratar algumas de suas limitações.

$\mathrm{O}$ algoritmo $\mathrm{ACO}$ requer uma quantidade de computação extremamente grande quando são utilizadas grandes quantidades de classes e atributos. Além disso, para trabalhar com atributos contínuos, se faz necessário adicionar uma etapa de pré-processamento ao algoritmo. Nessa etapa, os atributos são convertidos para valores discretos, o que pode diminuir a TA e aumentar o tempo de processamento.

O algoritmo PSO lida com atributos categóricos de uma maneira menos natural que o ACO. Para permitir que o PSO tratasse atributos categóricos multivalorados, o algoritmo padrão foi estendido, recebendo o nome de PSO Discreto (Discrete PSO - DPSO). A idéia básica desse algoritmo é que cada valor possivel para um atributo categórico é atribuído a um índice numérico, que então é convertido para uma cadeia binária. Em seguida, o PSO binário 
padrão pode ser aplicado. Porém, a conversão em uma cadeia binária resulta em alguns inconvenientes para as características do PSO, como discutido em (Holden \& Freitas, 2005).

Uma vez que tarefas de classificação usualmente envolvem valores de atributos contínuos e categóricos, as características dos algoritmos PSO e do ACO foram combinadas, de modo a resolver as limitações dos valores dos atributos. De uma maneira geral, a idéia básica da hibridização é criar uma "população de colônia de formigas" (Holden \& Freitas, 2005).

O algoritmo usa uma abordagem seqüencial para descobrir as regras de classificação. Inicialmente, o conjunto de regras é vazio. Para cada nível hierárquico de classes e para cada classe do nível, o algoritmo $\mathrm{PSO} / \mathrm{ACO}$ realiza o procedimento de produção de uma regra. Em outras palavras, a cada iteração, uma regra de classificação é obtida para uma determinada classe. Dessa forma, em essência, o algoritmo híbrido PSO/ACO é um algoritmo de classificação plana em sua fase de treinamento, pois a cada iteração do algoritmo é produzida uma regra para apenas um nó, tratando-se assim de um problema de classificação plana (Freitas \& Carvalho, 2007). Porém, ao final da execução do algoritmo, tem-se como resultado um conjunto hierárquico de regras.

Na classificação de um novo exemplo no conjunto de teste, o exemplo é apresentado à raiz da hierarquia e é classificado com base no conjunto de regras associado aos nós pertencente ao primeiro nível da hierarquia. No próximo nível, o exemplo será classificado com base no conjunto de regras associado aos nós filhos da classe a qual o exemplo foi associado no nível anterior. E assim o procedimento é repetido até que se atinja a copa (nível mais profundo) da árvore.

Em (Holden \& Freitas, 2006), foi utilizado o mesmo algoritmo híbrido proposto em (Holden \& Freitas, 2005), apenas com algumas modificações na maneira como é calculada a qualidade de cada regra no processo de treinamento e no modo como é medida a TA, como é discutido na Seção 4.4.

Secker et al. (2007) propuseram uma variação da abordagem Top-Down, denominada Selective Top-Down, que utiliza múltiplas técnicas de AM na geração do modelo de classificação. Para isso, a cada iteração do algoritmo, um procedimento seletivo é utilizado para decidir qual técnica deve ser utilizada na geração do classificador. Em (Secker et al., 2007), um algoritmo Selective Top-Down foi implementado baseado em dez técnicas: Naive Bayes (Mitchell, 1997); Redes Bayesianas (BayesNet) (Friedman et al., 1997); KNN (Cover \& Hart, 1967), com $K=3$; C4.5 (Quinlan, 1993); ANNs (Haykin, 1999b); SMO (Keerthi et al., 2001); PART (Frank \& Witten, 1998); Naive Bayes Tree (Kohavi, 1996); AIRS2 (um classificador baseado no paradigma de sistemas imunológicos artificiais (Watkins et al., 2004)); e Conjunctive Rules Learner (Mitchell, 
1997). No procedimento seletivo, para cada iteração, $20 \%$ dos dados de treinamento foram reservados para validação e $80 \%$ dos dados foram utilizados para induzir um classificador para cada técnica, de forma a selecionar o classificador com a maior TA. Além do algoritmo Selective Top-Down, foram implementados dez algoritmos Top-Down convencionais, cada um deles baseado em umas das técnicas utilizadas na implementação do Selective Top-Down.

\subsubsection{Classificação Hierárquica Big-Bang}

Dois exemplos da abordagem Big-Bang são: (Clare \& King, 2003) e (Blockeel et al., 2002).

Clare \& King (2003) utilizaram o método DMP (Data Mining Prediction) (King et al., 2000), com algumas modificações, para predição de classes funcionais para ORFs de Saccharomyces cerevisiae (leveduras). A partir do banco de dados relacional contendo descrições de seqüências, o método DMP foi utilizado para gerar regras para predição das classes funcionais das proteínas.

Em sua forma padrão, o DMP utiliza o WARMR, um algoritmo de ILP Inductive Logic Programimg (Muggleton, 1999), e os algoritmos de AM C4.5 e C5.0, como pode ser visto na Figura 4.1.

O DMP utiliza o WARMR detectar padrões freqüentes nas descrições das seqüências. Os padrões são então utilizados na geração das regras com atributos booleanos, ou seja, o atributo tem valor 1 se o padrão está presente, e valor 0 , caso contrário. A geração das regras de classificação é realizada pelos algoritmos C4.5 e C5.0. Após a geração das regras, aquelas mais significativas estatisticamente são selecionadas a partir da etapa de validação, na qual são utilizados dados gerados pelo WARMR que foram separados para essa etapa de seleção das melhores regras.

Porém, em (Clare \& King, 2003), algumas modificações foram necessárias nos algoritmos utilizados no método original, que foi aplicado aos genomas da M.tuberculosis e da E.coli.

Devido ao fato de as leveduras possuírem um genoma maior que M.tuberculosis e E.coli, o algoritmo WARMR não foi capaz de processar a grande quantidade de dados. Assim, foi desenvolvido um novo algoritmo baseado no WARMR, o PolyFARM. Este algoritmo foi desenvolvido especificamente para essa tarefa e pode ser executado de forma distribuída.

Além disso, o sistema de classificação funcional para leveduras permite que ORFs pertençam a mais de uma classe, consistindo assim em um problema de classificação multirótulos. Esse requisito exigiu modificações no algoritmo $\mathrm{C} 4.5$ no que diz respeito à entropia, medida interna para escolha da melhor decisão a cada estágio. Estruturas de dados, métodos de poda e 


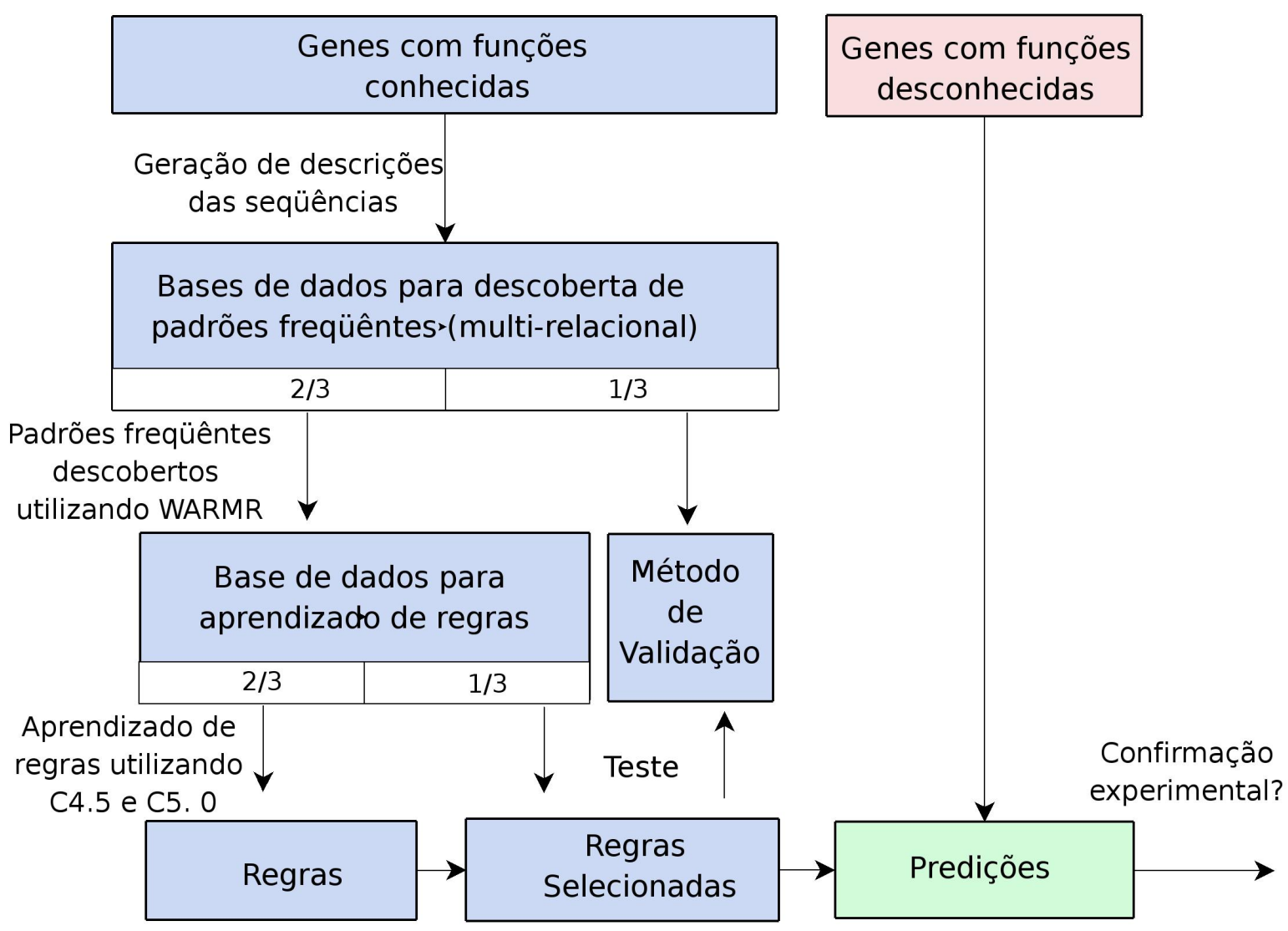

Figura 4.1: Esquema Geral do DMP (King et al., 2000).

geração de regras também necessitaram ser modificados. Adicionalmente, a estrutura hierárquica do problema também exigiu modificações no algoritmo C4.5. Tais modificações levaram em consideração que classes em níveis mais gerais tendem a ter menor entropia que classes mais específicas, nos níveis mais próximos à copa da árvore.

Como a versão hierárquica do $\mathrm{C} 4.5$, denominada de $\mathrm{HC} 4.5$, considerou a hierarquia de classes inteira durante seu treinamento e produziu um modelo de classificação hierárquico em uma única execução do algoritmo, este trabalho pode ser considerado um exemplo da abordagem "Big-Bang" (Freitas \& Carvalho, 2007).

Em (Blockeel et al., 2002), foi descrito um algoritmo para classificação hierárquica multirótulos, denominado de CLUS, que gera uma única $\mathrm{AD}$ para 
toda a hierarquia. Esse algoritmo de indução da $\mathrm{AD}$ é baseado na noção de predictive clustering trees (Blockeel et al., 1998).

Um algoritmo para indução da árvore é essencialmente um TDIDT (Topdown induction of decision trees) padrão. Dessa forma, a idéia geral do CLUS consiste em particionar recursivamente o conjunto de dados de maneira que a variância intra-cluster seja minimizada. Esse cálculo é utilizado para selecionar os testes que serão inseridos como nós da $\mathrm{AD}$. Em seguida, uma parte de dados é selecionada para treinamento e então busca-se no loop principal do algoritmo o teste valor-atributo que melhor pode ser escolhido. Se o teste for encontrado, então é criado um nó e o algoritmo é chamado recursivamente. Se o teste não puder ser encontrado, então é criada uma folha.

O CLUS possui uma série de opções como: definição de parte do conjunto de treinamento para ser utilizado na poda da $\mathrm{AD}$, especificação de conjuntos de testes e especificação do número de partições para a realização de $k$-fold cross-validation.

Na Tabela 4.4, são resumidas as informações discutidas nesse tópico.

\subsection{Avaliação e Medidas de Desempenho}

Nesta seção são mostradas as medidas utilizadas para a avaliar o desempenho preditivo dos modelos gerados pelos métodos de classificação hierárquica descritos neste capítulo. As definições das principais medidas de avaliação de desempenho foram apresentadas na Seção 3.4. Algumas medidas são introduzidas no decorrer desta seção.

Weinert \& Lopes (2004) calcularam o desempenho de classificação de duas maneiras. A primeira levou em conta a TA média de todas as partições do cross-validation. Adicionalmente, também foi utilizada a medida de desempenho baseada na sensibilidade e na especificidade. Em (Jensen et al., 2002), o desempenho foi medido por meio de uma relação entre sensibilidade e taxa de falsos positivos.

Assim como em (Jensen et al., 2002), em (Jensen et al., 2003) o desempenho preditivo foi medido por meio de uma relação entre sensibilidade e taxa de falsos positivos. Em (Laegreid et al., 2003) e (Barutcuoglu et al., 2006), a qualidade da classificação foi medida com o cálculo da AUC. Barutcuoglu et al. (2006) reportaram os resultados antes e depois da aplicação do framework Bayesiano.

Em (Clare \& King, 2001), foi utilizada a estimativa-m (m-estimate), utilizada originalmente em (Clark \& Boswell, 1991). A estimativa-m é uma generalização da estimativa de Laplace, levando em conta a probabilidade a priori da 
Tabela 4.4: Abordagens e metodologias.

\begin{tabular}{|c|c|c|c|}
\hline Trabalho & Predição de Classe & $\begin{array}{ll}\text { Algoritmo } & \text { de } \\
\text { Classificação } & \end{array}$ & Abordagem \\
\hline (Jensen et al., 2002) & $\begin{array}{l}\text { Plana: só considera o pri- } \\
\text { meiro nivel }\end{array}$ & Plano: ANNs & $\begin{array}{l}\text { Transformação } \\
\text { para classifi- } \\
\text { cação plana }\end{array}$ \\
\hline $\begin{array}{l}\text { (Weinert \& Lopes, } \\
\text { 2004) }\end{array}$ & $\begin{array}{l}\text { Plana: só considera algu- } \\
\text { mas classes dos niveis mais } \\
\text { altos }\end{array}$ & Plano: ANNs & $\begin{array}{l}\text { Transformação } \\
\text { para classifi- } \\
\text { cação plana }\end{array}$ \\
\hline (Clare \& King, 2001) & $\begin{array}{l}\text { Plana: considera todos os } \\
\text { niveis, mas um de cada vez }\end{array}$ & Plano: C4.5 & $\begin{array}{l}\text { Conjunto de } \\
\text { problemas de } \\
\text { classificação } \\
\text { plana }\end{array}$ \\
\hline (Jensen et al., 2003) & $\begin{array}{l}\text { Hierárquica: Pode ser em } \\
\text { qualquer nivel dependendo } \\
\text { das classes selecionadas } \\
\text { para geração dos classifica- } \\
\text { dores }\end{array}$ & Plano: ANNs & $\begin{array}{l}\text { Conjunto de } \\
\text { problemas de } \\
\text { classificação } \\
\text { plana }\end{array}$ \\
\hline (Laegreid et al., 2003) & $\begin{array}{l}\text { Hierárquica: pode ser em } \\
\text { qualquer nivel dependendo } \\
\text { das classes selecionadas } \\
\text { para geração dos classifica- } \\
\text { dores }\end{array}$ & $\begin{array}{l}\text { Plano: indução } \\
\text { de regras basea- } \\
\text { das na teoria de } \\
\text { rough-set e um } \\
\text { AG }\end{array}$ & $\begin{array}{l}\text { Conjunto de } \\
\text { problemas de } \\
\text { classificação } \\
\text { plana }\end{array}$ \\
\hline (Tu et al., 2004) & $\begin{array}{l}\text { Hierárquica: pode ser em } \\
\text { qualquer nivel dependendo } \\
\text { das classes selecionadas } \\
\text { para geração dos classifica- } \\
\text { dores }\end{array}$ & Plano: ANNs & $\begin{array}{l}\text { Conjunto de } \\
\text { problemas de } \\
\text { classificação } \\
\text { plana }\end{array}$ \\
\hline $\begin{array}{l}\text { (Barutcuoglu et al., } \\
\text { 2006) }\end{array}$ & $\begin{array}{l}\text { Hierárquica: considera to- } \\
\text { dos os niveis. }\end{array}$ & $\begin{array}{l}\text { Plano: SVMs com } \\
\text { as saídas com- } \\
\text { binadas por um } \\
\text { framework Baye- } \\
\text { siano }\end{array}$ & $\begin{array}{l}\text { Conjunto de } \\
\text { problemas de } \\
\text { classificação } \\
\text { plana }\end{array}$ \\
\hline $\begin{array}{l}\text { (Holden \& Freitas, } \\
\text { 2005), Holden \& Frei- } \\
\text { tas (2006) }\end{array}$ & $\begin{array}{l}\text { Hierárquica: considera to- } \\
\text { dos os niveis }\end{array}$ & $\begin{array}{l}\text { Algoritmo híbrido } \\
\text { PSO/ACO plano, } \\
\text { mas com aborda- } \\
\text { gem hierárquica }\end{array}$ & Top-Down \\
\hline Secker et al. (2007) & $\begin{array}{l}\text { Hierárquica: considera to- } \\
\text { dos os niveis }\end{array}$ & $\begin{array}{l}\text { Algoritmo com } \\
\text { procedimento se- } \\
\text { letivo envolvendo } \\
\text { dez técnicas de } \\
\text { AM }\end{array}$ & $\begin{array}{l}\text { Selective Top- } \\
\text { Down }\end{array}$ \\
\hline (Clare \& King, 2003) & $\begin{array}{l}\text { Hierárquica. Considera to- } \\
\text { dos os niveis. }\end{array}$ & $\begin{array}{l}\text { Hierárquica: } \\
\text { C4.5. Abordagem } \\
\text { hierárquica. }\end{array}$ & Big-Bang \\
\hline (Blockeel et al., 2002) & $\begin{array}{l}\text { Hierárquica. Considera to- } \\
\text { dos os niveis. }\end{array}$ & $\begin{array}{l}\text { Hierárquica: ADs } \\
\text { baseadas em pre- } \\
\text { dictive clustering } \\
\text { trees }\end{array}$ & Big-Bang \\
\hline
\end{tabular}

classe. A fórmula para o cálculo dessa medida é dada pela Equação 4.1, na qual $P$ é o número total de exemplos positivos, $N$ é o número total de exemplos negativos, $p$ é o número de exemplos positivos cobertos pela regra $r, n$ é o número de exemplos negativos cobertos pela regra $r$, e $m$ é um parâmetro cuja função é dar peso à probabilidade a priori. 


$$
M(r)=\frac{p+m \frac{P}{P+N}}{p+n+m}
$$

Como pode ser observado na equação dada, o objetivo dessa medida é estimar a TA de cada regra. Com base nas estimativas obtidas para as regras, foi calculada uma TA média para o conjunto de regras. Uma discussão mais aprofundada dessa medida é feita em (Cestnik \& Bratko, 1991).

Tu et al. (2004) utilizaram o ATI para avaliar o desempenho da classificação. Para cada gene, foi aplicada a fórmula representada na Equação 4.2, em que $O g$ é o vetor de saída verdadeiro para o gene $g$ e o $P g$ é o vetor de predições:

$$
T I(g)=\frac{\sum_{i=1}^{q} o_{g i} * p_{g i}}{\sum_{i=1}^{q} o_{g i} * p_{g i}+\sum_{i=1}^{q}\left(1-o_{g i}\right) * p_{g i}+\sum_{i=1}^{q} o_{g i} *\left(1-p_{g i}\right)}
$$

Após o índice TI ter sido calculado para todos os genes, o ATI foi obtido pela fórmula apresentada na Equação 4.3, em que $E(P)$ é o conjunto de exemplos.

$$
A T I(p)=\frac{\sum_{g \in E(P)} T I(g)}{\|E(P)\|}
$$

Em (Holden \& Freitas, 2005), foi empregado um processo de avaliação de cada regra, durante o processo de treinamento, para a seleção das regras mais relevantes. A qualidade da regra foi medida pelo produto da sensibilidade pela especificidade. Embora esse cálculo não tenha sido utilizado no cálculo final do desempenho preditivo, é importante ressaltar o modo como as regras foram avaliadas, pois esse procedimento interfere diretamente na qualidade do modelo de classificação induzido. O desempenho final do modelo de classificação foi medido pela TA média dos cinco folds utilizados no processo de cross-validation.

Em (Holden \& Freitas, 2006), foi feita uma modificação no cálculo da qualidade das regras, para situações em que a regra prevê a classe minoritária (com menor número de exemplos). Para esses casos, a qualidade da regra foi obtida pelo produto sensibilidade pela precisão, de modo que a precisão colaborasse para a minimização dos falsos positivos, uma vez que a maioria 
dos dados não pertence à classe positiva. Assim como em (Holden \& Freitas, 2005), foi utilizada a TA para a avaliação do algoritmo de classificação, porém com a diferença de que a medida de custo utilizada foi baseada na distância considerando a profundidade.

Em (Secker et al., 2007), todos os experimentos foram realizados utilizando o método 10-fold cross-validation. Por considerações estatísticas, esse processo de particionamento foi repetido trinta vezes. Ao final dos experimentos com os 300 conjuntos de testes gerados, o desempenho preditivo foi medido por meio da média das TAs obtidas para esses conjuntos.

Clare \& King (2003) reportaram os resultados por meio da TA média observada para cada nível. Em (Blockeel et al., 2002), assim como em (Holden \& Freitas, 2006), a avaliação foi baseada na TA dependente da profundidade. Recentemente, Blockeel et al. (2006) fizeram um estudo comparativo entre os métodos descritos em (Clare \& King, 2003) e (Blockeel et al., 2002), utilizando precisão e sensibilidade (precision-recall) para realizar a avaliação dos classificadores gerados.

Apesar das diferenças entre as abordagens utilizadas para a avaliação dos modelos de classificação relacionados nesta seção, o cálculo da medida de desempenho de todos os trabalhos, com exceção de (Holden \& Freitas, 2006) e (Blockeel et al., 2002), está apoiada na idéia binária de erros e acertos do custo uniforme, ou seja, são atribuídos valores unitários para erros e acertos no processo de classificação.

Em (Holden \& Freitas, 2006) e (Blockeel et al., 2002), foram atribuídos pesos nas ligações entre as classes da hierarquia, de modo a considerar a profundidade no cálculo da distância. Os pesos foram atribuídos de modo a decrescer exponencialmente com o aumento da profundidade na hierarquia. Esse procedimento considera a diferença no grau de dificuldade de predição de um nível para outro na hierarquia, que aumenta com a profundidade do nível em que a classe se encontra. Predição em níveis superiores são mais fáceis e, portanto, erros de classificação para tais classes devem ser menos tolerados do que em níveis mais profundos.

A adoção de medidas de cálculo de erros de classificação baseadas na hierarquia é de grande importância para que os modelos hierárquicos sejam avaliados de modo mais adequado. Medidas hierárquicas só não fazem sentido para a abordagem em que o problema de classificação hierárquica é reduzido a um problema de classificação plana no primeiro nível, como em (Weinert \& Lopes, 2004) e (Jensen et al., 2002). 
Tabela 4.5: Avaliação de desempenho.

\begin{tabular}{|c|c|}
\hline Trabalho & $\begin{array}{c}\text { Medida de avaliação do } \\
\text { desempenho }\end{array}$ \\
\hline (Weinert \& Lopes, 2004) & TA e Especificidade-Sensibilidade \\
\hline (Jensen et al., 2002) & $\begin{array}{l}\text { Taxa de falsos positivos e sensibili- } \\
\text { dade }\end{array}$ \\
\hline (Clare \& King, 2001) & Estimativa-m \\
\hline (Jensen et al., 2003) & $\begin{array}{l}\text { Taxa de falsos positivos e sensibili- } \\
\text { dade }\end{array}$ \\
\hline (Laegreid et al., 2003) & Cálculo da AUC \\
\hline (Tu et al., 2004) & ATI \\
\hline (Barutcuoglu et al., 2006) & Cálculo da AUC \\
\hline (Blockeel et al., 2002) & $\begin{array}{l}\text { TA considerando custos de classi- } \\
\text { ficação baseados na distância de- } \\
\text { pendente da profundidade. Depois } \\
\text { foi feita uma nova avaliação utili- } \\
\text { zando precision-recall em (Blockeel } \\
\text { et al., 2006) }\end{array}$ \\
\hline (Clare \& King, 2003) & $\begin{array}{l}\text { TA. Depois foi feita uma nova avali- } \\
\text { ação utilizando precision-recall em } \\
\text { (Blockeel et al., 2006) }\end{array}$ \\
\hline $\begin{array}{l}\text { (Holden \& Freitas, 2005), (Secker } \\
\text { et al., 2007) }\end{array}$ & TA \\
\hline (Holden \& Freitas, 2006) & $\begin{array}{l}\text { TA considerando custos de classi- } \\
\text { ficação baseados na distância de- } \\
\text { pendente da profundidade }\end{array}$ \\
\hline
\end{tabular}

\subsection{Considerações Finais}

Neste capítulo foram descritos doze trabalhos envolvendo classificação hierárquica em Bioinformática, caracterizados quanto ao tipo da hierarquia, à abordagem, ao nível de predição e à avaliação do desempenho. Para cada um desses aspectos, que caracterizam um problema hierárquico, foi feita uma descrição detalhada.

Quanto à abordagem utilizada para a resolução do problema hierárquico, deve-se destacar, dentre os trabalhos descritos, àqueles que se baseiam na abordagem Big-Bang e na abordagem Top-Down, pois tais abordagens consideram a hierarquia em todo o processo de classificação.

Dentre os trabalhos descritos, o algoritmo HC4.5 foi utilizado nos experimentos, reportados no próximo capítulo, com o intuito de comparar os seus resultados com os resultados dos algoritmos Top-Down implementados. 


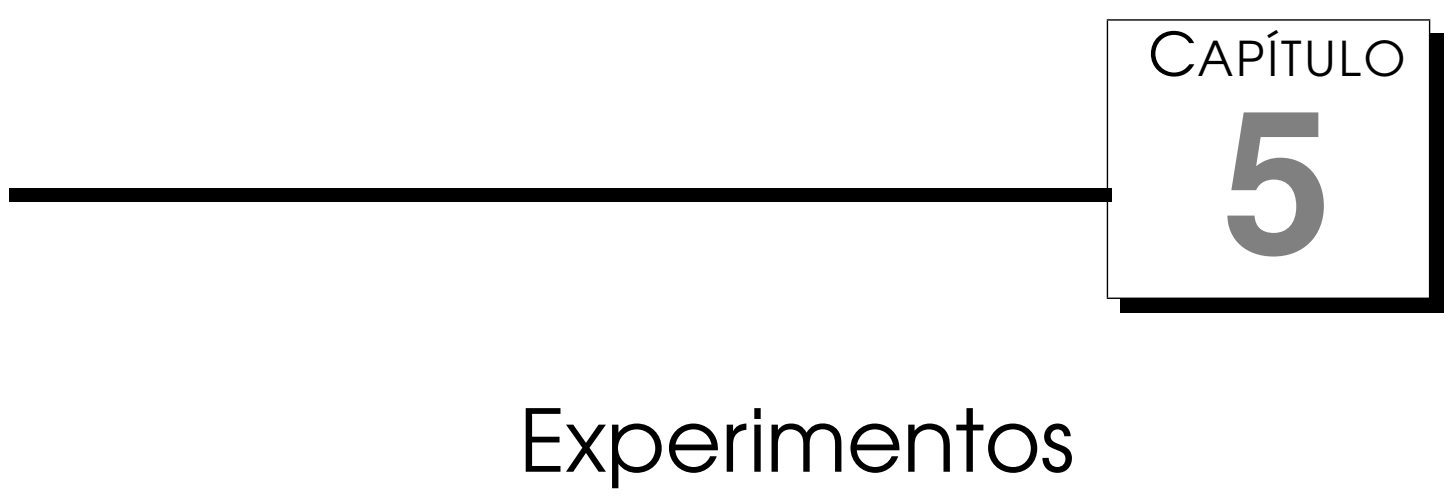

Neste capítulo, os algoritmos Top-Down descritos no Capítulo 3 são avaliados por meio de experimentos envolvendo a classificação hierárquica de dois conjuntos de dados biológicos. Os experimentos e a análise dos resultados obtidos podem ser divididos basicamente em quatro estágios. Inicialmente, foram comparados os resultados de cinco algoritmos baseados na abordagem Top-Down convencional, na qual o algoritmo utiliza uma única técnica para geração dos classificadores. As técnicas de AM utilizadas para construção desses algoritmos foram: C4.5, RIPPER, Redes Bayesianas, SVMs e KNN. Num segundo momento, foram realizados experimentos utilizando um algoritmo baseado na abordagem Selective Top-Down e seus resultados foram comparados àqueles obtidos pelos algoritmos Top-Down convencionais. Posteriormente, experimentos foram realizados utilizando algoritmos baseados nas estratégias propostas para combinação hierárquica de classificadores. Por fim, algoritmos das três vertentes da abordagem Top-Down - convencional, selective e ensemble (combinada) - foram selecionados e comparados com um algoritmo Big-Bang.

Este capítulo está organizado da seguinte maneira: na Seção 5.1, são descritos os dois conjuntos de dados utilizados nos experimentos; na Seção 5.2, é descrita a metodologia utilizada para condução dos experimentos e análise dos resultados; os principais resultados obtidos são apresentados e discutidos na Seção 5.3; por fim, algumas considerações finais com relação aos experimentos e aos resultados obtidos são apresentadas na Seção 5.4. 


\subsection{Conjuntos de Dados}

Para a realização dos experimentos, foram selecionados dois conjuntos de dados biológicos: o conjunto GPCR, que contém dados da família de proteínas G-Protein-Coupled Receptor (GPCR), e o conjunto EC, que contém dados de enzimas classificados de acordo com a nomenclatura definida pela Enzyme Comission (Nomenclature, 1972). Tais conjuntos foram disponibilizados pelos autores dos trabalhos (Holden \& Freitas, 2006) e (Holden \& Freitas, 2005), nos quais os dados foram utilizados originalmente.

Os dois conjuntos de dados foram utilizados para a geração de modelos de classificação capazes de predizer, com certo grau de confiança (que varia de algoritmo para algoritmo), classes funcionais de proteínas. Essa tarefa de predição de classes é importante porque possibilita a realização de inferências a respeito das funções de proteínas, uma vez que proteínas pertencentes a mesma classe funcional possuem a mesma função ou funções similares, ou estão envolvidas processos biológicos relacionados.

Holden \& Freitas (2006) e Holden \& Freitas (2005) utilizaram as bases de dados UniProt (Apweiler et al., 2004) e GPCRDB (GPCRDB, 2006) para extração dos dados utilizados na construção dos conjuntos GPCR e EC. Uniprot é uma base de dados que contém seqüências e anotações a respeito de um grande número de proteínas. Além disso, o Uniprot possui referência cruzada com outras bases de dados. Ao contrário do Uniprot, o GPCRDB é uma base de dados específica para dados de GPCRs.

O conjunto de atributos de predição dos dois conjuntos de dados é constituído por entradas Interpro (Apweiler et al., 2001), peso molecular e comprimento da seqüência da proteína. Interpro integra várias bases de dados de assinaturas de proteínas (Gene3D, PANTHER, PIRSF, Pfam, PRINTS, PROSITE, SMART, SUPERFAMILY e TIGRFAM) e consiste em uma linguagem que descreve muitos padrões, que são seqüências específicas de aminoácidos utilizadas para identificar uma dada proteína ou grupo de proteínas. Os atributos formados a partir de entradas Interpro indicam a presença ou a ausência de um determinado padrão na seqüência protéica. Dessa forma, os atributos dos conjuntos de dados são booleanos (nos quais o valor 1 indica a presença de uma padrão na seqüência e 0 a sua ausência), com exceção de dois atributos (peso molecular e comprimento das seqüências), que possuem valores contínuos.

Detalhes dos conjuntos de dados são apresentados na Tabela 5.1. Nessa tabela, para cada conjunto de dados, são apresentadas as seguintes informações: número total de exemplos (\#Total Dados), número mínimo e máximo de exemplos nos conjuntos de treinamentos (\#Min., Max. Treinamento), que 
foram obtidos a partir de um particionamento 5-fold cross-validation; número mínimo e máximo de exemplos nos conjuntos de testes (\#Min., Max. Teste); número de níveis considerados da hierarquia de classes (\#Niveis); número total de classes pertencentes à hierarquia (\#Total Classes); número de classes contidas em cada nivel (\#Classes / Nivel) - niveis 1/2/3/4, respectivamente; número de atributos contínuos e booleanos (\#Atrib. cont. / bool.), que são os dois tipos de atributos presentes nos conjuntos de dados; número mínimo, máximo e médio de exemplos por classes em cada nível da hierarquia (\#Min., Max., Med. ex./ classe (N1-N4)), no qual N1, N2, N3 e N4 representam o primeiro, segundo, terceiro e quarto níveis, respectivamente; e a TA majoritária no nível 1 (TAM - Nível 1).

A TAM consiste na TA que seria obtida caso a classe majoritária (que tem maior freqüência no conjunto de treinamento) fosse escolhida como a classe predita para todos os exemplos. A TAM foi calculada no conjunto de teste dos 5 folds utilizados para particionar os dados, e o resultado reportado é a média das taxas obtidas nesses conjuntos. A TAM é mostrada para o primeiro nível com o intuito de prover uma visão geral do conjunto de dados. Entretanto, não seria viável reportar esssa taxa para todos os níveis porque em cada nível ocorrem vários processos de classificação (e não apenas um processo de classificação por nível, como ocorre no primeiro nível), uma vez que o percurso na hierarquia é Top-Down. Logo, uma taxa teria que ser reportada a cada nó em que se dá um processo de classificação, ou seja, cada nó que represente uma classe que tenha duas ou mais subclasses.

Como pode ser observado na linha da Tabela 5.1 que corresponde ao número mínimo, máximo é médio de exemplos por classe, algumas classes têm um número de exemplos consideravelmente maior do que o número de exemplos de outras classes. Porém, como ocorrem muitos processos de classificação durante uma classificação Top-Down, na maioria das vezes, numa esfera local, o conjunto não é tão desbalanceado quanto pode-se concluir em uma primeira análise da tabela. Em outras palavras, em muitas classificações locais essa disparidade diminui. Nesses casos, estão envolvidas ou classes com poucos exemplos ou classes com muitos exemplos, dependendo do nó em que a classificação ocorre. Uma exceção a essa observação é o primeiro nível do conjunto GPCR, no qual há uma grande disparidade entre o número de exemplos das classes envolvidas num mesmo processo de classificação. Porém esse desbalanceamento diminui nos demais processos de classificação ao longo da hierarquia. 
Tabela 5.1: Principais características dos conjuntos de dados.

\begin{tabular}{|l|c|c|}
\cline { 2 - 3 } \multicolumn{1}{c|}{} & GPCR & EC \\
\hline \#Total Dados & 6935 & 5194 \\
\hline \#Min., Max. Treinamento & $5548 / 5548$ & $4155 / 4156$ \\
\hline \#Min., Max. Teste & $1387 / 1387$ & $1038 / 1039$ \\
\hline \#Níveis & 4 & 4 \\
\hline \#Total Classes & 198 & 158 \\
\hline \#Classes / Nível & $12 / 54 / 82 / 50$ & $2 / 21 / 48 / 87$ \\
\hline \#Atrib. cont. / bool. & $2 / 448$ & $2 / 1214$ \\
\hline \#Min., Max., Med. ex./ classe (N1) & $25 / 4396 / 577.92$ & $2369 / 2825 / 2597$ \\
\hline \#Min., Max., Med. ex./ classe (N2) & $10 / 2101 / 121.61$ & $12 / 1490 / 247.33$ \\
\hline \#Min., Max., Med. ex./ classe (N3) & $10 / 339 / 59.23$ & $10 / 732 / 108.21$ \\
\hline \#Min., Max., Med. ex./ classe (N4) & $10 / 166 / 30.68$ & $10 / 732 / 55.97$ \\
\hline TAM - Nível 1 & 63.39 & 54.38 \\
\hline
\end{tabular}

\section{GPCR - G-Protein-Coupled Receptor}

Proteínas da família GPCR, ou simplesmente GPCRs, são particularmente importantes para aplicações da área médica devido a sua influência em reações químicas que se dão no interior das células. De acordo com Filmore (2004), 40 a 50\% dos medicamentos atuais envolvem interações com GPCRs. As classes funcionais de GPCRs são dadas de maneira única pelos índices hierárquicos providos pelo GPCRDB, um sistema de informação molecular específico para essa família protéica. As classes nessa hierarquia são dispostas em uma estrutura de árvore que tem cinco níveis. Entretanto, somente quatro níveis de classes foram considerados na geração do conjunto dos dados. O quinto nível não foi considerado porque as suas classes não apresentavam um número suficiente de exemplos que possibilitasse o treinamento de classificadores.

O conjunto de dados GPCR possui 450 atributos e 12/54/82/50 classes por nível (número de classes nos níveis $1 / 2 / 3 / 4$, respectivamente). Originalmente, o conjunto possuía 7461 exemplos (proteínas). Porém, depois da etapa de pré-processamento para retirada dos exemplos pertencentes aos nós internos da hierarquia, como descrito na próxima seção, o conjunto passou a ter 6935 exemplos.

Uma observação importante diz respeito à divisão do número de classes entre os níveis da hierarquia GPCR. O número de classes no quarto nível é menor do que o número de classes no terceiro nível, indicando que muitos ramos da hierarquia de classes se estendem apenas até o terceiro nível. Essa característica da hierarquia GPCR, que pode ser considerada como um desbalanceamento na distribuição das classes ao longo da hierarquia, pode ser observada mais claramente quando comparada à hierarquia de enzimas (EC), que possui $2 / 21 / 48 / 87$ classes por nível. Demais detalhes do conjunto de 
dados GPCR podem ser verificados na Tabela 5.1.

\section{Enzimas}

Enzimas constituem um subconjunto de proteínas cuja principal função é acelerar reações químicas das células, sendo assim importantes catalisadores. Cada enzima é geralmente muito específica, somente catalisando um único tipo de reação. As classes funcionais de enzimas são dadas de maneira única pela codificação EC. Assim como na hierarquia GPCR, na hierarquia EC as classes estão dispostas em uma estrutura de árvore. Essa hierarquia possui quatro niveis e todos eles foram usados na criação do conjunto de dados.

O conjunto de dados EC contém 1216 atributos, um número consideravelmente maior do que o presente no conjunto GPCR, 450 atributos. Esse grande número de atributos fez com que houvesse um alto custo computacional para a execução dos experimentos com esse conjunto. Assim, para esse conjunto, foi adotado um passo adicional no pré-processamento dos dados para a redução do número de exemplos do conjunto de dados. Ao final do pré-processamento, o conjunto, que tinha originalmente 14036 exemplos e 6/41/96/187 classes por nível, foi reduzido para 5194 exemplos e $2 / 21 / 48 / 87$ classes por nível. Os passos de pré-processamento são descritos em mais detalhes na próxima seção. Demais detalhes do conjunto de dados EC podem ser verificados na Tabela 5.1.

\subsection{Metodologia}

Nesta seção, é descrita a metodologia adotada para a condução dos experimentos. São fornecidas informações relevantes com relação ao pré-processamento dos dados, às ferramentas de software utilizadas, aos procedimentos utilizados para avaliação dos modelos de classificação, e aos testes estatísticos utilizados para na comparação dos resultados dos algoritmos. A principal motivação para uma definição clara e detalhada da metodologia utilizada é facilitar a análise e compreensão dos resultados apresentados neste capítulo, além de possibilitar uma posterior reprodução dos experimentos descritos.

\subsubsection{Pré-processamento dos Dados}

Durante a fase de pré-processamento, foram feitos alguns ajustes nos conjuntos de dados. Tais ajustes consistiram na retirada de exemplos dos conjuntos de dados. Além disso, os dados foram particionados em conjuntos de 
treinamento e de teste para a realização dos experimentos. Esses procedimentos são descritos a seguir.

Tanto o conjunto GPCR quanto o EC possuíam, originalmente, uma pequena parte dos exemplos que pertencia apenas a nós internos da hierarquia, ou seja, não era fornecida a informação quanto à disposição de tais dados em relação às classes mais específicas da hierarquia. Porém, como os algoritmos implementados neste projeto consideram predição obrigatória em nós-folhas, essa característica dos conjuntos traria possíveis problemas na avaliação dos modelos de classificação gerados: ao avaliar a classificação de um exemplo pertencente a apenas um nó interno da hierarquia, não seria possível afirmar se a classificação nos nós mais específicos foi bem sucedida ou não. Dessa forma, optou-se por retirar do conjunto de dados tais exemplos, uma vez que esses constituíam apenas uma pequena parte dos dados, não comprometendo assim a condução dos experimentos.

Além disso, um passo adicional foi realizado para o conjunto EC para a redução do número de exemplos desse conjunto de dados. Com 1217 atributos e 14036 exemplos, o conjunto EC apresentou um custo computacional muito elevado, tornando necessária a retirada de uma parte dos exemplos para a viabilização dos experimentos. A alternativa encontrada foi fazer a redução da estrutura da hierarquia de classes, não comprometendo assim a qualidade da predição para as classes remanescentes na hierarquia. Foram mantidas duas das seis classes presentes no primeiro nível da hierarquia EC, além de todas as suas classes descendentes. As classes selecionadas para permanência na hierarquia foram as classes 1 e 2 (seguindo a nomenclatura definida pela Enzyme Commision). Tais classes foram escolhidas por serem as duas classes mais representativas em termos de número de exemplos e número de classes descendentes. Depois dessa redução, a hierarquia passou de 6/41/96/187 para 2/21/48/87 classes por nivel e os exemplos cujas classes foram retiradas da hierarquia foram conseqüentemente retirados do conjunto de dados.

Para o particionamento dos dados em conjuntos de teste e treinamento, foi utilizado o método 5-fold stratified cross-validation, também conhecido como validação cruzada estratificada com 5 partições.

Além disso, os valores dos atributos contínuos dos conjuntos de dados - peso molecular e comprimento da seqüência - foram normalizados para a aplicação da técnica SVM. Nas demais técnicas, essa normalização não foi necessária ou porque a técnica já implementa internamente essa normalização ou porque a normalização não faz diferença no desempenho preditivo da técnica.

Para normalização dos dados, foi utilizado um método que consiste em ajustar os valores do conjunto de treinamento de modo que a média $(\bar{m})$ seja 
igual a 0 e desvio padrão $\left(s_{d}\right)$ seja igual a 1 para cada um dos atributos que deseja-se normalizar. Para isso, para cada um desses atributos, são obtidos a média e o desvio padrão para os dados de treinamento e esses valores são usados para ajustar cada valor $V_{i}$ dos dados de treinamento de acordo com o cálculo mostrado na Equação 5.1. O mesmo cálculo é então utilizado para normalização dos dados de teste. Porém, a média e o desvio padrão usados no cálculo são os mesmos do conjunto de treinamento, pois é assumido que informações do conjunto de teste não estão disponíveis.

$$
V_{i}=\frac{V_{i}-\bar{m}}{s_{d}}
$$

\subsubsection{Ferramentas de Software}

Para implementação e simulação dos modelos de classificação, foi utilizada a linguagem funcional e ambiente de software R (Venables et al., 2006), que é uma importante ferramenta para computação estatística. R é um software livre e pode ser instalado em uma variedade de plataformas Unix/Linux, Windows e Macintoshes, e arquiteturas de computadores, como Intel, Power PC e sistemas Alpha. Além disso, ele pode ser utilizado de uma maneira interativa, que permite que usuários mais avançados desenvolvam suas próprias funções e, até mesmo, adicionem novas funcionalidades aos pacotes já existentes, uma vez que seu código é aberto.

$\mathrm{O} R$ possui inúmeros pacotes disponíveis, muitos deles voltados para a resolução de problemas de AM e DM. Para a implementação dos algoritmos TopDown utilizados neste projeto, foram utilizados os seguintes pacotes: e1071 (Dimitriadou et al., 2006) e RWeka (Hornik et al., 2007). O pacote e1071 é um pacote que contém várias funcionalidades estatísticas, além de implementações das técnicas de aprendizado estatístico SVM e Naive Bayes. Esse pacote foi utilizado para a geração dos classificadores SVM. O pacote RWeka é uma interface $\mathrm{R}$ para alguns do principais métodos que fazem parte da ferramenta Weka (Witten et al., 1999), que reúne uma coleção de algoritmos para DM e AM. Os classificadores baseados em Redes Bayesianas, KNN, RIPPER e C4.5 foram gerados a partir das implementações providas por esse pacote.

No Weka, algumas implementações recebem nomes diferentes dos algoritmos em que foram baseadas, como o C4.5, RIPPER e KNN. A implementação do C4.5 é denominada de J48, a implementação do RIPPER é denominada de JRip, e a implementação do KNN é denominada de iBK. Entretanto, no texto desta dissertação foram mantidos os nomes originais das técnicas, ao invés do nome de suas implementações. Outra observação importante é que a técnica de Redes Bayesianas é mencionada no texto como BayesNet por motivos 
de simplificação do nome da técnica, além desse ser um nome comumente utilizado na comunidade de AM para referência a essa técnica.

\subsubsection{Avaliação}

A avaliação dos modelos de classificação foi feita nível a nível da hierarquia, ou seja, para cada nível da hierarquia foi reportado um valor resultante da avaliação do desempenho preditivo. Para que isso fosse possível, foi gerada uma matriz de confusão para cada nível da hierarquia, seguindo a seqüência de passos descrita na Seção 3.4.1.

Uma vez obtidas as matrizes de confusão, diferentes medidas podem ser utilizadas para a avaliação dos modelos de classificação. Quatro tipos de medidas foram adotadas para avaliação dos resultados obtidos dos experimentos: TA convencional, TA baseada em distância, TA dependente da profundidade e uma medida denominada $F$-measure hierárquica, que combina as medidas sensibilidade hierárquica e precisão hierárquica baseadas em ancestrais. Uma descrição detalhada de cada uma dessas medidas pode ser encontrada na Seção 2.5 .

As quatro medidas de avaliação foram utilizadas no primeiro estágio dos experimentos para avaliação dos algoritmos Top-Down convencionais, com o objetivo de analisar diferenças de comportamento entre cada uma delas. Para as demais etapas da condução dos experimentos, a TA dependente da profundidade foi utilizada. A motivação para escolha dessa medida foi porque ela considera os relacionamentos hierárquicos entre as classes, como diferença no grau de dificuldade de predição de um nível para outro na hierarquia, na atribuição de penalizações aos erros de classificação. Além disso, ela reporta a TA, uma medida que é muito utilizada para reportar resultados de trabalhos na comunidade de AM.

Os pesos utilizados para ponderar o cálculo da distância para a TA dependente da profundidade foram $(0.26,0.13,0.07,0.04)$, em que 0.26 é o peso de uma ligação entre o nó raiz e qualquer uma de suas subclasses (as classes do primeiro nível), 0.13 é o peso de uma ligação entre uma classe do primeiro nível e qualquer uma de suas subclasses no segundo nível, e assim por diante. O raciocínio utilizado para a atribuição desses pesos foi o de que predições incorretas em níveis mais profundos devem ser mais toleradas do que predições incorretas em níveis mais próximos a raiz. Tais pesos foram utilizados originalmente em (Holden \& Freitas, 2006). 


\subsubsection{Testes Estatísticos}

$\mathrm{Na}$ análise do resultados obtidos por meio dos experimentos, foram utilizados testes estatísticos, que vêm recebendo cada vez mais atenção da comunidade de AM como um instrumento para validação de experimentos e comparação de resultados.

Todas as comparações empregadas neste capítulo envolvem múltiplos algoritmos. Nesses casos, a idéia básica de testes estatísticos é comparar os resultados obtidos pelos algoritmos de aprendizado sobre um conjunto de dados, de modo a verificar se os resultados diferem uns dos outros com significância estatística.

O teste estatístico escolhido foi o t de Student para dados pareados corrigido. Esse teste foi escolhido por ser bem aceito pela comunidade de AM e por atender às características dos experimentos realizados. No decorrer do projeto foi cogitada a possibilidade de se utilizar o teste Wilcoxon Signed-Ranks (Wilcoxon, 1945), que é uma alternativa não paramétrica ao teste de hipóteses pareado (Mitchell, 1997). Porém, como os experimentos envolveram apenas dois conjuntos de dados, o teste Wilcoxon Signed-Ranks não seria adequado.

O teste t de Student pareado consiste em calcular a diferença entre os resultados de dois classificadores para os vários conjuntos de teste, de modo a verificar se a média da diferença entre eles é estatisticamente diferente de 0 (Demsar, 2006). Dessa forma, para comparar um algoritmo A com um algoritmo $\mathrm{B}$, basta comparar o desempenho preditivo do classificador gerado por $\mathrm{A}$ $\left(C_{A}\right)$ com o do classificador gerado por $\mathrm{B}\left(C_{B}\right)$. Dado os $k$ conjuntos de teste gerados pelo método $k$-fold cross-validation, essa comparação de desempenho é feita pela diferença, para cada conjunto de teste $i$, entre os resultados obtidos para o classificador A $\left(R_{i}\left(C_{A}\right)\right)$ com os resultados obtidos para o classificador $B\left(R_{i}\left(C_{B}\right)\right)$, como pode ser observado na Equação 5.2. O resultado $(R)$ pose ser qualquer medida de avaliação empregada para medir o desempenho preditivo dos classificadores, como TA ou TE, por exemplo. Como para o particionamento dos conjuntos de dados envolvidos nos experimentos foi utilizado o método 5-fold cross-validation, essa diferença foi calculada para cada um dos cinco conjuntos de teste gerados.

$$
d i f_{i}=R_{i}\left(C_{A}\right)-R_{i}\left(C_{B}\right)
$$

Após o cálculo da diferença dos resultados dos classificadores para os $k$ conjuntos de teste, é calculada a média $\left(\bar{m}_{d}\right)$ e o desvio padrão $\left(s_{d}\right)$ das diferenças. Os cálculos para a média e para o desvio padrão são apresentados nas equações 5.3 e 5.4, respectivamente. 


$$
\begin{gathered}
\bar{m}_{d}=\frac{1}{k} \sum_{i=1}^{k} d i f_{i} \\
s_{d}=\sqrt{\frac{1}{k-1} \sum_{i=1}^{k}\left(d i f_{i}-\bar{m}_{d}\right)^{2}}
\end{gathered}
$$

Os valores da média e do desvio padrão são então utilizados para calcular o valor de $t$ observado $\left(t_{o b s}\right)$, cujo cálculo é apresentado na Equação 5.5 (Nadeau \& Bengio, 2003):

$$
t_{o b s}=\frac{\left|\bar{m}_{d}\right|}{\sqrt{\left(\frac{1}{k}+\frac{1}{k-1}\right) s_{d}^{2}}}
$$

A hipótese nula - de que não há significância estatística na diferença dos resultados obtidos pelos algoritmos - é rejeitada se $t_{\text {obs }}$ for maior do que $t_{\left(k-1, \frac{\alpha}{2}\right)}$, que corresponde ao valor de $t$ na distribuição t de Student $\operatorname{com} k-1$ graus de liberdade e com um nível de confiança $\alpha$ (o nível de confiança indica a probabilidade de que um valor seja reconhecido como tendo significância estatística quando na verdade não tem). Uma vez rejeitada a hipótese nula, pode-se afirmar que a diferença dos resultados obtidos pelos classificadores gerados pelos algoritmos A e por B é estatisticamente significativa para um nível de confiança $\alpha$.

O procedimento descrito é apropriado para a comparação de dois algoritmos. Entretanto, quando múltiplos algoritmos estão sendo comparados, algumas modificações são necessárias para garantir a validade do teste estatístico. Ao testar a significância entre vários pares de algoritmos, a chance de ocorrer uma significância ao acaso é proporcional ao número de comparações realizadas no teste estatístico. Assim, quanto maior foi o número de comparações realizadas, maior será a chance da significância ocorrer ao acaso. Uma solução para esse problema é ajustar o nível de significância do teste em relação ao número de comparações realizadas entre os algoritmos. Um procedimento que tem sido utilizado com freqüência para o ajuste do nível de significância é denominado de Correção de Bonferroni. Essa correção consiste em determinar um novo nível de significância $\left(\alpha^{*}\right)$ com base no nível de significância original $(\alpha)$ e no número de comparações $(n)$. A fórmula que relaciona essas variáveis é dada pela Equação 5.6.

$$
\alpha=1-\left(1-\alpha^{*}\right)^{n}
$$

A Correção de Bonferroni foi aplicada para cada estudo comparativo reali- 
zado neste projeto. Assim, o valor de $\alpha$, que foi escolhido originalmente como 0.05, foi ajustado dependendo do número de algoritmos que são considerados em cada comparação de resultados. Neste capítulo, a medida que os resultados dos experimentos são discutidos, são fornecidas informações resumidas a respeito das análises estatísticas. Os detalhes de todos os testes estatísticos realizados são apresentados no Apêndice A.

\subsection{Resultados}

Nesta seção, são apresentados os resultados obtidos experimentalmente para os dois conjuntos de dados utilizados, GPCR e EC. Os resultados foram separados em subseções de acordo com os quatro estágios em que a condução dos experimentos foi dividida: (1) Experimentos com algoritmos TopDown convencionais; (2) Experimentos com um algoritmo Selective Top-Down e comparação dos resultados com aqueles obtidos na abordagem convencional; (3) Experimentos com algoritmos implementados com combinação hierárquica de classificadores; (4) Comparação dos resultados obtidos a partir das várias abordagens empregadas, incluindo um algoritmo Big-Bang.

\subsection{Algoritmos Top-Down Convencionais}

Inicialmente, foram realizados experimentos utilizando a abordagem convencional Top-Down. Foram implementados cinco algoritmo Top-Down, cada um deles baseado em uma das seguintes técnicas de AM: C4.5, RIPPER, Redes Bayesianas (BayesNet), SVMs e KNN. Nesses experimentos, assim como nos demais experimentos reportados neste capítulo, foram utilizados os parâmetros default para as técnicas empregadas. A única exceção se refere à técnica SVM, para a qual foram fornecidos alguns valores para os parâmetros diferentes do default: foram utilizados os valores custo $=100$ e $\gamma=0.01$. A motivação para escolha de tais parâmetros se deu pelo fato desses serem parâmetros freqüentemente escolhidos em trabalhos envolvendo SVMs, apresentando bons resultados. Além disso, os dados foram normalizados para a aplicação da técnica SVM, como discutido na Seção 5.2.1. Para o KNN, utilizou-se K=5.

$\mathrm{O}$ algoritmo Top-Down convencional baseado na técnica $\mathrm{C} 4.5$ é referenciado no texto como Top-Down C4.5, ou simplesmente TP-C4.5 . A mesma regra de nomenclatura é válida para as outras técnicas de AM. Nas tabelas de resultados, por questão de espaço, os algoritmos são referenciados apenas pelo nome da técnica empregada em sua implementação. Por exemplo, o TP-C4.5 é identificado apenas como $\mathrm{C} 4.5$ nas tabelas de resultados.

Os resultados foram reportados nível a nível, por meio de quatro medidas 
de avaliação: TA convencional, TA baseada em distância, TA dependente da profundidade e F-measure hierárquica. A motivação para se reportar os resultados usando diferentes medidas foi a de verificar se os resultados diferiam conforme a medida utilizada.

Nas tabelas 5.2, 5.3, 5.4 e 5.5, são apresentados os resultados para o primeiro, o segundo, o terceiro e o quarto níveis do conjunto GPCR, respectivamente. Além de se reportar a média das medidas para as cinco partições de teste geradas pelo método 5-fold cross-validation e o desvio padrão, também é fornecida uma informação correspondente ao ranking entre as técnicas. Para cada nivel e para cada medida, $\mathrm{R} 1$ representa a técnica com a maior taxa reportada, $\mathrm{R} 2$ representa a técnica com segunda maior taxa, e assim consecutivamente.

Tabela 5.2: Medidas de desempenho dos 5 algoritmos Top-Down convencionais no primeiro nível da base GPCR.

\begin{tabular}{|l|c|c|c|c|}
\cline { 2 - 6 } \multicolumn{1}{c|}{} & TA uniforme & TA distância & TA profundidade & F-measure \\
\hline C4.5 & $93.11(0.35)-$ R2 & $93.11(0.35)-$ R2 & $93.11(0.35)-$ R2 & $93.11(0.35)-$ R2 \\
\hline RIPPER & $89.91(0.65)-$ R4 & $89.91(0.65)-$ R4 & $89.91(0.65)-$ R4 & $89.91(0.65)-$ R4 \\
\hline SVM & $92.34(0.53)-$ R3 & $92.34(0.53)-$ R3 & $92.34(0.53)-$ R3 & $92.34(0.53)-$ R3 \\
\hline KNN & $93.27(0.58)-$ R1 & $93.27(0.58)-$ R1 & $93.27(0.58)-$ R1 & $93.27(0.58)-$ R1 \\
\hline BayesNet & $85.55(1.71)-$ R5 & $85.55(1.71)-$ R5 & $85.55(1.71)-$ R5 & $85.55(1.71)-$ R5 \\
\hline
\end{tabular}

Tabela 5.3: Medidas de desempenho dos 5 algoritmos Top-Down convencionais no segundo nível da base GPCR.

\begin{tabular}{|l|c|c|c|c|}
\cline { 2 - 5 } \multicolumn{1}{c|}{} & TA uniforme & TA distância & TA profundidade & F-measure \\
\hline C4.5 & $87.70(0.96)-$ R2 & $90.22(0.60)-$ R2 & $91.05(0.47)-$ R2 & $90.21(0.58)-$ R2 \\
\hline RIPPER & $81.82(0.86)-$ R4 & $85.59(0.72)-$ R4 & $86.84(0.70)-$ R4 & $85.58(0.72)-$ R4 \\
\hline SVM & $86.08(0.79)-$ R3 & $89.00(0.66)-$ R3 & $89.97(0.62)-$ R3 & $89.00(0.67)-$ R3 \\
\hline KNN & $88.16(0.85)-$ R1 & $90.54(0.71)-$ R1 & $91.32(0.67)-$ R1 & $90.53(0.70)-$ R1 \\
\hline BayesNet & $76.68(1.23)-$ R5 & $80.75(1.52)-$ R5 & $82.09(1.62)-$ R5 & $80.73(1.51)-$ R5 \\
\hline
\end{tabular}

Tabela 5.4: Medidas de desempenho dos 5 algoritmos Top-Down convencionais no terceiro nível da base GPCR.

\begin{tabular}{|l|c|c|c|c|}
\cline { 2 - 5 } \multicolumn{1}{c|}{} & TA uniforme & TA distância & TA profundidade & F-measure \\
\hline C4.5 & $52.43(0.80)-$ R2 & $78.28(0.42)-$ R2 & $85.28(0.37)-$ R2 & $77.71(0.41)-$ R2 \\
\hline RIPPER & $45.53(1.00)-$ R4 & $73.54(0.69)-$ R4 & $80.53(0.63)-$ R4 & $71.82(0.68)-$ R4 \\
\hline SVM & $49.06(0.78)-$ R3 & $76.60(0.71)-$ R3 & $83.65(0.74)-$ R3 & $75.48(0.82)-$ R3 \\
\hline KNN & $53.37(0.77)-$ R1 & $79.12(0.53)-$ R1 & $85.88(0.59)-$ R1 & $78.36(0.64)-$ R1 \\
\hline BayesNet & $39.50(1.56)-$ R5 & $67.95(1.77)-$ R5 & $75.46(1.92)-$ R5 & $66.67(1.69)-$ R5 \\
\hline
\end{tabular}

No primeiro nível da hierarquia, todas a medidas apresentam os mesmos valores com respeito ao desempenho preditivo (o mesmo pode ser observado 
Tabela 5.5: Medidas de desempenho dos 5 algoritmos Top-Down convencionais no quarto nivel da base GPCR.

\begin{tabular}{|l|c|c|c|c|}
\cline { 2 - 5 } \multicolumn{1}{c|}{} & TA uniforme & TA distância & TA profundidade & F-measure \\
\hline C4.5 & $78.55(2.54)-\mathrm{R} 1$ & $83.92(2.01)-\mathrm{R} 2$ & $85.48(1.91)-\mathrm{R} 2$ & $83.04(2.20)-\mathrm{R} 2$ \\
\hline RIPPER & $61.89(1.71)-\mathrm{R} 4$ & $74.02(1.78)-\mathrm{R} 4$ & $75.36(2.11)-\mathrm{R} 4$ & $69.24(2.04)-\mathrm{R} 4$ \\
\hline SVM & $73.84(2.85)-\mathrm{R} 3$ & $82.94(2.00)-\mathrm{R} 3$ & $85.11(1.90)-\mathrm{R} 3$ & $81.52(2.40)-\mathrm{R} 3$ \\
\hline KNN & $78.38(2.04)-\mathrm{R} 2$ & $84.93(1.45)-\mathrm{R} 1$ & $86.30(1.54)-\mathrm{R} 1$ & $83.25(1.86)-\mathrm{R} 1$ \\
\hline BayesNet & $55.39(2.22)-\mathrm{R} 5$ & $66.39(2.84)-\mathrm{R} 5$ & $68.47(3.46)-\mathrm{R} 5$ & $63.02(2.71)-\mathrm{R} 5$ \\
\hline
\end{tabular}

para o conjunto EC). Isso ocorre porque no primeiro nível não há relações de classes e subclasses, fazendo com que todas as medidas sejam reduzidas a um mesmo cálculo. A demonstração das razões dessa igualdade é apresentada no final desta seção.

Para os demais níveis, as medidas apresentam valores diferentes. Nesses niveis, a TA dependente da profundidade é a que tem maior valor entre as TAs. Isso ocorre porque essa medida é mais flexível com relação a erros que acontecem em níveis mais profundos. Essa característica se contrasta com a TA convencional, que sempre considera erros unitários. Por essa razão, a TA convencional apresenta o menor valor dentre as TAs.

Como pode ser observado nas tabelas para os três primeiros níveis do conjunto GPCR, os cinco algoritmos apresentaram a mesma ordem de desempenho preditivo entre si. O TP-KNN apresentou o melhor desempenho preditivo, seguido, nessa ordem, pelas algoritmos: TP-C4.5, TP-SVM, TP-RIPPER e TPBayesNet. Essa ordem manteve-se a mesma para todas as medidas de avaliação utilizadas. Para o quarto nível, a ordem manteve-se a mesma para a TA baseada em distância, TA dependente da profundidade e $F$-measure hierárquica. A única medida que apresentou uma alteração da ordem de desempenho foi a TA convencional. A mudança ocorreu na ordem das duas primeiras posições: o TP-C4.5 apresentou o melhor desempenho, enquanto que o TP-KNN apresentou o segundo melhor desempenho. Porém, a diferença entre o desempenho do TP-KNN em relação ao TP-C4.5 não é estatisticamente significativa para nenhuma das medidas de avaliação consideradas. Portanto, apesar das medidas reportarem resultados diferentes para o quarto nivel e poderem levar a conclusões diferentes nesse nível, a diferença entre as conclusões não apresenta significância estatística.

Considerando os valores (taxas de desempenho) assumidos pelas técnicas para as várias medidas, pode-se observar que os algoritmos TP-KNN, TP-C4.5 e TP-SVM apresentam desempenhos bem próximos entre si, com ligeiras diferenças. Uma diferença um pouco maior separa o desempenho do TP-RIPPER das três técnicas com melhor desempenho. Uma diferença similar a essa se- 
para o desempenho do TP-RIPPER e do TP-BayesNet. Segundo as análises estatísticas realizadas, os algoritmos TP-KNN, TP-C4.5 e TP-SVM não apresentam uma diferença de desempenho que seja estatisticamente significativa para qualquer um dos níveis da hierarquia, quando a medida considerada é a TA convencional. O mesmo ocorre na comparação dos resultados do TPRIPPER e TP-BayesNet. Entretanto, os resultados do TP-KNN, TP-C4.5 e TPSVM apresentam diferença estatisticamente significativa quando comparados aos resultados do TP-RIPPER e do TP-BayesNet.

Para as demais medidas de avaliação - TA baseada em distância, TA dependente da profundidade e $F$-measure hierárquica, houveram algumas diferenças quanto às análises estatísticas. Para essas três medidas, os resultados do TP-SVM e do TP-C4.5 para o segundo nível apresentaram diferenças estatísticas. Para a TA dependente da profundidade, diferenças estatísticas para esses algoritmos também são apresentadas no terceiro nível. Adicionalmente, para a TA baseada em distância e $F$-measure hierárquica, os algoritmos TP-RIPPER e TP-BayesNet apresentam diferenças que são estatisticamente significativas para os resultados do terceiro nível.

Um fator interessante com relação ao desempenho preditivo dos algoritmos para o conjunto GPCR é que todas eles apresentam um melhor desempenho no quarto nível do que no terceiro nível, com algumas exceções. Como a abordagem Top-Down possui a desvantagem de propagação de erros, além das predições nos níveis mais profundos ser mais difícil, espera-se que os valores reportados pelas medidas de avaliação diminuam com o aumento da profundidade. Porém, a hierarquia GPCR possui algumas peculiaridades que fazem com que o quarto nível apresente maiores valores do que o terceiro. Essa hierarquia tem mais classes no terceiro nível do que no quarto nível, indicando que muitos ramos da árvore avançam apenas até o terceiro nível. Isso faz com que alguns erros que estavam sendo propagados pela hierarquia sejam propagados apenas até o terceiro nível. Assim, alguns erros não são contabilizados no quarto nível, podendo colaborar para um aumento dos valores das medidas de desempenho nesse nível. Além disso, os ramos que avançam até o quarto nível são os que apresentam menor propagação de erros, o que também colabora para uma avaliação mais alta no quarto nível. Entretanto, algumas diferenças de comportamento são observadas entre as medidas. Essa diferença entre os resultados no terceiro e quarto nível diminuem para as medidas TA baseada em distância, TA dependente da profundidade e $F$-measure hierárquica, uma vez que elas são mais flexíveis (tolerantes) em relação a erros que ocorrem apenas nos niveis mais profundos. Isso fez com que alguns erros que ocorriam apenas no terceiro nível e não eram propagados para o quarto nivel fossem mais tolerados, aumentando as taxas reportadas para aquele ní- 
vel. Para os resultados do TP-RIPPER medidos segundo a TA dependente da profundidade, o desempenho no quarto nível foi pior do que no terceiro nível. O mesmo ocorre para os resultados do TP-RIPPER medidos segundo as medidas TA baseada em distância, TA dependente da profundidade e $F$-measure hierárquica.

Além dos resultados do conjunto GPCR, também são reportados nesta seção os resultados obtidos dos experimentos realizados com o conjunto EC. As tabelas 5.6, 5.7, 5.8 e 5.9 apresentam os resultados para o primeiro, o segundo, o terceiro e o quarto níveis do conjunto EC, respectivamente.

Tabela 5.6: Medidas de desempenho dos 5 algoritmos Top-Down convencionais no primeiro nível da base EC.

\begin{tabular}{|l|c|c|c|c|}
\cline { 2 - 5 } \multicolumn{1}{c|}{} & TA uniforme & TA distância & TA profundidade & F-measure \\
\hline C4.5 & $98.55(0.36)-$ R3 & $98.56(0.36)-$ R3 & $98.56(0.36)-$ R3 & $98.56(0.36)-$ R3 \\
\hline RIPPER & $98.09(0.44)-$ R4 & $98.09(0.44)-$ R4 & $98.09(0.44)-$ R4 & $98.09(0.44)-$ R4 \\
\hline SVM & $99.96(0.09)-$ R1 & $99.96(0.09)-$ R1 & $99.96(0.09)-$ R1 & $99.96(0.09)-$ R1 \\
\hline KNN & $99.83(0.14)-$ R2 & $99.83(0.14)-$ R2 & $99.83(0.14)-$ R2 & $99.83(0.14)-$ R2 \\
\hline BayesNet & $94.44(0.39)-$ R5 & $94.44(0.39)-$ R5 & $94.44(0.39)-$ R5 & $94.44(0.39)-$ R5 \\
\hline
\end{tabular}

Tabela 5.7: Medidas de desempenho dos 5 classificadores Top-Down no segundo nível da base EC.

\begin{tabular}{|l|c|c|c|c|}
\cline { 2 - 5 } \multicolumn{1}{c|}{} & TA uniforme & TA distância & TA profundidade & F-measure \\
\hline C4.5 & $97.75(0.27)-$ R3 & $98.15(0.23)-$ R3 & $98.29(0.26)-$ R3 & $98.15(0.23)-$ R3 \\
\hline RIPPER & $97.15(0.40)-$ R4 & $97.62(0.38)-$ R4 & $97.78(0.39)-$ R4 & $97.62(0.38)-$ R4 \\
\hline SVM & $99.38(0.15)-$ R1 & $99.67(0.09)-$ R1 & $99.77(0.08)-$ R1 & $99.67(0.09)-$ R1 \\
\hline KNN & $99.15(0.40)-$ R2 & $99.49(0.27)-$ R2 & $99.60(0.23)-$ R2 & $99.49(0.27)-$ R2 \\
\hline BayesNet & $90.78(0.55)-$ R5 & $92.61(0.40)-$ R5 & $93.22(0.38)-$ R5 & $92.61(0.40)-$ R5 \\
\hline
\end{tabular}

Tabela 5.8: Medidas de desempenho dos 5 algoritmos Top-Down convencionais no terceiro nível da base EC.

\begin{tabular}{|l|c|c|c|c|}
\cline { 2 - 5 } \multicolumn{1}{c|}{} & TA uniforme & TA distância & TA profundidade & F-measure \\
\hline C4.5 & $97.05(0.42)-$ R3 & $97.79(0.28)-$ R3 & $98.10(0.27)-$ R3 & $97.79(0.28)-$ R3 \\
\hline RIPPER & $96.48(0.47)-$ R4 & $97.24(0.38)-$ R4 & $97.58(0.38)-$ R4 & $97.24(0.38)-$ R4 \\
\hline SVM & $98.50(0.25)-$ R2 & $99.28(0.14)-$ R1 & $99.58(0.11)-$ R1 & $99.28(0.14)-$ R1 \\
\hline KNN & $98.61(0.38)-$ R1 & $99.20(0.30)-$ R2 & $99.45(0.24)-$ R2 & $99.20(0.30)-$ R2 \\
\hline BayesNet & $89.06(0.67)-$ R5 & $91.43(0.46)-$ R5 & $92.58(0.40)-$ R5 & $91.43(0.46)-$ R5 \\
\hline
\end{tabular}

Conforme os resultados apresentados nas tabelas para o conjunto EC, pode-se observar que os valores reportados pelas medidas de avaliação são bem altos, quase 100\%. Isso se deve às características do conjunto de dados, uma vez que todos os algoritmos apresentaram um alto desempenho preditivo 
Tabela 5.9: Medidas de desempenho dos 5 algoritmos Top-Down convencionais no quarto nível da base EC.

\begin{tabular}{|l|c|c|c|c|}
\cline { 2 - 5 } \multicolumn{1}{c|}{} & TA uniforme & TA distância & TA profundidade & F-measure \\
\hline C4.5 & $95.98(0.35)-$ R3 & $97.40(0.29)-$ R3 & $97.89(0.28)-$ R3 & $97.29(0.29)-$ R3 \\
\hline RIPPER & $95.04(0.72)-$ R4 & $96.75(0.49)-$ R4 & $97.32(0.43)-$ R4 & $96.64(0.49)-$ R4 \\
\hline SVM & $96.83(0.34)-$ R2 & $98.72(0.18)-$ R2 & $99.36(0.13)-$ R1 & $98.67(0.19)-$ R2 \\
\hline KNN & $97.51(0.56)-$ R1 & $98.86(0.31)-$ R1 & $99.32(0.25)-$ R2 & $98.80(0.34)-$ R1 \\
\hline BayesNet & $87.30(0.76)-$ R5 & $90.62(0.46)-$ R5 & $92.10(0.39)-$ R5 & $90.31(0.50)-$ R5 \\
\hline
\end{tabular}

para esse conjunto, o que não foi constatado para nenhum dos algoritmos no conjunto GPCR.

Para os dois primeiros níveis, os cinco algoritmos apresentaram a mesma ordem de desempenho preditivo entre si. O TP-SVM apresentou o melhor desempenho, seguido, nessa ordem, pelos algoritmos: TP-KNN, TP-C4.5, TPRIPPER e TP-BayesNet. Essa ordem manteve-se a mesma para todas as medidas de avaliação utilizadas. Para o terceiro nível, as medidas, com exceção da TA convencional, mantiveram a mesma ordem apresentada para os dois primeiros niveis. Para a TA convencional houve uma troca entre as duas primeiras posições: o TP-KNN passou para a primeira posição e o TP-SVM para a segunda. Essa nova ordem (TP-KNN com o melhor desempenho e TP-SVM com o segundo melhor desempenho) foi obtida no quarto nível para a TA convencional, a TA baseada em distância e a $F$-measure hierárquica. Apenas a distância ponderada apresentou a mesma ordem entre as técnicas para todos os niveis.

Nesse conjunto houveram mais diferenças no ranking de desempenho preditivo dos algoritmos, quando são consideradas medidas diferentes. Além de diferenças no quarto nível, houve uma diferença entre as medidas no terceiro nível (no conjunto GPCR só houve uma diferença no quarto nível). Entretanto, observou-se por meio de análises estatísticas que a diferença entre o desempenho TP-KNN em relação ao TP-SVM, que são os algoritmos para os quais as mudanças na ordem de desempenho são observadas, não apresenta significância estatística.

Considerando as taxas de desempenho assumidas pelos algoritmos, podese observar que os algoritmos TP-KNN e TP-SVM apresentaram desempenho bem próximo entre si, com ligeiras diferenças. O mesmo aconteceu para os algoritmos TP-C4.5 e TP-RIPPER. Uma diferença um pouco maior separa o desempenho do algoritmo TP-BayesNet do desempenho dos demais algoritmos. Porém, análises estatísticas fornecem um parâmetro mais seguro do que apenas análise dos valores das taxas. Assim, os resultados das análises estatísticas feitas para os resultados dos algoritmos para o conjunto EC são 
resumidas no parágrafo seguinte.

Para todas as medidas, as análises estatísticas mostraram que as diferenças dos resultados dos algoritmos TP-KNN, TP-SVM, TP-C4.5 e TP-RIPPER em relação aos resultados do TP-BayesNet são estatisticamente significativas para todos os níveis. Além disso, o TP-KNN e o TP-RIPPER também apresentam diferenças estatísticas entre si para os resultados de todas as medidas nos quatro níveis. Os mesmo acontece entre os resultados do TP-SVM e TP-C4.5. Adicionalmente, diferenças estatisticamente significativas ocorreram entre os resultados do TP-KNN e TP-C4.5 no segundo nível para a TA convencional e no quarto nível para as outras três medidas.

Ao contrário dos resultados obtidos para o conjunto GPCR, os resultados para o conjunto EC apresentam melhor desempenho preditivo no terceiro nível do que no quarto nível, o que é esperado em classificações feitas de maneira Top-Down. Essa diferença de resultados entre os conjuntos ocorreu porque a hierarquia de enzimas é mais completa do que a hierarquia GPCR. Existem mais classes no quarto nível do que no terceiro nível. Dessa forma, o quarto nível no conjunto EC é mais afetado pela propagação de erros do que no conjunto GPCR.

Com relação ao estudo das medidas para os dois conjuntos, pode-se concluir que elas fazem considerações diferentes nos cálculos dos erros, fazendo com que os valores das taxas reportadas sejam mais altos ou mais baixos dependendo da flexibilidade da penalização dos tipos de erros possíveis. Porém, nos resultados dos experimentos realizados, embora a diferença de resultados entre os algoritmos tenha aumentado ou diminuído em alguns casos, a ordem de desempenho manteve-se a mesma, com algumas exceções. Nesses casos em que a ordem de desempenho foi modificada, as diferenças entre os resultados dos algoritmos que mudaram de posição não foram estatisticamente significativas. Entretanto, nas análises estatísticas dos resultados, as medidas apresentaram comportamentos diferentes para alguns casos. Algumas significâncias estatísticas foram detectadas entre resultados de um grupo de medidas e não foram por outro. Adicionalmente, para o conjunto GPCR, o desempenho preditivo no terceiro nível se aproximou do desempenho no quarto nível (em alguns casos ultrapassou) para as medidas TA baseada em distância, TA dependente da profundidade e $F$-measure hierárquica. Isso contrasta com os resultados reportados para esses dois níveis pela TA convencional, em que o desempenho do terceiro nível foi notavelmente inferior ao do quarto nível. 
Demonstração da lgualdade das Medidas no Primeiro Nível da Hierarquia

As duas taxas que apresentam uma fácil demonstração do porquê de seus valores serem iguais são a TA baseada em distância e a TA dependente da profundidade. Para essas duas medidas, primeiramente é obtida uma TE, para depois ser obtida a TA. Portanto, basta constatar que as TEs são iguais para que se demonstre porque as TAs são iguais. As duas medidas utilizam o cálculo da distância para calcular o erro de predição, com a diferença de que a medida que considera a profundidade usa pesos no cálculo da distância. No primeiro nível, o único erro possível é classificar o exemplo erroneamente em uma outra classe do primeiro nível. Logo, a distância entre a classe verdadeira e a classe predita, em caso de erro, será 1 para a distância convencional e 2P para a distância ponderada, em que $\mathrm{P}$ é o peso da ligação do nó-raiz a suas subclasses (classes do primeiro nível). Após o cálculo da distância, esse valor é normalizado, para as duas medidas, por meio da sua divisão pelo valor da maior distância possível entre uma classe verdadeira e a classe predita. No primeiro nível, a pior distância possível é a distância de uma classe no primeiro nível para outra classe do primeiro nível. Assim, a pior distância possível no caso da medida baseada em distância convencional será 2 , enquanto no caso da medida que utiliza que a distância ponderada será 2P. Dessa forma, no primeiro nível, a distância normalizada será 1 em caso de erro e 0 em caso de acerto para as duas medidas. Isso explica o motivo da igualdade dessas duas medidas.

A TA convencional pode ser obtida pelo complemento da TE convencional, assim como nas duas medidas que usam distância (convencional e ponderada). Assim, basta demonstrar que essa TE convencional é igual a TE para tais medidas. Como a TE é calculada pelo número de erros dividido pelo número de exemplos, pode-se afirmar que esse cálculo é igual a somar 1 sempre que houver um erro de classificação e depois dividir resultado final do somatório pelo número de exemplos, como ocorre, no primeiro nível, nas medidas que consideram a distância. Isso explica porque as três medidas que consideram a TA são idênticas no primeiro nível.

Por fim, o raciocínio a seguir demonstra porque a medida $F$-measure hierárquica, que é baseada no conceitos de classes ancestrais, é igual às demais medidas no primeiro nível da hierarquia. No primeiro nível, tanto a classe predita quanto a classe verdadeira só têm uma classe no conjunto de ancestrais, que é a própria classe. Assim, a classe predita e a classe verdadeira não têm nenhum ancestral em comum quando há um erro de classificação e têm um ancestral em comum quando não há um erro. Dessa forma, tanto o valor da sensibilidade hierárquica quanto da precisão hierárquica (ver Seção 
3.4.2) serão igual a 1 em caso de acerto e 0 em caso de erro. Aplicando os valores de precisão e sensibilidade na fórmula de $F$-measure (ver 2.5), obtémse um valor de $F$-measure, $\operatorname{com} \beta=1$, igual $1 \mathrm{em}$ caso de acerto e 0 em caso de erro. Para obter o valor final da F-measure hierárquica, soma-se o valor de $F$-measure para cada exemplo classificado e depois divide-se o valor resultante pelo número de exemplos. Isso é exatamente igual ao cálculo da TA convencional e, conseqüentemente, da TA baseada em distância e da TA dependente da profundidade.

\subsubsection{Selective Top-Down}

Nesta seção são apresentados os resultados do segundo estágio na condução dos experimentos. Foram realizados experimentos utilizando um algoritmo Selective Top-Down baseado nas mesmas técnicas utilizadas para a implementação dos algoritmos Top-Down convencionais: C4.5, RIPPER, BayesNet, SVMs e KNN. Para a implementação do procedimento seletivo do Selective Top-Down foi utilizado um conjunto de validação igual a $20 \%$ do conjunto de treinamento total. Cada uma das técnicas envolvidas nesse algoritmo foi utilizada da mesma maneira que nos algoritmos em que utilizada individualmente, considerando os mesmos parâmetros e os mesmos procedimentos para preparação dos dados.

Esses experimentos foram realizados com o intuito de comparar o desempenho preditivo do Selective Top-Down com os algoritmos Top-Down convencionais, em que cada técnica é utilizada individualmente em um algoritmo. Dessa forma, nas tabelas 5.10 e 5.11 são mostradas as TAs dependente da profundidade para os algoritmos Top-Down convencionais e para o algoritmo Selective Top-Down, obtidas para os conjuntos de dados GPCR e EC, respectivamente. Nessa tabelas são apresentados as TAs dos conjuntos de teste gerados pelo método 5-fold cross-validation e o desvio padrão para cada taxa. Ao contrário das tabelas apresentadas apresentadas na seção anterior, nessas tabelas não são apresentadas explicitamente informações da ordem de desempenho preditivo entre os algoritmos. Tais informações foram omitidas por limitação de espaço e pelo fato da ordem de desempenho se manter a mesma para todos os níveis dos dois conjuntos, facilitando assim a observação dessas informações pelo valores apresentados nas tabelas.

Como pode ser observado na Tabela 5.10, para o conjunto GPCR a ordem obtida de desempenho preditivo entre os algoritmos Top-Down convencionais, começando pelo algoritmo com maior desempenho, foi: TP-KNN, TP-C4.5, TPSVM, TP-RIPPER e TP-BayesNet (essa ordem é a mesma para todos os niveis). Além de obter um melhor desempenho entre os algoritmos com técnicas indi- 
Tabela 5.10: Desempenho dos 5 algoritmos Top-Down convencionais comparados ao desempenho do Selective Top-Down para o conjunto de dados GPCR, considerando a TA dependente da profundidade.

\begin{tabular}{|c|c|c|c|c|c|c|}
\cline { 2 - 7 } \multicolumn{1}{c|}{} & C4.5 & RIPPER & SVM & KNN & BayesNet & S. Top-Down \\
\hline N1 & $93.11(0.35)$ & $89.91(0.65)$ & $92.34(0.53)$ & $93.27(0.58)$ & $85.55(1.71)$ & $93.12(0.52)$ \\
\hline N2 & $91.05(0.47)$ & $86.84(0.70)$ & $89.97(0.62)$ & $91.32(0.67)$ & $82.09(1.62)$ & $91.12(0.68)$ \\
\hline N3 & $85.28(0.37)$ & $80.53(0.63)$ & $83.65(0.74)$ & $85.88(0.59)$ & $75.46(1.92)$ & $85.73(0.77)$ \\
\hline N4 & $85.48(1.91)$ & $75.36(2.11)$ & $85.11(1.90)$ & $86.30(1.54)$ & $68.47(3.46)$ & $86.01(1.58)$ \\
\hline
\end{tabular}

Tabela 5.11: Desempenho dos 5 algoritmos Top-Down convencionais comparados ao desempenho do Selective Top-Down para o conjunto de dados EC, considerando a TA dependente da profundidade.

\begin{tabular}{|c|c|c|c|c|c|c|}
\cline { 2 - 7 } \multicolumn{1}{c|}{} & C4.5 & RIPPER & SVM & KNN & BayesNet & S. Top-Down \\
\hline N1 & $98.56(0.36)$ & $98.09(0.44)$ & $99.96(0.09)$ & $99.83(0.14)$ & $94.44(0.39)$ & $99.96(0.09)$ \\
\hline N2 & $98.29(0.26)$ & $97.78(0.39)$ & $99.77(0.08)$ & $99.60(0.23)$ & $93.22(0.38)$ & $99.77(0.08)$ \\
\hline N3 & $98.10(0.27)$ & $97.58(0.38)$ & $99.58(0.11)$ & $99.45(0.24)$ & $92.58(0.40)$ & $99.59(0.12)$ \\
\hline N4 & $97.89(0.28)$ & $97.32(0.43)$ & $99.36(0.13)$ & $99.32(0.25)$ & $92.10(0.39)$ & $99.43(0.13)$ \\
\hline
\end{tabular}

viduais, o algoritmo TP-KNN também obteve um desempenho preditivo melhor do que o obtido pelo algoritmo Selective Top-Down. Com relação aos demais algoritmos Top-Down, o Selective Top-Down obteve um melhor desempenho preditivo para todos os niveis.

Embora possa-se imaginar que o Selective Top-Down sempre obtenha um melhor desempenho em relação a utilização das técnicas individuais, isso nem sempre é verdade. Embora em cada passo do algoritmo Selective Top-Down haja um procedimento seletivo para escolha da técnica com maior número de acertos nos conjunto de validação, é possível que uma técnica seja melhor no conjunto de validação, mas não o seja no conjunto de teste. Por esse motivo, os resultados obtidos para o Selective Top-Down não se mostraram melhores do que os obtidos para a utilização da técnica KNN individualmente.

Considerando as análises estatísticas realizadas para os resultados do conjunto GPCR, a diferença entre os resultados do Selective Top-Down e o TPKNN não foi considerada significativa em termos estatísticos. Os resultados do Selective Top-Down apresentaram-se estatisticamente melhores do que TPRIPPER e TP-BayesNet. Para os demais algoritmos Top-Down convencionais, as diferenças dos resultados em relação ao Selective Top-Down não apresentaram significância estatística.

Para o conjunto de dados EC (Tabela 5.11), a ordem obtida de desempenho preditivo entre os algoritmos Top-Down convencionais, começando pelo algoritmo com maior desempenho, foi: TP-SVM, TP-KNN, TP-C4.5, TP-RIPPER e TP-BayesNet (assim como para o conjunto GPCR, essa ordem é a mesma para 
todos os níveis). Nesse conjunto, o algoritmo Selective Top-Down apresenta melhores valores de desempenho preditivo quando comparado aos algoritmos com técnicas individuais. A exceção para essa observação se refere aos resultados dos dois primeiros níveis do TP-SVM, que apresentam os mesmos valores para TA que o Selective Top-Down. Além disso, para os demais níveis, os resultados obtidos para o Selective Top-Down e o TP-SVM são muito próximos. Esse fato sugere uma forte colaboração da técnica SVM na geração dos classificadores do Selective Top-Down.

Segundo as análises estatísticas para os resultados obtidos para o conjunto EC, o algoritmo Selective Top-Down se mostrou estatisticamente superior em termos de desempenho preditivo em relação ao TP-C4.5, TP-RIPPER e TP-BayesNet. As diferenças em relação ao TP-SVM e ao TP-KNN não apresentaram significância estatística nos testes realizados.

\subsubsection{Combinações Hierárquicas de Classificadores}

Nesta seção são apresentados os resultados do terceiro estágio na condução dos experimentos. Foram realizados experimentos com cinco algoritmos Ensemble Top-Down, que são algoritmos que implementam a combinação de classificadores na abordagem Top-Down. As técnicas de AM para geração dos diferentes classificadores foram as mesmas consideradas no processo seletivo do Selective Top-Down: C4.5, RIPPER, BayesNet, SVMs e KNN.

A diferença entre os algoritmos Ensemble Top-Down diz respeito a forma como foram combinadas as saídas dos diferentes classificadores. Dessa forma, as variações realizadas na combinação das saídas dos classificadores originou cinco algoritmos diferentes: Ensemble Top-Down com Votação por Maioria (EnsTPVotM), Ensemble Top-Down com Votação Ponderada (EnsTPVotP), Ensemble Top-Down com Votação Ponderada por Ranking (EnsTPVotR), Stack Ensemble Top-Down (StackEnsTP), e Stack Ensemble Top-Down com Procedimento Seletivo (StackEnsTPSel). Para maiores detalhes a respeito das características de cada uma dessas estratégias de combinação, consultar a Seção 3.3 .

Os resultados obtidos para os experimentos envolvendo os algoritmos Ensemble Top-Down para o conjunto GPCR são mostrados na Tabela 5.12. Nessa tabela, a taxa de acerto dependente da profundidade foi utilizada para reportar os resultados das predições. Além da média das TAs dos conjuntos de teste gerados pelo método 5-fold cross-validation, o desvio padrão para cada média é mostrado entre parênteses. A ordem de desempenho dos algoritmos é apresentada em uma tabela separada (Tabela 5.13).

Como pode ser observado nas tabelas de resultados apresentadas, os al- 
Tabela 5.12: Desempenho dos 5 algoritmos Ensemble Top-Down para o conjunto de dados GPCR, considerando a TA dependente da profundidade.

\begin{tabular}{|c|c|c|c|c|c|}
\cline { 2 - 6 } \multicolumn{1}{c|}{} & EnsTPVotM & EnsTPVotP & EnsTPVotR & StackEnsTP & StackEnsTPSel \\
\hline N1 & $93.06(0.66)$ & $92.62(0.51)$ & $93.54(0.37)$ & $93.61(0.61)$ & $93.61(0.58)$ \\
\hline N2 & $90.90(1.00)$ & $90.45(0.79)$ & $91.56(0.57)$ & $91.60(0.66)$ & $91.64(0.52)$ \\
\hline N3 & $85.07(1.09)$ & $84.68(0.59)$ & $85.94(0.33)$ & $86.03(0.56)$ & $86.02(0.62)$ \\
\hline N4 & $84.12(2.91)$ & $83.38(2.65)$ & $85.83(2.19)$ & $86.27(1.76)$ & $86.40(1.87)$ \\
\hline
\end{tabular}

Tabela 5.13: Ordem de desempenho preditivo entre os 5 algoritmos Ensemble Top-Down para o conjunto de dados GPCR.

\begin{tabular}{|c|c|c|c|c|c|}
\cline { 2 - 6 } \multicolumn{1}{c|}{} & EnsTPVotM & EnsTPVotP & EnsTPVotR & StackEnsTP & StackEnsTPSel \\
\hline N1 & R4 & R5 & R3 & R2* & R1* \\
\hline N2 & R4 & R5 & R3 & R2 & R1 \\
\hline N3 & R4 & R5 & R3 & R1 & R2 \\
\hline N4 & R4 & R5 & R3 & R2 & R1 \\
\hline
\end{tabular}

goritmos StackEnsTP e StackEnsTPSel se alternaram entre o melhor desempenho preditivo. O algoritmo StackEnsTP obteve melhor desempenho no segundo nível, enquanto que o algoritmo StackEnsTPSel obteve melhor desempenho nos terceiro e quarto níveis. No primeiro nível eles obtiveram exatamente a mesma TA, porém a primeira posição foi atribuída ao StackEnsTPSel por esse apresentar um menor desvio padrão. O sinal “*” foi colocado em R1 e R2 para destacar a ocorrência do empate entre os algoritmos e a realização do desempate por meio da análise do desvio padrão. Os algoritmos EnsTPVotR, EnsTPVotM e EnsTPVotP se mantiveram nas terceira, quarta e quinta posições, respectivamente, para todos os níveis.

Nas análises estatísticas realizadas para esses resultados, foi encontrada significância estatística apenas na diferença dos resultados obtidos pelos algoritmos EnsTPVotP e EnsTPVotR para os três primeiros niveis da hierarquia GPCR. Para os demais algoritmos não foi constatada significância estatística entre as diferenças de desempenho preditivo.

Assim como para o conjunto GPCR, os resultados obtidos para o conjunto EC por meio da realização dos experimentos envolvendo os algoritmos Ensemble Top-Down são mostrados em duas tabelas. Na Tabela 5.14, são mostrados as TAs médias e o desvio padrão para cada taxa. Na Tabela 5.15, é apresentada a ordem de desempenho preditivo dos algoritmos, com base nas informações da Tabela 5.14.

Como pode ser observado nas duas tabelas de resultados apresentadas para o conjunto EC, no primeiro nivel houveram dois empates: (1) um empate entre os algoritmos EnsTPVotR, StackEnsTP e StackEnsTPSel; e (2) um 
Tabela 5.14: Desempenho dos 5 algoritmos Ensemble Top-Down para o conjunto de dados EC, considerando a TA dependente da profundidade.

\begin{tabular}{|c|c|c|c|c|c|}
\cline { 2 - 6 } \multicolumn{1}{c|}{} & EnsTPVotM & EnsTPVotP & EnsTPVotR & StackEnsTP & StackEnsTPSel \\
\hline N1 & $99.69(0.13)$ & $99.69(0.13)$ & $99.96(0.09)$ & $99.96(0.09)$ & $99.96(0.09)$ \\
\hline N2 & $99.44(0.14)$ & $99.46(0.13)$ & $99.71(0.12)$ & $99.81(0.09)$ & $99.79(0.10)$ \\
\hline N3 & $99.28(0.17)$ & $99.30(0.16)$ & $99.55(0.16)$ & $99.66(0.12)$ & $99.64(0.15)$ \\
\hline N4 & $99.13(0.19)$ & $99.15(0.17)$ & $99.40(0.17)$ & $99.52(0.13)$ & $99.52(0.14)$ \\
\hline
\end{tabular}

Tabela 5.15: Ordem de desempenho preditivo entre os 5 algoritmos Ensemble Top-Down para o conjunto de dados EC.

\begin{tabular}{|c|c|c|c|c|c|}
\cline { 2 - 6 } \multicolumn{1}{c|}{} & EnsTPVotM & EnsTPVotP & EnsTPVotR & StackEnsTP & StackEnsTPSel \\
\hline N1 & R4-R5 & R4-R5 & R1-R3 & R1-R3 & R1-R3 \\
\hline N2 & R5 & R4 & R3 & R1 & R2 \\
\hline N3 & R5 & R4 & R3 & R1 & R2 \\
\hline N4 & R4 & R5 & R3 & R1* & R2* \\
\hline
\end{tabular}

empate entre os algoritmos EnsTPVotM e EnsTPVotP, que apresentaram um desempenho preditivo inferior em comparação aos outros três algoritmos. Nos empates, tanto as TAs quanto os desvios padrão se apresentaram iguais. Por esse motivo, adotou-se a notação "R1-R3" e "R4-R5” para indicar para quais posições houve o empate. "R1-R3" indica que houve empate para as primeira, segunda e terceira posições da ordem de desempenho preditivo entre os algoritmos.

Para os demais níveis, o algoritmo StackEnsTP apresentou o maior desempenho preditivo e o algoritmo StackEnsTPSel ocupou a segunda posição na ordem de desempenho. Entretanto, é importante destacar que, para o quarto nivel, houve um empate entre as TAs, como indicado pela notação "R1*" e "R2*”. Porém, a primeira posição foi atribuída ao algoritmo StackEnsTP, por esse ter apresentado um menor desvio padrão. Para o segundo e terceiro níveis, os algoritmos EnsTPVotR, EnsTPVotP e EnsTPVotM se mantiveram nas terceira, quarta e quinta posições, respectivamente. Para o quarto nível, os algoritmos EnsTPVotM e EnsTPVotP inverteram entre si as posições que ocuparam nos segundo e terceiro níveis.

De acordo com os testes estatísticos, o desempenho do algoritmo EnsTPVotM foi considerado estatisticamente inferior ao desempenho dos algoritmos StackEnsTP e StackEnsTPSel para o segundo e terceiro níveis. No quarto nível, a diferença de resultados entre os algoritmos EnsTPVotR e StackEnsTPSel foi considerada estatisticamente significativa.

Com o intuito de verificar a diversidade dos classificadores bases utilizados na geração dos modelos de classificação Ensemble Top-Down, no Apêndice B 
são descritos os resultados para a análise de diversidade para o algoritmo EnsTPVotM.

\subsubsection{Comparações de Diferentes Abordagens}

Por fim, foram realizados experimentos com um algoritmo baseado na abordagem Big-Bang denominado HC4.5 (Clare \& King, 2003). Os resultados obtidos foram comparados com alguns dos resultados obtidos para os algoritmos baseados na abordagem Top-Down. O objetivo desse estudo não foi apenas comparar as abordagens Big-Bang e Top-Down, mas sim comparar os resultados da abordagem Top-Down convencional e suas variações - Selective TopDown e Ensemble Top-Down - entre si e com a abordagem Big-Bang. A motivação principal foi a de analisar o comportamento das diferentes abordagens para os dois conjuntos envolvidos nos experimentos.

O HC4.5 foi desenvolvido originalmente para problemas hierárquicos e multilabel. Além disso, a predição também pode ser feita nos nós internos da hierarquia, ou seja, o algoritmo não possui predição obrigatória em nós-folha. Assim, alguns ajustes foram feitos na implementação original do algoritmo de forma que ele se adequasse às características dos algoritmos Top-Down implementados, que possuem predição obrigatória em nós-folha, e dos conjuntos de dados, que não são multilabel. As modificações consistiram em incluir as restrições de que a predição fosse feita apenas para os nós-folha e que apenas uma classe fosse predita para cada exemplo.

Os resultados dos algoritmos Top-Down utilizados nesse estudo comparativo foram selecionados de três algoritmos: um algoritmo baseado na abordagem Top-Down convencional, o algoritmo Selective Top-Down e um algoritmo Ensemble Top-Down. O critério de escolha de um dentre os algoritmos TopDown convencionais foi o de qual algoritmo apresentou o melhor resultado. $\mathrm{O}$ mesmo critério foi seguido para escolha de um dos algoritmos Ensemble TopDown. Assim, para cada conjunto de dados, foram selecionados os algoritmos com os melhores resultados.

Nas tabelas 5.16 e 5.17 são apresentados os resultados dos algoritmos paras as diferentes abordagens (ou variações de abordagem) para os conjuntos de dados GPCR e EC, respectivamente. Para o conjunto GPCR foram considerados os algoritmos HC4.5, TP-KNN, Selective Top-Down e StackEnsTPSel (Stack Ensemble Top-Down com Procedimento Seletivo). Para o conjunto EC foram considerados os algoritmos HC4.5, TP-SVM, Selective Top-Down e StackEnsTP (Stack Ensemble Top-Down). A diferença entre quais algoritmos Top-Down foram selecionados se deve à diferença de resultados entre os algoritmos para os conjuntos EC e GPCR (os algoritmos que apresentaram os 
melhores resultados diferiram de um conjunto para outro).

Além das informações referentes às TAs e ao desvio padrão para cada taxa, são fornecidas nas tabelas informações a respeito da ordem entre os algoritmos com respeito ao desempenho preditivo. A TA utilizada nesse estudo comparativo também foi a TA dependente da profundidade.

Tabela 5.16: Desempenho de algoritmos de diferentes abordagens para o conjunto de dados GPCR, considerando a TA dependente da profundidade.

\begin{tabular}{|c|c|c|c|c|}
\cline { 2 - 5 } \multicolumn{1}{c|}{} & KNN & S. Top-Down & StackEnsembleSel & HC4.5 \\
\hline N1 & $93.27(0.58)-$ R2 & $93.12(0.52)-$ R3 & $93.61(0.58)-$ R1 & $92.42(0.53)-$ R4 \\
\hline N2 & $91.32(0.67)-$ R2 & $91.12(0.68)-$ R3 & $91.64(0.52)-$ R1 & $87.66(0.47)-$ R4 \\
\hline N3 & $85.88(0.59)-$ R2 & $85.73(0.77)-$ R3 & $86.02(0.62)-$ R1 & $80.97(0.83)-$ R4 \\
\hline N4 & $86.30(1.54)-$ R2 & $86.01(1.58)-$ R3 & $86.40(1.87)-$ R1 & $81.84(1.64)-$ R4 \\
\hline
\end{tabular}

Tabela 5.17: Desempenho de algoritmos de diferentes abordagens para o conjunto de dados GPCR, considerando a TA dependente da profundidade.

\begin{tabular}{|l|c|c|c|c|}
\cline { 2 - 5 } \multicolumn{1}{c|}{} & SVM & S. Top-Down & StackEnsemble & HC4.5 \\
\hline N1 & $99.96(0.09)-($ R1-R3) & $99.96(0.09)-(\mathrm{R} 1-R 3)$ & $99.96(0.09)-(\mathrm{R} 1-\mathrm{R} 3)$ & $99.36(0.42)-\mathrm{R} 4$ \\
\hline N2 & $99.77(0.08)-(\mathrm{R} 2-\mathrm{R} 3)$ & $99.77(0.08)-(\mathrm{R} 2-\mathrm{R} 3)$ & $99.81(0.09)-\mathrm{R} 1$ & $98.98(0.52)-\mathrm{R} 4$ \\
\hline N3 & $99.58(0.11)-\mathrm{R} 3$ & $99.59(0.12)-\mathrm{R} 2$ & $99.66(0.12)-\mathrm{R} 1$ & $98.71(0.58)-\mathrm{R} 4$ \\
\hline N4 & $99.36(0.13)-\mathrm{R} 3$ & $99.43(0.13)-\mathrm{R} 2$ & $99.52(0.13)-\mathrm{R} 1$ & $98.63(0.55)-\mathrm{R} 4$ \\
\hline
\end{tabular}

Para o conjunto GPCR, a mesma ordem de desempenho se manteve para todos os níveis da hierarquia. O algoritmo StackEnsembleSel obteve a maior TA, seguido, nessa ordem, pelos algoritmos: TP-KNN, Selective Top-Down e HC4.5. Entretanto, foi detectada significância estatística apenas para a diferença de resultados do $\mathrm{HC} 4.5$ em relação aos demais algoritmos utilizados no estudo para os segundo e terceiro níveis da hierarquia. No primeiro e no quarto nível não foi detectada significância estatística na diferença de desempenho observada entre os algoritmos.

Para o conjunto EC, houve um empate entre os três algoritmos Top-Down quanto ao melhor desempenho no primeiro nível da hierarquia. Nesse nível, assim como nos demais, a quarta posição quanto ao desempenho preditivo ficou com o HC4.5. No segundo nível, o StackEnsemble apresentou o melhor desempenho preditivo e os algoritmos TP-SVM e Selective Top-Down continuaram empatados. Nos terceiro e quarto níveis, a ordem de desempenho entre os algoritmos foi a mesma: StackEnsemble, Selective Top-Down, TP-SVM e HC4.5.

Embora o HC4.5 tenha obtido o pior desempenho nos dois conjuntos, para o conjunto EC nenhum algoritmo se mostrou estatisticamente superior a ele. Isso ocorreu pelo fato de a diferença de resultados do HC4.5 em relação aos 
demais algoritmos ter apresentado um desvio padrão relativamente maior do que na comparação dos demais algoritmos entre si. Nos três últimos níveis da hierarquia, o StackEnsemble foi considerado estatisticamente superior em relação ao TP-SVM. Para o segundo nível, a diferença de desempenho entre o StackEnsemble e o Selective Top-Down apresentou significância estatística.

\subsection{Considerações Finais}

Neste capítulo, foram apresentados os estágios empregados na condução dos experimentos e as informações relevantes quanto a realização dos mesmos: conjuntos de dados utilizados - GPCR (conjunto com dados da família de proteínas G-Protein-Coupled Receptor) e EC (conjuntos com dados de enzimas), passos de pré-processamento dos dados, recursos de software utilizados para implementação dos algoritmos, medidas empregadas na avaliação do desempenho preditivo dos algoritmos e testes estatísticos empregados para análise dos resultados.

Inicialmente, foram realizados experimentos utilizando cinco algoritmos baseados na abordagem Top-Down convencional. As seguintes técnicas foram utilizadas: C4.5, RIPPER, BayesNet, SVMs e KNN. Para a avaliação dos algoritmos, foram utilizadas quatro medidas diferentes, com o intuito de analisar o comportamento de cada medida: TA convencional, TA baseada em distância, TA dependente da profundidade e $F$-measure hierárquica. Os resultados apresentaram ligeiras diferenças para as medidas no terceiro nível (no caso do conjunto EC) e quarto nível (para os dois conjuntos) da hierarquia de classes. Entretanto, no geral, para o conjunto GPCR, o algoritmo TP-KNN obteve o melhor resultado, enquanto que para o conjunto EC, o algoritmo TP-SVM obteve o melhor resultado.

Num segundo estágio da condução dos experimentos, investigou-se os resultados obtidos pelo algoritmo Selective Top-Down em comparação com os resultados obtidos pelos algoritmos baseados na abordagem Top-Down convencional. Na implementação do Selective Top-Down foram utilizadas as cinco técnicas envolvidas no estudo dos algoritmos Top-Down convencionais. Os resultados obtidos foram reportados por meio da TA dependente da profundidade. De acordo com os resultados, no geral, o Selective Top-Down apresentou melhoras no desempenho preditivo em relação à utilização das técnicas individualmente. Entretanto, para o conjunto GPCR, os resultados do algoritmo TP-KNN foram ligeiramente melhores do que os obtidos pelo Selective Top-Down para todos os níveis da hierarquia.

Num terceiro estágio, foram realizados experimentos com a variação proposta para a abordagem Top-Down: Ensemble Top-Down. Essa nova abor- 
dagem consiste em utilizar combinações de classificadores para a construção do modelo hierárquico de classificação. Foram utilizadas cinco estratégias para a combinação das saídas dos classificadores do modelo combinado, dando origem assim a cinco algoritmos diferentes: Ensemble Top-Down com Votação por Maioria (EnsTPVotM), Ensemble Top-Down com Votação Ponderada (EnsTPVotP), Ensemble Top-Down com Votação Ponderada por Ranking (EnsTPVotR), Stack Ensemble Top-Down (StackEnsTP), e Stack Ensemble TopDown com Procedimento Seletivo (StackEnsTPSel). Para o conjunto GPCR, o algoritmo StackEnsTPSel obteve melhor desempenho preditivo, enquanto que para o conjunto EC, o algoritmo StackEnsTP obteve um melhor desempenho. Porém, para os dois conjuntos de dados, os dois algoritmos obtiveram resultados bem próximos. Para a implementação de cada um dos algoritmos, foram utilizadas as mesmas cinco técnicas de AM adotadas para o SelectiveTop-Down e a avaliação dos resultados foi feita utilizando a TA dependente da profundidade.

Por fim, foi realizado um estudo comparativo entre algoritmos desenvolvidos a partir das diferentes abordagens envolvidas nos experimentos: TopDown convencional, Selective Top-Down e Ensemble Top-Down. Como foram desenvolvidos cinco algoritmos tanto para a abordagem Top-Down convencional como para o Ensemble Top-Down, para cada conjunto de dados foram selecionados o algoritmo Top-Down convencional e o algoritmo Ensemble TopDown com melhores resultados. Adicionalmente, foram utilizados no estudo resultados dos experimentos envolvendo um algoritmo Big-Bang denominado HC4.5. Assim como nos dois estágios anteriores, o resultados foram reportados utilizando a TA dependente da profundidade (as quatro medidas diferentes foram utilizadas apenas num primeiro estágio dos experimentos com o intuito de se analisar o comportamento das medidas). Para o conjunto GPCR, o algoritmo representante da abordagem Ensemble Top-Down - StackEnsTPSel obteve melhor desempenho preditivo para todos os níveis da hierarquia. Para o conjunto EC, o algoritmo representante da abordagem Ensemble Top-Down - StackEnsTP - obteve melhor desempenho preditivo para os três últimos níveis e se equiparou no primeiro nível aos resultados do algoritmo Selective Top-Down e do algoritmo TP-SVM (algoritmo representante da abordagem TopDown convencional para o conjunto EC).

Detalhes das análises estatísticas feitas para os resultados reportados neste capítulo podem ser verificados no Apêndice A. No próximo capítulo é apresentada a conclusão desta dissertação. 


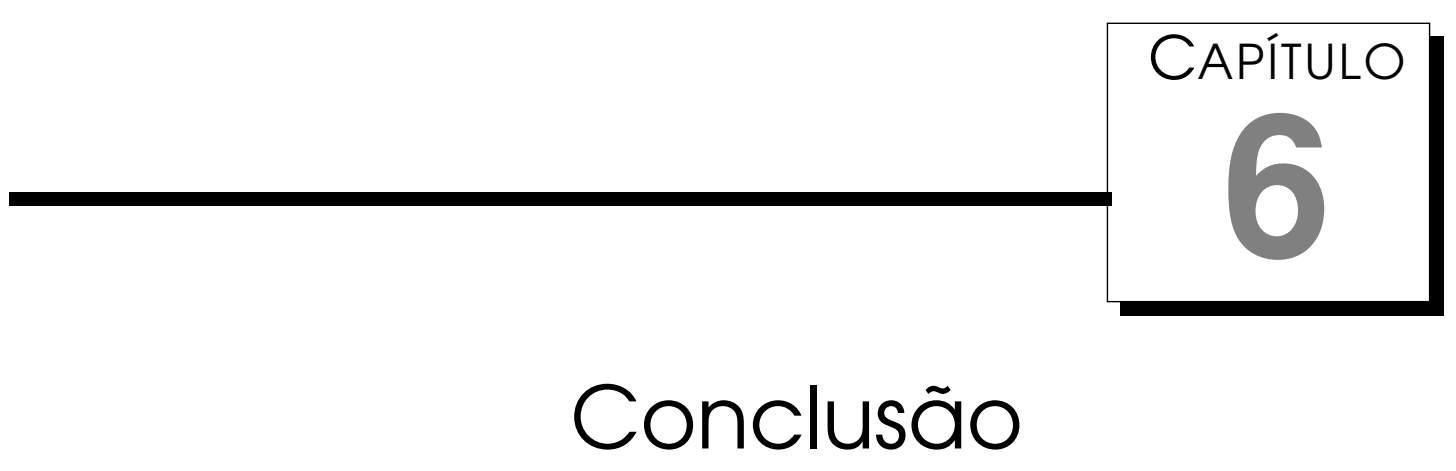

Esta dissertação apresentou um estudo sobre técnicas de classificação hierárquica, que consiste em um problema de classificação em que as classes envolvidas podem apresentar relacionamentos hierárquicos entre si, ou seja, relacionamentos entre classes e subclasses ou entre classes e superclasses. Problemas de classificação desse tipo são muito comuns na Biologia, nos quais muitos processos e elementos celulares podem ser caracterizados de maneira hierárquica. Por essa razão, foi selecionado um problema de Bioinformática para aplicação das técnicas investigadas. Mais especificante, métodos de classificação hierárquica foram utilizados para a classificação de proteínas.

Os métodos de classificação hierárquica podem ser agrupados basicamente em quatro tipos de abordagens: transformação do problema hierárquico em um problema de classificação plana, predição hierárquica utilizando algoritmos de classificação plana, classificação Top-Down e classificação Big-Bang. Desses quatro tipos, a abordagem Top-Down foi escolhida como base para a investigação e desenvolvimento dos métodos. Essa abordagem realiza a classificação em um processo passo a passo por meio da estratégia "Dividir para Conquistar". Isso permite que um algoritmo Top-Down seja desenvolvido com base em técnicas de classificação convencionais.

De modo a realizar um estudo comparativo entre diferentes algoritmos TopDown, foram desenvolvidos cinco algoritmos, cada um deles utilizando uma das seguintes técnicas de AM: C4.5, RIPPER, Redes Bayesianas, SVMs e KNN.

Além da abordagem Top-Down convencional, foram utilizadas duas variações dessa abordagem. A primeira, denominada de Selective Top-Down, foi proposta recentemente na literatura e emprega um mecanismo seletivo entre 
múltiplas técnicas de AM em cada passo do algoritmo Top-Down. Em um algoritmo Top-Down convencional, apenas uma técnica é utilizada para a geração dos classificadores que integram o modelo hierárquico de classificação. A segunda variação da abordagem Top-Down foi proposta no decorrer deste estudo e foi denominada de Ensemble Top-Down. Essa abordagem recebeu esse nome por empregar métodos de combinação de classificadores, também chamados de métodos de Ensemble, na geração do modelo de classificação.

Para a combinação de classificadores empregada pelos algoritmos baseados na abordagem Ensemble Top-Down, cinco estratégias foram utilizadas, dando origem assim a cinco algoritmos diferentes: Ensemble Top-Down com Votação por Maioria (EnsTPVotM), Ensemble Top-Down com Votação Ponderada (EnsTPVotP), Ensemble Top-Down com Votação Ponderada por Ranking (EnsTPVotR), Stack Ensemble Top-Down (StackEnsTP), e Stack Ensemble TopDown com Procedimento Seletivo (StackEnsTPSel)

Com o intuito de comparar os resultados dos algoritmos Top-Down com um algoritmo de uma outra abordagem, experimentos foram realizados com um algoritmo Big-Bang denominado HC4.5. Para que os resultados desse algoritmo pudessem ser comparados com os obtidos para os algoritmos TopDown, algumas modificações foram feitas no HC4.5.

Os experimentos realizados envolveram dois conjuntos de dados protéicos: o conjunto GPCR, que contém dados da família de proteínas G-Protein-Coupled Receptor (GPCR), e o conjunto EC, que contém dados de enzimas classificados de acordo com a nomenclatura provida pela Enzyme Comission.

Os resultados das predições foram avaliados de acordo com uma medida específica para problemas hierárquicos. Essa medida, denominada TA dependente da profundidade, é derivada da TA convencional e considera importantes aspectos hierárquicos na atribuição de penalizações aos erros de classificação.

Com o intuito de investigar o comportamento de diferentes medidas na avaliação de predições realizadas em um contexto hierárquico, parte dos resultados foram reportados por meio de mais três medidas de avaliação, além da TA dependente da profundidade: TA convencional, TA baseada em distância e F-measure hierárquica baseada em ancestrais.

Todas as comparações entre o desempenho preditivo dos algoritmos foram analisadas por meio de testes estatísticos, de modo a avaliar a significância estatística no caso em que os desempenhos se mostraram diferentes para os algoritmos envolvidos na comparação. O teste estatístico escolhido foi o $t$ de Student para dados pareados corrigido. Como foram realizadas comparações entre múltiplos algoritmos, o nível de significância dos testes estatísticos foi ajustado por meio da Correção de Bonferroni.

Este capítulo está organizado da seguinte forma: na Seção 6.1, é apre- 
sentado um resumo dos principais resultados obtidos experimentalmente; na Seção 6.2, são destacadas as contribuições deste estudo; por fim, possibilidades de trabalhos futuros são mencionadas na Seção 6.3.

\section{1 Principais Resultados}

Entre os algoritmos Top-Down convencionais, os algoritmos baseados nas técnicas KNN (TP-KNN), SVM (TP-SVM) e C4.5 (TP-C4.5) obtiveram os melhores resultados. Entre elas, pode-se destacar o algoritmo TP-KNN, que obteve o melhor desempenho preditivo para o conjunto GPCR, e o TP-SVM que obteve o melhor desempenho preditivo para o conjunto EC. Para nenhum dos dois conjuntos de dados foi encontrada significância estatística na diferença de desempenho preditivo entre esses dois algoritmos. Porém, deve-se destacar que o TP-KNN foi o único algoritmo Top-Down convencional que obteve um desempenho melhor do que o algoritmo Selective Top-Down. Isso ocorreu para o conjunto GPCR, embora a diferença de desempenho preditivo entre esses dois algoritmos não tenha sido considerada significativa pelos testes estatísticos. Para esse conjunto, o desempenho superior do Selective Top-Down em relação ao TP-SVM e TP-C4.5 também não foi considerado estatisticamente significativo. Para o conjunto EC, o Selective Top-Down superou em desempenho preditivo todos os algoritmos Top-Down convencionais, embora sem significância estatística para com o TP-KNN e o TP-SVM.

Com relação aos algoritmos Ensemble Top-Down, deve-se destacar os dois algoritmos que utilizaram um classificador para a combinação das saídas dos classificadores bases (generalização stack): StackEnsTP e StackEnsTPSel. Esses dois algoritmos alternaram-se entre o melhor e o segundo melhor desempenho nos dois conjuntos de dados. O algoritmo StackEnsTPSel obteve melhor desempenho preditivo para três niveis do conjunto GPCR: o primeiro, o segundo e o quarto nível. O StackEnsTP obteve o melhor desempenho no terceiro nível. Para o conjunto EC, o algoritmo StackEnsTP obteve o melhor desempenho nos três últimos níveis e se equiparou ao StackEnsTPSel no primeiro nível. Não foi encontrada significância estatística na diferença de desempenho preditivo entre esses dois algoritmos.

Na comparação entre algoritmos representantes das diversas abordagens, o algoritmo representante da abordagem Ensemble Top-Down, para cada conjunto de dados, obteve um desempenho preditivo superior aos dos demais algoritmos. Em contrapartida, o algoritmo HC4.5 (representante da abordagem Big-Bang) obteve o pior desempenho nos dois conjuntos. Nesse estudo comparativo, as seguintes significâncias estatísticas foram encontradas: na diferença de desempenho do HC4.5 em relação aos demais algoritmos nos três 
últimos níveis do conjunto GPCR; na diferença de desempenho entre o StackEnsTP (representante da abordagem Ensemble Top-Down para o conjunto EC) e o TP-SVM (representante da abordagem Top-Down convencional para o conjunto EC) nos três últimos níveis do conjunto EC; e na diferença entre de desempenho entre o StackEnsTP e o Selective Top-Down para o segundo nível do conjunto EC.

Com base nesses resultados, pode-de observar a melhora de desempenho dos StackEnsTP e StackEnsTPSel em relação aos demais algoritmos investigados. Entretanto, deve-se ressaltar também que em alguns casos essa diferença de desempenho não foi considerada significativa pelos testes estatísticos. Apesar disso, os resultados para a abordagem Ensemble Top-Down podem ser considerados promissores.

\subsection{Contribuições do Trabalho}

Uma das principais contribuições deste estudo foi a proposta da abordagem Ensemble Top-Down. Não se tem conhecimento de trabalhos prévios que utilizaram combinação de classificadores no contexto hierárquico. Além disso, os resultados apresentados para os algoritmos desenvolvidos para essa abordagem foram promissores. Para dois desses algoritmos - StackEnsTP e StackEnsTPSel - o desempenho preditivo foi superior aos demais algoritmos investigados.

Outra importante contribuição foi com relação à avaliação de classificadores hierárquicos. Além da pesquisa bibliográfica das principais medidas utilizadas em trabalhos de classificação hierárquica, que gerou uma publicação (Costa et al., 2007a), pode-se destacar a importância do estudo empírico entre as quatro medidas de avaliação utilizadas para avaliar parte dos experimentos reportados nesta dissertação. A definição de uma metodologia clara para a avaliação dos classificadores hierárquicos, incluindo os passos para a geração de uma matriz de confusão para cada nível da hierarquia, também pode ser destacada como uma contribuição.

Também foram feitas contribuições na área de Bioinformática, as quais foram relatadas por meio de uma publicação (Costa et al., 2007b). Nesse artigo, foram comparados vários algoritmos baseados em $\mathrm{ADs}$ com o intuito de mostrar a importância do uso de técnicas de classificação hierárquica para a predição de funções de proteínas.

Em uma menor escala, pode-se destacar a contribuição das modificações feitas no algoritmo HC4.5 (Clare \& King, 2003). Essas modificações foram feitas de modo que o algoritmo pudesse ser aplicado: a conjuntos de dados que não fossem multirótulos; e em problemas de predição obrigatória em nós- 
folha. Originalmente, o algoritmo HC4.5 foi desenvolvido para problemas de predição opcional em nós-folha e conjuntos de dados multirótulos.

As revisões bibliográficas também podem ser consideradas uma contribuição para o estudo de classificação hierárquica em AM. Além da revisão das medidas de avaliação específicas para esse contexto, pode-se destacar a análise dos principais modelos de classificação hierárquica desenvolvidos para problemas biológicos.

\subsection{Trabalhos Futuros}

Muitas direções podem ser apontadas como objeto de estudo para trabalhos futuros. Entre elas, pode-se destacar a investigação de métodos de classificação para problemas de predição opcional em nós-folha, em que o nivel de classificação mais profundo associado a cada exemplo de entrada seja automaticamente definido pelo sistema, sem a restrição de que os exemplos sejam sempre associados a classes representadas por nós-folha. Além disso, o desenvolvimento de métodos Big-Bang também apresenta grande potencial para pesquisa, embora o seu desenvolvimento seja mais complexo do que para métodos Top-Down.

Com relação à abordagem Top-Down, uma importante melhora que poderia ser feita é a correção dos erros propagados em conseqüência do mecanismo "passo a passo" empregado por essa abordagem para tratar problemas hierárquicos. O desenvolvimento de mecanismos de correção seria uma importante estratégia para amenizar os efeitos da propagação de erros, que é a principal deficiência dos métodos Top-Down. Isso poderia ser feito por meio da detecção, em cada passo, dos exemplos de entrada que foram previamente classificados de forma incorreta e posterior reclassificação desses. Mecanismos como esses naturalmente melhorariam o desempenho de predição dos modelos de classificação Top-Down.

A combinação de classificação hierárquica com classificação multirótulos também é um objeto de estudo promissor, principalmente quando aplicações biológicas estão envolvidas. Muitos problemas biológicos são intrinsecamente multirótulos, consistindo em um importante campo de pesquisa para a aplicação de métodos de classificação hierárquica multirótulos.

A avaliação de classificadores hierárquicos também apresenta boas oportunidades para estudos. Embora nesta dissertação um estudo tenha sido feito envolvendo quatro medidas de avaliação diferentes, muitas considerações adicionais poderiam ser feitas em um estudo com enfoque apenas para a avaliação em classificação hierárquica. Novas medidas de avaliação têm sido propostas nos últimos anos, o que leva naturalmente a uma necessidade 
de uma análise empírica dessas medidas, além de proporcionar espaço para a propostas de novas medidas com base nas deficiências das medidas propostas até o momento.

Por fim, uma outra direção de pesquisa consiste na análise de diversidade de classificadores em métodos de ensemble e no uso de informações extraídas por meio dessa análise para a construção de modelos Ensemble Top-Down. Um estudo inicial de análise de diversidade para os classificadores bases induzidos pelo algoritmo EnsTPVotM é apresentado no Apêndice B. 


\section{Referências Bibliográficas}

Apweiler, R., Attwood, T., Bairoch, A., Bateman, A., Birney, E., Biswas, M., Bucher, P., Cerutti, L., Corpet, F., Croning, M., et al. (2001). The InterPro database, an integrated documentation resource for protein families, domains and functional sites. Nucleic Acids Research, 29(1):37-40. Citado na página 90.

Apweiler, R., Bairoch, A., Wu, C. H., Barker, W. C., Boeckmann, B., Ferro, S., Gasteiger, E., Huang, H., Lopez, R., Magrane, M., et al. (2004). UniProt: the Universal Protein knowledgebase. Nucleic Acids Research, 32:D115-D1 19. Citado na página 90.

Barutcuoglu, Z., Schapire, R. E., \& Troyanskaya, O. G. (2006). Hierarchical multi-label prediction of gene function. Bioinformatics, 22(7):830-836. Citado nas páginas $72,73,74,75,76,79,83,84$, e 87.

Benson, D., Karsch-Mizrachi, I., Lipman, D., Ostell, J., \& Wheeler, D. (2007). GenBank. Nucleic Acids Research, 35(Database issue):D21-D25. Citado na página 1 .

Bernstein, F. C., Koetzle, T. F., Williams, G. J., Meyer, E. F., Brice, M. D., Rodgers, J. R., Kennard, O., Shimanouchi, T., \& Tasumi, M. (1977). The Protein Data Bank. A computer-based archival file for macromolecular structures. FEBS Journal, 80(2):319-324. Citado na página 75.

Blake, J. (2003). Gene Ontology(GO) Tutorial "http://www. geneontology • org/teaching_resources/tutorials/2003_MBL_jblake.pdf". [Online; accessed April 07, 2006]. Citado na página 4.

Blockeel, H., Bruynooghe, M., Dzeroski, S., Ramon, J., \& Struyf, J. (2002). Hierarchical multi-classification. In Proceedings of the ACM SIGKDD 2002 Workshop on Multi-Relational Data Mining (MRDM 2002), p. 21-35. Citado nas páginas $61,72,73,74,75,81,82,84,86$, e 87 . 
Blockeel, H., Raedt, L. D., \& Ramon, J. (1998). Top-down induction of clustering trees. In Proceedings of the Fifteenth International Conference on $\mathrm{Ma}$ chine Learning, p. 55-63. Citado na página 83.

Blockeel, H., Schietgat, L., Struyf, J., Dzeroski, S., \& Clare, A. (2006). Decision trees for hierarchical multilabel classification: A case study in functional genomics. In Knowledge Discovery in Databases:PKDD 2006, 10th European Conference on Principles and Practice of Knowledge Discovery in Databases, Proceedings, volume 4213 of Lecture Notes in Artificial Intelligence, p. 18-29. Springer. URL: http://www.cs.kuleuven.ac.be/cgi-bindtai/publ_info.pl?id=42302. Citado nas páginas 86 e 87.

Breiman, L. (1996). Bagging Predictors. Machine Learning, 24(2):123-140. Citado na página 24.

Breiman, L. (2001). Random Forests. Machine Learning, 45(1):5-32. Citado na página 24.

Cai, L. \& Hofmann, T. (2004). Hierarchical document categorization with support vector machines. In Proceedings of the Thirteenth ACM conference on Information and knowledge management, p. 78-87. Citado na página 67.

Carvalho, A. C. P. L. F., Delben, A., Simões, E. V., Telles, G., \& Romero, R. (2004). Computação Bioinspirada. Anais do CSBC'2004. Citado na página 2.

Cesa-Bianchi, N., Gentile, C., \& Zaniboni, L. (2006). Hierarchical classification: combining Bayes with SVM. In Proceedings of the 23rd international conference on Machine learning, p. 177-184. ACM Press New York, NY, USA. Citado na página 67.

Cestnik, B. \& Bratko, I. (1991). On estimating probabilities in tree pruning. Springer-Verlag New York, Inc. New York, NY, USA. Citado na página 85.

Chen, P., Lin, C., \& Schoelkopf, B. (2005). A tutorial on $\nu$-support vector machines. Applied Stochastic Models in Business and Industry, 21(2):111-136. Citado na página 19.

Clare, A. \& King, R. D. (2001). Knowledge Discovery in Multi-label Phenotype Data. In Proceedings of the 5th European Conference on Principles of Data Mining and Knowledge Discovery, volume 2168 of Lecture Notes in Computer Science, p. 42-53. Springer. Citado nas páginas 72, 73, 74, 75, 76, 83, 84, e 87. 
Clare, A. \& King, R. D. (2003). Predicting gene function in Saccharomyces cerevisiae. Bioinformatics, 19(90002):42-49. Citado nas páginas 5, 43, 72, $73,74,75,81,84,86,87,112$, e 120.

Clark, P. \& Boswell, R. (1991). Rule induction with CN2: Some recent improvements. In Proceedings of the Fifth European Working Session on Learning, volume 482, p. 151-163. Citado na página 83.

Cohen, W. (1995). Fast effective rule induction. Proceedings of the Twelfth International Conference on Machine Learning, p. 115-123. Citado nas páginas 5 e 17.

Costa, E. P., Lorena, A. C., Carvalho, A. P. L. F., \& Freitas, A. A. (2007a). A review of Performance Evaluation Measures for Hierarchical Classifiers. In Proceedings of the AAAIO7 - Workshop on Evalution Methods for Machine Learning II, p. 1-6. AAI Press. Citado na página 120.

Costa, E. P., Lorena, A. C., Carvalho, A. P. L. F., Freitas, A. A., \& Holden, N. (2007b). Comparing Several Approaches for Hierarchical Classification of Proteins with Decision Trees. In LNBI 4643 - Proceedings of Second Brazilian Symposium on Bioinformatics, p. 126-137. Springer. Citado na página 120.

Cover, T. \& Hart, P. (1967). Nearest neighbor pattern classification. Information Theory, IEEE Transactions on, 13(1):21-27. Citado nas páginas 5, 22, e 80.

Cristianini, N. \& Shawe-Taylor, J. (2000). An Introduction to Support Vector Machines and other kernel-based learning methods. Cambridge University Press. Citado nas páginas 5 e 18.

Demsar, J. (2006). Statistical comparisons of classifiers over multiple data sets. Journal of Machine Learning Research, 7(1):1-30. Citado nas páginas 97 e 133.

Dietterich, T. (2000). Ensemble methods in machine learning. Lecture Notes in Computer Science, 1857:1-15. Citado na página 23.

Dietterich, T. \& Bakiri, G. (1991). Error-correcting output codes: A general method for improving multiclass inductive learning programs. Proceedings of the Ninth National Conference on Artificial Intelligence (AAAI-91), p. 572577. Citado na página 25.

Dimitriadou, E., Hornik, K., Leisch, F., Meyer, D., \& Weingessel, A. (2006). e1071: Misc Functions of the Department of Statistics (e1071). TU Wien, p. 1-5. Citado na página 95. 
Eisner, R., Poulin, B., Szafron, D., Lu, P., \& Greiner, R. (2005). Improving Protein Function Prediction using the Hierarchical Structure of the Gene Ontology. In Proceedings of the 2005 IEEE Symposium on Computational Intelligence in Bioinformatics and Computational Biology - CIBCB'05, p. 110. Citado na página 67.

Fawcett, T. (2004). ROC Graphs: Notes and Practical Considerations for Researchers. Machine Learning, 31. Citado na página 31.

Filmore, D. (2004). It's a GPCR world. Modern drug discovery, 1(17):24-28. Citado na página 92.

Frank, E. \& Witten, I. (1998). Generating accurate rule sets without global optimization. Proc. 15th International Conf. on Machine Learning, p. 144151. Citado na página 80.

Freitas, A. A. \& Carvalho, A. C. P. F. (2007). A Tutorial on Hierarchical Classification with Applications in Bioinformatics, volume 1, p. 176-209. Idea Group. Citado nas páginas $1,35,36,37,38,65,67,77,80$, e 82.

Freund, Y. \& Schapire, R. (1999). A short introduction to boosting. Journal of Japanese Society for Artificial Intelligence, 14(5):771-780. Citado na página 24.

Friedman, N., Geiger, D., \& Goldszmidt, M. (1997). Bayesian Network Classifiers. Machine Learning, 29(2):131-163. Citado nas páginas 5, 18, e 80.

GPCRDB (2006). Information system for G protein-coupled receptors (GPCR) "http://www.gpcr.org/7tm/". [Online; accessed July-2006]. Citado nas páginas 72 e 90.

Haykin, S. (1999a). Neural networks. Prentice Hall Upper Saddle River, NJ. Citado na página 14.

Haykin, S. (1999b). Neural Networks-a comprehensive foundation, volume 2. Printice Hall, New Jersey, USA. Citado na página 80.

Holden, N. \& Freitas, A. A. (2005). A hybrid particle swarm/ant colony algorithm for the classification of hierarchical biological data. In Swarm Intelligence Symposium, 2005 Proceedings 2005 IEEE, p. 100-107. Citado nas páginas $6,72,73,74,75,79,80,84,85,86,87$, e 90.

Holden, N. \& Freitas, A. A. (2006). Hierarchical Classification of G-ProteinCoupled Receptors with PSO/ACO Algorithm. In Swarm Intelligence Symposium, 2006. Proceedings 2006 IEEE, p. 77-84. Citado nas páginas 6, 61, $64,72,73,74,75,79,80,84,85,86,87,90$, e 96. 
Hornik, K., Zeileis, A., Hothorn, T., \& Buchta, C. (2007). RWeka: An R Interface to Weka "http://CRAN.R-project.org". [Online; accessed July2006]. Citado na página 95.

Ipeirotis, P., Gravano, L., \& Sahami, M. (2001). Probe, count, and classify: categorizing hidden web databases. In Proceedings of the 2001 ACM SIGMOD international conference on Management of data, p. 67-78. ACM Press New York, NY, USA. Citado na página 65.

Iyer, V., Eisen, M., Ross, D., Schuler, G., Moore, T., Lee, J., Trent, J., Staudt, L., Hudson Jr., J., Boguski, M., Lashkari, D., Shalon, D., Botstein, D., \& Brown, P. (1999). The Transcriptional Program in the Response of Human Fibroblasts to Serum. Science, 283(5398):83-87. Citado na página 77.

Jensen, L. J., Gupta, R., Blom, N., Devos, D., Tamames, J., Kesmir, C., Nielsen, H., Stærfeldt, H. H., Rapacki, K., Workman, C., Andersen, C. A. F., Knudsen, S., Krogh, A., Valencia, A., \& Brunak, S. (2002). Prediction of human protein function from post-translational modifications and localization features. Journal of Molecular Biology, 319(5):1257-1265. Citado nas páginas $72,73,75,76,83,84,86$, e 87.

Jensen, L. J., Gupta, R., Stærfeldt, H. H., \& Brunak, S. (2003). Prediction of human protein function according to Gene Ontology categories. Bioinformatics, 19(5):635-642. Citado nas páginas 72, 73, 74, 75, 76, 78, 83, 84, e 87 .

Keerthi, S., Shevade, S., Bhattacharyya, C., \& Murthy, K. (2001). Improvements to Platt's SMO Algorithm for SVM Classifier Design. Neural Computation, 13(3):637-649. Citado na página 80.

King, R., Karwath, A., Clare, A., \& Dephaspe, L. (2000). Genome scale prediction of protein functional class from sequence using data mining. Proceedings of the sixth ACM SIGKDD international conference on Knowledge discovery and data mining, p. 384-389. Citado nas páginas 81 e 82 .

Kiritchenko, S., Matwin, S., \& Famili, A. (2004). Hierarchical Text Categorization as a Tool of Associating Genes with Gene Ontology Codes. In Proceedings of the 2nd European Workshop on Data Mining and Text Mining for Bioinformatics, p. 26-30. Citado nas páginas 66 e 67.

Kohavi, R. (1996). Scaling up the accuracy of Naive-Bayes classifiers: a decision-tree hybrid. In Proceedings of the Second International Conference on Knowledge Discovery and Data Mining, p. 202-207. Citado na página 80. 
Kolodner, J. (1993). Case-based reasoning. Morgan Kaufmann Publishers Inc. San Francisco, CA, USA. Citado na página 22.

Kuncheva, L. (2004). Combining Pattern Classifiers: Methods and Algorithms. Wiley-Interscience. Citado nas páginas 23, 25, e 26.

Kuncheva, L. \& Whitaker, C. (2003). Measures of Diversity in Classifier Ensembles and Their Relationship with the Ensemble Accuracy. Machine Learning, 51(2):181-207. Citado nas páginas 26 e 152.

Laegreid, A., Hvidsten, T. R., Midelfart, H., Komorowski, J., \& Sandvik, A. K. (2003). Predicting Gene Ontology Biological Process From Temporal Gene Expression Patterns. Genome Research, 13(5):965-979. Citado nas páginas $72,73,74,75,76,77,78,79,83,84$, e 87.

Lord, P., Stevens, R., Brass, A., \& Goble, C. (2003). Investigating semantic similarity measures across the Gene Ontology: the relationship between sequence and annotation. Bioinformatics, 19(10):1275-1283. Citado nas páginas 62 e 67.

Lorena, A. C. (2006). Investigação de Estratégias para a Geração de Máquinas de Vetores de Suporte Multiclasses. Tese de Doutorado, Instituto de Ciências Matemáticas e de Computação, Universidade de São Paulo, São Carlos, Brasil. Disponivel em : http://www.teses.usp.br/teses/disponiveis/ 55/55134/t de-26052006-111406/. Citado na página 19.

Meidanis, J. \& Setúbal, J. C. (1997). Introduction to Computacional Molecular Biology. PWS Publishing Company. Citado na página 1.

Mewes, H., Hani, J., Pfeiffer, F., \& Frishman, D. (1999). MIPS: a database for protein sequences and complete genomes. Nucleic Acids Research, 26(1):3337. Citado na página 73.

Mitchell, M. (1996). An Introduction to Genetic Algorithms. Mit Press. Citado na página 77 .

Mitchell, T. M. (1997). Machine Learning. McGraw-Hill Higher Education. Citado nas páginas $10,16,17,18,80$, e 97.

Monard, M. C. \& Baranauskas, J. A. (2003). Conceitos sobre Aprendizado de Máquina, Capítulo 4 In Solange Oliveira Rezende. Sistemas Inteligentes: Fundamentos e Aplicações. Citado nas páginas 11, 12, 14, 16, e 29.

Muggleton, S. (1999). Inductive Logic Programming. In The MIT Encyclopedia of the Cognitive Sciences (MITECS). MIT Press. Citado na página 81 . 
Nadeau, C. \& Bengio, Y. (2003). Inference for the Generalization Error. Machine Learning, 52(3):239-281. Citado na página 98.

Nomenclature, E. (1972). of the IUPAC-IUB. American Elsevier Pub. Co., New York, NY, p. 104. Citado nas páginas 3 e 90.

Parpinelli, R. S., Lopes, H. S., \& Freitas, A. A. (2002). Data mining with an ant colony optimization algorithm. IEEE Transactions on Evolutionary Computation, 6(4):321-332. Citado na página 79.

Pawlak, Z. (1992). Rough Sets: Theoretical Aspects of Reasoning about Data. Kluwer Academic Publishers Norwell, MA, USA. Citado na página 77.

Poulin, B. (2004). Sequenced-based protein function prediction. Dissertação de Mestrado, Department of Computing Science, University of Alberta, Edmonton, Alberta, Canada. Citado na página 67.

Quinlan, J. R. (1986). Induction of decision trees. Machine Learning, 1(1):81106. Citado nas páginas 11 e 16.

Quinlan, J. R. (1993). C4.5: Programs for Machine Learning. Morgan Kaufmann. Citado nas páginas 5, 16, 76, e 80 .

Riley, M. (1993). Functions of the gene products of Escherichia coli. Microbiology and Molecular Biology Reviews, 57(4):862-952. Citado na página 72.

Secker, A., Davies, M. N., Freitas, A. A., Timmis, J., Mendao, M., \& Flower, D. R. (2007). An experimental comparison of classification algorithms for the hierarchical prediction of protein function. In Freitas, A. A., editor, 3rd UK Data mining and Knowledge Discovery Symposium (UKKDD 2007), p. 13-18. Citado nas páginas $5,41,72,73,74,75,79,80,84,86$, e 87.

Sokolova, M., Japkowicz, N., \& Szpakowicz, S. (2006). Beyond Accuracy, Fscore and ROC: a Family of Discriminant Measures for Performance Evaluation. Proceedings of the 19th ACS Australian Joint Conference on Artificial Intelligence (AI-2006), p. 1015-1021. Citado na página 29.

Sousa, T., Silva, A., \& Neves, A. (2004). Particle swarm based Data Mining Algorithms for classification tasks. Parallel Computing, 30(5-6):767-783. Citado na página 79 .

Sun, A. \& Lim, E. P. (2001). Hierarchical text classification and evaluation. In Proceedings of the 2001 IEEE International Conference on Data Mining, p. 521-528. IEEE Computer Society Washington, DC, USA. Citado nas páginas 59, 64, e 71 . 
Sun, A., Lim, E. P., \& Ng, W. K. (2003a). Hierarchical text classification methods and their specification. Cooperative Internet Computing, p. 236256. Citado na página 71 .

Sun, A., Lim, E. P., \& Ng, W. K. (2003b). Performance measurement framework for hierarchical text classification. Journal of the American Society for Information Science and Technology, 54(11):1014-1028. Citado na página 71.

Tan, P., Steinbach, M., \& Kumar, V. (2005). Introduction to Data Mining. Addison-Wesley Longman Publishing Co., Inc. Boston, MA, USA. Citado nas páginas 21 e 23.

Tu, K., Yu, H., Guo, Z., \& Li, X. (2004). Learnability-based further prediction of gene functions in Gene Ontology. Genomics, 84(6):922-928. Citado nas páginas $72,73,74,75,76,78,79,84,85$, e 87 .

Vapnik, V. N. (1995). The nature of Statistical learning theory. Springer-Verlag, New York. Citado na página 18.

Venables, W. N., Smith, D. M., \& the R Development Core Team (2006). An introduction to $\mathrm{R}$ - version 2.4.1, http://cran.r-project.org/doc/ manuals/R-intro.pdf. [Online; accessed August-2006]. Citado na página 95.

Verspoor, K., Cohn, J., Mniszewski, S., \& Joslyn, C. (2006). A categorization approach to automated ontological function annotation. Protein Science, 15(6):1544-1549. Citado nas páginas 66 e 67.

Wang, K., Zhou, S., \& He, Y. (2001). Hierarchical classification of real life documents. In Proceedings of the 1st (SIAM) International Conference on Data Mining, p. 1-16. Citado na página 67.

Wang, K., Zhou, S., \& Liew, S. (1999). Building hierarchical classifiers using class proximity. In Proceedings of the 25th International Conference on Very Large Data Bases, p. 363-374. Citado na página 59.

Watkins, A., Timmis, J., \& Boggess, L. (2004). Artificial immune recognition system (AIRS): An immune-inspired supervised machine learning algorithm. Genetic Programming and Evolvable Machines, 5(3):291-317. Citado na página 80.

Weinert, W. R. \& Lopes, H. S. (2004). Neural networks for protein classification. Applied Bioinformatics, 3(1):41-48. Citado nas páginas 72, 73, 75, 83, 84,86 , e 87. 
Wilcoxon, F. (1945). Individual Comparisons by Ranking Methods. Biometrics Bulletin, 1(6):80-83. Citado na página 97.

Witten, I., Frank, E., Trigg, L., Hall, M., Holmes, G., \& Cunningham, S. (1999). Weka: Practical Machine Learning Tools and Techniques with Java Implementations. ICONIP/ANZIIS/ANNES, p. 192-196. Citado na página 95.

Witten, I. H. \& Frank, E. (2000). Data Mining - practical machine learning tools and techniques with Java implementations. Morgan Kauffmann Publishers. Citado na página 67.

Wu, H., Su, Z., Mao, F., Olman, V., \& Xu, Y. (2005). Prediction of functional modules based on comparative genome analysis and Gene Ontology application. Nucleic Acids Research, 33(9):2822-2837. Citado na página 67. 
Referências Bibliográficas 


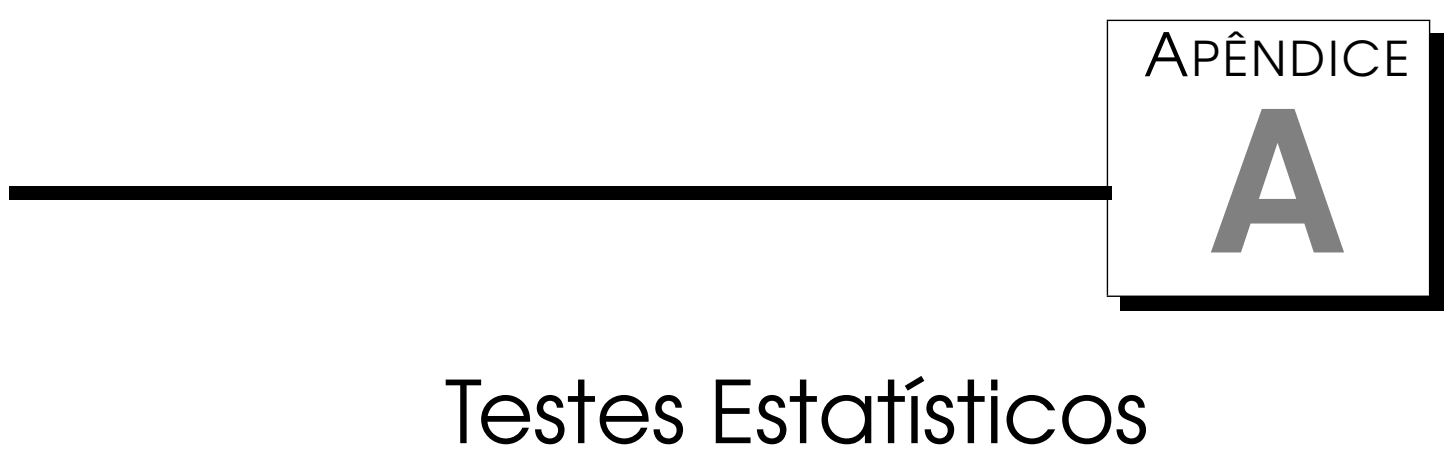

Neste apêndice, são descritos os testes estatísticos realizados para os resultados obtidos para os experimentos descritos no Capítulo 5. Essa análise estatística foi feita com o intuito de verificar a significância estatística na comparação do desempenho preditivo dos modelos de classificação.

O teste estatístico escolhido foi o t de Student para dados pareados corrigido, que consiste em calcular a diferença entre os resultados de dois classificadores para vários conjuntos de teste, de modo a verificar se a média da diferença entre eles é estatisticamente diferente de 0 (Demsar, 2006).

Como todas as comparações realizadas no Capítulo 5 envolvem múltiplos algoritmos, foram feitos ajustes no nível de significância do teste estatístico para cada estudo comparativo. Esse ajuste foi feito por meio da Correção de Bonferroni, que consiste em determinar um novo nível de significância $\left(\alpha^{*}\right)$ com base no nível de significância original $(\alpha)$ e no número de comparações empregadas. Para todos os testes o nível de significância foi determinado originalmente como $5 \%(\alpha=0.05)$.

Os resultados dos testes estatísticos estão divididos em quatro seções, que correspondem aos quatro estágios empregados na condução dos experimentos: (1) comparações entre os algoritmos Top-Down convencionais; (2) comparação do algoritmo Selective Top-Down com os algoritmos Top-Down convencionais; (3) comparações entre os algoritmos Ensemble Top-Down; e (4) comparações entre várias abordagens. Os resultados dos testes estatísticos para esses estudos comparativos são mostrados, nessa ordem, nas seções A.1, A.2, A. 3 e A. 4 .

Em cada uma dessas seções, são mostrados os resultados dos testes esta- 
tísticos para os dois conjuntos de dados utilizados nos experimentos: conjunto GPCR e conjunto EC. Adicionalmente, para cada conjunto de dados, os testes estatísticos são feitos nível a nível.

Como no estudo comparativo realizado para os algoritmos Top-Down convencionais foram utilizadas quatro medidas de avaliação - TA convencional, TA baseada em distância, TA dependente da profundidade e F-measure hierárquica, testes estatísticos foram realizados para as taxas de desempenho reportadas por meio de cada uma dessas medidas. Nos demais estudos comparativos, a medida de avaliação utilizada foi a TA dependente da profundidade.

De modo a facilitar o entendimento da análise estatística realizada em cada estudo comparativo, os resultados dos testes são mostrados em forma de tabelas. Para isso, foram utilizados os símbolos mostrados na Tabela A. 1. Para cada célula das tabelas de resultados, os símbolos indicam uma relação dos resultados do algoritmo representado pela linha para com os resultados do algoritmo representado na coluna. É importante observar que são mostradas apenas informações para as células localizadas na parte superior à diagonal principal da tabela (matriz triangular superior). As informações para a parte inferior da tabela podem ser obtidas pelo complemento da parte superior.

Tabela A. 1: Legenda para as tabelas com os resultados dos testes estatísticos.

\begin{tabular}{|c|l|}
\hline Símbolo & \multicolumn{1}{c|}{ Significado } \\
\hline$\Delta$ & $\begin{array}{l}\text { Indica que o algoritmo representado na linha da tabela ob- } \\
\text { teve resultados estatisticamente melhores do que o algo- } \\
\text { ritmo representado pela coluna da tabela }\end{array}$ \\
\hline$\Delta$ & $\begin{array}{l}\text { Indica que o algoritmo representado na linha da tabela ob- } \\
\text { teve resultados melhores do que o algoritmo representado } \\
\text { pela coluna da tabela, mas a diferença dos resultados não } \\
\text { é estatisticamente significativa }\end{array}$ \\
\hline$\square$ & $\begin{array}{l}\text { Indica que o algoritmo representado na linha da tabela ob- } \\
\text { teve exatamente os mesmos resultados obtidos pelo algo- } \\
\text { ritmo representado pela coluna da tabela }\end{array}$ \\
\hline$\nabla$ & $\begin{array}{l}\text { Indica que o algoritmo representado na linha da tabela } \\
\text { obteve resultados piores do que o algoritmo representado } \\
\text { pela coluna da tabela, mas a diferença dos resultados não } \\
\text { é estatisticamente significativa }\end{array}$ \\
\hline$\nabla$ & $\begin{array}{l}\text { Indica que o algoritmo representado na linha da tabela ob- } \\
\text { teve resultados estatisticamente piores do que o algoritmo } \\
\text { representado pela coluna da tabela }\end{array}$ \\
\hline
\end{tabular}




\section{A. 1 Algoritmos Top-Down Convencionais}

Nesta seção, são apresentados os resultados do testes estatísticos para os algoritmos Top-Down convencionais. Foram implementados 5 algoritmos Top-Down, cada um deles baseado em uma das seguintes técnicas: C4.5, RIPPER, Redes Bayesianas (BayesNet), SVMs e KNN. Como esses algoritmos são comparados dois a dois, foram realizadas dez comparações para cada conjunto de dados. Depois da aplicação da Correção de Bonferroni, o nível de significância foi ajustado para $0.5 \%\left(\alpha^{*}=0.005\right)$.

Por questões de simplificação, uma nomenclatura específica foi utilizada para referenciar os algoritmos Top-Down convencionais no texto e nas tabelas. No texto, a seguinte regra de nomenclatura foi utilizada: TP- $<$ Nome da Técnica>. Dessa forma, o algoritmo Top-Down convencional baseado na técnica C4.5 é referenciado no texto como TP-C4.5, por exemplo. Nas tabelas, os algoritmos são referidos apenas pelo nome da técnica empregada em sua implementação. Por exemplo, o TP-C4.5 é identificado apenas como C4.5 nas tabelas de resultados.

\section{Análise dos Resultados do Conjunto GPCR}

Para o primeiro nível do conjunto GPCR, uma mesma taxa de desempenho é reportada para todas as medidas utilizadas (uma discussão a respeito dessa igualdade é feita no final da Seção 5.3.1). Dessa forma, o resultado das análises estatísticas é o mesmo para as quatro medidas. Esse resultado é mostrado na Tabela A.2. Como pode ser observado, os algoritmos TP-KNN, TP-C4.5 e TPSVM ocupam a primeira, a segunda e a terceira posição, respectivamente, na ordem de desempenho preditivo (a primeira posição corresponde ao algoritmo que obteve o melhor desempenho preditivo nos experimentos). Entretanto, a diferença de desempenho entre eles não foi considerada estatisticamente significativa. O mesmo ocorre na comparação dos resultados do TP-RIPPER e TP-BayesNet, que ocupam a quarta e a quinta posição, respectivamente. Significâncias estatísticas foram detectadas na comparação dos resultados dos algoritmos TP-KNN, TP-C4.5 e TP-SVM com os algoritmos TP-RIPPER e TPBayesNet.

Para os demais níveis da hierarquia, as medidas de avaliação reportaram taxas de desempenho diferentes para os resultados de cada um dos algoritmos. Isso ocorreu porque tais medidas fazem considerações diferentes nos cálculos dos erros de classificação, fazendo com que os valores das taxas reportadas sejam mais altas ou mais baixas dependendo da flexibilidade da penalização dos tipos de erros possíveis. Porém, nos resultados dos expe- 
Tabela A.2: Análise estatística dos resultados obtidos para os algoritmos TopDown convencionais para o primeiro nivel do conjunto GPCR.

\begin{tabular}{|l|c|c|c|c|}
\cline { 2 - 5 } \multicolumn{1}{c|}{} & C4.5 & KNN & RIPPER & BayesNet \\
\hline SVM & $\nabla$ & $\nabla$ & $\Delta$ & $\Delta$ \\
\hline C4.5 & & $\nabla$ & $\Delta$ & $\Delta$ \\
\hline KNN & & & $\Delta$ & $\Delta$ \\
\hline RIPPER & & & & $\Delta$ \\
\hline
\end{tabular}

rimentos realizados, embora a diferença entre o desempenho preditivo dos algoritmos tenha aumentado ou diminuído em alguns casos, a ordem de desempenho manteve-se a mesma, com algumas exceções. Dessa forma, alguns resultados de testes estatísticos para diferentes medidas foram iguais. Nesses casos, uma mesma tabela foi utilizada para representar os resultados de diferentes medidas.

No segundo nível, os testes estatísticos apresentaram os mesmos resultados na análise das taxas de desempenho representadas por meio de três medidas diferentes: TA convencional, TA baseada na distância e F-measure. Esses resultados são mostrados na Tabela A.3. A única medida para a qual os testes estatísticos apresentaram resultados diferentes foi a TA dependente da profundidade, como pode ser observado na Tabela A.4. Apesar das duas tabelas serem distintas em termos estatísticos, a ordem de desempenho preditivo entre os algoritmos é a mesma.

Como pode ser observado na Tabela A.3, além das significâncias estatísticas já detectadas no primeiro nível, a diferença de desempenho preditivo entre o TP-SVM e o TP-C4.5 também foi considerada estatisticamente significativa pelos testes. Adicionalmente, foi detectada significância estatística para a diferença de desempenho preditivo entre o TP-RIPPER e o TP-BayesNet. A diferença desses resultados para os apresentados para a TA dependente da profundidade (Tabela A.4) é que não foi detectada significância estatística na diferença de desempenho entre TP-RIPPER e o TP-BayesNet para os resultados reportados por meio dessa medida. Os demais resultados dos testes estatísticos são os mesmos.

Tabela A.3: Análise estatística dos resultados obtidos para os algoritmos TopDown convencionais para o segundo nivel do conjunto GPCR, utilizando a TA convencional, TA baseada na distância e F-measure.

\begin{tabular}{|l|c|c|c|c|}
\cline { 2 - 5 } \multicolumn{1}{c|}{} & C4.5 & KNN & RIPPER & BayesNet \\
\hline SVM & $\boldsymbol{\nabla}$ & $\nabla$ & $\boldsymbol{\Delta}$ & $\boldsymbol{\Delta}$ \\
\hline C4.5 & & $\nabla$ & $\boldsymbol{\Delta}$ & $\boldsymbol{\Delta}$ \\
\hline KNN & & & $\boldsymbol{\Delta}$ & $\boldsymbol{\Delta}$ \\
\hline RIPPER & & & & $\boldsymbol{\Delta}$ \\
\hline
\end{tabular}


Tabela A.4: Análise estatística dos resultados obtidos para os algoritmos TopDown convencionais para o segundo nível do conjunto GPCR, utilizando a TA dependente da profundidade.

\begin{tabular}{|l|c|c|c|c|}
\cline { 2 - 5 } \multicolumn{1}{c|}{} & C4.5 & KNN & RIPPER & BayesNet \\
\hline SVM & $\boldsymbol{\nabla}$ & $\nabla$ & $\Delta$ & $\Delta$ \\
\hline C4.5 & & $\nabla$ & $\Delta$ & $\Delta$ \\
\hline KNN & & & $\Delta$ & $\Delta$ \\
\hline RIPPER & & & & $\Delta$ \\
\hline
\end{tabular}

Assim como no segundo nível, no terceiro nível o resultado dos testes estatísticos é o mesmo para a TA convencional, TA baseada na distância e $F$ measure. Esse resultado é mostrado na Tabela A.5. Como pode ser observado na tabela, esse é o mesmo resultado estatístico apresentado para as medidas no primeiro nível: as significâncias estatísticas verificadas para os pares (TPC4.5,TP-SVM) e (TP-RIPPER,TP-BayesNet) no segundo nível não foram detectadas nesse nível. Os resultados da análise feita para as taxas de desempenho reportadas por meio da TA dependente na profundidade se mantiveram iguais aos obtidos para o segundo nível. Esses resultados são mostrados na Tabela A.6. Para todas as medidas, a ordem de desempenho preditivo dos algoritmos é a mesma apresentada nos dois primeiros níveis.

Tabela A.5: Análise estatística dos resultados obtidos para os algoritmos TopDown convencionais para o terceiro nível do conjunto GPCR, utilizando a TA convencional, TA baseada na distância e F-measure.

\begin{tabular}{|l|c|c|c|c|}
\cline { 2 - 5 } \multicolumn{1}{c|}{} & C4.5 & KNN & RIPPER & BayesNet \\
\hline SVM & $\nabla$ & $\nabla$ & $\Delta$ & $\Delta$ \\
\hline C4.5 & & $\nabla$ & $\Delta$ & $\Delta$ \\
\hline KNN & & & $\Delta$ & $\Delta$ \\
\hline RIPPER & & & & $\Delta$ \\
\hline
\end{tabular}

Tabela A.6: Análise estatística dos resultados obtidos para os algoritmos TopDown convencionais para o terceiro nível do conjunto GPCR, utilizando a TA dependente da profundidade.

\begin{tabular}{|l|c|c|c|c|}
\cline { 2 - 5 } \multicolumn{1}{c|}{} & C4.5 & KNN & RIPPER & BayesNet \\
\hline SVM & $\boldsymbol{\nabla}$ & $\nabla$ & $\Delta$ & $\Delta$ \\
\hline C4.5 & & $\nabla$ & $\Delta$ & $\Delta$ \\
\hline KNN & & & $\Delta$ & $\Delta$ \\
\hline RIPPER & & & & $\Delta$ \\
\hline
\end{tabular}

Para o quarto e último nível, significâncias estatísticas foram detectadas para a diferença de desempenho preditivo entre os mesmos pares de algoritmos para todas as medidas. Esses são os mesmos pares de algoritmos 
para os quais significâncias estatísticas foram detectadas no primeiro nível. Entretanto, os resultados dos testes estatísticos para a TA convencional são mostrados em uma tabela diferente das demais medidas porque houve uma mudança na ordem de desempenho preditivo entre os algoritmos para essa medida, embora essa mudança não tenha sido considerada estatisticamente significativa segundo os testes estatísticos. Segundo a TA convencional, o TPC4.5 apresenta melhor desempenho preditivo do que o TP-KNN (o inverso do que o reportado pelas outras medidas). Os resultados estatísticos para a TA convencional são mostrados na Tabela A.7. Os resultados estatísticos para as demais medidas são mostrados na Tabela A.8.

Tabela A.7: Análise estatística dos resultados obtidos para os algoritmos TopDown convencionais para o quarto nível do conjunto GPCR, utilizando a TA convencional.

\begin{tabular}{|l|c|c|c|c|}
\cline { 2 - 5 } \multicolumn{1}{c|}{} & C4.5 & KNN & RIPPER & BayesNet \\
\hline SVM & $\nabla$ & $\nabla$ & $\Delta$ & $\Delta$ \\
\hline C4.5 & & $\Delta$ & $\Delta$ & $\Delta$ \\
\hline KNN & & & $\Delta$ & $\Delta$ \\
\hline RIPPER & & & & $\Delta$ \\
\hline
\end{tabular}

Tabela A.8: Análise estatística dos resultados obtidos para os algoritmos TopDown convencionais para o quarto nivel do conjunto GPCR, utilizando a TA baseada na distância, TA dependente da profundidade e F-measure.

\begin{tabular}{|l|c|c|c|c|}
\cline { 2 - 5 } \multicolumn{1}{c|}{} & C4.5 & KNN & RIPPER & BayesNet \\
\hline SVM & $\nabla$ & $\nabla$ & $\Delta$ & $\Delta$ \\
\hline C4.5 & & $\nabla$ & $\Delta$ & $\Delta$ \\
\hline KNN & & & $\Delta$ & $\Delta$ \\
\hline RIPPER & & & & $\Delta$ \\
\hline
\end{tabular}

\section{Análise dos Resultados do Conjunto EC}

Assim como ocorreu para o conjunto GPCR, no primeiro nível do conjunto EC a análise estatística é a mesma para todas as medidas, uma vez que as taxas de desempenho preditivo reportadas pelas medidas são as mesmas. Os resultados dos testes estatísticos são mostrados na Tabela A.9. Como pode ser observado nessa tabela, os testes estatísticos mostraram que a diferença de desempenho o TP-BayesNet e cada um dos demais algoritmos Top-Down é estatisticamente significativa para esse nivel (o mesmo foi observado para os outros níveis). Além disso, o TP-KNN e o TP-RIPPER também apresentaram desempenhos preditivos com diferença estatística entre si. O mesmo aconteceu para os desempenhos do TP-SVM e do TP-C4.5. Com relação à ordem 
de desempenho preditivo para esse nível, o algoritmo TP-SVM obteve o melhor desempenho, seguido, nessa ordem, pelos algoritmos: TP-KNN, TP-C4.5, TP-RIPPER e TP-BayesNet.

Tabela A.9: Análise estatística dos resultados obtidos para os algoritmos TopDown convencionais para o primeiro nível do conjunto EC.

\begin{tabular}{|l|c|c|c|c|}
\cline { 2 - 5 } \multicolumn{1}{c|}{} & C4.5 & KNN & RIPPER & BayesNet \\
\hline SVM & $\Delta$ & $\Delta$ & $\Delta$ & $\Delta$ \\
\hline C4.5 & & $\nabla$ & $\Delta$ & $\Delta$ \\
\hline KNN & & & $\Delta$ & $\Delta$ \\
\hline RIPPER & & & & $\Delta$ \\
\hline
\end{tabular}

No segundo nível, os resultados dos testes estatísticos para a TA convencional diferiram dos resultados apresentados para as demais medidas, que mantiveram o mesmo resultado dos testes estatísticos para o primeiro nível. Além das significâncias estatísticas detectadas no primeiro nível, os testes estatísticos para a TA convencional detectaram significância estatística na diferença de desempenho preditivo entre o TP-C4.5 e o TP-KNN. Os resultados para os testes estatísticos para a TA convencional são mostrados na Tabela A.10. Para as demais medidas, os resultados estatísticos são mostrados na Tabela A.11. Para esse nível, a mesma ordem de desempenho preditivo entre os algoritmos para o primeiro nível é mantida para todas as medidas.

Tabela A.10: Análise estatística dos resultados obtidos para os algoritmos Top-Down convencionais para o segundo nível do conjunto EC, utilizando a TA convencional.

\begin{tabular}{|l|c|c|c|c|}
\cline { 2 - 5 } \multicolumn{1}{c|}{} & C4.5 & KNN & RIPPER & BayesNet \\
\hline SVM & $\Delta$ & $\Delta$ & $\Delta$ & $\Delta$ \\
\hline C4.5 & & $\boldsymbol{\nabla}$ & $\Delta$ & $\Delta$ \\
\hline KNN & & & $\Delta$ & $\Delta$ \\
\hline RIPPER & & & & $\Delta$ \\
\hline
\end{tabular}

Tabela A.11: Análise estatística dos resultados obtidos para os algoritmos Top-Down convencionais para o segundo nível do conjunto $\mathrm{EC}$, utilizando a TA baseada na distância, TA dependente da profundidade e $F$-measure.

\begin{tabular}{|l|c|c|c|c|}
\cline { 2 - 5 } \multicolumn{1}{c|}{} & C4.5 & KNN & RIPPER & BayesNet \\
\hline SVM & $\Delta$ & $\Delta$ & $\Delta$ & $\Delta$ \\
\hline C4.5 & & $\nabla$ & $\Delta$ & $\Delta$ \\
\hline KNN & & & $\Delta$ & $\Delta$ \\
\hline RIPPER & & & & $\Delta$ \\
\hline
\end{tabular}

Para o terceiro nível, significâncias estatísticas foram detectadas para a diferença de desempenho preditivo entre os mesmos pares de algoritmos para 
todas as medidas. Esses são os mesmos pares de algoritmos para os quais significâncias estatísticas foram detectadas no primeiro nível. Ao contrário do que ocorreu para a TA convencional no segundo nível, não foi constatada significância estatística na diferença de desempenho preditivo entre os algoritmos TP-KNN e TP-RIPPER.

Apesar das significâncias estatísticas detectadas serem as mesmas para todas as medidas, os resultados dos testes estatísticos para a TA convencional são mostrados em uma tabela diferente das demais medidas devido a uma mudança na ordem de desempenho preditivo entre os algoritmos para essa medida. Segundo a TA convencional, o TP-KNN apresenta melhor desempenho preditivo do que o TP-SVM (o inverso do que o reportado pelas outras medidas). Entretanto, essa mudança na ordem de desempenho preditivo não é estatisticamente significativa porque a diferença entre esses dois algoritmos não é significativa para nenhuma das medidas. Os resultados estatísticos para a TA convencional são mostrados na Tabela A.12. Os resultados estatísticos para as demais medidas são mostrados na Tabela A.13.

Tabela A.12: Análise estatística dos resultados obtidos para os algoritmos Top-Down convencionais para o terceiro nível do conjunto EC, utilizando a TA convencional.

\begin{tabular}{|l|c|c|c|c|}
\cline { 2 - 5 } \multicolumn{1}{c|}{} & C4.5 & KNN & RIPPER & BayesNet \\
\hline SVM & $\Delta$ & $\nabla$ & $\Delta$ & $\Delta$ \\
\hline C4.5 & & $\nabla$ & $\Delta$ & $\Delta$ \\
\hline KNN & & & $\Delta$ & $\Delta$ \\
\hline RIPPER & & & & $\Delta$ \\
\hline
\end{tabular}

Tabela A.13: Análise estatística dos resultados obtidos para os algoritmos Top-Down convencionais para o terceiro nivel do conjunto EC, utilizando a TA baseada na distância, TA dependente da profundidade e F-measure.

\begin{tabular}{|l|c|c|c|c|}
\cline { 2 - 5 } \multicolumn{1}{c|}{} & C4.5 & KNN & RIPPER & BayesNet \\
\hline SVM & $\boldsymbol{\Delta}$ & $\triangle$ & $\boldsymbol{\Delta}$ & $\boldsymbol{\Delta}$ \\
\hline C4.5 & & $\nabla$ & $\Delta$ & $\boldsymbol{\Delta}$ \\
\hline KNN & & & $\boldsymbol{\Delta}$ & $\boldsymbol{\Delta}$ \\
\hline RIPPER & & & & $\boldsymbol{\Delta}$ \\
\hline
\end{tabular}

Os resultados dos testes estatísticos para a TA convencional para o quarto nível são mostrados na Tabela A.14. Como pode ser observado, esses resultados são iguais aos obtidos para o terceiro nível: as significâncias estatísticas foram detectadas para os mesmos pares de algoritmos e o desempenho preditivo do TP-KNN foi reportado como superior ao do TP-SVM.

Para as demais medidas, significâncias estatísticas foram detectadas para 
a diferença de desempenho preditivo entre os mesmos pares de algoritmos. Ao contrário dos resultados estatísticos reportados para essas medidas nos três primeiros níveis, foi constatada significância estatística na diferença de desempenho entre os algoritmos TP-KNN e do TP-RIPPER (essa mesma significância foi detectada para os testes estatísticos para a TA convencional no segundo nível). Entretanto, os resultados dos testes estatísticos para a TA dependente da profundidade são mostrados em uma tabela diferente dos resultados para a TA baseada na distância e para a $F$-measure devido a uma mudança na ordem de desempenho preditivo entre os algoritmos para essas duas últimas medidas. Para essas medidas, assim como para a TA convencional, o desempenho preditivo do TP-KNN foi considerado superior em relação ao desempenho do TP-SVM, porém não em termos estatísticos. Os resultados estatísticos para a TA baseada na distância e na $F$-measure são mostrados na Tabela A.15. Os resultados estatísticos para a TA dependente da profundidade são mostrados na Tabela A. 16.

Tabela A.14: Análise estatística dos resultados obtidos para os algoritmos Top-Down convencionais para o quarto nível do conjunto EC, utilizando a TA convencional.

\begin{tabular}{|l|c|c|c|c|}
\cline { 2 - 5 } \multicolumn{1}{c|}{} & C4.5 & KNN & RIPPER & BayesNet \\
\hline SVM & $\Delta$ & $\nabla$ & $\Delta$ & $\Delta$ \\
\hline C4.5 & & $\nabla$ & $\Delta$ & $\Delta$ \\
\hline KNN & & & $\Delta$ & $\Delta$ \\
\hline RIPPER & & & & $\Delta$ \\
\hline
\end{tabular}

Tabela A.15: Análise estatística dos resultados obtidos para os algoritmos Top-Down convencionais para o quarto nível do conjunto EC, utilizando a TA baseada na distância e F-measure.

\begin{tabular}{|l|c|c|c|c|}
\cline { 2 - 5 } \multicolumn{1}{c|}{} & C4.5 & KNN & RIPPER & BayesNet \\
\hline SVM & $\boldsymbol{\Delta}$ & $\nabla$ & $\boldsymbol{\Delta}$ & $\boldsymbol{\Delta}$ \\
\hline C4.5 & & $\boldsymbol{\nabla}$ & $\Delta$ & $\boldsymbol{\Delta}$ \\
\hline KNN & & & $\boldsymbol{\Delta}$ & $\boldsymbol{\Delta}$ \\
\hline RIPPER & & & & $\boldsymbol{\Delta}$ \\
\hline
\end{tabular}

\section{A.2 Algoritmo Selective Top-Down}

Nesta seção, são apresentados os testes estatísticos para as comparações do algoritmo Selective Top-Down com cada um dos algoritmos Top-Down convencionais. Dessa forma, foram realizadas 5 comparações para cada conjunto 
Tabela A.16: Análise estatística dos resultados obtidos para os algoritmos Top-Down convencionais para o quarto nivel do conjunto EC, utilizando a TA dependente da profundidade.

\begin{tabular}{|l|c|c|c|c|}
\cline { 2 - 5 } \multicolumn{1}{c|}{} & C4.5 & KNN & RIPPER & BayesNet \\
\hline SVM & $\boldsymbol{\Delta}$ & $\triangle$ & $\boldsymbol{\Delta}$ & $\boldsymbol{\Delta}$ \\
\hline C4.5 & & $\boldsymbol{\nabla}$ & $\Delta$ & $\boldsymbol{\Delta}$ \\
\hline KNN & & & $\boldsymbol{\Delta}$ & $\boldsymbol{\Delta}$ \\
\hline RIPPER & & & & $\boldsymbol{\Delta}$ \\
\hline
\end{tabular}

de dados. Depois da aplicação da Correção de Bonferroni, o nível de significância foi ajustado para $1 \%\left(\alpha^{*}=0.01\right)$. Os resultados foram obtidos de acordo com uma única medida de avaliação: TA dependente da profundidade.

\section{Análise dos Resultados do Conjunto GPCR}

Na Tabela A.17, são mostrados os resultados dos testes estatísticos para as comparações entre as taxas de desempenho todos os niveis do conjunto GPCR. As significâncias estatísticas são as mesmas para todos os níveis: o algoritmo Selective Top-Down foi considerado estatisticamente superior em desempenho preditivo em relação aos algoritmos TP-RIPPER e TP-BayesNet. Em relação aos algoritmos TP-C4.5 e TP-SVM, o algoritmo Selective Top-Down apresentou desempenho superior, porém sem significância estatística. O único algoritmo Top-Down convencional que apresentou desempenho superior ao Selective Top-Down foi o TP-KNN. Porém, a diferença de desempenho preditivo entre esses algoritmos não foi considerada estatisticamente significativa.

Tabela A.17: Análise estatística dos resultados obtidos para o algoritmo $S$. Top-Down para o conjunto GPCR.

\begin{tabular}{|c|c|c|c|c|c|}
\cline { 2 - 6 } \multicolumn{1}{c|}{} & SVM & C4.5 & KNN & RIPPER & BayesNet \\
\hline S. Top-Down - N1 & $\triangle$ & $\triangle$ & $\nabla$ & $\Delta$ & $\Delta$ \\
\hline S. Top-Down - N2 & $\triangle$ & $\triangle$ & $\nabla$ & $\Delta$ & $\Delta$ \\
\hline S. Top-Down - N3 & $\triangle$ & $\triangle$ & $\nabla$ & $\Delta$ & $\Delta$ \\
\hline S. Top-Down - N4 & $\triangle$ & $\triangle$ & $\nabla$ & $\Delta$ & $\Delta$ \\
\hline
\end{tabular}

\section{Análise dos Resultados do Conjunto EC}

Na Tabela A. 18, são mostrados os resultados dos testes estatísticos para as comparações entre as taxas de desempenho todos os níveis do conjunto EC. As significâncias estatísticas são as mesmas para todos os níveis: o algoritmo Selective Top-Down foi considerado estatisticamente superior em desempenho de predição em relação aos algoritmos TP-C4.5, TP-RIPPER e TP-BayesNet. 
Em relação aos demais algoritmos, o desempenho de predição do Selective Top-Down foi superior, mas a diferença de desempenho não foi considerada estatisticamente significativa. Nos dois primeiros níveis, o Selective Top-Down e o TP-SVM apresentaram exatamente o mesmo desempenho de predição.

Tabela A.18: Análise estatística dos resultados obtidos para o algoritmo $S$. Top-Down para o conjunto EC.

\begin{tabular}{|l|c|c|c|c|c|}
\cline { 2 - 6 } \multicolumn{1}{c|}{} & SVM & C4.5 & KNN & RIPPER & BayesNet \\
\hline S. Top-Down - N1 & $\square$ & $\Delta$ & $\triangle$ & $\Delta$ & $\Delta$ \\
\hline S. Top-Down - N2 & $\square$ & $\Delta$ & $\triangle$ & $\Delta$ & $\Delta$ \\
\hline S. Top-Down - N3 & $\triangle$ & $\Delta$ & $\triangle$ & $\Delta$ & $\Delta$ \\
\hline S. Top-Down - N4 & $\triangle$ & $\Delta$ & $\triangle$ & $\Delta$ & $\Delta$ \\
\hline
\end{tabular}

\section{A.3 Algoritmos Ensemble Top-Down}

Nesta seção, são apresentados os testes estatísticos para as comparações empregadas entre as taxas de desempenho reportadas para os algoritmos Ensemble Top-Down. Foram implementados cinco algoritmos baseados nessa abordagem, uma vez que foram utilizadas cinco estratégias diferentes para a combinação das saídas dos classificadores bases: Ensemble Top-Down com Votação por Maioria (EnsTPVotM), Ensemble Top-Down com Votação Ponderada (EnsTPVotP), Ensemble Top-Down com Votação Ponderada por Ranque (EnsTPVotR), Stack Ensemble Top-Down (StackEnsTP), e Stack Ensemble TopDown com Procedimento Seletivo (StackEnsTPSel). Dessa forma, foram realizadas 10 comparações para cada conjunto de dados. Depois da aplicação da Correção de Bonferroni, o nível de significância foi ajustado para $0.5 \%$ $\left(\alpha^{*}=0.005\right)$. Os resultados foram obtidos de acordo com uma única medida de avaliação: TA dependente da profundidade.

\section{Análise dos Resultados do Conjunto GPCR}

Os resultados das análises estatísticas para o primeiro, o segundo, o terceiro e o quarto nível do conjunto GPCR são apresentados nas tabelas A.19, A.20, A.21, e A.22, respectivamente. Como pode ser observado nas tabelas, os algoritmos StackEnsTP e StackEnsTPSel se alternaram entre o melhor desempenho de predição. O algoritmo StackEnsTP obteve melhor desempenho no segundo nível, enquanto que o algoritmo StackEnsTPSel obteve melhor desempenho no primeiro, no terceiro e no quarto nível. Entretanto, a diferença de desempenho de predição entre esses dois algoritmos não é estatisticamente significativa para nenhum dos níveis. Os algoritmos EnsTPVotR, EnsTPVotM 
e EnsTPVotP se mantiveram nas terceira, quarta e quinta posições, respectivamente, para todos os níveis. Para os três primeiros níveis, foi encontrada significância estatística para a diferença de desempenho de predição entre os algoritmos EnsTPVotP e EnsTPVotR.

Tabela A.19: Análise estatística dos resultados obtidos para os algoritmos Ensemble Top-Down para o primeiro nível do conjunto GPCR.

\begin{tabular}{|l|c|c|c|c|}
\cline { 2 - 5 } \multicolumn{1}{c|}{} & EnsTPVotP & EnsTPVotR & StackEnsTP & StackEnsTPSel \\
\hline EnsTPVotM & $\triangle$ & $\nabla$ & $\nabla$ & $\nabla$ \\
\hline EnsTPVotP & & $\mathbf{V}$ & $\nabla$ & $\nabla$ \\
\hline EnsTPVotR & & & $\nabla$ & $\nabla$ \\
\hline StackEnsTP & & & & $\nabla$ \\
\hline
\end{tabular}

Tabela A.20: Análise estatística dos resultados obtidos para os algoritmos Ensemble Top-Down para o segundo nível do conjunto GPCR.

\begin{tabular}{|l|c|c|c|c|}
\cline { 2 - 5 } \multicolumn{1}{c|}{} & EnsTPVotP & EnsTPVotR & StackEnsTP & StackEnsTPSel \\
\hline EnsTPVotM & $\Delta$ & $\nabla$ & $\nabla$ & $\nabla$ \\
\hline EnsTPVotP & & $\nabla$ & $\nabla$ & $\nabla$ \\
\hline EnsTPVotR & & & $\nabla$ & $\nabla$ \\
\hline StackEnsTP & & & & $\nabla$ \\
\hline
\end{tabular}

Tabela A.21: Análise estatística dos resultados obtidos para os algoritmos Ensemble Top-Down para o terceiro nível do conjunto GPCR.

\begin{tabular}{|l|c|c|c|c|}
\cline { 2 - 5 } \multicolumn{1}{c|}{} & EnsTPVotP & EnsTPVotR & StackEnsTP & StackEnsTPSel \\
\hline EnsTPVotM & $\Delta$ & $\nabla$ & $\nabla$ & $\nabla$ \\
\hline EnsTPVotP & & $\nabla$ & $\nabla$ & $\nabla$ \\
\hline EnsTPVotR & & & $\nabla$ & $\nabla$ \\
\hline StackEnsTP & & & & $\Delta$ \\
\hline
\end{tabular}

Tabela A.22: Análise estatística dos resultados obtidos para os algoritmos Ensemble Top-Down para o quarto nível do conjunto GPCR.

\begin{tabular}{|l|c|c|c|c|}
\cline { 2 - 5 } \multicolumn{1}{c|}{} & EnsTPVotP & EnsTPVotR & StackEnsTP & StackEnsTPSel \\
\hline EnsTPVotM & $\Delta$ & $\nabla$ & $\nabla$ & $\nabla$ \\
\hline EnsTPVotP & & $\nabla$ & $\nabla$ & $\nabla$ \\
\hline EnsTPVotR & & & $\nabla$ & $\nabla$ \\
\hline StackEnsTP & & & & $\nabla$ \\
\hline
\end{tabular}

\section{Análise dos Resultados do Conjunto EC}

Os resultados das análises estatísticas para o primeiro, o segundo, o terceiro e o quarto nível do conjunto GPCR são apresentados nas tabelas A.23, 
A.24, A.25, e A.26, respectivamente. Como pode ser observado nas tabelas, no primeiro nível houveram dois empates quanto ao desempenho de predição: (1) um empate entre os algoritmos EnsTPVotR, StackEnsTP e StackEnsTPSel; e (2) um empate entre os algoritmos EnsTPVotM e EnsTPVotP, que apresentaram um desempenho de predição inferior em comparação aos outros três algoritmos. Não foi detectada significância estatística no primeiro nível.

Para os demais níveis não ocorreram mais empates entre os algoritmos. $\mathrm{O}$ algoritmo StackEnsTP apresentou o melhor desempenho de predição e o algoritmo StackEnsTPSel ocupou a segunda posição na ordem de desempenho. Entretanto, o StackEnsTP só foi considerado estatisticamente superior em relação ao EnsTPVotM no segundo e no terceiro nível. O StackEnsTPSel, por sua vez, foi considerado estatisticamente superior em relação ao EnsTPVotM no segundo e no terceiro nível e em relação ao EnsTPVotM no quarto nível. Os algoritmos EnsTPVotR, EnsTPVotP e EnsTPVotM se mantiveram na terceira, na quarta e na quinta posição, respectivamente, na ordem de desempenho para o segundo e o terceiro nível. Para o quarto nivel, os algoritmos EnsTPVotM e EnsTPVotP inverteram entre si as posições que ocuparam no segundo e no terceiro nível.

Tabela A.23: Análise estatística dos resultados obtidos para os algoritmos Ensemble Top-Down para o primeiro nível do conjunto EC.

\begin{tabular}{|l|c|c|c|c|}
\cline { 2 - 5 } \multicolumn{1}{c|}{} & EnsTPVotP & EnsTPVotR & StackEnsTP & StackEnsTPSel \\
\hline EnsTPVotM & $\square$ & $\nabla$ & $\nabla$ & $\nabla$ \\
\hline EnsTPVotP & & $\nabla$ & $\nabla$ & $\nabla$ \\
\hline EnsTPVotR & & & $\square$ & $\square$ \\
\hline StackEnsTP & & & & $\square$ \\
\hline
\end{tabular}

Tabela A.24: Análise estatística dos resultados obtidos para os algoritmos Ensemble Top-Down para o segundo nível do conjunto EC.

\begin{tabular}{|l|c|c|c|c|}
\cline { 2 - 5 } \multicolumn{1}{c|}{} & EnsTPVotP & EnsTPVotR & StackEnsTP & StackEnsTPSel \\
\hline EnsTPVotM & $\nabla$ & $\nabla$ & $\boldsymbol{\nabla}$ & $\boldsymbol{\nabla}$ \\
\hline EnsTPVotP & & $\nabla$ & $\nabla$ & $\nabla$ \\
\hline EnsTPVotR & & & $\nabla$ & $\nabla$ \\
\hline StackEnsTP & & & & $\Delta$ \\
\hline
\end{tabular}

\section{A.4 Comparação entre várias abordagens}

Nesta seção, são apresentados os testes estatísticos para o estudo comparativo envolvendo várias abordagens. Esse estudo envolveu resultados da 
Tabela A.25: Análise estatística dos resultados obtidos para os algoritmos Ensemble Top-Down para o terceiro nível do conjunto EC.

\begin{tabular}{|l|c|c|c|c|}
\cline { 2 - 5 } \multicolumn{1}{c|}{} & EnsTPVotP & EnsTPVotR & StackEnsTP & StackEnsTPSel \\
\hline EnsTPVotM & $\nabla$ & $\nabla$ & $\mathbf{\nabla}$ & $\mathbf{\nabla}$ \\
\hline EnsTPVotP & & $\nabla$ & $\nabla$ & $\nabla$ \\
\hline EnsTPVotR & & & $\nabla$ & $\nabla$ \\
\hline StackEnsTP & & & & $\Delta$ \\
\hline
\end{tabular}

Tabela A.26: Análise estatística dos resultados obtidos para os algoritmos Ensemble Top-Down para o quarto nivel do conjunto EC.

\begin{tabular}{|l|c|c|c|c|}
\cline { 2 - 5 } \multicolumn{1}{c|}{} & EnsTPVotP & EnsTPVotR & StackEnsTP & StackEnsTPSel \\
\hline EnsTPVotM & $\triangle$ & $\nabla$ & $\nabla$ & $\nabla$ \\
\hline EnsTPVotP & & $\nabla$ & $\nabla$ & $\mathbf{\nabla}$ \\
\hline EnsTPVotR & & & $\nabla$ & $\nabla$ \\
\hline StackEnsTP & & & & $\Delta$ \\
\hline
\end{tabular}

abordagem Top-Down convencional e suas variações - Selective Top-Down e Ensemble Top-Down e da abordagem Big-Bang.

Cada abordagem foi representada por um algoritmo nela baseada. O representante da abordagem Big-Bang foi um algoritmo baseado em uma modificação da técnica C4.5, denominado HC4.5. O representante da abordagem Selective Top-Down foi o algoritmo utilizado no segundo estágio da condução dos experimentos. Como foram implementados cinco algoritmos tanto para a abordagem Top-Down convencional, quanto para sua variação Ensemble TopDown, foi estabelecido um critério de escolha para o representante de cada uma dessas abordagens. Decidiu-se por selecionar o algoritmo com o melhor desempenho preditivo entre os algoritmos desenvolvidos para cada abordagem. Como essa seleção foi feita de modo independente para cada conjunto de dados (isto é, a escolha do melhor algoritmo foi feita para cada conjunto de dados, levando-se em conta apenas o desempenho preditivo medido para o conjunto em questão), os algoritmos são diferentes para cada conjunto de dados.

Como foram comparados quatro algoritmos entre si, foram realizadas seis comparações para cada conjunto de dados. Depois da aplicação da Correção de Bonferroni, o nível de significância foi ajustado para $0.8 \%\left(\alpha^{*}=0.008\right)$. Os resultados foram obtidos de acordo com uma única medida de avaliação: TA dependente da profundidade. 


\section{Análise dos Resultados do Conjunto GPCR}

Os resultados dos testes estatísticos para o primeiro, o segundo, o terceiro e o quarto nível do conjunto GPCR são apresentados nas tabelas A.27, A.28, A.29, e A.30, respectivamente. Nesse estudo comparativo foram considerados os algoritmos HC4.5, TP-KNN, Selective Top-Down e StackEnsTPSel (Stack Ensemble Top-Down com Procedimento Seletivo).

Como pode ser observado nas tabelas, a mesma ordem de desempenho se manteve para todos os niveis da hierarquia. O algoritmo StackEnsembleSel obteve o maior desempenho preditivo, seguido, nessa ordem, pelos algoritmos: TP-KNN, Selective Top-Down e HC4.5. Entretanto, foi detectada significância estatística apenas para a diferença de desempenho preditivo do HC4.5 em relação aos demais algoritmos para o segundo e o terceiro nivel da hierarquia. No primeiro e no quarto nível não foi detectada significância estatística na diferença de desempenho observada entre os algoritmos.

Tabela A.27: Análise estatística dos resultados obtidos para os algoritmos representantes de quatro abordagens para o primeiro nivel do conjunto GPCR.

\begin{tabular}{|l|c|c|c|}
\cline { 2 - 4 } \multicolumn{1}{c|}{} & S. Top-Down & StackEnsTPSel & HC4.5 \\
\hline KNN & $\Delta$ & $\nabla$ & $\Delta$ \\
\hline S. Top-Down & & $\nabla$ & $\Delta$ \\
\hline StackEnsTPSel & & & $\Delta$ \\
\hline
\end{tabular}

Tabela A.28: Análise estatística dos resultados obtidos para os algoritmos representantes de quatro abordagens para o segundo nível do conjunto GPCR.

\begin{tabular}{|l|c|c|c|}
\cline { 2 - 4 } \multicolumn{1}{c|}{} & S. Top-Down & StackEnsTPSel & HC4.5 \\
\hline KNN & $\Delta$ & $\nabla$ & $\Delta$ \\
\hline S. Top-Down & & $\nabla$ & $\Delta$ \\
\hline StackEnsTPSel & & & $\boldsymbol{\Delta}$ \\
\hline
\end{tabular}

Tabela A.29: Análise estatística dos resultados obtidos para os algoritmos representantes de quatro abordagens para o terceiro nível do conjunto GPCR.

\begin{tabular}{|l|c|c|c|}
\cline { 2 - 4 } \multicolumn{1}{c|}{} & S. Top-Down & StackEnsTPSel & HC4.5 \\
\hline KNN & $\Delta$ & $\nabla$ & $\boldsymbol{\Delta}$ \\
\hline S. Top-Down & & $\nabla$ & $\boldsymbol{\Delta}$ \\
\hline StackEnsTPSel & & & $\boldsymbol{\Delta}$ \\
\hline
\end{tabular}


Tabela A.30: Análise estatística dos resultados obtidos para os algoritmos representantes de quatro abordagens para o quarto nível do conjunto GPCR.

\begin{tabular}{|l|c|c|c|}
\cline { 2 - 4 } \multicolumn{1}{c|}{} & S. Top-Down & StackEnsTPSel & HC4.5 \\
\hline KNN & $\Delta$ & $\nabla$ & $\Delta$ \\
\hline S. Top-Down & & $\nabla$ & $\Delta$ \\
\hline StackEnsTPSel & & & $\Delta$ \\
\hline
\end{tabular}

\section{Análise dos Resultados do Conjunto EC}

Os resultados dos testes estatísticos para o primeiro, o segundo, o terceiro e o quarto nível do conjunto EC são apresentados nas tabelas A.31, A.32, A.33, e A.34, respectivamente. Para esse estudo comparativo foram considerados os algoritmos HC4.5, TP-SVM, Selective Top-Down e StackEnsTP (Stack Ensemble Top-Down).

No primeiro nível do conjunto EC, houve um empate entre os três algoritmos Top-Down quanto ao melhor desempenho preditivo. Nesse nível, assim como nos demais, a quarta posição quanto ao desempenho ficou com o HC4.5. Nenhuma significância estatística foi detectada para a diferença de desempenho entre os algoritmos no primeiro nível.

No segundo nível, o StackEnsemble apresentou o melhor desempenho de predição e os algoritmos TP-SVM e Selective Top-Down continuaram empatados. Dentre essas comparações de resultados, o StackEnsemble mostrou desempenho de predição estatisticamente superior em relação ao Selective Top-Down e TP-SVM.

No terceiro e no quarto nível, a ordem de desempenho entre os algoritmos foi a mesma: StackEnsemble, Selective Top-Down, TP-SVM e HC4.5. Assim como no segundo nível, nos dois últimos níveis da hierarquia o StackEnsemble foi considerado estatisticamente superior em relação ao TP-SVM.

Embora o HC4.5 tenha obtido o pior desempenho nos dois conjuntos, nenhum algoritmo se mostrou estatisticamente superior a ele para o conjunto EC. Isso ocorreu pelo fato de a diferença de desempenho preditivo do HC4.5 em relação aos demais algoritmos ter apresentado um desvio padrão relativamente maior do que na comparação dos demais algoritmos entre si.

Tabela A.31: Análise estatística dos resultados obtidos para os algoritmos representantes de quatro abordagens para o primeiro nível do conjunto EC.

\begin{tabular}{|l|c|c|c|}
\cline { 2 - 4 } \multicolumn{1}{c|}{} & S. Top-Down & StackEnsTP & HC4.5 \\
\hline SVM & $\square$ & $\square$ & $\triangle$ \\
\hline S. Top-Down & & $\square$ & $\Delta$ \\
\hline StackEnsTP & & & $\triangle$ \\
\hline
\end{tabular}


Tabela A.32: Análise estatística dos resultados obtidos para os algoritmos representantes de quatro abordagens para o segundo nível do conjunto EC.

\begin{tabular}{|l|c|c|c|}
\cline { 2 - 4 } \multicolumn{1}{c|}{} & S. Top-Down & StackEnsTP & HC4.5 \\
\hline SVM & $\square$ & $\boldsymbol{\nabla}$ & $\Delta$ \\
\hline S. Top-Down & & $\boldsymbol{V}$ & $\Delta$ \\
\hline StackEnsTP & & & $\triangle$ \\
\hline
\end{tabular}

Tabela A.33: Análise estatística dos resultados obtidos para os algoritmos representantes de quatro abordagens para o terceiro nível do conjunto EC.

\begin{tabular}{|l|c|c|c|}
\cline { 2 - 4 } \multicolumn{1}{c|}{} & S. Top-Down & StackEnsTP & HC4.5 \\
\hline SVM & $\nabla$ & $\nabla$ & $\Delta$ \\
\hline S. Top-Down & & $\nabla$ & $\Delta$ \\
\hline StackEnsTP & & & $\Delta$ \\
\hline
\end{tabular}

Tabela A.34: Análise estatística dos resultados obtidos para os algoritmos representantes de quatro abordagens para o quarto nivel do conjunto EC.

\begin{tabular}{|l|c|c|c|}
\cline { 2 - 4 } \multicolumn{1}{c|}{} & S. Top-Down & StackEnsTP & HC4.5 \\
\hline SVM & $\nabla$ & $\nabla$ & $\Delta$ \\
\hline S. Top-Down & & $\nabla$ & $\Delta$ \\
\hline StackEnsTP & & & $\Delta$ \\
\hline
\end{tabular}

\section{A.5 Considerações Finais}

Neste apêndice, foram descritos os testes estatísticos realizados para os resultados obtidos para os experimentos descritos no Capítulo 5. O teste estatístico escolhido foi o t de Student para dados pareados corrigido, com a Correção de Bonferroni para ajuste do níveis de significância dos testes.

Assim como ocorreu para a ordem de desempenho preditivo entre os algoritmos, não houveram muitas diferenças com relação as significâncias estatísticas detectadas para os dois conjuntos de dados envolvidos nos experimentos - GPCR e EC. Entretanto, em alguns casos, algoritmos que foram considerados estatisticamente superiores a outros para um conjunto de dados, não o foram para o outro. Por exemplo, na comparação entre várias abordagens, o algoritmo HC4.5 foi o único que apresentou diferença de desempenho preditivo estatisticamente significativa em relação aos demais algoritmos (o algoritmo HC4.5 se mostrou estatisticamente inferior aos demais para o segundo e o terceiro nível da hierarquia). Entretanto, para o conjunto EC, esse foi o único algoritmo para o qual o algoritmo StackEnsemble não se mostrou superior, em termos estatísticos, em nenhum dos níveis; embora o HC4.5 tenha obtido o menor desempenho preditivo. 


\section{—可 \\ Diversidade em Combinações de Classificadores}

Neste apêndice, são descritos os resultados relacionados a uma análise de diversidade dos classificadores bases gerados para o algoritmo EnsTPVotM. Como as mesmas técnicas de AM - C4.5, RIPPER, Redes Bayesianas (BayesNet), SVMs e KNN - foram utilizadas pelos cinco algoritmos Ensemble TopDown desenvolvidos, há pouca variação na análise de diversidade de um algoritmo para outro. Por esse motivo, a análise de apenas um desses algoritmos é apresentada. Algumas pequenas variações podem ocorrer devido a possíveis diferenças quanto à propagação de erros dos modelos induzidos pelos algoritmos, uma vez que cada um deles utiliza um método diferente para a combinação das saídas dos classificadores bases.

A principal motivação para essa análise de diversidade foi verificar porque alguns algoritmos Ensemble Top-Down (o algoritmo EnsTPVotM, por exemplo) obtiveram desempenhos preditivos inferiores aos de alguns algoritmos TopDown convencionais (o algoritmo TP-KNN, por exemplo), e porque, em alguns casos, a melhora de desempenho dos algoritmos Ensemble Top-Down em relação aos Top-Down convencionais não foi estatisticamente significativa. Entretanto, deve-se ressaltar que esse foi apenas um estudo inicial nesse sentido. Para um estudo mais detalhado, um número maior de considerações devem ser feitas com relação aos conjuntos de dados, aos algoritmos e às técnicas de AM utilizadas.

Duas medidas foram utilizadas para a análise da diversidade dos classificadores bases: Medida de Dissimilaridade (MD) e Medida de Duplo Erro (MDE). 
Uma descrição sucinta dessas medidas foi apresentada na Seção 2.4. Para uma descrição mais detalhada dessas e de outras medidas de diversidade de ensembles, consultar (Kuncheva \& Whitaker, 2003).

A análise de diversidade foi feita para as predições de cada nível da hierarquia. Dessa forma, em cada nível, foram considerados apenas os exemplos para os quais foram feitas predições. Em alguns casos, principalmente para o conjunto GPCR, alguns ramos da hierarquia não se estendem até o terceiro ou o quarto nível. Por isso, é importante que a soma da MD e da MDE não seja confundida com a TE, embora os seus valores estejam relacionados. Por exemplo, se um exemplo do terceiro nível foi classificado incorretamente em um nó-folha do segundo nível, esse erro de classificação contribui para o aumento da TE no terceiro nível, assim como no primeiro e no segundo nível. Entretanto, como nenhuma predição foi feita para o terceiro nível, esse exemplo não é computado no cálculo da diversidade de classificadores desse nível.

MD e MDE são medidas pairwise, ou seja, elas consideram a diversidade entre cada par de classificadores bases. Isso é interessante para uma análise mais específica, uma vez que são apresentados valores de diversidade para todos os pares de classificadores isoladamente. Além disso, para uma análise mais geral, um único valor pode ser obtido por meio da média desses valores.

Como os conjuntos de dados foram particionados por meio do método 5fold cross-validation, ao final, os algoritmos foram utilizados para a realização de predições para cinco conjuntos de teste diferentes. De modo a considerar todos os resultados na análise da diversidade dos classificadores, as medidas MD e MDE foram aplicadas aos resultados de cada um desses conjuntos. Dessa forma, os valores reportados neste apêndice correspondem a média dos valores da MD e da MDE calculados para os resultados dos cinco conjuntos de testes.

Na Seção B.1, são apresentados os resultados para a análise de diversidade dos classificadores bases induzidos para o conjunto GPCR. Os resultados para a análise de diversidade realizada para o conjunto EC são apresentados na Seção B.2. Por fim, algumas considerações finais são feitas na Seção B.3.

\section{B. 1 Análise dos Resultados do Conjunto GPCR}

Os valores obtidos por meio da MD para o conjunto GPCR para o primeiro, o segundo, o terceiro e o quarto nível são apresentados, respectivamente, nas tabelas B.1, B.2, B.3 e B.4. Como pode ser observado nessas tabelas, os valores reportados para as comparações dos classificadores induzidos pela técnica BayesNet com os demais classificadores são um pouco maiores do que os valores reportados para as demais comparações. Porém, essa maior diversidade 
pode ser mal interpretada como uma vantagem da utilização dessa técnica sobre as demais no modelo combinado de classificadores. Em uma análise mais específica da causa dessa maior diversidade, observou-se que ela foi causada, em grande parte, pelos erros cometidos apenas pelos classificadores induzidos pela técnica BayesNet (isto é, pelos exemplos classificados incorretamente pelos classificadores BayesNet e corretamente pelos demais classificadores). Para ilustrar essa observação, considere a Tabela B.5. Nessa tabela, é representada a complementaridade preditiva para cada par de classificadores bases induzidos para classificação dos exemplos no primeiro nível do conjunto GPCR. O valor contido em cada célula consiste na média de exemplos que foram classificados incorretamente pelos classificadores bases induzidos pela técnica correspondente à linha da tabela e corretamente pelos classificadores bases induzidos pela técnica correspondente à coluna. Essa média foi calculada com base nas predições realizadas para os conjuntos de teste gerados por meio do método 5-fold cross-validation.

Considere o par (SVM e BayesNet), por exemplo. Em média, os classificadores induzidos pela técnica SVM classificaram incorretamente 30 exemplos (aproximadamente), que foram classificados corretamente pelos classificadores induzidos pela técnica BayesNet. Entretanto, ao analisar a relação inversa, percebe-se que a média de exemplos classificados corretamente pelos classificadores induzidos pela técnica SVM e incorretamente pelos classificadores induzidos pela técnica BayesNet é bem maior - 124 exemplos. Fato semelhante ocorre para as demais comparações envolvendo a técnica BayesNet. Para os demais pares de classificadores, essa proporção é mais equilibrada, com exceção dos classificadores induzidos pela técnica RIPPER, para a qual pode ser feita a mesma observação feita para a BayesNet, em uma escala um pouco menor.

Basicamente, o que ocorreu foi que a técnica BayesNet induziu classificadores com menor desempenho preditivo, como pode ser observado pelos resultados do algoritmo Top-Down convencional baseado em Redes Bayesianas (ver Seção 5.3.1). No cálculo da diversidade, esses erros adicionais por parte desses classificadores fizeram com que ocorresse um aumento nos valores da MD envolvendo a técnica BayesNet. Portanto, com relação ao aumento do desempenho preditivo da combinação dos classificadores bases, essa técnica não apresenta uma contribuição maior do que as demais técnicas, apesar dos valores de MD serem maiores.

Os valores obtidos por meio da MDE para o primeiro, o segundo, o terceiro e o quarto nível são apresentados, respectivamente, nas tabelas B.6, B.7, B.8 e B.9. Como pode ser observado nas tabelas, não há discrepância de valores entre os pares de algoritmos, que são bem próximos entre si. As comparações 
Tabela B.1: Medida de Dissimilaridade para os classificadores bases do algoritmo EnsTPVotM induzidos para o primeiro nível da hierarquia do conjunto GPCR.

\begin{tabular}{|l|c|c|c|c|}
\cline { 2 - 5 } \multicolumn{1}{c|}{} & C4.5 & KNN & RIPPER & BayesNet \\
\hline SVM & 0.0518 & 0.0681 & 0.0777 & 0.1109 \\
\hline C4.5 & & 0.0483 & 0.0946 & 0.1185 \\
\hline KNN & & & 0.0872 & 0.1293 \\
\hline RIPPER & & & & 0.1145 \\
\hline
\end{tabular}

Tabela B.2: Medida de Dissimilaridade para os classificadores bases do algoritmo EnsTPVotM induzidos para o segundo nível da hierarquia do conjunto GPCR.

\begin{tabular}{|l|c|c|c|c|}
\cline { 2 - 5 } \multicolumn{1}{c|}{} & C4.5 & KNN & RIPPER & BayesNet \\
\hline SVM & 0.0382 & 0.0361 & 0.0347 & 0.0470 \\
\hline C4.5 & & 0.0301 & 0.0416 & 0.0563 \\
\hline KNN & & & 0.0470 & 0.0594 \\
\hline RIPPER & & & & 0.0455 \\
\hline
\end{tabular}

Tabela B.3: Medida de Dissimilaridade para os classificadores bases do algoritmo EnsTPVotM induzidos para o terceiro nível da hierarquia do conjunto GPCR.

\begin{tabular}{|l|c|c|c|c|}
\cline { 2 - 5 } \multicolumn{1}{c|}{} & C4.5 & KNN & RIPPER & BayesNet \\
\hline SVM & 0.1635 & 0.1609 & 0.0805 & 0.1106 \\
\hline C4.5 & & 0.1029 & 0.1572 & 0.1655 \\
\hline KNN & & & 0.1694 & 0.1755 \\
\hline RIPPER & & & & 0.0977 \\
\hline
\end{tabular}

Tabela B.4: Medida de Dissimilaridade para os classificadores bases do algoritmo EnsTPVotM induzidos para o quarto nível da hierarquia do conjunto GPCR.

\begin{tabular}{|l|c|c|c|c|}
\cline { 2 - 5 } \multicolumn{1}{c|}{} & C4.5 & KNN & RIPPER & BayesNet \\
\hline SVM & 0.0288 & 0.0249 & 0.0394 & 0.0606 \\
\hline C4.5 & & 0.0205 & 0.0243 & 0.0591 \\
\hline KNN & & & 0.0310 & 0.0583 \\
\hline RIPPER & & & & 0.0606 \\
\hline
\end{tabular}

dos classificadores induzidos pela técnica BayesNet com os demais classificadores são ligeiramente maiores do que a maioria dos valores reportados para as demais comparações.

Na Tabela B.10, para cada uma das medidas de diversidade utilizadas MD e MDE - e para cada um dos quatro niveis da hierarquia, os valores calculados para os pares de classificadores são resumidos por meio da sua média 
Tabela B.5: Complementaridade de erros de predições para o primeiro nível do conjunto GPCR.

\begin{tabular}{|l|c|c|c|c|c|}
\cline { 2 - 6 } \multicolumn{1}{c|}{} & SVM & C4.5 & IBK & RIPPER & BayesNet \\
\hline SVM & & 41.2 & 53.6 & 37.0 & 29.8 \\
\hline C4.5 & 30.6 & & 34.6 & 43.4 & 29.8 \\
\hline IBK & 40.8 & 32.4 & & 37.2 & 36.2 \\
\hline RIPPER & 70.8 & 87.8 & 83.8 & & 49.2 \\
\hline BayesNet & 124.0 & 134.6 & 143.2 & 109.6 & \\
\hline
\end{tabular}

O valor contido em cada célula consiste na média de exemplos que foram classificados incorretamente pelos classificadores bases induzidos pela técnica correspondente à linha da tabela e corretamente pelos classificadores bases induzidos pela técnica correspondente à coluna.

Tabela B.6: Medida de Duplo Erro para os classificadores bases do algoritmo EnsTPVotM induzidos para o primeiro nível da hierarquia do conjunto GPCR.

\begin{tabular}{|l|c|c|c|c|}
\cline { 2 - 5 } \multicolumn{1}{c|}{} & C4.5 & KNN & RIPPER & BayesNet \\
\hline SVM & 0.0469 & 0.0379 & 0.0499 & 0.0551 \\
\hline C4.5 & & 0.0440 & 0.0376 & 0.0474 \\
\hline KNN & & & 0.0405 & 0.0412 \\
\hline RIPPER & & & & 0.0655 \\
\hline
\end{tabular}

Tabela B.7: Medida de Duplo Erro para os classificadores bases do algoritmo EnsTPVotM induzidos para o segundo nível da hierarquia do conjunto GPCR.

\begin{tabular}{|l|c|c|c|c|}
\cline { 2 - 5 } \multicolumn{1}{c|}{} & C4.5 & KNN & RIPPER & BayesNet \\
\hline SVM & 0.1151 & 0.1140 & 0.1255 & 0.1270 \\
\hline C4.5 & & 0.1172 & 0.1223 & 0.1226 \\
\hline KNN & & & 0.1174 & 0.1189 \\
\hline RIPPER & & & & 0.1366 \\
\hline
\end{tabular}

Tabela B.8: Medida de Duplo Erro para os classificadores bases do algoritmo EnsTPVotM induzidos para o terceiro nível da hierarquia do conjunto GPCR.

\begin{tabular}{|l|c|c|c|c|}
\cline { 2 - 5 } \multicolumn{1}{c|}{} & C4.5 & KNN & RIPPER & BayesNet \\
\hline SVM & 0.3587 & 0.3604 & 0.4117 & 0.4025 \\
\hline C4.5 & & 0.3864 & 0.3703 & 0.3720 \\
\hline KNN & & & 0.3646 & 0.3674 \\
\hline RIPPER & & & & 0.4173 \\
\hline
\end{tabular}

e do seu desvio padrão. Como pode ser observado, para o primeiro nível da hierarquia GPCR, o valor da MD é maior do que o valor da MDE. Isso indica que, nas comparações entre os pares de classificadores bases no primeiro nível, a proporção de exemplos classificados incorretamente por apenas um dos classificadores é maior do que a proporção de exemplos classificados incorretamente por dois classificadores. No segundo nível, essa situação se inverte: 
Tabela B.9: Medida de Duplo Erro para os classificadores bases do algoritmo EnsTPVotM induzidos para o quarto nível da hierarquia do conjunto GPCR.

\begin{tabular}{|l|c|c|c|c|}
\cline { 2 - 5 } \multicolumn{1}{c|}{} & C4.5 & KNN & RIPPER & BayesNet \\
\hline SVM & 0.0424 & 0.0424 & 0.0417 & 0.0454 \\
\hline C4.5 & & 0.0447 & 0.0492 & 0.0462 \\
\hline KNN & & & 0.0440 & 0.0447 \\
\hline RIPPER & & & & 0.0500 \\
\hline
\end{tabular}

o valor da MD apresenta um decréscimo, indicando uma diminuição na diversidade entre os classificadores, e o valor da MDE aumenta, indicando um aumento no erro compartilhado por pares de classificadores. Embora no terceiro nível o valor da MD seja maior do que nos dois primeiros níveis, ele é consideravelmente menor do o valor da MDE. No quarto nível, ambas medidas apresentam uma diminuição de valores, aproximando-se entre si, embora o valor da MDE tenha permanecido maior do que o valor da MD.

Para as duas medidas, o maior valor apresentado foi no terceiro nível da hierarquia. Essa observação coincide com a baixa TA apresentada pelos algoritmos no terceiro nível da hierarquia GPCR.

Tabela B.10: Média e desvio padrão dos valores da MD e da MDE para o conjunto GPCR.

\begin{tabular}{|c|c|c|}
\cline { 2 - 3 } \multicolumn{1}{c|}{} & MD & MDE \\
\hline N1 & $0.0901(0.0284)$ & $0.0466(0.0086)$ \\
\hline N2 & $0.0436(0.0094)$ & $0.1217(0.0068)$ \\
\hline N3 & $0.1384(0.0359)$ & $0.3811(0.0219)$ \\
\hline N4 & $0.0408(0.0170)$ & $0.0451(0.0028)$ \\
\hline
\end{tabular}

\section{B.2 Análise dos Resultados do Conjunto EC}

Para o conjunto EC, os valores obtidos por meio da MD para o primeiro, o segundo, o terceiro e o quarto nível são apresentados, respectivamente, nas tabelas B.11, B.12, B.13 e B.14. Assim como para o conjunto GPCR, os valores reportados para as comparações dos classificadores induzidos pela técnica BayesNet com os demais classificadores são relativamente maiores do que os valores reportados para as demais comparações, o que revela que tais classificadores apresentam maior diversidade em relação aos demais. Entretanto, como mencionado nas observações para o conjunto GPCR, essa maior diversidade deve ser observada com cuidado, para que não haja problemas de interpretação dos resultados (ver Seção B.1). De forma resumida, a maior 
quantidade de erros dos classificadores induzidos pela técnica BayesNet contribuiu para o aumento dos valores da MD.

Tabela B.11: Medida de Dissimilaridade para os classificadores bases do algoritmo EnsTPVotM induzidos para o primeiro nível da hierarquia do conjunto EC.

\begin{tabular}{|l|c|c|c|c|}
\cline { 2 - 5 } \multicolumn{1}{c|}{} & C4.5 & KNN & RIPPER & BayesNet \\
\hline SVM & 0.0144 & 0.0013 & 0.0187 & 0.0553 \\
\hline C4.5 & & 0.0154 & 0.0196 & 0.0585 \\
\hline KNN & & & 0.0192 & 0.0539 \\
\hline RIPPER & & & & 0.0655 \\
\hline
\end{tabular}

Tabela B.12: Medida de Dissimilaridade para os classificadores bases do algoritmo EnsTPVotM induzidos para o segundo nível da hierarquia do conjunto EC.

\begin{tabular}{|l|c|c|c|c|}
\cline { 2 - 5 } \multicolumn{1}{c|}{} & C4.5 & KNN & RIPPER & BayesNet \\
\hline SVM & 0.0073 & 0.0067 & 0.0094 & 0.0479 \\
\hline C4.5 & & 0.0052 & 0.0063 & 0.0452 \\
\hline KNN & & & 0.0081 & 0.0447 \\
\hline RIPPER & & & & 0.0466 \\
\hline
\end{tabular}

Tabela B.13: Medida de Dissimilaridade para os classificadores bases do algoritmo EnsTPVotM induzidos para o terceiro nível da hierarquia do conjunto EC.

\begin{tabular}{|l|c|c|c|c|}
\cline { 2 - 5 } \multicolumn{1}{c|}{} & C4.5 & KNN & RIPPER & BayesNet \\
\hline SVM & 0.0117 & 0.0114 & 0.0106 & 0.0270 \\
\hline C4.5 & & 0.0056 & 0.0048 & 0.0260 \\
\hline KNN & & & 0.0066 & 0.0241 \\
\hline RIPPER & & & & 0.0265 \\
\hline
\end{tabular}

Tabela B.14: Medida de Dissimilaridade para os classificadores bases do algoritmo EnsTPVotM induzidos para o quarto nível da hierarquia do conjunto EC.

\begin{tabular}{|l|c|c|c|c|}
\cline { 2 - 5 } \multicolumn{1}{c|}{} & C4.5 & KNN & RIPPER & BayesNet \\
\hline SVM & 0.0158 & 0.0135 & 0.0166 & 0.0269 \\
\hline C4.5 & & 0.0092 & 0.0077 & 0.0215 \\
\hline KNN & & & 0.0112 & 0.0175 \\
\hline RIPPER & & & & 0.0229 \\
\hline
\end{tabular}

Os valores obtidos por meio da MDE para o primeiro, o segundo, o terceiro e o quarto nível são apresentados, respectivamente, nas tabelas B.15, B.16, 
B.17 e B.18. Para todos os níveis da hieraquia EC, os valores reportados por meio da MDE são bem próximos entre si, com exceção do primeiro nível, em que os pares (C4.5 e RIPPER), (C4.5 e BayesNet) e (RIPPER e BayesNet) apresentaram valores para essa medida relativamente maiores do que os demais pares. Além disso, os valores da MDE para o conjunto EC podem ser considerados baixos quando comparados àqueles obtidos para o conjunto GPCR, indicando que os classificadores possuem poucos erros em comum.

Em uma análise geral dos valores da MD e MDE, os baixos valores apresentados por essas medidas podem ser explicados pelo alto desempenho preditivo que os classificadores apresentam quando utilizados isoladamente, como pode ser observado no desempenho dos algoritmos Top-Down convencionais (Seção 5.3.1). Em situações como essas, o uso de combinações de classificadores de várias técnicas pode se mostrar pouco útil, pois é possível que não haja melhora no desempenho preditivo, além do custo computacional exigido ser maior do que quando são usados apenas classificadores gerados por uma técnica. Entretanto, apesar da baixa diversidade, alguns algoritmos Ensemble Top-Down obtiveram desempenhos preditivos superiores aos desempenhos observados para os algoritmos Top-Down convencionais (ver seções 5.3.3 e 5.3.4).

Tabela B.15: Medida de Duplo Erro para os classificadores bases do algoritmo EnsTPVotM induzidos para o primeiro nível da hierarquia do conjunto EC.

\begin{tabular}{|l|c|c|c|c|}
\cline { 2 - 5 } \multicolumn{1}{c|}{} & C4.5 & KNN & RIPPER & BayesNet \\
\hline SVM & 0.0002 & 0.0004 & 0.0004 & 0.0004 \\
\hline C4.5 & & 0.0004 & 0.0069 & 0.0058 \\
\hline KNN & & & 0.0008 & 0.0017 \\
\hline RIPPER & & & & 0.0046 \\
\hline
\end{tabular}

Tabela B. 16: Medida de Duplo Erro para os classificadores bases do algoritmo EnsTPVotM induzidos para o segundo nível da hierarquia do conjunto EC.

\begin{tabular}{|l|c|c|c|c|}
\cline { 2 - 5 } \multicolumn{1}{c|}{} & C4.5 & KNN & RIPPER & BayesNet \\
\hline SVM & 0.0069 & 0.0060 & 0.0069 & 0.0069 \\
\hline C4.5 & & 0.0089 & 0.0106 & 0.0104 \\
\hline KNN & & & 0.0085 & 0.0094 \\
\hline RIPPER & & & & 0.0108 \\
\hline
\end{tabular}

Na Tabela B.19, para cada uma das medidas de diversidade utilizadas - MD e MDE - e para cada um dos quatro níveis da hierarquia, os valores calculados para os pares de classificadores são resumidos por meio da sua média e do seu desvio padrão. Pode-se observar que os valores da MD diminuem para os níveis mais profundos. Isso pode ser interpretado como uma diminuição 
Tabela B.17: Medida de Duplo Erro para os classificadores bases do algoritmo EnsTPVotM induzidos para o terceiro nível da hierarquia do conjunto EC.

\begin{tabular}{|l|c|c|c|c|}
\cline { 2 - 5 } \multicolumn{1}{c|}{} & C4.5 & KNN & RIPPER & BayesNet \\
\hline SVM & 0.0103 & 0.0095 & 0.0109 & 0.0127 \\
\hline C4.5 & & 0.0103 & 0.0117 & 0.0111 \\
\hline KNN & & & 0.0098 & 0.0111 \\
\hline RIPPER & & & & 0.0109 \\
\hline
\end{tabular}

Tabela B.18: Medida de Duplo Erro para os classificadores bases do algoritmo EnsTPVotM induzidos para o quarto nível da hierarquia do conjunto EC.

\begin{tabular}{|l|c|c|c|c|}
\cline { 2 - 5 } \multicolumn{1}{c|}{} & C4.5 & KNN & RIPPER & BayesNet \\
\hline SVM & 0.0149 & 0.0160 & 0.0169 & 0.0146 \\
\hline C4.5 & & 0.0143 & 0.0175 & 0.0135 \\
\hline KNN & & & 0.0158 & 0.0155 \\
\hline RIPPER & & & & 0.0152 \\
\hline
\end{tabular}

da diversidade dos classificadores em função ao aumento da profundidade da hierarquia. Ao contrário do que ocorre com os valores da $\mathrm{MD}$, os valores da MDE apresentam um aumento para os niveis mais profundos, indicando que a proporção de exemplos que são classificados incorretamente por mais de um classificador base é maior para esses níveis.

Tabela B.19: Média e desvio padrão dos valores da MD e da MDE para o conjunto EC.

\begin{tabular}{|c|c|c|}
\cline { 2 - 3 } \multicolumn{1}{c|}{} & MD & MDE \\
\hline N1 & $0.0322(0.0232)$ & $0.0022(0.0026)$ \\
\hline N2 & $0.0228(0.0201)$ & $0.0085(0.0018)$ \\
\hline N3 & $0.0154(0.0093)$ & $0.0108(0.0009)$ \\
\hline N4 & $0.0163(0.0062)$ & $0.0154(0.0012)$ \\
\hline
\end{tabular}

\section{B.3 Considerações Finais}

Neste apêndice, foram descritos os resultados relacionados a uma análise de diversidade dos classificadores bases gerados para o algoritmo EnsTPVotM. Duas medidas pairwise foram utilizadas para a análise da diversidade dos classificadores bases: MD e MDE.

Para o conjunto EC, foram obtidos baixos valores reportados pela MD e pela MDE, decorrentes do alto desempenho preditivo que cada um dos classificadores apresentam quando são utilizados isoladamente, como pode ser observado no desempenho dos algoritmos Top-Down convencionais. 
Para o conjunto GPCR, embora os valores da MD tenham sido maiores do que para o conjunto EC, os valores reportados não indicam uma alta diversidade entre os classificadores. Isso explica porque alguns dos algoritmos Ensemble Top-Down não apresentaram TAs superiores a alguns algoritmos Top-Down convencionais. Por exemplo, o algoritmo EnsTPVotM obteve desempenho preditivo menor do que o algoritmo Top-Down baseado no KNN e do que o algoritmo Top-Down baseado no C4.5, para o conjunto GPCR.

Deve-se ressaltar, entretanto, que esse foi apenas um estudo inicial. Além disso, a utilização de outras medidas de diversidade pode proporcionar uma maior quantidade de informações para uma análise mais detalhada, oferecendo um maior suporte à interpretação dos resultados. 